REPORT TITLE: Long Term Field Development of a Surfactant Modified Zeolite/ Vapor Phase Bioreactor System for Treatment of Produced Waters for Power Generation

REPORT TYPE: Final Technical Report

REPORT PERIOD: 1 November 2004 - 31 October 2007

PRINCIPAL AUTHORS: Lynn E. Katz, Kerry A. Kinney, Robert S. Bowman, Enid .J. Sullivan, Soondong Kwon, Elaine B. Darby, Li-Jung Chen and Craig R. Altare

REPORT ISSUE DATE: June 2008

DOE AWARD NUMBER: DE-FC26-04NT15546

This project, jointly funded by the U.S. Department of Energy, National Energy Technology Laboratory (No. DE-FC26-04NT15546), included participation by The University of Texas at Austin, Los Alamos National Lab and New Mexico Tech. 


\section{Long Term Field Development of a Surfactant Modified Zeolite/ Vapor Phase Bioreactor System for Treatment of Produced Waters for Power Generation}

Final Technical Report

1 November 2004 - 31 October 2007

DOE AWARD NUMBER: DE-FC26-04NT15546

DISCLAIMER: This report was prepared as an account of work sponsored by an agency of the United States Government. Neither the United States Government nor any agency thereof, nor any of their employees, makes any warranty, express or implied, or assumes any legal liability or responsibility for the accuracy, completeness, or usefulness of any information, apparatus, product, or process disclosed, or represents that its use would not infringe privately owned rights. Reference herein to any specific commercial product, process, or service by trade name, trademark, manufacturer, or otherwise does not necessarily constitute or imply its endorsement, recommendation, or favoring by the United States Government or any agency thereof. The views and opinions of authors expressed herein do not necessarily state or reflect those of the United States Government or any agency thereof.

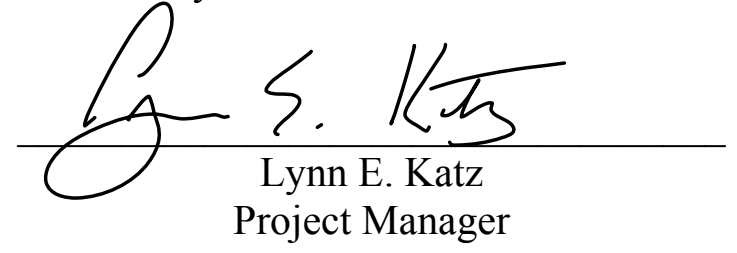




\section{EXECUTIVE SUMMARY}

The main goal of this research was to investigate the feasibility of using a combined physicochemical/biological treatment system to remove the organic constituents present in saline produced water. In order to meet this objective, a physical/chemical adsorption process was developed and two separate biological treatment techniques were investigated. Two previous research projects focused on the development of the surfactant modified zeolite adsorption process (DE-AC26-99BC15221) and development of a vapor phase biofilter (VPB) to treat the regeneration off-gas from the surfactant modified zeolite (SMZ) adsorption system (DE-FC26-02NT15461). In this research, the SMZ/VPB was modified to more effectivtly attenuate peak loads and to maintain stable biodegradation of the BTEX constituents from the produced water. Specifically, a load equalization system was incorporated into the regeneration flow stream. In addition, a membrane bioreactor (MBR) system was tested for its ability to simultaneously remove the aromatic hydrocarbon and carboxylate components from produced water. The specific objectives related to these efforts included the following:

(1) Optimize the performance VPBs treating the transient loading expected during SMZ regeneration.

- Evaluate the impact of biofilter operating parameters on process performance under stable operating conditions.

- Investigate how transient loads affect biofilter performance, and identify an appropriate technology to improve biological treatment performance during the transient regeneration period of an SMZ adsorption system.

- Examine the merits of a load equalization technology to attenuate peak VOC loads prior to a VPB system.

- Evaluate the capability of an SMZ/VPB to remove BTEX from produced water in a field trial.

(2) Investigate the feasibility of MBR treatment of produced water.

- Evaluate the biodegradation of carboxylates and BTEX constituents from synthetic produced water in a laboratory-scale MBR.

- Evaluate the capability of an SMZ/MBR system to remove carboxylates and BTEX from produced water in a field trial.

Laboratory experiments were conducted to provide a better understanding of each component of the SMZ/VPB and SMZ/MBR process. Laboratory VPB studies were designed to address the issue of influent variability and periodic operation (see DE-FC2602NT15461). These experiments examined multiple influent loading cycles and variable concentration loadings that simulate air sparging as the regeneration option for the SMZ system. Two pilot studies were conducted at a produced water processing facility near Farmington, New Mexico. The first field test evaluated SMZ adsorption, SMZ 
regeneration, VPB buffering, and VPB performance, and the second test focused on MBR and SMZ/MBR operation. The design of the field studies were based on the results from the previous field tests and laboratory studies.

Both of the biological treatment systems were capable of removing the BTEX constituents in the laboratory and in the field over a range of operating conditions. For the VPB, separation of the BTEX constituents from the saline aqueous phase yielded high removal efficiencies. However, carboxylates remained in the aqueous phase and were not removed in the combined VPB/SMZ system. In contrast, the MBR was capable of directly treating the saline produced water and simultaneously removing the BTEX and carboxylate constituents. The major limitation of the MBR system is the potential for membrane fouling, particularly when the system is treating produced water under field conditions. The combined process was able to effectively pretreat water for reverse osmosis treatment and subsequent downstream reuse options including utilization in power generation facilities. The specific conclusions that can be drawn from this study are summarized below.

\section{Vapor Phase Biofilter Treatment of SMZ Regeneration Gas Stream}

VPBs packed with polyurethane foam and compost-based materials can achieve high BTEX removal efficiencies when provided a steady volatile organic compound (VOC) feed and an adequate nutrient supply. However, frequent nutrient additions are required to maintain performance in polyurethane foam reactors - a fact that would be cumbersome at some field applications where minimal operating support is provided. For compost-based VPBs, mixing of a concentrated nutrient solution during biofilter start up ensured high removals of BTEX for extended periods without external nutrient addition.

Both foam and compost-packed biofilters can recover rapidly from short-term shutdowns indicating that these systems are resilient to the short-term, discontinuous feed conditions that are common in field applications. Both biofilters show improved performance after repeated one-day shutdowns but as the shutdown period increases to 2.8 days, however, the negative impact on VOC removal efficiencies following resumption of the VOC feed is more significant. Also, biofilters have a limited capacity to handle sudden variations in inlet VOC concentration as would be expected during the regeneration of a SMZ column treating produced water.

\section{Load Equalization System}

A short, fixed bed adsorption column containing granular activated carbon (GAC) can be used to attenuate and smooth the gas-phase VOC concentrations entering a downstream biofilter. The fixed bed adsorption system can be operated in a passive mode such that VOCs adsorb to the GAC during periods of high inlet concentration, and desorb VOCs during periods of low inlet concentration. At low-RH conditions (below 10\%), inlet toluene concentrations as high as $1000 \mathrm{ppm}_{\mathrm{v}}$ can be reduced by $97 \%$ in a GAC bed operated at a one second-EBCT. However, the buffering capacity of the GAC will 
diminish after repeated adsorption/air regeneration cycles if the sorbed VOCs are not regenerated completely in a given regeneration period.

The regenerated gas stream from an SMZ column is saturated with water which can diminish the adsorption capacity of a fixed bed adsorption system containing GAC. Using single-adsorption equilibrium parameters and SBA-determined kinetic parameters, the HSDM can be used to predict the adsorption of VOC mixtures under these high RH conditions. The film diffusion coefficient determined in the SBA experiments were more consistent with those predicted using a gas phase film transfer correlation whereas the experimentally determined surface diffusion coefficients were more consistent with aqueous surface diffusion estimates. Competitive adsorption of benzene and toluene was predicted very well by IAST, however, the accuracy of the model was improved by applying the correction factor (P). The calibrated HSDM predicted very well the bi-solute column data under continuous and variable loading conditions.

\section{SMZ/VPB Field Demonstration}

A treatment system consisting of a SMZ column coupled with a VPB can be used to remove the BTEX constituents from produced water. A field test of this coupled system performed well over repeated feed and regeneration cycles demonstrating the viability of the process for BTEX removal. Regeneration of the SMZ using air sparging was found to be sufficient in the field to maintain the SMZ adsorption capacity and to allow continuous operation of the system. As expected, the BTEX concentrations in the regeneration off gas streams were initially very high in a given regeneration cycle. However, a GAC-fixed bed adsorption column placed upstream of the VPB reduced the peak BTEX concentrations to acceptable levels for the VPB. Compared to the effective removal of BTEX in the SMZ/VPB system, the carboxylates present in the produced water were not effectively removed; therefore, another treatment option may be required depending on the desired reuse application.

\section{Membrane Bioreactor Treatment of Produced Water}

A submerged MBR system can simultaneously biodegrade the carboxylate and BTEX constituents present in saline produced water. An aerobic, submerged MBR operated at a 9.6-hr HRT achieved 92\% removal of acetate and malonate from synthetic produced water containing $10 \mathrm{~g} / \mathrm{L}$ TDS. When BTEX was simultaneously supplied to the MBR in the gaseous phase, approximately $80 \%$ of the BTEX was biodegraded and when the BTEX was introduced in the aqueous phase, approximately $95 \%$ was biodegraded.

Fouling of an MBR membrane by inorganic precipitates is a significant problem that leads to high transmembrane pressure (TMP) and ultimately reduced flux across the membrane. For the synthetic produced water investigated in this research, decreasing the $\mathrm{pH}$ of the solution crossing the membrane was effective at reducing the TMP. However, the optimal $\mathrm{pH}$ that maximizes biological activity while minimizing the TMP must still be determined. 


\section{SMZ/MBR Field Demonstration}

A coupled SMZ/MBR system can be used to simultaneously remove the carboxylate and BTEX constituents present in produced water under field conditions. Acetate (the predominant organic anion detected in the produced water at the field site in New Mexico) was not removed in the SMZ column; however it was removed to below detection limits in the MBR. The SMZ column removed most of the BTEX constituents in the produced water during the field trial. Approximately $95 \%$ of the BTEX that penetrated the SMZ and subsequent tly entered the MBR was biodegraded in the MBR. Prediction of effluent benzene concentrations using lab-determined kinetic coefficients ( $K_{V}$ and $k_{d} \bullet X$ ) were reasonable, and suggest that the removal of benzene from produced water in the MBR is primarily controlled by biodegradation. Overall, the combined $\mathrm{SMZ} / \mathrm{MBR}$ system achieved TOC removal efficiencies ranging from approximately 75 to $90 \%$. 


\section{Table of Contents}

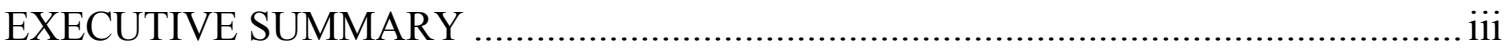

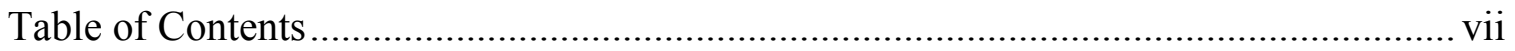

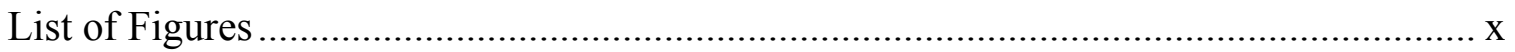

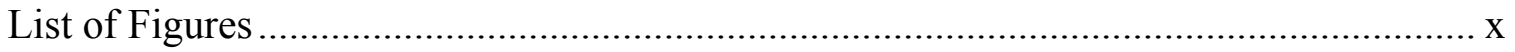

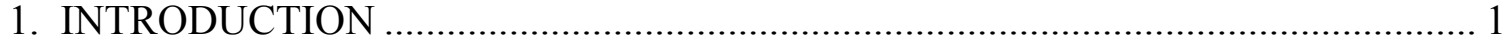

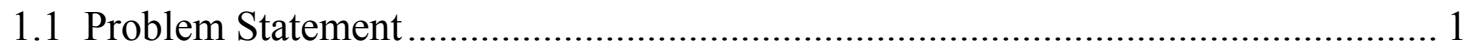

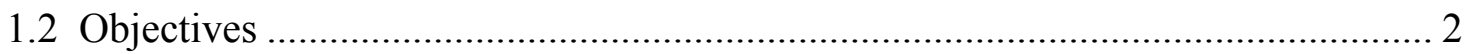

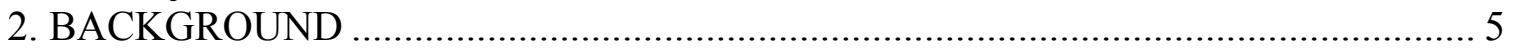

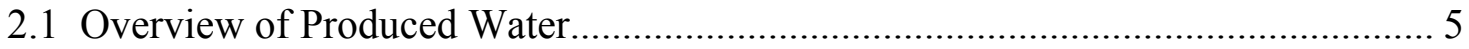

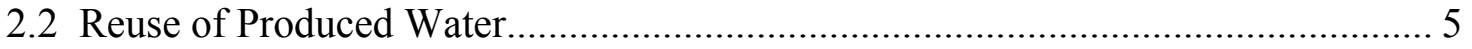

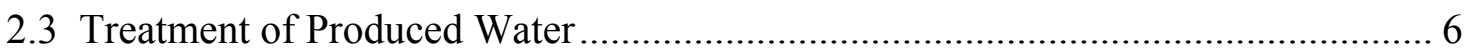

2.4 Treatment of Produced Water by Surfactant-Modified Zeolite (SMZ) .................. 7

2.5 Biological Treatment of Produced Water ............................................................ 7

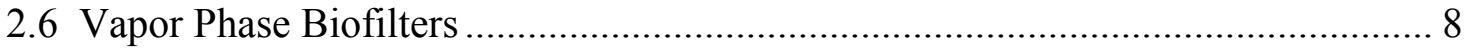

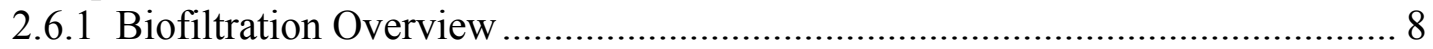

2.6.2 Pollutants and Microorganisms.................................................................. 8

2.6.3 Biofiltration Applications ...................................................................... 9

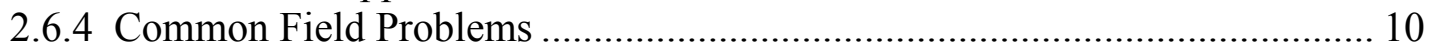

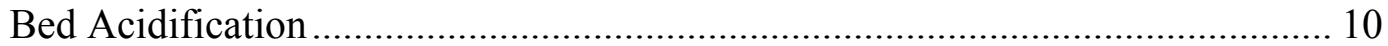

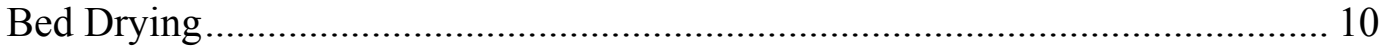

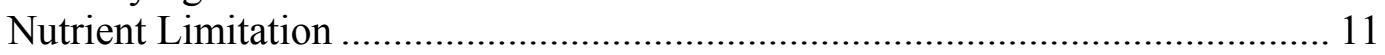

Bed Compaction and Pressure Drop .............................................................. 11

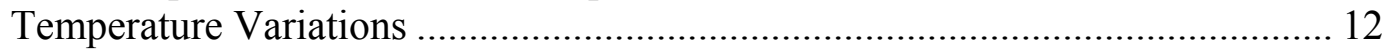

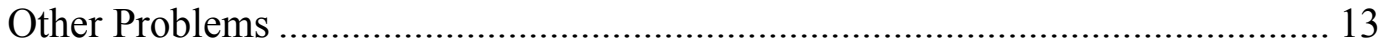

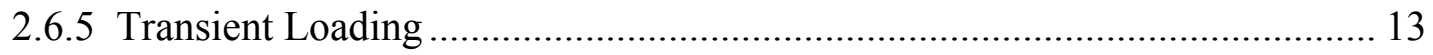

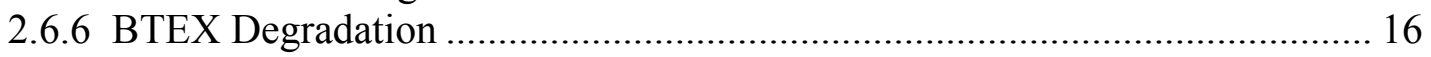

2.6.7 Application of VPBs to the Treatment of Produced Water .......................... 17

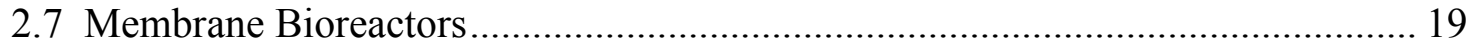

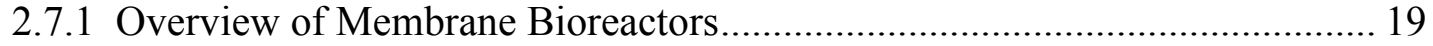

2.7.2 Comparison of MBRs with Activated Sludge Systems .............................. 19

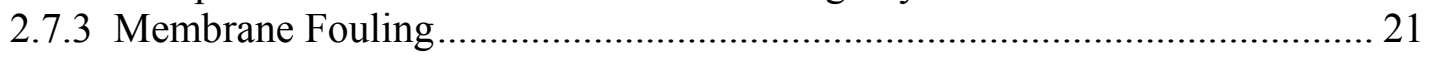

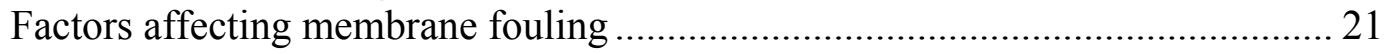

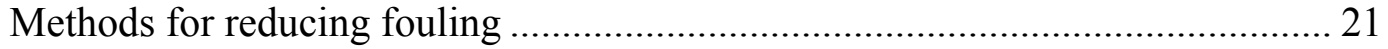

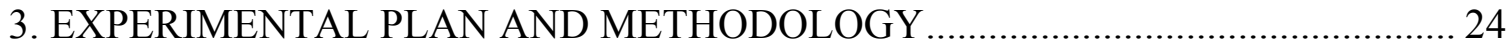

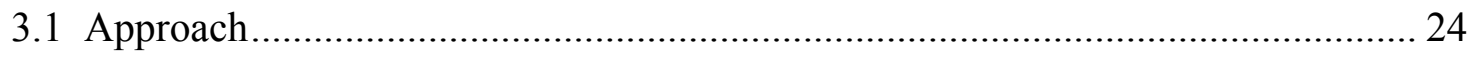

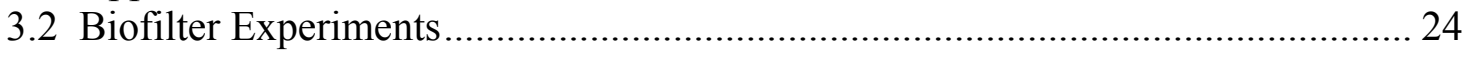

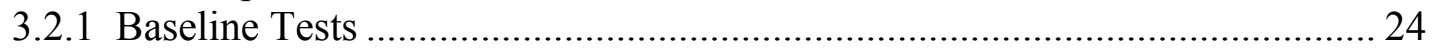

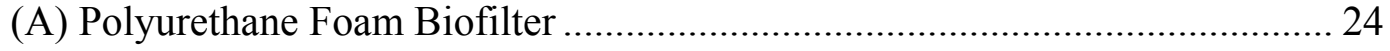

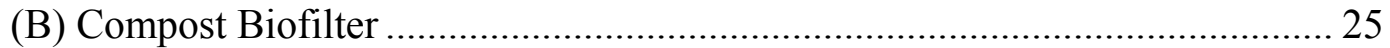

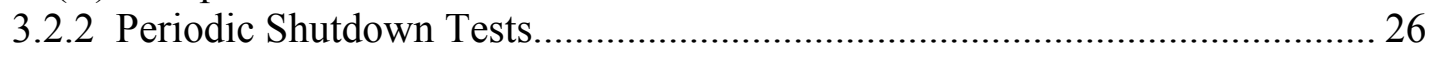

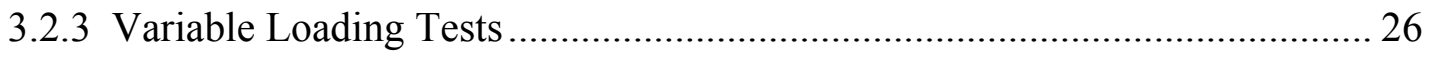

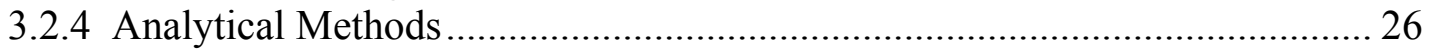

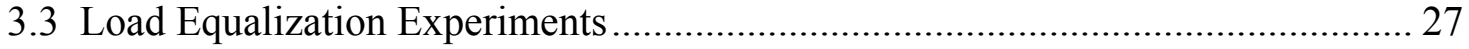

3.3.1 Experimental Column Reactors and Adsorption Studies............................... 27 
(A) SMZ- Fixed Bed Adsorption Column ..................................................... 27

(B) GAC-Fixed Bed Adsorption Column ...................................................... 27

3.3.2 Experimental Methods for Water Saturated Adsorption Experiments ........... 28

3.3.2.1 Column Experiments ...................................................................... 28

3.3.2.2 Activated Carbon Adsorption ............................................................. 28

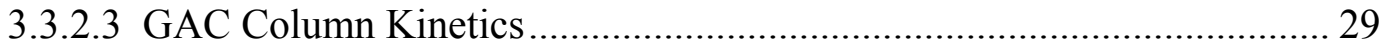

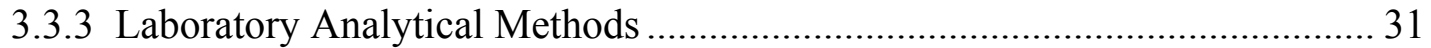

3.4 Field SMZ/VPB Methods ........................................................................... 31

3.4.1 Field SMZ/VPB Experimental Methods.................................................... 31

3.4.2 Field Analytical Methods......................................................................... 32

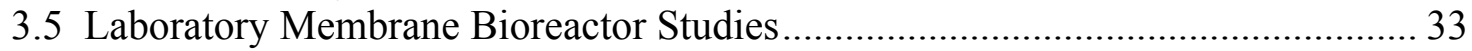

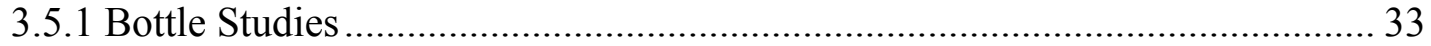

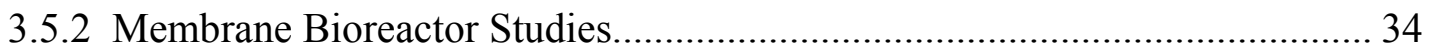

3.5.3 Analytical Methods ............................................................................... 37

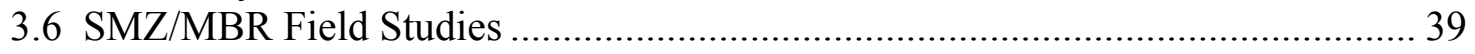

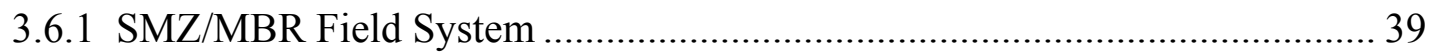

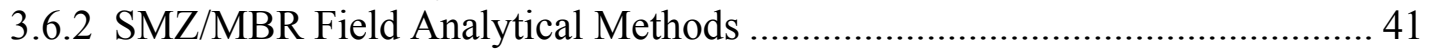

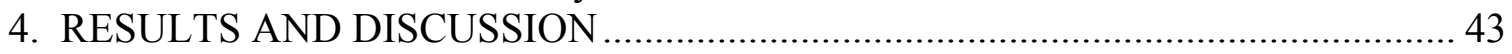

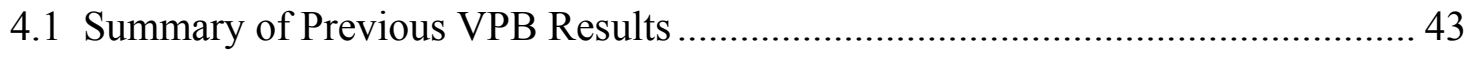

4.1.1 Baseline Biofilter Experiments ............................................................. 43

4.1.2 Response of Biofilters to Periodic Shutdown Conditions.............................. 44

4.1.3 Response of Biofilter to Variable Loading Conditions................................... 44

4.2 Load Equalization by a Fixed Bed Adsorption Column ...................................... 47

4.2.1 Load Equalization for Dry-Gas Streams Containing A Single VOC ............ 48

4.2.1.1 Load Equalization Test with SMZ ..................................................... 48

4.2.1.2 Load Equalization Test with GAC ................................................... 50

4.2.1.3 Summary .................................................................................... 53

4.2.2 Load Equalization for Water-Saturated Gas Streams Containing A VOC

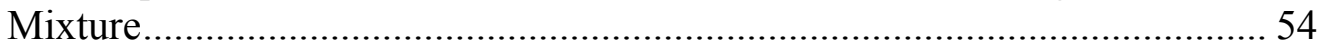

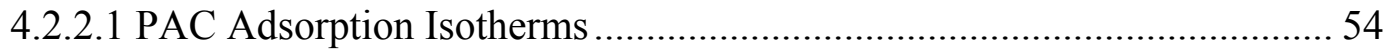

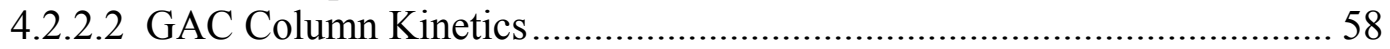

4.2.2.3 HSDM Model Predictions for Developing Design Criteria...................... 64

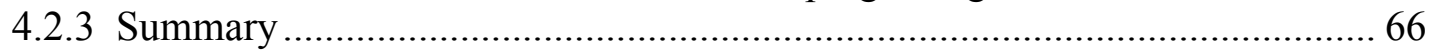

4.3 Field Application of an SMZ/VPB System to Treat Produced Water ................... 66

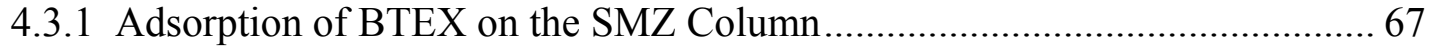

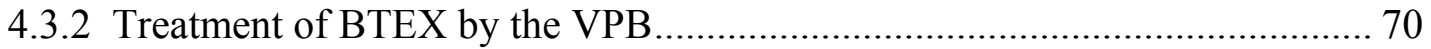

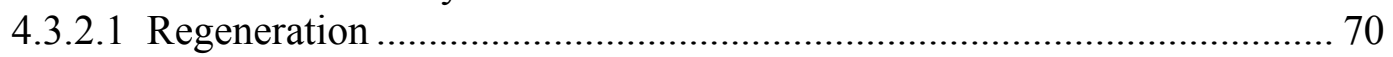

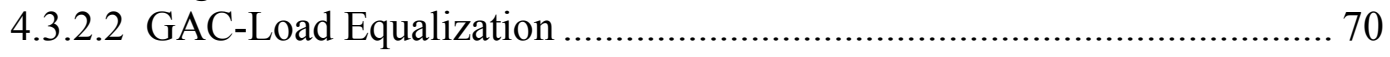

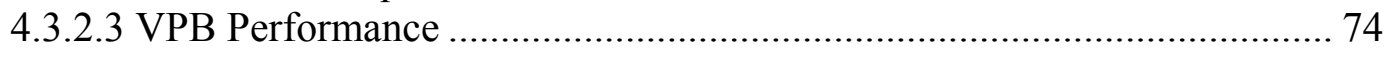

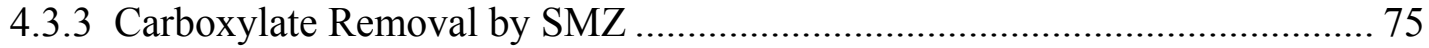

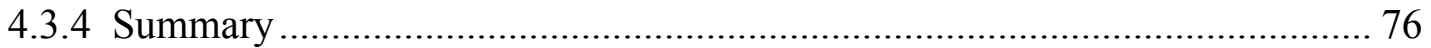

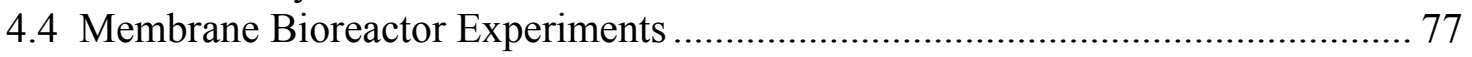

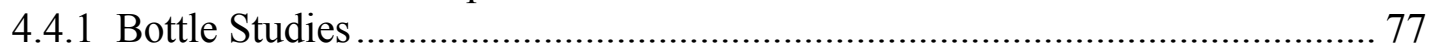

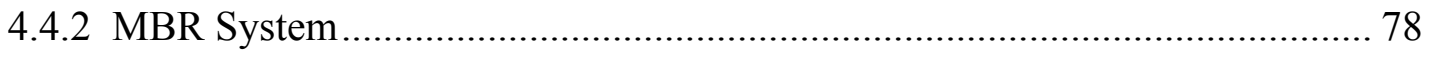

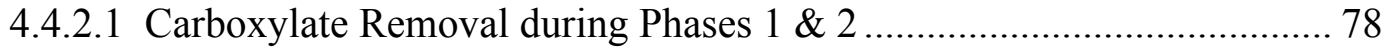

4.4.2.2 BTEX Removal during Phase 2 .................................................... 80 
4.4.2.3 Biomass Concentrations and Trans-Membrane Pressure during Phases $1 \& 2$ 81

4.4.2.4 Abiotic Studies for BTEX Volatilization ............................................. 83

4.4.2.5 Biomass Concentrations and Carboxylate Removal during Phases $3 \& 486$

4.4.2.6 BTEX Removal during Phase 3 ......................................................... 86

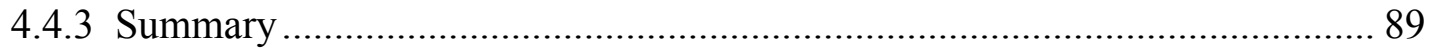

4.5 Field Application of SMZ/MBR System To Treat Produced Water ..................... 90

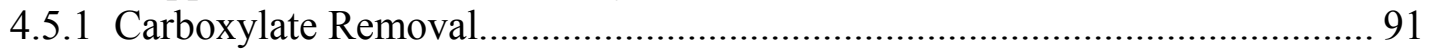

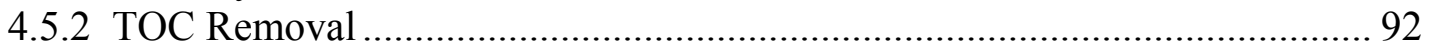

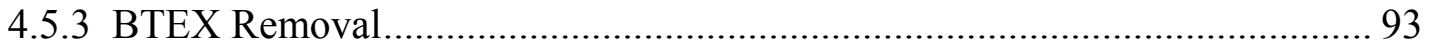

4.5.4 Trans-Membrane Pressure …………………….................................... 99

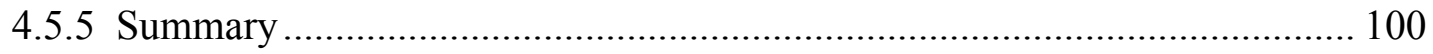

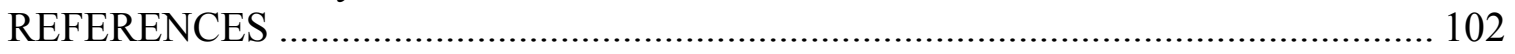




\section{List of Figures}

Figure 2-1. Schematic diagram of the SMZ/VPB system for treating produced water.... 18

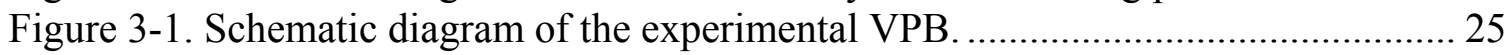

Figure 3-2. Schematic of the GAC-fixed bed adsorption column experimental setup.... 30

Figure 3-3. Schematic diagram of the SMZ/VPB treatment system used to treat produced water at the McGrath Salt Disposal/Treatment facility near Farmington, New Mexico. 32

Figure 3-4. Schematic of experimental MBR system during Phases 1 \& 2 (Gaseous BTEX feeding)

Figure 3-5. Schematic of experimental MBR system during Phases $3 \& 4$ (Aqueous

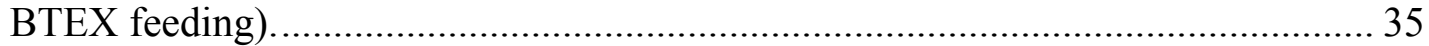

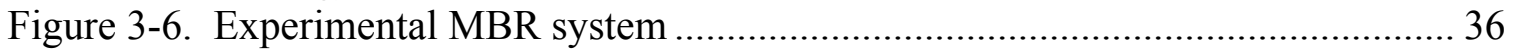

Figure 3-7. Ultrasonically welded polyethylene membrane sheet on an ABS plastic housing. Membrane was provided by Enviroquip, Inc. (Austin, TX) . .................... 37

Figure 3-8. Schematic diagram of the SMZ/MBR treatment system used to treat produced water at the McGrath Salt Disposal/Treatment facility near Farmington, New Mexico.

Figure 4-1. Typical concentration profile of gas phase effluent during the regeneration of a saturated SMZ column. Air flow rate for the regeneration was $7.5 \mathrm{ml} / \mathrm{min}$. ( $\square$; Benzene, $\square$; Toluene, $\circ$; Ethylbenzene, $\bullet$; $p \& m$ xylene, $\Delta$; o-xylene). Column dimensions; $0.4 \mathrm{~cm}$ (radius) X $10 \mathrm{~cm}$ (length). SMZ size; 0.15-0.18 mm. Experimental results provided by Craig Altare at New Mexico Tech (Altare et al., 2006)

Figure 4-2. Response of the compost biofilter to a BTEX variable loading. The total BTEX concentration to the VPB was suddenly increased to $380 \mathrm{ppm}_{\mathrm{v}}$, and then decreased exponentially. ( $\boldsymbol{\Delta}$; BTEX concentration introduced to VPB, and $\Delta$; effluent BTEX concentration from VPB)

Figure 4-3. Response of the compost biofilter to repeated BTEX variable loading cycles. In each 24 hour cycle, a high loading of BTEX was provided for 8 hours as shown in Figure 3-13. During the remaining 16 hours of each cycle, clean air was passed through the biofilter. (B; benzene, $\mathrm{T}$; toluene, E; ethylbenzene, p\&m-x; para \& meta-xylene, $o$-x; ortho-xylene) ....

Figure 4-4. Pre-saturation/regeneration of the SMZ column with toluene. 10 secondEBCT

Figure 4-5. Response of the SMZ-packed column to a transient feed of toluene. 10 second-EBCT.

Figure 4-6. Pre-saturation/regeneration of the GAC column with toluene. 1 secondEBCT

Figure 4-7. Response of the GAC-fixed bed adsorption column to a sudden increase in toluene concentration. Toluene was supplied for 8 hours as a transient load followed by 32 hours of clean air. GAC (BPL 4 x 6 mesh, Cargon Carbon Corp.) was used as a buffering agent. 1 second-EBCT. 52

Figure 4-8. Response of the GAC-fixed bed adsorption column to repeated toluene transients. As depicted in the inset, each toluene transient was supplied for 8 hours 
followed by 16 hours of clean air. Each arrow represents the start of transient loading period.

Figure 4-9. Individual adsorption isotherm for benzene and toluene, benzene $\mathrm{C}_{0}=53$

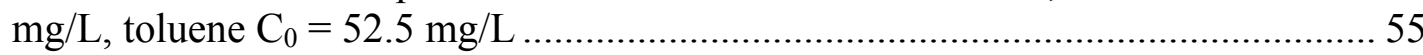

Figure 4-10. Benzene and toluene competitive isotherms, benzene $\mathrm{C}_{0}=53 \mathrm{mg} / \mathrm{L}$, toluene

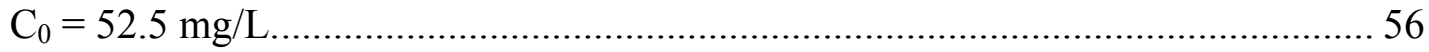

Figure 4-11. Benzene and toluene competitive isotherms, benzene $\mathrm{C}_{0}=53 \mathrm{mg} / \mathrm{L}$, toluene

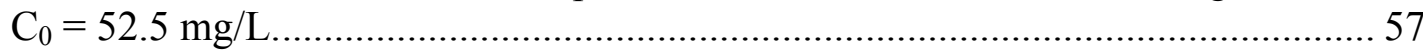

Figure 4-12. Benzene and toluene competitive isotherms, benzene $\mathrm{C}_{0}=53 \mathrm{mg} / \mathrm{L}$, toluene

$\mathrm{C}_{0}=52.5 \mathrm{mg} / \mathrm{L}, \mathrm{P}=1.06$ for benzene, 1.12 for toluene. ..................................... 58

Figure 4-13. Benzene SBA data and HSDM fit for water saturated BPL GAC, $\mathrm{C}_{0}=500$

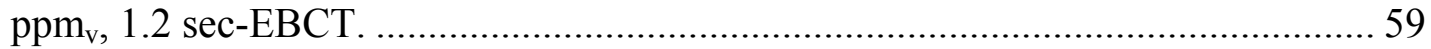

Figure 4-14. Toluene SBA data and HSDM fit for water saturated BPL GAC, $\mathrm{C}_{0}=500$ $\mathrm{ppm}_{\mathrm{v}}, 1.2 \mathrm{sec}-\mathrm{EBCT}$.

Figure 4-15. Benzene fixed bed adsorber data and HSDM-predictions for water saturated $\mathrm{BPL}$ GAC, $\mathrm{C}_{0}=500 \mathrm{ppm}_{\mathrm{v}}, 3 \mathrm{sec}-\mathrm{EBCT}$. 60

Figure 4-16. Toluene fixed bed adsorber data and HSDM-predictions for water saturated BPL GAC, $\mathrm{C}_{0}=500 \mathrm{ppm}_{\mathrm{v}}, 3$ sec-EBCT.

Figure 4-17. Single and bi-solute benzene and toluene column adsorption data, benzene $\mathrm{C}_{0}=500 \mathrm{ppm}_{\mathrm{v}}$, toluene $\mathrm{C}_{0}=500 \mathrm{ppm}_{\mathrm{v}}, 3$ sec-EBCT.

Figure 4-18. Measured and HSDM-predicted benzene and toluene adsorption in a fixed bed BPL GAC adsorber, benzene $\mathrm{C}_{0}=500 \mathrm{ppm}_{\mathrm{v}}$, toluene $\mathrm{C}_{0}=500 \mathrm{ppm}_{\mathrm{v}}, 3 \mathrm{sec}-$ EBCT

Figure 4-19. Measured benzene \& toluene fixed bed adsorber data for varying influent concentrations. 1.8 sec-EBCT

Figure 4-20. Measured and HSDM-predicted benzene \& toluene fixed bed adsorber data for varying influent concentrations shown in Figure 4-19, 1.8 sec-EBCT.............. 64

Figure 4-21. HSDM-predicted benzene \& toluene effluent concentrations from a GACfixed bed adsorption column. (A): at 1, 3, and 5 second-EBCTs. Inlet maximum concentrations: $200 \mathrm{ppm}_{\mathrm{v}}$ for benzene, $500 \mathrm{ppm}_{\mathrm{v}}$ for toluene. (B): at 200, 500, 1000 $\mathrm{ppm}_{\mathrm{v}}$ of inlet-benzene Maximum concentrations, $500 \mathrm{ppm}_{\mathrm{v}}$ of toluene Maximum concentration. 1 second-EBCT.

Figure 4-22. Breakthrough of BTEX on virgin SMZ at the flow rate of 27 gph. ( $\square$; Benzene, $\mathbf{\square}$; Toluene, o ; Ethylbenzene, $\bullet$; $p \& m$ xylene, $\Delta$; o-xylene). 1 hourEBCT

Figure 4-23. Cumulative mass of benzene adsorbed on SMZ at different produced water flow rates.

Figure 4-24. Comparison of benzene breakthrough curves on virgin and regenerated SMZ. ( ; Benzene adsorption on virgin SMZ, $\square$; Benzene adsorption on regenerated $\mathrm{SMZ})$

Figure 4-25. BTEX concentration profiles of gas phase effluent during regeneration of SMZ columns with air. (A): Regeneration in the field (B): Regeneration in the lab (Altare et al., 2007). In the field test, the SMZ column being regenerated was completely saturated with respect to benzene and only partially saturated with respect to the other VOCs. In the lab test, the SMZ column was completely 
saturated with BTEX prior to regeneration ( $\square$ : Benzene, $\mathbf{m}$ : Toluene, $\bigcirc$ :

Ethylbenzene, $\bullet$ : $p \& m$-xylene, $\Delta$ : $o$-xylene)

Figure 4-26. Response of the GAC-fixed bed adsorption column to regenerated VOCs from the saturated SMZ column. (A): 1 second-EBCT, (B): 5 second-EBCT. ( $\mathbf{m :}$

Benzene influent, $\square$ : Benzene effluent, $\bullet$ : Toluene influent, $\circ$ : Toluene effluent). . 72

Figure 4-28. Buffering capacity of GAC (five second-EBCT) for repeated cycles of adsorption/regeneration. The BTEX concentrations exiting the fixed bed adsorption column between SMZ regeneration periods were not measured due to limitations imposed by the site operating schedule.

Figure 4-29. Performance of the VPB treating the VOC-laden gas exiting the GAC-fixed bed adsorption column during the SMZ/VPB field trial. (A): Biomass accustomed to low concentrations $\left(12 \mathrm{ppm}_{\mathrm{v}}\right)$ of benzene, $(\mathrm{B})$ : Biomass accustomed to higher

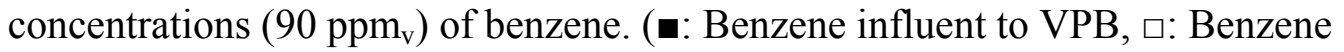
effluent from VPB, $\bullet$ : Toluene influent to VPB, ०: Toluene effluent from VPB)... 75 Figure 4-30. Breakthrough curves for carboxylates on virgin SMZ during the field trial in New Mexico. The produced water flow rate was $27 \mathrm{gph}$. 76

Figure 4-31. Removal of carboxylates and BTEX in a synthetic produced water solution containing $10 \mathrm{~g} / \mathrm{L}$ TDS 78

Figure 4-32. Removal of carboxylates and BTEX in a synthetic produced water solution containing $100 \mathrm{~g} / \mathrm{L}$ TDS

Figure 4-33. Removal of acetate and malonate in the MBR during Phases $1 \& 2$........... 79

Figure 4-34. BTEX removal in the MBR during Phase 2.............................................. 80 Figure 4-35. Biomass concentrations (MLVSS) and TMP in the MBR during Phases $1 \&$ 2.

Figure 4-36. TMP change as the $\mathrm{pH}$ was decreased in the MBR. 83

Figure 4-37. Carboxylate removal and biomass concentration in the MBR during Phases $3 \& 4$ 87

Figure 4-38. BTEX removal in the MBR during Phase 3.............................................. 87

Figure 4-39. Acetate concentrations during SMZ/MBR operation. ................................. 92

Figure 4-40. TOC concentrations during SMZ/MBR operation.......................93

Figure 4-41. Liquid phase BTEX concentrations during SMZ/MBR operation. ............. 94

Figure 4-42. BTEX amount degraded by biomass in MBR........................................... 95

Figure 4-43. TMP in the MBR system during the field test........................................ 100 


\section{List of Tables}

Table 2-1. Industries using biofilters ....................................................................... 9

Table 2-2. Major categories of membrane cleaning chemicals. ...................................... 23

Table 3-1. Composition of synthetic produced water solutions ........................................ 33

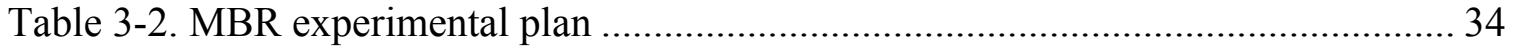

Table 3-3. Operating conditions of the MBR system ………………………………........ 38

Table 3-4. Composition of synthetic produced water solutions ........................................ 39

Table 3-5. Operating conditions of the SMZ/MBR system............................................ 41

Table 4-1. Summary of adsorption parameters from single component studies................ 54

Table 4-2. Freundlich parameters for benzene and toluene from previous studies.......... 55

Table 4-3. Comparison of calculated and experimentally determined kinetic coefficients

Table 4-4. Composition of produced water at the saltwater processing facility, NM ...... 67

Table 4-5. Potential malonate species in the MBR at different pHs................................ 80

Table 4-6. Maximum BTEX concentrations in the MBR liquid phase effluent during

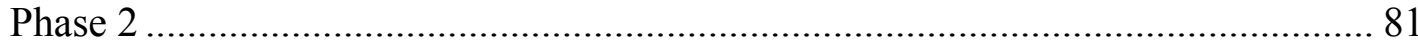

Table 4-7. Recovery of toluene with different air flow rate during abiotic MBR operation

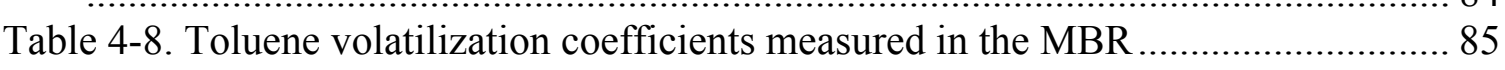

Table 4-9. BTEX volatilization rate coefficients $\left(K_{V}\right)$ measured in the MBR $(10 \mathrm{~L} / \mathrm{min}$

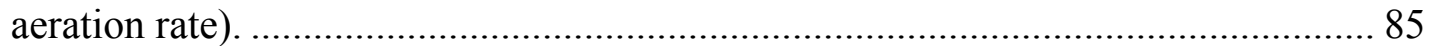

Table 4-10. BTEX removal in the MBR during Phase 3............................................... 88

Table 4-11. BTEX biodegradation coefficients $\left(k_{d} \bullet \mathrm{X}\right)$ measured in the MBR $(10 \mathrm{~L} / \mathrm{min}$

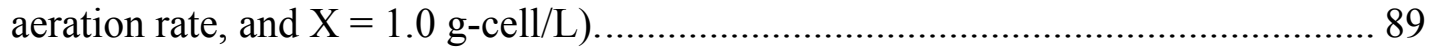

Table 4-12. Composition of produced water at the field salt water disposal facility, NM, 2007.

Table 4-13. Maximum BTEX concentrations in the MBR liquid phase effluent............. 94

Table 4-14. BTEX removal in MBR......................................................................... 95

Table 4-15. Benzene concentrations measured in field test and estimated using laboratory-determined kinetic coefficients. ........................................................... 98

Table 4-16 TOC concentrations during SMZ/MBR operation TOC concentrations during SMZ/MBR operation. Kinetic coefficients $\left(K_{V}\right.$ and $\left.k_{d} \bullet X\right)$ for benzene removal in field test and comparison with values in lab test. 


\section{INTRODUCTION}

\subsection{Problem Statement}

Co-produced water from the oil and gas industry represents a significant waste stream in the United States. Produced water is characterized by high levels of total dissolved solids (TDS), dissolved organics and oil and grease. Among the wide variety of organics present in the water, the concentration of hazardous substances such as benzene, toluene, ethylbenzene, and xylenes (BTEX) can reach $600 \mathrm{mg} / \mathrm{L}$ and the concentration of nonhazardous carboxylates can be as high as $10,000 \mathrm{mg} / \mathrm{L}$ (API, 2002). Over $90 \%$ of onshore produced water is currently disposed of by reinjecting it into the subsurface (API 2000), while the remaining water is discharged onto the surface via irrigation, evaporation pits, and application to roads (USEPA, 2000). In some areas, however, reinjection is geologically infeasible and for small producers, it can be economically prohibitive. Also, regulations governing the disposal of produced water are tightening and interest in reusing treated produced water is increasing in the United States particularly in regions with scarce water supplies. In order to reuse produced water for power generation or other applications, removal of both the inorganic dissolved solids and hazardous organics such as BTEX is necessary.

Dissolved organics that can foul the membranes utilized in desalination technologies (e.g., reverse osmosis) must be removed to facilitate inorganic salts removal. In particular, carboxylates (mainly acetate and malonate), which can represent $50 \%$ of the total organic carbon (TOC) in produced water (Katz et al., 2006) should be reduced prior to desalination of produced water. Current treatment methods primarily focus on the separation of oil and grease from produced water using oil/water separation tanks, hydrocyclones, and gas flotation devices; however, these methods are not efficient for removing dissolved organic compounds. For the removal of dissolved hydrocarbons, chemical clarifiers, membrane filtration systems, photocatalytic oxidation, phytoremediation, bubbler separation, and adsorption processes have been used.

Although many of these physicochemical treatment options are successful at reducing the organic content of produced waters, they can not always meet the levels of the current or proposed regulations cost-effectively. In addition, secondary treatment will likely be required, if the water needs to be treated to a level suitable for re-use.

Generally, biological treatment systems are considered environmentally friendly and cost efficient technologies, but due to the high salinity in produced water, relatively little attention has been paid to biological treatment options. Although direct biological treatment of briny produced water can be challenging, many of the organic contaminants in produced water are amenable to biological treatment. One approach to simplifying biological treatment is to separate the organics from the produced water. An adsorbent such as activated carbon could be used to remove volatile organics from produced water; however, physical separation does not yield complete destruction of the organics and regeneration and disposal can be cost prohibitive. Adsorbents that can be readily regenerated on-site, and processes that yield complete chemical destruction to innocuous products offer substantial promise., 
The research described in this report is an extension of two previous research projects focused on the development of a technology for treating produced water (DOE Projects DE-AC26-99BC15221 and DE-FC26-02NT15461) using a combined surfactant modified zeolite/vapor phase bioreactor system. The process involves use of surfactant-modified zeolite (SMZ) for physical separaton of BTEX and other organic contaminants followed by biological treatment of the SMZ regeneration off-gas. Surfactant-modified zeolite is an innovative filtration/sorption medium that can be cost-effectively produced using naturally occurring zeolites and commercially available surfactant. The projects demonstrated the potential of SMZ for BTEX removal at laboratory and pilot scale and the potential for vapor phase bioreactor treatment of the off-gas. This project is a follow up to these projects to refine the process as required for use as a pretreatment step for produced water reuse scenarios.

In the DE-FC26-02NT15461 project, we determined that surfactant modified zeoloite (SMZ) could remove benzene, toluene, ethylbenzene and xylenes (BTEX) from produced water and be regenerated over numerous cycles without loss of BTEX capacity. We developed a vapor phase biofilter (VPB) system that can treat the vapor phase BTEX released during regeneration of the SMZ. The VPB system was tested for its ability to withstand spikes in influent concentration, and periodic shutdowns. The system was found to be resilient to spikes, although loss of efficiency may require dilution of the influent stream at the initial period of regeneration depending on the off-gas effluent limitations at a site. The recovery time after periodic shutdowns was dependent on the length and frequency of the shutdown. The VPB acclimated to the frequent shutdowns and the performance of the system was maintained. Pilot testing of the process was performed at a site in New Mexico.

\subsection{Objectives}

The overall goal of the current project was to evaluate and modify the SMZ/VPB system to produce an effluent that was suitable for downstream water reuse processing (e.g. reverse osmosis) and to demonstrate the modified system at field scale. The design of the field-scale system was based on our prior project results that demonstrated that surfactant-modified zeolite (SMZ) is an effective sorptive medium for removing dissolved organics from produced water and vapor phase biofilters are capable of degrading BTEX in the SMZ regeneration off-gas. SMZ offers a low-cost, easily regenerable option for producers who want or need to treat their produced water. Longterm laboratory-scale column tests (50 sorption and regeneration cycles; $5000 \mathrm{PV}$ total water treated) showed that SMZ retained its ability to remove BTEX compounds over many cycles. Although observed $K d$ values exhibited a weakly decreasing trend over the 50 cycles, additional HDTMA could easily be pumped through a field column as needed to restore surfactant loading on the SMZ. 
Based on the results of our prior research, two major modifications to the produced water treatment system were addressed in this research. First, a load equalization system was developed for the vapor phase bioreactor to attenuate peak loads and maintain stable biodegradation of the BTEX constituents of the produced water. Second, a membrane bioreactor was evaluated for its potential to reduce the concentration of carboxylate ions (e.g. organic acid anions) identified in the produced water wastestreams evaluated in this work. Justification for these modifications is as follows.

Results of laboratory scale VPB studies indicated that biofilters packed with a compost system was better suited to field conditions. Another consideration that became evident in the prior research is that VPBs have difficulty treating transient contaminant loads such as those that result when it is coupled with an SMZ system. Although numerous studies have been conducted to monitor the adverse effects of transient inlet conditions on biofilter performance, relatively little attention has been directed toward finding solutions to these problems. Introducing a separate load equalization system is a potentially effective method for successful operation of a biofilter experiencing transient feed conditions in a field application.

Field trials conducted in Wyoming as part of a previous project (DE-AC26-99BC15221) suggested that a significant portion of total organic carbon remained in the SMZ effluent even though BTEX removal was excellent. Laboratory testing of produced water from the New Mexico site studied in this project and project DE-FC26-02NT15461 identified three organic anions in the influent produced water at the following average concentrations: acetate $(259 \mathrm{mg} / \mathrm{L})$, malonate $(170 \mathrm{mg} / \mathrm{L})$ and propionate $(30 \mathrm{mg} / \mathrm{L})$. That these organic anions would be poorly removed in SMZ column tests is not surprising as the carboxylic anions (carboxylates) are highly soluble and at these concentrations the anion exchange capacity of the SMZ would be rapidly exhausted.

MBRs have been in development for over 30 years, and have been successfully used to treat municipal wastewater and drinking water. However, the application of MBR systems to treat industrial wastewaters is still in its infancy due to the significant variations in wastewater composition (Chen and Chen, 2004). Treatment of saline produced water in an MBR is promising for several reasons. MBRs can be operated at longer solids retention times (SRTs), resulting in significantly higher biomass concentrations than in traditional activated sludge systems. These longer SRTs might also improve the degradation of recalcitrant pollutants and improve biological treatment in harsh environments such as in briny wastewater. In fact, a few studies have found that MBRs can efficiently reduce the chemical oxygen demand (COD) level in saline wastewater. The success of this prior work prompted consideration of MBR technology for carboxylate and VOC reduction in produced water in this research.

As a result, specific goals were developed to address these two major modifications to the SMZ/VPB process. These objectives include: 
Assess VPB treatment, and optimize VPB performance for transient loading of VOCs expected during SMZ regeneration.

- Evaluate the impact of biofilter operating parameters on process performance under stable operating conditions.

- Investigate how transient loads affect biofilter performance, and identify an appropriate technology to improve biological treatment performance during the transient regeneration period of an SMZ adsorption system.

- Examine the merits of a load equalization technology to attenuate peak VOC loads prior to a VPB system.

- Evaluate the capability of an SMZ/VPB to remove BTEX from produced water in a field trial.

Investigate the feasibility of MBR treatment of produced water.

- Evaluate the biodegradation of carboxylates and BTEX constituents from synthetic produced water in a laboratory-scale MBR.

- Evaluate the capability of an SMZ/MBR system to remove carboxylates and BTEX from produced water in a field tria. 


\section{BACKGROUND}

This chapter provides an introduction to produced water and its treatment. Since extensive characterization of SMZ adsorption properties was completed in a previous project (DE-FC26-02NT15461), biological treatment of produced water constituents are emphasized below as they provide the basis for research in this project. Specifically, VPBs and MBRs are discussed in detail. Sections 2.1 through 2.5 describe produced water including reuse applications, physicochemical treatment methods, and biological options. Sections 2.6 and 2.7 discuss VPBs and MBRs, respectively. Section 2.6 summarizes common problems encountered during VPB application in field applications. Previous solutions proposed to address these concerns are also reported. In Section 2.7, a description of MBRs is provided and the process is compared with traditional activated sludge systems. Concerns regarding membrane fouling are also described.

\subsection{Overview of Produced Water}

Co-produced water from the oil and gas industry accounts for a significant waste stream in the United States. The produced water waste stream includes both formation water and water injected to enhance the recovery of oil and gas. For each barrel (bbl) of oil produced, an average of $10 \mathrm{bbl}$ of water is produced for an annual total of about 17.9 billion barrels (API, 2000). This is the largest single waste stream in the country, aside from non-hazardous industrial wastes (Allen and Rosselot, 1994). Characteristics of produced water include high TDS content, dissolved organic constituents, an oil and grease component, heavy metals, radionuclides, and chemicals added during the oilproduction process (Stephenson, 1992). Dissolved organics in produced water include volatile aromatic hydrocarbons such as benzene, toluene, ethylbenzene and xylenes (BTEX), aliphatic hydrocarbons, phenols, carboxylates such as monofunctional acetic acid and difunctional malonic acid (API, 2002). The toxicity of this water is due, in large part, to the presence of oil, grease and hazardous aromatic compounds such as BTEX (Fucik, 1992). Among various organics, hazardous BTEX concentrations can range from 0.068 to $600 \mathrm{mg} / \mathrm{L}$ (API, 2002).

\subsection{Reuse of Produced Water}

Treatment of produced water for re-use, instead of re-injection will be driven by economic and environmental incentives for the oil and gas industry. Industries potentially benefiting from the re-use of treated produced water include the power, oil and gas, and agriculture industries (Burnett, 2004; Hays and Arthur, 2004; Zammit and DeFillippo, 2004). Each of these end users will require industry-specific water quality criteria and will be regulated by different local, state, and federal rules and regulations. Power plants use water in cooling systems, steam generation, and air pollution control, while the majority of water use is in cooling systems. Regional water shortages and associated cost increases of traditional source waters can prompt the use of produced water for their facilities. The primary concerns are the TDS, chlorides, and BTEX when produced water is used in the power industry. Produced water can be diluted by blending with river water but this is unlikely to meet the water quality standards necessary for use 
in power plants. Another option is to pre-treat the produced water to remove the undesirable constituents to levels acceptable for use in a power plant. Produced water can also be used in oil and gas industries for drilling operations or for pressurizing formations. Again, treatment would be required to reduce the TDS as well as reducing hydrogen sulfide levels. If treated produced water is of sufficient quality, it could be used for wildlife or livestock watering or other agricultural uses. Regulations and criteria differ significantly for these applications. In fact, some produced water from coal bed methane (CBM) wells, which has low BTEX and TDS concentrations, has already been used for agriculture in Wyoming and Montana.

\subsection{Treatment of Produced Water}

Over $90 \%$ of onshore produced water is currently disposed of via re-injection into the subsurface (API, 2000) with the remaining percentage used for irrigation or application to roads or disposed of in evaporation pits (USEPA, 2000). However, re-injection is geologically infeasible for some areas and often economically infeasible for small producers.

Current treatment methods focus on the separation of oil and grease from produced water using oil/water separation tanks, hydrocyclones, and gas flotation devices; however these methods are not efficient for removal of dissolved organic compounds. For the removal of dissolved hydrocarbons, chemical clarifiers, membrane filtration, photocatalytic oxidation, phytoremediation, bubbler separation, and adsorption processes have been used.

Membrane filtration systems have been successful in treatment of some produced waters, but the results varied with influent water quality. The systems are not only costly but they require frequent maintenance (Santos and Wiesner, 1997). Particularly, reverse osmosis (RO) can remove sodium chloride, other monovalent salts, and some organics from produced water (IOGCC and ALL, 2006); however, operating costs increase as dissolved and particulate matter in the feed water deposit on the membrane surface (membrane fouling). Several types of fouling can occur including inorganic fouling (Gwon et al., 2003), particulate and colloidal fouling (Ning and Troyer, 2007), organic fouling (Agenson and Urase, 2007), and bio-fouling (Al-Ahmad et al., 2000). Therefore, proper pretreatment is required for the efficient operation of RO systems. Photocatalytic oxidation treatment using titanium oxide semiconductors has been used to remove BTEX from produced water (Bessa et al., 2001). This innovative technique is likely to be cost prohibitive. Phytoremediation of produced water was discussed by Negri and Hinchman (1997) using several halophilic plants. This low-maintenance process has the potential to economically reduce salt concentrations in produced water. Another method for removing dissolved organics from produced water is air stripping. Thoma et al. (1999) observed $40 \%$ removal of dissolved toluene and ethylbenzene from produced water in a bubbler separation process. Fang and Lin (1988) also reported greater than $99 \%$ benzene removal after less than 1 hour of air stripping. However, air stripping alone does not remove non-volatile compounds and does not provide complete destruction of the 
contaminants. A secondary treatment technique is required to degrade gaseous VOCs generated during air stripping.

Adsorption systems such as GAC have also been used to remove dissolved organic contaminants from produced water. GAC adsorption works effectively for organic compounds but is not effective for salinity reduction. In addition, the relatively high cost of GAC and difficulty in regeneration of saturated GAC are limiting factors for widespread use of GAC in these applications (Hansen and Davies, 1994). Recently, SMZ, a low cost sorbent that can be regenerated with relative ease, has been shown to remove hydrophobic organic contaminants from produced water (Ranck et al., 2005).

\subsection{Treatment of Produced Water by Surfactant-Modified Zeolite (SMZ)}

SMZ has been evaluated for the removal of a number of dissolved contaminants from aqueous solutions, particularly for BTEX compounds (Janks and Cadena, 1992; Neel and Bowman, 1992; Bowman et al., 1995; Ranck et al., 2005). Zeolites are hydrated aluminum tectosilicates characterized by cage-like structures having high internal and external surface areas, and high cation exchange capacities (CECs). Low organic carbon contents $(<0.5 \%)$ in natural zeolite limit the sorption of organic compounds, and this problem can be solved by adding a surfactant such as hexadecyltrimethylammonium (HDTMA) to the natural zeolite. HDTMA is commonly used in products such as hair conditioner, mouthwash, and fabric softener and was also found to be very stable on zeolite surfaces (Li and Bowman, 1998). Once SMZ is saturated with VOCs, it can be regenerated using air sparging (Li and Bowman, 2001). Ranck et al. (2005) reported successful removal of BTEX from produced water by adsorption on virgin and regenerated SMZ. They also verified that there was no significant reduction of sorption capacity of the SMZ for BTEX over 100 sorption/regeneration cycles (Altare et al., 2007). This ability to regenerate $\mathrm{SMZ}$ and its low cost $(\$ 460 / \mathrm{MT})$ make it a very promising sorbent for the treatment of produced water. However, the regeneration process produces a gas stream contaminated with VOCs. Thus a secondary treatment technique is necessary for gaseous VOCs.

\subsection{Biological Treatment of Produced Water}

Due to the high salinity of produced water, relatively little attention has been paid to biological treatment options although a few studies have been completed. Tellez et al. (2005) operated a field-scale activated sludge system to remove petroleum hydrocarbons from produced water. Researchers achieved 92\% removal of COD with a 12-hr HRT (Hydraulic Retention Time) and 20-day SRT in produced water containing 34,110 mg/L TDS. Dalmacija et al. (1996) increased the performance of an activated sludge system by adding powdered activated carbon (PAC) and diluting the oil-field brine wastewater with river water.

MBRs also offer promise for produced water treatment. Although no other researchers have used MBRs for produced water, they have been used to treat briny wastewaters. 
Bakx et al. (2000) observed more than $83 \%$ removal of COD in oil-contaminated water (sea water) from naval warships using an MBR. In other research, an MBR removed $88 \%$ of the COD and $99 \%$ of the BOD (biochemical oxygen demand) from a briny tannery effluent (Scholz et al., 2005). These results imply that biological options can be applied to the treatment of produced water.

Although direct biological treatment of briny produced water is difficult, biological destruction of the pollutants is possible if the organic contaminants are separated from the produced water prior to the biological treatment step. For example, a VPB can be used to treat the volatile compounds in the gas streams used to regenerate a saturated adsorbent such as SMZ. This method can be applied without concern regarding the salinity of the produced water.

\subsection{Vapor Phase Biofilters}

\subsubsection{Biofiltration Overview}

Biofiltration technology was initially applied to remove odorous compounds, such as $\mathrm{H}_{2} \mathrm{~S}$ from wastewater treatment plants. Since the 1980s, biofiltration has also been used to eliminate VOCs from a wide range of processes (Leson and Winer, 1991). In the biofiltration process, VOCs from the waste gas diffuse into an aqueous biofilm where they are converted to less harmless compounds such as $\mathrm{H}_{2} \mathrm{O}$ and $\mathrm{CO}_{2}$ by biological oxidation. Biofiltration technologies can be divided into three basic types: biofilters, bioscrubbers, and biotrickling filters. Biofilters are the simplest type of biological air pollution control. The contaminated gas stream passes through a packed bed on which biomass is attached. Biodegradable contaminants are absorbed into the biofilm and biologically oxidized into $\mathrm{CO}_{2}$ and $\mathrm{H}_{2} \mathrm{O}$. Bioscrubbers combine physicochemical removal with biological degradation by combining an absorption column in series with a bioreactor. Contaminated gas is first passed through an absorption tower packed with inert media where the pollutants are transferred from the gas to liquid phase. The liquid with the dissolved pollutants is subsequently treated in a separate bioreactor. The circulating liquid makes it easier to control reaction conditions in the bioscrubber as compared to the biofilter. However, bioscrubbers are effective only for highly water soluble compounds. Biotrickling filters are similar to biofilters in that the microorganisms growing on the packing media degrade the contaminants from the air stream. However, a liquid stream is sprayed over the bed continuously (or periodically), which makes it easier to control the operating conditions. Although these systems can achieve high removal efficiencies, they are prone to excess biomass accumulation in the bed (Alonso et al., 1997).

\subsubsection{Pollutants and Microorganisms}

A wide range of chemical pollutants can be treated by biofiltration including volatile organics and reduced sulfur and nitrogen compounds (Delhomenie and Heitz, 2005; Swanson and Loehr, 1997). The biodegradation of pollutants in biofilters consists of two 
steps: (1) mass transfer of pollutants from the gas phase to a liquid biofilm containing microorganisms, and (2) biological degradation of the pollutants by the microorganisms comprising the biofilm. Less volatile, readily degradable, and non toxic chemicals are more easily removed in these systems. Various microorganisms are responsible for pollutant degradation in biofiltration systems. Bacteria are most common in biofilters; however, fungal biofilters can also be effective particularly under adverse operating conditions such as transient loading, low moisture content and low $\mathrm{pH}$ (Cox and Deshusses, 1999; Pakula and Freeman, 1996; Woertz et al., 2001).

\subsubsection{Biofiltration Applications}

Historically, biofiltration has been used to remove odorous compounds such as $\mathrm{H}_{2} \mathrm{~S}$ from air emissions at wastewater treatment plants. Since the 1980s, however, it has also been used to eliminate VOCs in gases from a wide range of processes (Leson and Winer, 1991). The Clean Air Act Amendments in 1990 motivated additional biofiltration research and the search for new biofiltration applications. Industries emitting large volumetric flow rates containing low concentrations of VOCs are most suitable for biofiltration. A summary of the industries that have used biofiltration in the past are summarized in Table 2-1. Biofiltration has been used at fuel-contaminated sites, in particular, to remove BTEX compounds after soil vapor extraction (SVE) or bioventing (Jutras et al., 1997; Leson and Smith, 1997; Swanson and Loehr, 1997), since BTEX makes up as much as $18 \%$ of a gasoline's mass composition (Calabrese et al., 1993).

Table 2-1. Industries using biofilters

\begin{tabular}{|c|c|}
\hline Adhesive production & Municipal Wastewater Treatment \\
Chemical operations & Paint Spray Booths \\
Chemical Storage & Pet Food Manufacturing \\
Coating operation & Pharmaceutical industry \\
Cocoa Roasing & Petroluem processing \\
Coffee Roasting & Print Shops \\
Composting Facilities & Pulp and paper mills \\
Flavor and Fragrances & Residential wastewater treatment plant \\
Film Coating & Site remediation \\
Fish Frying & Slaughter Houses \\
Fish rendering & Tobacco Processing \\
Industrial Wastewater Treatment & Wood processing \\
Investment Foundries & Waste Oil Recycling \\
Landfill Gas Extraction & \\
\hline
\end{tabular}

(Leson and Winer, 1991; Wani et al., 1997) 


\subsubsection{Common Field Problems}

This section summarizes the common problems encountered when biofilters are operated in the field. These problems include bed acidification, bed drying, nutrient limitations, bed compaction and temperature variations. Where applicable, potential solutions proposed by other researchers are identified and discussed. Transient loading, which includes intermittent feeding periods and fluctuations in inlet VOC concentration, is one of the most important issues restricting the application of biofilters. The effects of these transient conditions on VPB performance are discussed in more detail in a separate section (Section 2.6.5) below.

\section{Bed Acidification}

During biofilter operation, $\mathrm{pH}$ drops occur frequently when acidic end products such as hydrochloric acid, nitric acid or sulfuric acid are produced as a result of the biodegradation process (Leson and Winer, 1991). Optimal pH for bacterial biofilters generally ranges from 6 to 9, while fungal biofilters can sustain growth at lower $\mathrm{pH}$ values (Leson and Winer, 1991; Madigan, 2000). A decrease in $\mathrm{pH}$ below the acceptable range inhibits microbial activity and can result in process failure (Swanson and Loehr, 1997). Also, acid gases and/or leachate can corrode ductwork, biofilter housing materials, and drainage systems (Ergas et al., 1995).

To maintain the $\mathrm{pH}$ within an acceptable range, various buffering materials are often mixed with compost packing materials in biofilter systems. These buffering materials include calcium carbonate (Smet et al., 1996), dolomite (Smet et al., 1999), oyster shells (Ergas et al., 1995), limestone and marl (Ottengraf and Vandenoever, 1983). Irrigating the packing media with a nutrient solution containing a $\mathrm{pH}$ buffer is also useful to prevent acidification of biofiltration systems such as bioscrubbers and biotrickling filters. Commonly used chemicals include $\mathrm{Ca}(\mathrm{OH})_{2}, \mathrm{NaOH}, \mathrm{NaHPO}_{4}$, and $\mathrm{NaHCO}_{3}$ (Tang et al., 1996; Zilli et al., 1996). Selecting a packing media with an inherent buffering capacity is another option. Soil has the best intrinsic $\mathrm{pH}$ buffering capacity, followed by compost and wood-chip materials (Smet et al., 1996; Kennes and Thalasso, 1998). In addition to adding an external buffer to the system, removing the source of acidic byproducts is another possible solution to the $\mathrm{pH}$ depression problem. Chitwood et al. (1999) used a two stage biofilter to treat $\mathrm{H}_{2} \mathrm{~S}$ and VOCs in off gas from a wastewater treatment plant. Because most of the $\mathrm{H}_{2} \mathrm{~S}$ was removed in the first stage of the biofilter, the second stage biofilter bed was protected from acidification that inhibits the removal of VOCs. In this manner, successful removal of both $\mathrm{H}_{2} \mathrm{~S}$ and VOCs was achieved in the biofiltration system.

\section{Bed Drying}

Stripping of moisture from the packed bed and subsequent desiccation of the biofilm is a common problem in field biofiltration systems. High gas flows and the increase of bed temperature caused by biological reaction can reduce the moisture content in the biofilter bed and inhibit microbial activity (Swanson and Loehr, 1997). Low bed moisture contents lead to bed desiccation and gas flow channeling, and deactivation of the VOC- 
degrading microorganisms. On the other hand, excessively high bed moisture contents lead to a reduction in the specific surface available for gas/liquid exchange and cause bed compaction and formation of anaerobic zones in the system (Leson and Winer, 1991). For compost beds, a moisture level of 40 to $50 \%$ is recommended (Bohn et al., 1992). Fungal biofilters can tolerate drier conditions and achieve high performance even at moisture contents ranging from 20 to $30 \%$ (Woertz et al., 2001).

Most biofilters use pre-humidification systems to saturate the inlet gas streams and prevent desiccation of the biofilter bed. Direct irrigation through a sprinkler at the top of the bed is also used (Leson and Winer, 1991; Swanson and Loehr, 1997). Sometimes both of these systems are used together to maintain moisture levels within the required range. A more advanced control option is the use of load cells which sense the weight of the filter, and then let the sprinkler work automatically as needed to maintain the weight (e.g., moisture level) in the packed bed.

\section{Nutrient Limitation}

Contaminant degradation in VPBs results in biomass growth. Nutrients such as nitrogen, phosphorous, sulfur, and trace elements are required for the growth of biomass in addition to the carbon supplied by the gas phase contaminants (Wani et al., 1997). Once free nutrients become limited via uptake by biomass or washout in the leachate, growth of the biofilm will slow until a stationary phase is reached, at which time nutrients are obtained from the lysis of dead cells (Morgenroth et al., 1996; Gribbins and Loehr, 1998).

Generally, there are two types of nutrient supply systems in biofilters. The packing media itself may contain nutrients. Compost is a commonly used packing media, since it generally contains the necessary nutrients required for the biomass growth. However, long term utilization of compost-based bed leads to exhaustion of the intrinsic nutrient resources (Corsi and Seed, 1995; Morgenroth et al., 1996; Song et al., 2003). Therefore, an external nutrient supply is inevitably required to maintain performance over long term operational periods. External nutrients are supplied in the solid form via nitrogen-based fertilizers (Cherry and Thompson, 1997; Gribbins and Loehr, 1998), directly mixed into the filter bed, or as a nutrient solution. For a synthetic packing media, frequent addition of a nutrient solution is essential and can be achieved by spraying a nutrient solution over the top of the biofilter. In some cases, nebulizers have been used to supply nutrients as a fine aerosol (Kinney et al., 1999; Song and Kinney, 2001), thus minimizing the liquid accumulation on the packing and reducing the pressure drop across the packed bed. For natural packing media such as compost, addition of a nutrient solution must be done cautiously since excess wetting may cause compaction of the packing media (Wright et al., 1997; Gribbins and Loehr, 1998). Mixing concentrated nutrient solution with compost prior to start up of the system is one potential solution (Kinney et al., 1999).

\section{Bed Compaction and Pressure Drop}

Excessive bed compaction and high pressure drops may result from moisture build up in the packing, excess biomass accumulation, the weight of the packed bed itself, or 
deposition of small particles from the gas streams into the packing media. These factors not only cause high pressure drops, but they can also hinder gas transfer across the bed, lead to gas channeling, and create anaerobic zones in the bed.

To prevent bed compaction, selection of a proper packing media is essential. Synthetic materials such as plastic pall rings, ceramic pellets, and foam have less compaction problems than do natural materials. In the case of natural materials, combining the natural material with inert bulking agents can be helpful. Wood chips, perlite, vermiculite, or polystyrene spheres are generally used as bulking agents (Swanson and Loehr, 1997). Williams and Miller (1992) suggested that the bed should contain at least $60 \%$ particles with a size greater than $4 \mathrm{~mm}$. Dividing a biofilter up into several packed sections can also reduce compaction since the weight of packing in each section is reduced. Another technique to reduce pressure buildup in a biofilter is to remove particles from the influent gas streams before it enters the packed bed.

In the case where excessive biomass growth is a problem, controlling nutrient levels can be used to minimize pressure drop problems, but this approach may also result in a decrease in system performance (Weber and Hartmans, 1996). Generally, biomass accumulates near the biofilter inlet where higher nutrient levels and VOC concentrations are present. One approach to evenly distribute the biomass is to operate the biofilter in directionally switching mode (Kinney et al., 1999; Song and Kinney, 2001). In this mode, the VOC feed is periodically alternated back and forth between the top and bottom of the column. Step feeding also distributes the biomass growth more evenly (Swanson et al., 1996). The VOC input in a step feeding system is split into several streams and introduced evenly to the biofilter bed.

After bed compaction has occurred, mechanical bed stirring (Laurenzis et al., 1998) and bed backwashing with water (counter-current washing) (Smith et al., 1996) can be used to remove the excess accumulated biomass. Chemical treatment (Cox and Deshusses, 1999) and introduction of biomass predators such as protozoa (Woertz et al., 2001) are also possible options.

\section{Temperature Variations}

Variations in packed bed temperature is another problem that affects the operation of biofilters in the field. The temperature of the source gas, ambient temperature variations as well as the level of microbial activity can all affect the temperature within the biofilter bed (Leson and Winer, 1991). Generally, bed temperatures between 20 to $40^{\circ} \mathrm{C}$ are often considered to be within the optimal temperature range for the microorganisms in biofilters (Kennes and Thalasso, 1998). However, the acceptable range will depend on the microbial community present in the biofilter. Biological activity roughly doubles for each $10^{\circ} \mathrm{C}$ rise in temperature, up to an optimum of about $37^{\circ} \mathrm{C}$ for mesophilic bacteria (Williams and Miller, 1992). Temperature control can be achieved by cooling or heating the influent air stream entering the biofilter. 


\section{Other Problems}

In addition to the problems described above, a range of other problems can hinder the performance of biofilters. For instance, the intrinsic biodegradability of a particular pollutant in a waste gas streams can affect the removals achievable in a biofilter system. Coupling a biofiltration system with an abiotic treatment system is one way to improve pollutant removal rates. For example, pollutants such as $O$-xylene are relatively difficult to biodegrade in gas phase biofilters. To enhance $o$-xylene degradation rates, Mohseni and Zhao (2006) coupled ultraviolet photolysis with biofiltration in a combined system. Some $o$-xylene was converted to biodegradable byproducts by photolysis prior to entering the biofilter yielding significantly increased overall removal of $o$-xylene in the coupled system. Some hydrophobic gaseous pollutants such as styrene are also relatively difficult to remove via biofiltration. In a manner similar to Mohseni and Zhao, van Groenestijm et al. (1994) used a UV-radiation photoreactor to convert styrene to readily degradable benzaldehyde prior to the biofiltration system. This combined process resulted in styrene elimination capacities that were three times higher than those achievable by a stand alone biofilter. In some applications such as the ventilation of road tunnels, the pollutants can be degraded in a biofilter but the volumetric flow rates are prohibitively high for biofiltration. Road tunnel ventilation gas contains very low concentrations $\left(50 \mathrm{mg} / \mathrm{m}^{3}\right)$ of $\mathrm{NO}$, but very large volumetric flow rates (many thousands of $\mathrm{m}^{3} / \mathrm{h}$ ), so direct application to a biofilter is inappropriate. In this case, pre-condensation onto activated carbon and thermal desorption before treatment in a downstream biofilter was found to be a feasible treatment combination (Chagnot et al., 1998).

\subsubsection{Transient Loading}

Extensive lab-scale studies of VOC destruction by VPBs have demonstrated that VPBs are an attractive method for gas phase pollutant treatment (Thomas et al., 1990; Morgan et al., 1993; Mallakin and Ward, 1996; Sorial et al., 1997; Wright et al., 1997; Lu et al., 2000). However, unlike many laboratory studies where stable conditions are maintained, field conditions are often quite variable and VPBs are subjected to transient pollutant loads (Dirk-Faitakis and Allen, 2003). A decrease in VPB performance is commonly observed in the field due to these variable operating conditions, which are unfavorable for biomass metabolism.

One common problem in the field is frequent shutdowns of the biofiltration system. Loss of biomass activity during carbon-deprived conditions can lead to poor performance of VPBs. For instance, Martin and Loehr (1996) observed that biomass activity dropped by almost $70 \%$ after 3 days of starvation, and it took 8 hours to recover full toluene removal capacity. Cox and Deshusses (2002) demonstrated that a biotrickling filter required 24 hours to reestablish full performance after 2-8 days shutdown. Moe and Qi (2004) observed the response of a fungal biofilter treating a gas phase solvent mixture during intermittent loading and showed that it required a longer time interval to recover its removal efficiency following long term (e.g., 9 day) VOC loading shutdown than it did for shorter periods of no loading. Wani et al. (1998) investigated the effect of starvation periods on a biofilter treating $\mathrm{H}_{2} \mathrm{~S}$. In their research, 25-30 hours was necessary to fully 
recover after 7 days of starvation, and 122 hours was necessary after 3 months of starvation.

In addition to frequent system shutdowns, variations in the VOC concentration in the waste gas streams are another challenge for VPBs. Sudden changes in the VOC concentration in the influent gas can cause poor performance of a biofiltration treatment system (Deshusses et al., 1997; Jorio et al., 2000; Wright et al., 2005). Most field tests report a wide range of VOC removal efficiencies in biofilters subjected to transient VOC loadings, even though the average removal was relatively high (Ergas et al., 1995; Leson and Smith, 1997; Wright et al., 1997; Chang et al., 2001; Choi et al., 2004).

Although numerous studies have examined the effects of transient loading on biofilter performance, little research has been done to mitigate these effects. In wastewater treatment facilities, load equalization basins are widely used as a pre-treatment process to minimize the effects of transient loading. Such equalization basins are not applicable to gas phase treatment systems but other approaches have been examined to minimize the negative effects of transient loading on biofilter performance.

Minimizing the decrease in biomass activity that occurs during periods of non loading is one possible solution. Park and Kinney (2001) demonstrated that a VPB supplied with a small but continuous VOC feed achieved much higher removal efficiencies following restart of the biofilter than did a system that was simply shut off and not provided any VOCs during the shutdown period. Aeration during non loading periods is also helpful to maintain biomass activity (Wani et al., 1998).

Mixing an adsorbent material into the biofilter packing media can also be used to buffer transient VOC loadings. GAC is a well known adsorbent that has been mixed with compost to provide buffering capacity against shock loads due to its high adsorption capacity (Medina et al., 1995); however coal particle, chaff, and diatomaceous earth, etc. are also used (Tang and Hwang, 1997; Chang et al., 2001). Abumaizar et al. (1998) investigated the effect that the quantity of GAC had on the performance of compost biofilters treating gas phase BTEX. For GAC quantities between 0 and $7 \%$ by volume, it was determined that increasing the GAC fraction in the compost packed bed, increased the removal efficiency achievable in compost biofilters subjected to BTEX concentrations varying from less than $50 \mathrm{ppm}_{\mathrm{v}}$ to $450 \mathrm{ppm}_{\mathrm{v}}$. However, these GAC mixed biofilters showed poor performance in response to sudden increases in BTEX concentration in the inlet gas stream. Weber and Hartmans (1995) also investigated the buffering efficiency of GAC when it was mixed with compost in a biofilter subjected to step feeds of high concentrations $\left(900 \mathrm{mg} / \mathrm{m}^{3}\right)$ of toluene. In this study, the authors found the GAC mixture provided negligible buffering capacity when the biofilter was subjected to high concentration fluctuations. Although the presence of GAC in the packing material appears to mitigate moderate fluctuations in inlet VOC concentration, the presence of water in a packed bed can greatly diminish the buffering capacity of activated carbon, since the contaminant must first diffuse through a water layer to reach the carbon surface (Weber and Hartmans, 1995). Although mixing adsorbent with packing media in a biofilter may be helpful to mitigate moderate concentration fluctuations, the proper 
quantity of adsorbent required for a given application is difficult to predict. Also, adjusting the load equalization capacity is difficult once the biofilter system has been installed. Thus, if the variations in inlet pollutant concentration vary to a greater extent than anticipated in the design, biofilter performance will suffer.

Al-Rayes et al. (2001) investigated the load dampening provided by a modified humidification system placed upstream of a biofilter. The water recirculating through the pre-humidification system absorbed the contaminants from the feed gas during periods of high concentration and desorbed them back to the gas stream when the inlet gas phase contaminant concentration declined. This system effectively buffered transient loading for hydrophilic compounds (acetone), but not for hydrophobic compounds. When an organic cosolvent was used in conjunction with water, hydrophobic compounds such as toluene were also effectively buffered. However, this system is effective only for shortterm variable concentration, and incurs extra energy costs for water recirculation and for operation of a heat exchanger to cool the recirculating water.

Another method to address transient loadings is to place a separate fixed bed adsorption column containing a buffering agent such as GAC in front of the biofilter bed. The GAC bed can accumulate VOCs during high concentration periods, and desorb contaminants during low concentration periods, resulting in more stable loading of VOCs to the VPB. Weber and Hartmans (1995) observed the performance of a GAC-fixed bed adsorption column during a series of toluene step feeding tests. When $1000 \mathrm{mg} / \mathrm{m}^{3}$ of toluene was introduced in a step feed manner ( $8 \mathrm{hrs}$ on/16hrs off), the GAC-fixed bed adsorption column attenuated the toluene concentration to a stable concentration of approximately $300 \mathrm{mg} / \mathrm{m}^{3}$. However, 16 hours per day was not enough time to completely desorb the adsorbed toluene. Thus, the buffering capacity of the GAC column would be expected to be greatly reduced over time if it was subjected to continuous step feed cycles.

Moe and $\mathrm{Li}$ (2005) also evaluated the effectiveness of a separate GAC-fixed bed adsorption column placed upstream of a biofilter subjected to step feeding of toluene and acetone. The response of the system to single-component contaminants and to contaminant mixtures was evaluated. As in the Weber and Hartmans (1995) study, contaminated air was supplied 8 hours per day and uncontaminated air was supplied 16 hours per day. When the toluene and acetone were supplied as single-component contaminants at concentrations ranging from $217 \mathrm{ppm}_{\mathrm{v}}$ to $868 \mathrm{ppm}_{\mathrm{v}}$, peak contaminant concentrations exiting the GAC column $(6.1 \mathrm{sec}-\mathrm{EBCT})$ were less than half of the influent concentration. However, when toluene and acetone were supplied as a mixture $\left(550 \mathrm{ppm}_{\mathrm{v}}\right.$ each), the acetone buffering was significantly reduced as a result of competitive sorption effects. As the more strongly adsorbed toluene accumulated in the carbon bed, it displaced the more weakly adsorbed acetone. The authors also investigated the relationship between toluene concentrations (from $210 \mathrm{ppm}_{\mathrm{v}}$ to 1000 $\mathrm{ppm}_{\mathrm{v}}$ ) and EBCTs (Empty Bed Contact Times) (from $1.5 \mathrm{sec}$ to $10 \mathrm{sec}$ ) on the performance of a GAC-fixed bed adsorption column (Li and Moe, 2005). They observed that the degree of load attenuation becomes more pronounced at lower contaminant concentrations and higher GAC EBCTs. As in the previous studies, however, the study only evaluated the response of the biofilter to step feeding ( $8 \mathrm{hr}$ on/16hrs off), in which a 
constant VOC loading was provided during each feed period. Those experiments can't truly mimic the field situation since actual contaminant concentrations in the field often change dynamically even during the loading period. Another limitation of previous GAC-fixed bed adsorption column tests is that they paid little attention to the humidity in gas streams. Numerous studies have shown that high RH in the inlet gas streams significantly decreases the adsorption capacity of solid adsorbents such as GAC, activated carbon cloth, and soil (Werner, 1985; Crittenden et al., 1988; Thibaud et al., 1993; Storey et al., 1995; Cal et al., 1996; Chen and Wu, 1998; Ruiz et al., 1998). Werner (1985) observed that TCE adsorption at a RH of $85 \%$ was only $9 \%$ of the amount adsorbed at a RH of $5 \%$ when $300 \mathrm{mg} / \mathrm{m}^{3}$ of TCE was applied. Crittenden et al. (1988) observed that $\mathrm{RH}$ values greater that $45 \%$ in a gas streams significantly decreased the adsorption of TCE on GAC. Cal et al. (1996) found that water vapor in a gas stream had little effect on benzene $\left(500 \mathrm{ppm}_{\mathrm{v}}\right)$ adsorption onto the activated carbon cloth until the $\mathrm{RH}$ exceeded $65 \%$, at which point a rapid decrease in adsorption capacity was observed. Thus, examining the effect of high RH on adsorption capacity is very important for developing proper design criteria for adsorbent-load equalization systems for VPB applications.

As noted above, a separate fixed bed adsorption column containing an adsorbent such as GAC is the most promising solution to mitigate the dynamic concentration changes expected during biofilter operation in the field. When this fixed bed adsorption column is operated passively, the gas streams containing the target pollutants simply passes through the fixed bed adsorption column where adsorption occurs when the concentration in the waste gas is high and subsequent regeneration occurs during periods of low inlet concentration. No external operator control or additional equipment is required, which minimizes the cost of the system. Also, replacing and adjusting the amount of GAC in a separate fixed bed adsorption column is easier than in biofilters where adsorbents have been pre-mixed with the packing material in the biofilter. However, the RH of the gas streams may significantly affect the buffering capacity. Also competitive adsorption of pollutants in the gas streams may be another issue that may diminish the buffering capacity of the GAC column. For successful application of an adsorbent-fixed bed adsorption column, additional research is necessary to determine the effect of these parameters on buffering capacity.

\subsubsection{BTEX Degradation}

Extensive studies of BTEX (Benzene, Toluene, Ethylbenzene, and three isomers of Xylene) biodegradation have been conducted over the last 10 years and high elimination capacities of these compounds have been obtained in biofilters over a wide range of loading rates (Thomas et al., 1990; Morgan et al., 1993; Mallakin and Ward, 1996; Sorial et al., 1997; Wright et al., 1997; Lu et al., 2000). Removal capacities of BTEX, however, vary considerably depending on the biofilter packing material utilized, operating conditions, microbial species present, concentration of each substrate, and inhibition by other compounds. 
Deeb et al. (2001) observed the degradation of BTEX by a pure strain, Rhodococcus rhodochrous, and by a microbial consortium derived from a gasoline-contaminated aquifer. In single component studies completed with each culture, toluene was degraded fastest, followed by benzene, ethylbenzene, and the xylenes. However when the cultures were provided BTEX mixtures, ethylbenzene degraded fastest, followed by toluene, benzene, and xylenes. Jorio et al. (1998) observed that the presence of a para, meta, and ortho - xylene mixture inhibited the biodegradation of toluene, but toluene negligibly inhibited the biodegradation of a xylene mixture in a peat biofilter. $m$-Xylene was degraded fastest, followed by $p$-xylene, and $o$-xylene among the xylene isomers. du Plessis et al. (2001) reported that toluene inhibited the degradation of benzene, ethylbenzene, and $m, o-$ xylene in a biofilter, which was acclimated to toluene, while $p$ xylene degradation was enhanced by the toluene. Also, toluene degradation was inhibited by the presence of benzene, ethylbenzene, and $m, o$-xylene. Lee et al. (2002) investigated the interaction of BTEX with Stenotrophomonas maltophilia T3-c. Xylene could not be degraded by the chosen culture, but the addition of toluene enabled the removal of xylene. Toluene degradation was enhanced in the presence of benzene, ethylbenzene, and xylene in binary systems. Benzene removal was also enhanced in the presence of toluene and xylene in a binary system, but decreased in the presence of ethylbenzene. In a compost biofilter, $p$-xylene inhibited the degradation of benzene and toluene, but the degradation of xylenes was not inhibited by the presence of benzene, toluene, and ethylbenzene (Quinlan et al., 1999).

Aerobic biodegradation kinetics of gasoline compounds by the enrichment of soil indigenous microbial population has been measured (Yerushalmi and Guiot, 1998). The presence of toluene and ethylbenzene suppressed benzene degradation, but the degradation rate of benzene increased when the relative concentrations of toluene and ethylbenzene in the mixture were lowered. The authors explained that the competitive inhibition was due to the fact that gasoline hydrocarbons have similar structures and share many enzymes in their respective biodegradation pathways.

Results of these studies indicate that substrate interactions in microbial systems such as VPBs vary with the microbial species present and substrate composition as well as the operating conditions of the microbial system. Therefore, one must be cautious when interpreting the reported results based on a specific set of conditions (Swanson and Loehr, 1997).

\subsubsection{Application of VPBs to the Treatment of Produced Water}

VPBs are typically used to treat biodegradable gas phase contaminants present in waste gas stream. However, VOCs present in a liquid phase can also be treated by VPBs, if the liquid phase contaminants are transferred to the gas phase. Treatment of produced water in an SMZ/VPB system is one such innovative method to treat liquid phase VOCs by coupling an SMZ adsorbent system with a VPB.

The SMZ/VPB system combines two technologies into one integrated system. Produced water passes through adsorbent beds of SMZ, which has high selectivity for produced 
water organics. Spent SMZ is regenerated via air stripping and the organic-laden air is directed to a VPB where the stripped organics are degraded to nontoxic products (Figure 2-1).

The most important issue for successful application of this combined SMZ/VPB system is to determine how to optimize the $\mathrm{SMZ}$ regeneration process for successful degradation of the BTEX constituents in a downstream VPB. The regenerated gas streams from used SMZ are expected to have very high concentrations of BTEX in the early stages of regeneration (on the order of thousands of $\mathrm{ppm}_{\mathrm{V}}$ or greater), but drop off exponentially as the air sparging process continues. As noted in numerous studies, biofilters often respond poorly to sudden changes in the VOC concentration in the influent gas streams (Deshusses, 1997; Jorio et al., 2000; Wright, 2005). For successful operation of a VPB coupled to an SMZ system therefore, a load equalization system before the biofilter is likely needed.

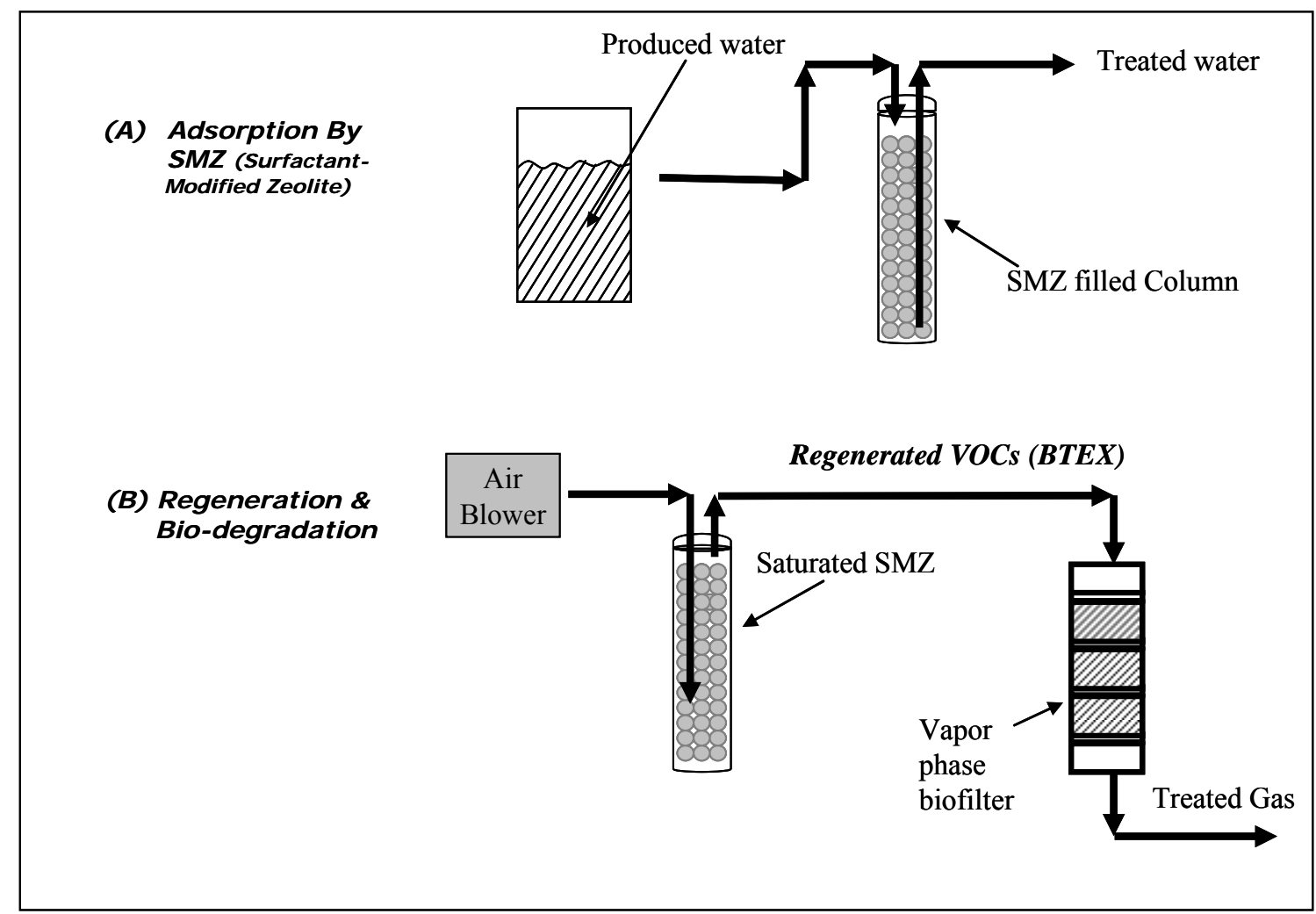

Figure 2-1. Schematic diagram of the SMZ/VPB system for treating produced water. 


\subsection{Membrane Bioreactors}

\subsubsection{Overview of Membrane Bioreactors}

MBRs have been in development for over 30 years and have been successfully used to treat municipal wastewater, industrial wastewater, and drinking water. MBR combines biological treatment and physical separation by a porous membrane in a single process. Organic pollutants in the influent are degraded biologically in a well mixed, aerated bioreactor by microorganisms, and microorganisms are removed from the treated wastewater by a membrane. The membrane provides a physical barrier for the suspended solids that retains all of the activated sludge in the bioreactor and produces a permeate free of suspended solid matter, bacteria, and viruses (Marrot et al., 2004). Separation of solids from the treated wastewater by the membrane is the main difference between MBR systems and traditional activated sludge systems where the effluent quality is highly dependent on clarifier operation. Currently, more than 2,200 MBRs are in operation or under construction worldwide with 75\% located in Great Britain, United States, Japan, France, China, South Korea, Germany, and Canada (Yang et al., 2006).

\subsubsection{Comparison of MBRs with Activated Sludge Systems}

Traditional activated sludge systems consist of an aeration tank followed by a clarifier as shown in Figure 2-2. Biodegradable organic compounds in the influent water are transformed to acceptable end products and new biomass by the microorganisms in the aeration tank. The treated wastewater containing biomass is then directed to a clarifier where the biomass and suspended solids are separated by gravity. The biomass solids settle to the bottom of the clarifier, and clean water exits the top of the clarifier. Some of the settled biomass is wasted while the remaining fraction is recycled to the aeration tank. The quality of effluent water strongly depends on the operation of the clarifier and high sludge concentrations in the aeration tank can lead to malfunctions in the clarifier. Generally, maintaining a biomass concentration in the aeration tank lower than 3,000 $\mathrm{mg} / \mathrm{L}$ is recommended for good clarification.

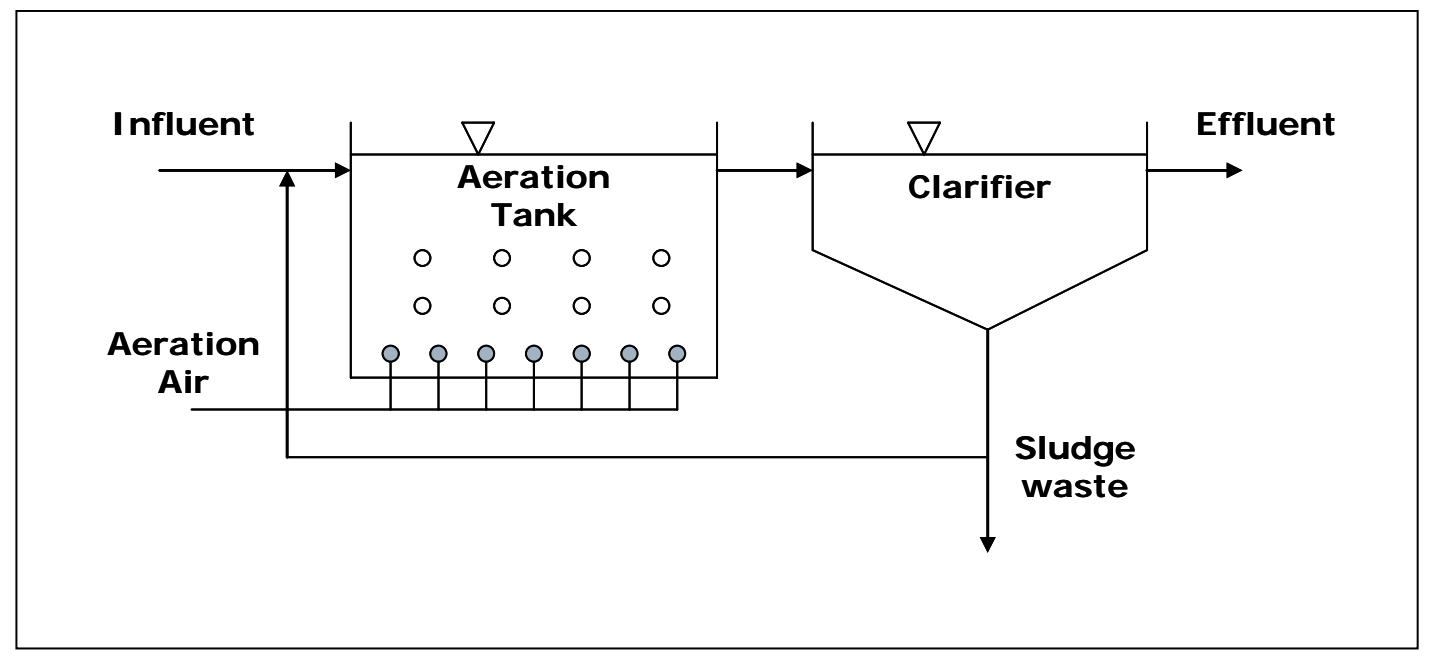

Figure 2-2. Schematic diagram of a traditional activated sludge system. 
An alternative method for achieving solid/liquid separation in wastewater treatment is to use membrane filtration instead of a clarifier. A MBR is an activated sludge system in which the clarifier is replaced by a microfiltration membrane. The membranes can be placed either outside or inside the bioreactor (Figure 2-3). For the external MBR, the mixed liquor is filtered under pressure in a separate module, whereas for the submerged MBR, the filtration is performed in the aeration tank via suction through a membrane separator. In the external MBR, the permeate flux generally varies between 50 and 120 $\mathrm{L} / \mathrm{hr}-\mathrm{m}^{2}$ and the TMP is in the range of 100 to $400 \mathrm{kPa}$. In the submerged MBR, the permeate flux varies between 15 and $50 \mathrm{~L} / \mathrm{hr}-\mathrm{m}^{2}$ and a typical TMP is approximately 50 $\mathrm{kPa}$ (Marrot et al., 2004). Submerged configurations are gaining favor recently since they have lower energy consumption (Huang et al., 2001).

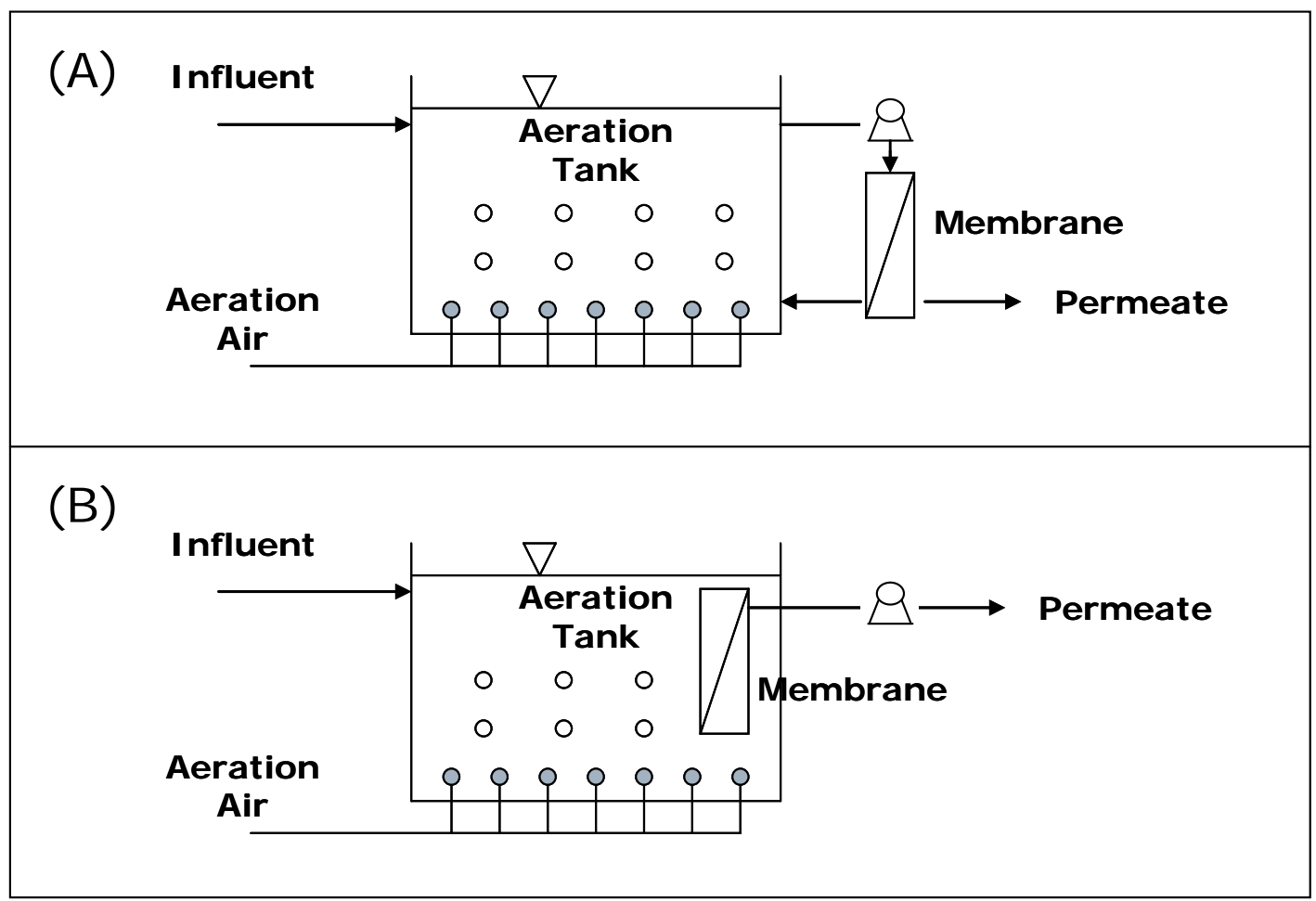

Figure 2-3. Configurations of the MBR: (A) external and (B) submerged.

When compared to traditional activated sludge systems, MBRs offer many potential advantages:

- Since the clarifier in a traditional activated sludge system is replaced by a membrane, the MBR is more compact, and the effluent water quality is independent of the sludge settling process.

- The MBR can be operated at higher biomass concentrations than can conventional activated sludge systems. To avoid malfunctioning of the clarifier, the traditional activated sludge system is operated at less than $3 \mathrm{~g} / \mathrm{L}$ biomass concentration, 
whereas MBRs can be operated at biomass concentrations as high as $20 \sim 30 \mathrm{~g} / \mathrm{L}$ (Jefferson et al., 2000; Yamamoto et al., 1989). Higher biomass concentrations in the MBR allow the treatment of higher strength organic wastes (Kurian et al., 2006). Also, MBRs can be operated at shorter HRTs, which reduces the size required for the aeration tank.

- Less disinfection is required since most bacteria and viruses are retained in the aeration tank by the membrane (Aim and Semmems, 2002)

- Sludge production is decreased by a factor of 2 to 3 , which results in a cost reduction (Gander et al., 2000).

Even though MBRs present many advantages, this technology also has some disadvantages including high capital costs, elevated energy costs, and high maintenance requirements. Membrane fouling also introduces some limitations to this technology and increases maintenance requirements as discussed below (Marrot et al., 2004).

\subsubsection{Membrane Fouling}

One of the major problems in the operation of membrane processes is membrane fouling. Membranes work by providing a selective barrier, rejecting the transport of some constituents when a driving force is applied. Mechanical sieving provides rejection of all particles larger than the pore size and partial rejection of particles smaller than the pore size. As particles accumulate on the membrane surface, they partially block the pores, reducing the effective pore size which reduces the flux through the membrane.

\section{Factors affecting membrane fouling}

The hydrophobicity of a membrane material affects membrane fouling. A hydrophobic membrane experiences higher fouling since it allows more organic compounds to accumulate on the membrane surface compared to a hydrophilic membrane (Choo et al., 2000; Sofia et al., 2004). Inorganic membranes can achieve higher fluxes than organic membranes, but the higher capital cost of inorganic membranes has prompted the use of membranes made of organic materials (Chen et al., 2005). Wastewater temperature is another factor affecting membrane fouling. Increasing the temperature of the wastewater decreases the viscosity of the fluid resulting in less fouling. However, energy costs and biomass activity effects must be considered before increasing temperatures. The existence of extracellular polymeric substances (EPS) in wastewater is thought to be the primary cause of membrane fouling (Sperandio et al., 2005; Lee et al., 2001). EPS are high molecular weight metabolites consisting of polysaccharides, proteins, nucleic acids, lipids and other biological macromolecules. Due to the hydrophobicity of these metabolites, EPS adsorbs inorganic and organic compounds in the MBR system and adheres to the membrane. High concentrations of more soluble EPS in wastewater have been related to increased membrane fouling (Fan et al., 2006; Rosenberger et al., 2003).

\section{Methods for reducing fouling}


Fouling can be reduced by increasing air sparging, backwashing the membrane, and/or by adding coagulants. When membrane operation is no longer feasible at high TMP, it must be cleaned, via physical and/or chemical means to restore the desired flux rate across the membrane.

Air Sparging. Air sparging is universally used in aerobic MBRs as the primary method to reduce membrane fouling. Vigorous aeration is applied beneath the membrane which scours the membrane in submerged membrane systems (Ognier et al., 2002; Kishino et al., 1996; Gui et al., 2003). Typically, medium to fine bubblers are used by running a gas line containing a series of one to two millimeter holes under the membrane.

Backwashing. Backwashing, also called back-flushing, uses pressure to flow the permeate water or air back through the membrane for a set period of time. Periodic backwashing improves membrane permeability and reduces fouling, thus leading to more stable hydraulic operating conditions (Bouhabila et al., 1998). The frequency and duration of backwashing depend on the operational parameters of the membrane system. One study found optimal backwashing with air in an aerobic MBR to be 15 minutes of operation for every 15 minutes of aeration. This increased the flux from 6 to $30 \mathrm{~L} / \mathrm{hr}-\mathrm{m}^{2}$ (Visvanathan et al., 1997). Bouhabila et al. (2001) also observed that air backwashing (15 sec every $5 \mathrm{~min}$ ) reduced the hydraulic resistance to less than a third of its value without backwashing.

Physical/Chemical Cleaning. Physical or chemical cleaning is not actually a method to reduce fouling; rather, it is a treatment to attempt to get the membrane back to its original flux capacity. Physical cleaning usually involves high pressure water and scrubber brushes to remove the deposits on the membrane surface. Chemicals commonly used for cleaning membranes in the water industry fall into five categories, as summarized in Table 2-2. Caustic solutions such as sodium hydroxide are used for organic and biological foulants while acidic solutions such as hydrochloric acid are used to remove inorganic foulants (Berube et al., 2006).

Addition of Additives. Another alternative approach is to modify the characteristics of the mixed liquor suspension using additives. The most common approach is the addition of powdered activated carbon (PAC) to the bioreactor. PAC addition affects fouling by reducing the concentration of EPS, increasing the average floc size, and providing shear force on the submerged membrane. PAC adsorbs fine colloids and dissolved organics, resulting in a shift to larger particle sizes. One study found that the mean particle size went from 7.5 to $22 \mu \mathrm{m}$ with the addition of $5 \mathrm{~g} / \mathrm{L}$ of PAC (Park et al., 1999). Another study using $1.7 \mathrm{~g} / \mathrm{L}$ PAC observed a similar trend which resulted in lower transmembrane pressures (TMPs) (Hu et al., 2007). Also, it is thought that PAC has a shear effect on a membrane. It scours particles that are deposited on the surface. Increasing PAC concentrations has been found to increase the flux at various TMPs (Ng et al., 2006; Seo et al., 2004). In other studies, PAC has been found to reduce the cake layer, stabilize influent conditions to avoid toxic shocks in the bioreactor, and increase the effluent water quality (Yoon et al., 2005; Seo et al., 2004). 
In addition to the fouling reduction, PAC addition to an MBR acts as a supporting medium for attached bacterial growth yielding biologically activated carbon (BAC). The biofilm on the PAC consists of immobilized (Dalmacija et al., 1996) and acclimatized bacteria (Lin et al., 2001) that can also partly bioregenerate the saturated BAC (Schloz and Martin, 1997). In addition, the bacteria in the PAC biofilm can enhance overall pollutant removal (Lin et al., 2001; Mochidzuki and Takeuchi, 1999).

Table 2-2. Major categories of membrane cleaning chemicals.

\begin{tabular}{|c|c|c|}
\hline Category & Major Functions & Typical Chemicals \\
\hline Caustic & $\begin{array}{c}\text { Hydrolysis } \\
\text { Solubilization }\end{array}$ & $\mathrm{NaOH}$ \\
\hline $\begin{array}{c}\text { Oxidants } \\
\text { Disinfectants }\end{array}$ & $\begin{array}{c}\text { Oxidation } \\
\text { Disinfection }\end{array}$ & $\begin{array}{c}\mathrm{NaOCl} \\
\mathrm{H}_{2} \mathrm{O}_{2}, \\
\text { Peroxyacetic acid }\end{array}$ \\
\hline Acids & Solubilization & $\begin{array}{c}\text { Citric acid } \\
\text { Nitric acid } \\
\text { Hydrochloric acid }\end{array}$ \\
\hline Chelating Agents & Chelation & $\begin{array}{l}\text { Citric acid } \\
\text { EDTA }\end{array}$ \\
\hline Surfactants & $\begin{array}{c}\text { Emulsion } \\
\text { Dispersion, } \\
\text { Surface conditioning }\end{array}$ & $\begin{array}{l}\text { Surfactants } \\
\text { Detergents }\end{array}$ \\
\hline
\end{tabular}

(Modified from Liu et al., 2000) 


\section{EXPERIMENTAL PLAN AND METHODOLOGY}

\subsection{Approach}

The research approach involved laboratory and field experimentation as indicated by the following tasks:

Task 1: Develop a load equalization process for the vapor phase bioreactor to reduce the concentration of BTEX at the front end of SMZ regeneration cycles

Task 2: Conduct a field test of the load equalization and SMZ/VPB system

Task 3: Evaluate the feasibility of utilizing a MBR system to remove carboxylate ions and BTEX from produced water

Task 4: Conduct a field test of the SMZ/MBR system.

Laboratory experiments were conducted to provide a better understanding of each component process. Laboratory VPB studies were designed to address the issue of influent variability and periodic operation. The majority of these studies were conducted as part our our previous project, DE-FC26-02NT15461. These experiments examined multiple cycles of influent loading and variable concentration loadings that simulated air sparging as the regeneration option for the SMZ system. Two pilot studies were conducted at a produced water processing facility near Farmington, New Mexico. The first field test evaluated SMZ adsorption, SMZ regeneration, VPB buffering, and VPB performance and the second test focused on MBR and SMZ/MBR operation. The design of the pilot study was based on the results from the previous experimental work.

\subsection{Biofilter Experiments}

\subsubsection{Baseline Tests}

\section{(A) Polyurethane Foam Biofilter}

The experimental biofilter column (I.D. $16 \mathrm{~cm}$, stainless steel) consisted of three individual sections bolted together (Figure 3-1). Each section was packed with polyurethane foam cubes $(1.5 \mathrm{~cm})$ to a height of approximately $19 \mathrm{~cm}$, which resulted in $12 \mathrm{~L}$ of total packing volume. A plenum located between each packed section allowed for gas sampling and redistribution of the contaminant stream between sections.

Microbial cultures that can degrade BTEX mixtures were developed prior to the inoculation of the VPB. The original culture was obtained from an activated sludge sample from the South Austin Wastewater Treatment Plant. Inoculation of the biofilter was accomplished by recirculating a BTEX-degrading microbial culture through the biofilter packing material for 12 hours. The design EBCT (media flow rate $(12 \mathrm{~L} / \mathrm{min}$ ) divided by reactor volume (12L)) for the gas phase was one minute and the total inlet BTEX concentration for the experiments was $130 \mathrm{ppm}_{\mathrm{v}}$ (Benzene 12, Toluene 24, Ethylbenzene 32 , para \& meta-xylene 22, ortho-xylene $40 \mathrm{ppm}_{\mathrm{v}}$ ). The ratio of each 
component in the BTEX mixture was selected to match the expected ratio in the waste gas produced during the SMZ regeneration process (Ranck et al., 2005).

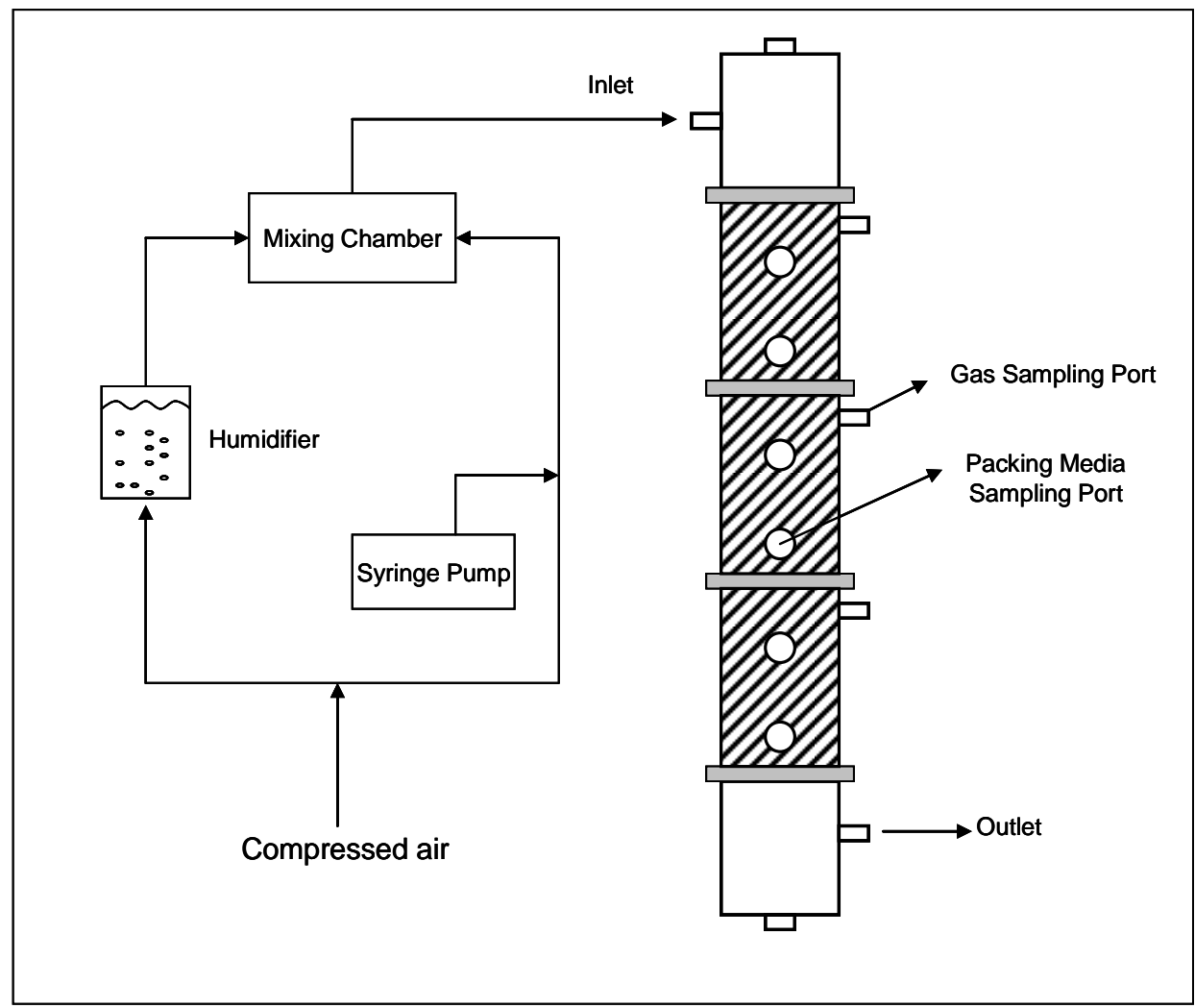

Figure 3-1. Schematic diagram of the experimental VPB.

The BTEX contaminants were injected into a small slip air stream using a syringe pump (Model 44, Harvard Apparatus, South Natick, MA). This contaminated air was mixed with humidified air in a mixing chamber prior to being introduced to the top of the biofilter (Figure 3-1). Twice a day, a modified hydrocarbon minimal medium was supplied as an external nutrient source to the biofilter for 30 minutes via a nutrient spray system.

\section{(B) Compost Biofilter}

The experimental reactor was similar to the polyurethane foam biofilter described previously, except that it was packed with a compost-based material. The compost filter media used to pack the columns consisted of the following materials (by volume): $60 \%$ compost, $36.5 \%$ perlite, and $3.5 \%$ crushed oyster shell. Before packing the media into the column, it was inoculated with a BTEX-degrading microbial consortium. To ensure the packing media would have enough nitrogen for an extended operating period, it was mixed with one liter of a concentrated nutrient solution prior to being placed in the biofilter column. The concentrated nutrient solution consisted of a hydrocarbon minimal medium (HCMM) solution that was modified by increasing the concentration of $\mathrm{KNO}_{3}$ by a factor of ten to $101 \mathrm{~g} / \mathrm{L}$. 


\subsubsection{Periodic Shutdown Tests}

The biofilter used in the continuous operation tests described previously was periodically subjected to shutdown tests that ranged from 1 to 2.8 days in length. During each shutdown test, no VOCs were provided to the column, but the air and humidity were supplied as usual. To ensure that the biofilter system stabilized between each shutdown test, the biofilter was supplied $130 \mathrm{ppm}_{\mathrm{v}}$ BTEX mixture continuously for a period of three days following each test. The recovery of the biofilter following each shutdown test was monitored until the total, overall removal efficiency of BTEX in the biofilter exceeded $90 \%$.

\subsubsection{Variable Loading Tests}

The compost-based biofilter system used in the previous task was used for the variable loading tests. During these experiments, the inlet BTEX concentration was increased rapidly (over 45 minutes) to approximately $380 \mathrm{ppm}_{\mathrm{v}}$ and then decreased to zero in an exponential fashion over an eight-hour period. Increases and/or decreases in BTEX concentration were obtained by adjusting the syringe pump feeding rate, while maintaining the air flow rate at $12 \mathrm{~L} / \mathrm{min}$. The relative composition of each BTEX component in the waste gas feed was consistent with the ratio provided during the continuous feed experiments (e.g., benzene $9.2 \%$, toluene $18.5 \%$, ethylbenzene $24.6 \%$, $p \& m$-xylene $16.9 \%$, o-xylene $30.8 \%$, by volume). After each variable loading test, the VOC feed to the biofilter was discontinued for 16 hours; although, the humidified air supply was continued during this period. These variable loading tests were intended to mimic the off-gas concentration profiles that would be expected from the SMZ system when it was being regenerated with air for 8 hours per day. The remaining 16 hours in which the biofilter received no contaminated air represented the period when the SMZ column(s) would be treating produced water and no contaminants would be fed to the downstream biofilter. Gas samples were collected with $0.5 \mathrm{~mL}$-gas tight syringes from sampling ports located along each column and immediately analyzed as described previously.

\subsubsection{Analytical Methods}

Gas samples were collected with $0.5-\mathrm{mL}$ gas tight syringes from sampling ports located along each column and immediately analyzed on a Hewlett-Packard 5890 gas chromatograph (GC) equipped with a flame-ionization detector (FID) was used to analyze BTEX. para- and meta- xylenes could not be distinguished from each other because they have the same retention time in GC-FID analysis. However, the sum of the para- and meta-xylene concentrations was determined. In addition, the distribution of biomass along the column, the pressure drop across the column as well as the ammonium, nitrate and moisture content were determined periodically as described previously (DEFC26-02NT15461). 


\subsection{Load Equalization Experiments}

\subsubsection{Experimental Column Reactors and Adsorption Studies}

\section{(A) SMZ- Fixed Bed Adsorption Column}

1,880 mg of SMZ (4-6 mesh) were packed in a fixed bed adsorption column (ID $16.2 \mathrm{~cm}$, stainless steel). The zeolite used in the study was obtained from the St. Cloud mine near Winston, New Mexico. Ranck et al. (2005) characterized the mineral composition of the zeolite as: $74 \%$ clinoptilolite, $5 \%$ smectite, $10 \%$ quartz/cristobalite, $10 \%$ feldspar, and $1 \%$ illute. HDTMA-Cl was used as the surfactant in the production of HDTMA-zeolite, as described by Bowman et al. (2001). Within the packed column, a perforated stainless steel plate was installed at the bottom of the packing to support the SMZ. Contaminant free air (average RH below 10\%) flowed through a pressure regulator. Liquid toluene (ACS reagent grade, Sigma, St, Louis, MO) was delivered by a syringe pump (KD Scientific, Boston, MA) and evaporated into the air stream. The air flow rate of the toluene laden air stream through the fixed bed adsorption column was maintained at 12 $\mathrm{L} / \mathrm{min}$ yielding a ten second-EBCT in the column. All experiments were conducted at an ambient laboratory temperature of $23^{\circ} \mathrm{C}$.

A pre-saturation/regeneration test was done to determine the adsorption capacity of SMZ for VOCs and to prepare for the following transient feed test. The adsorbent used as the buffering agent will experience continuous adsorption and regeneration cycles. Virgin adsorbent generally has higher adsorption capacity than regenerated adsorbent, which has already experienced adsorption and subsequent regeneration. Since simple air sparging may not regenerate all of the adsorbed VOCs from the adsorbent completely (Moe and Li, 2005), a decreased number of adsorption sites is available for the next adsorption/regeneration cycle. To determine the actual adsorptive capacity of the fixed bed adsorption column, it is more realistic to use a preconditioned adsorbent that has already experienced at least one cycle of adsorption and regeneration. To this end, air containing $920 \mathrm{ppm}_{\mathrm{v}}$ of toluene was introduced to the fixed bed adsorption column continuously until the effluent concentration from the fixed bed adsorption column equaled the influent concentration, at which point it was concluded that equilibrium had been reached. After three hours at equilibrium, the chemical feed was disconnected and the outlet concentration from the fixed bed adsorption column was monitored. The preconditioned SMZ-fixed bed adsorption column was then subjected to a variation in inlet toluene concentration. The peak concentration $\left(1000 \mathrm{ppm}_{\mathrm{v}}\right)$ of toluene was fed for 15 minutes, and then decreased exponentially. After eight hours, the chemical feed was disconnected and the concentration of toluene exiting the fixed bed adsorption column was monitored.

\section{(B) GAC-Fixed Bed Adsorption Column}

GAC was tested as an alternative adsorbent for the fixed bed adsorption column. $88 \mathrm{mg}$ of BPL GAC (4-6 mesh, Calgon Carbon Corp., Pittsburgh, PA) was packed in a fixed bed adsorption column (ID $10.16 \mathrm{~cm}, \mathrm{PVC}$ ). BPL GAC has a reported surface area of 1040

$\mathrm{m}^{2} / \mathrm{g}$ (Vidic, 1997). Contaminant-free air (average RH below 10\%) flowed through a 
pressure regulator at $12 \mathrm{~L} / \mathrm{min}$ resulting in a one second-EBCT in the fixed bed adsorption column. All experiments were conducted at the ambient laboratory temperature of $23^{\circ} \mathrm{C}$. Fresh GAC was completely saturated by introducing $1000 \mathrm{ppm}_{\mathrm{v}}$ of toluene continuously, and then regenerated by clean air until the exit toluene concentration from the fixed bed adsorption column declined below $0.01 \mathrm{ppm}_{\mathrm{v}}$. Following the pre-saturation/regeneration step to precondition the GAC, a series of toluene transient feed tests were conducted. In each transient feed test, an initial peak concentration $\left(1000 \mathrm{ppm}_{\mathrm{v}}\right)$ of toluene was supplied to the biofilter for a period of 15 minutes; the toluene concentration in the inlet waste gas stream was then reduced exponentially over the next 8 hours. After eight hours, the toluene feed to the column was discontinued, and the outlet concentration from the fixed bed adsorption column was measured continuously to monitor desorption of toluene from the GAC. To determine how the system would respond to repetitive cycles of toluene transient feeds, this 8-hours on/16-hours off pattern was repeated several times.

\subsubsection{Experimental Methods for Water Saturated Adsorption Experiments}

\subsubsection{Column Experiments}

This section describes the experimental procedures used in activated carbon-fixed bed adsorption columns for the transient loading of benzene and toluene in water saturated gas streams. Benzene and toluene were selected for study because they were the major components identified in the gas phase produced during SMZ regeneration in previous produced water laboratory and field tests (Ranck et al., 2005). As explained previously, gas streams produced during SMZ regeneration were saturated with water. Therefore, liquid phase adsorption isotherms were performed to quantify the adsorption capacity. Internal and external mass transfer coefficients were measured in SBA tests, and the HSDM was used to predict the fixed bed adsorption column behavior for the water saturated gas streams using the measured parameters.

\subsubsection{Activated Carbon Adsorption}

Individual activated carbon liquid phase adsorption isotherms were measured for benzene and toluene on BPL carbon. Competitive adsorption isotherms were also conducted for the mixture of both chemicals in order to compare IAST (Ideal Adsorbed Solution Theory) predicted competitive behavior to actual experimental behavior. IAST was developed by Myers and Prausnitz (1965) to predict competitive adsorption behavior from single component isotherm parameters. IAST is based on the concept of spreading pressure $(\pi)$, which is defined as the difference in surface tension between water on a clean surface and water on a surface covered with adsorbate. As the concentration of organics increases, the surface tension of the mixture tends to decrease, resulting in an increase of the spreading pressure. In IAST, the single component spreading pressure is equal to the spreading pressure of the mixture of compounds. Thus, the first step in applying IAST is to quantify single component adsorption equilibria. Crittenden et al. 
(1985) utilized the Freundlich isotherm model with IAST to predict multiple component equilibrium with heterogeneous adsorbents such as GAC.

All isotherms in this research used Calgon BPL GAC (Calgon Corp., Pittsburgh, PA). It was prepared for experiments by crushing, sieving, and washing as described by Peel and Benedek (1980) and Randtke and Snoeyink (1983). To accelerate the equilibration in isotherm tests, the $200 \times 325$ mesh size fraction (powdered activated carbon, particle size range of $45 \mu \mathrm{m}$ to $74 \mu \mathrm{m}$ ) was used in the bottle point experiments (Radntke and Snoeyink, 1983). The sieved carbon was washed to remove fines then dried overnight in an oven at $105^{\circ} \mathrm{C}$. After drying, the GAC was stored in amber bottles with PTFE-lined lids until used in the experiments. To calculate the actual dry weight of GAC used in the experiments, the moisture content of GAC was determined prior to each experiment, and typically ranged from $1.6 \sim 3.8 \%$.

Bottle-point isotherm tests were used for single components and dual component tests (Peel and Benedek, 1980; Randtke and Snoeyink, 1983). In the bottle-point method, each bottle was injected with identical amounts of benzene and/or toluene but contained varying masses of activated carbon. This procedure resulted in a different equilibrium concentration in each bottle. Bottles were agitated end-over-end for two weeks on a rotary mixer to achieve equilibrium. Equilibrium concentrations were then measured with a GC-FID.

\subsubsection{GAC Column Kinetics}

After the liquid phase isotherm tests were completed, GAC-fixed bed adsorption column experiments were run to estimate adsorption kinetic parameters including the film transfer coefficient $\left(k_{f}\right)$ and surface diffusion coefficient $\left(D_{s}\right)$ via HSDM and SBA technique.

The HSDM was used to predict the buffering behavior of the GAC column for transient loading of VOCs in water saturated gas streams. The HSDM is a widely accepted model that assumes that surface diffusion controls internal mass transfer, the adsorption of individual compounds follows the Freundlich isotherm, and IAST describes the competition among sorbates (Sontheimer et al., 1988). HSDM incorporates bulk and solid phase mass balances, an equation that combines the mass balances, and initial and boundary conditions for the mass balances. The model uses an orthogonal collocation method to convert the partial differential equations into a set of ordinary differential equations.

The SBA is an adsorber column sufficiently short in length to allow incipient breakthrough of the compounds being studied, yet still exhibiting hydrodynamic properties comparable to those of a deep-bed adsorber (Weber and Liu, 1980). Estimation of film transfer coefficients from SBA data assumes that film transfer dominates the initial stage of breakthrough in short beds and intraparticle diffusion the latter. 
A fixed bed adsorption column containing GAC (BPL activated carbon $4 \times 6$ mesh, Calgon Corp., Pittsburgh, PA) was constructed for use in a laboratory-scale evaluation of the buffering efficiency as depicted in Figure 3-2. The fixed bed adsorption column was made of stainless steel with an inner diameter of $5.08 \mathrm{~cm}$ and length of $30 \mathrm{~cm}$. Adsorptive and volatile losses were minimized by using only stainless steel, glass, and Teflon throughout the system. The column was packed with several materials to keep the GAC in place, promote plug flow through the column, and prevent short-circuiting. The GAC was supported by a stainless steel screen placed at the bottle of the column. Large glass beads, small glass beads, and a short section of glass wool were placed on top of the screen. After packing the GAC, glass wool and glass beads were placed on top of the GAC. A humidified gas streams was generated by passing hydrocarbon free air through an Erlenmeyer flask containing water to obtain a water saturated gas stream $(100 \% \mathrm{RH})$. VOCs were delivered by syringe pump in a separate line and were mixed with a humidified gas streams in a mixing chamber prior to introduction into the fixed bed adsorption column. All columns were operated in down-flow mode. The overall gas flow rate pumped to the column was $3.5 \mathrm{~L} / \mathrm{min}$ and all column experiments were performed at room temperature.

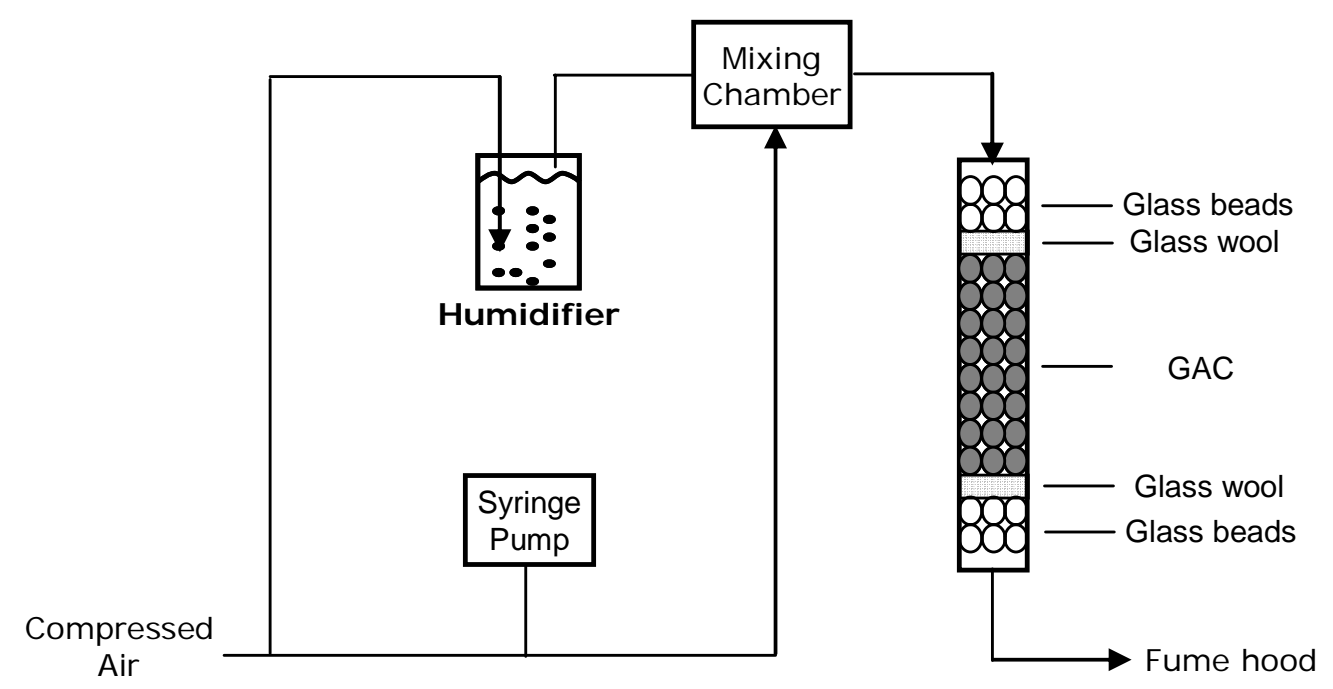

Figure 3-2. Schematic of the GAC-fixed bed adsorption column experimental setup. 


\subsubsection{Laboratory Analytical Methods}

For the SMZ-fixed bed adsorption column, gas samples were collected from inlet and outlet sampling ports to determine the toluene buffering capacity of the SMZ column. Samples were collected with gas-tight syringes and immediately analyzed using a gas chromatograph equipped with a flame ionization detector as described earlier in Section 3.1.2. For the GAC-fixed bed adsorption column, a sample of the gas entering and exiting the fixed bed adsorption column was diverted to a total hydrocarbon (THC) analyzer (3000 HD heated FID, K2BW Environmental Equipment Co.) and monitored automatically. Gas sampling lines were constructed using Teflon tubing. The RH and temperature of the gas stream were measured by a traceable hydrometer/thermometer (Fisher Scientific, Pittsburgh, PA).

\subsection{Field SMZ/VPB Methods}

\subsubsection{Field SMZ/VPB Experimental Methods}

A test of the coupled SMZ adsorption and VPB system was done at a Salt Disposal/Treatment facility near Farmington, New Mexico. Two Culligan fiberglass tanks (14" ID, 48" H) were packed with SMZ to a total packed capacity of $3.7 \mathrm{ft}^{3}$. The zeolite used in the study was obtained from the St. Cloud mine near Winston, New Mexico. It was subsequently crushed and sieved to grain sizes of 1.4 0.4 mm (14-40 mesh). Ranck et al. (2005) characterized the mineral composition of the zeolite as: $74 \%$ clinoptilolite, $5 \%$ smectite, $10 \%$ quartz/cristobalite, $10 \%$ feldspar, and $1 \%$ illute. HDTMA-Cl was used as the surfactant in the bulking production of HDTMA-zeolite, as described by Bowman et al. (2001). The same compost-based VPB (i.e., 12 L of total packing volume with three individual sections) and GAC-fixed bed adsorption column, operated in the laboratory tests described in the previous section were used in the field test. One additional section containing $4 \mathrm{~L}$ of fresh compost packing media was added to the existing biofilter to increase the total packed volume of the VPB to $16 \mathrm{~L}$.

Figure 3-3 shows the schematic diagram of the SMZ/VPB treatment system used in the field test. During the field test, produced water was passed through the two SMZ adsorption columns placed in series. Three different produced water flow rates were evaluated $(5,10$, and $27 \mathrm{gph})$. When the first column reached the target BTEX breakthrough for a given test (e.g., $30 \%$ to $100 \%$ ), the water flow to the first column was terminated, and the SMZ column was regenerated by air sparging, while the second column continued to treat produced water. After the first SMZ column was regenerated with air, it was connected again downstream of the second SMZ column and continued to treat produced water, resulting in a two column configuration again.

Prior to regenerating a saturated SMZ column, the water remaining in the column was drained by a peristaltic pump for 40 minutes. During regeneration, $13 \mathrm{~L} / \mathrm{min}$ of ambient air (Temperature $=20 \sim 28{ }^{\circ} \mathrm{C}, \mathrm{RH}=26 \sim 70 \%$ ) was supplied by an air blower to regenerate the drained SMZ column. Regeneration periods ranging from 4.9 hours to 44 hours were evaluated. The regenerated gas stream from an SMZ column was passed 
through a fixed bed adsorption column containing GAC. EBCTs of one and five seconds were chosen based on the HSDM predictions described in Chapter 4. Finally, the buffered gas stream passed through a humidifier and then flowed into the VPB, which was operated at an EBCT of 73 seconds. A drum of activated carbon was placed at the outlet of the VPB to capture any VOCs that escaped the VPB during field testing (Figure 3-3).

\subsubsection{Field Analytical Methods}

For the on-site analysis of BTEX concentrations in aqueous samples, $2.5 \mathrm{~mL}$-aliquots of each water sample was placed in a $10 \mathrm{~mL}$ vial fitted with a Teflon-faced butyl septum. The vial was placed in a heating block to equilibrate at $80{ }^{\circ} \mathrm{C}$ for 15 minutes. A $0.5 \mathrm{~mL}$ gas-tight syringe was used to extract gaseous samples from the headspace for subsequent analysis on a field GC. Gaseous samples from the inflow and outflow sampling ports of the VPB and GAC-fixed bed adsorption column were also collected with $0.5 \mathrm{~mL}$ gastight syringes. Gaseous samples were then injected into a HP Model 5890 Series II GC with a 30 m Restek capillary column (RTX-5; ID 0.53; DF 1.5). The RH and temperature of the regenerated gas stream were measured by a traceable hydrometer/thermometer (Fisher scientific, Pittsburgh, PA).

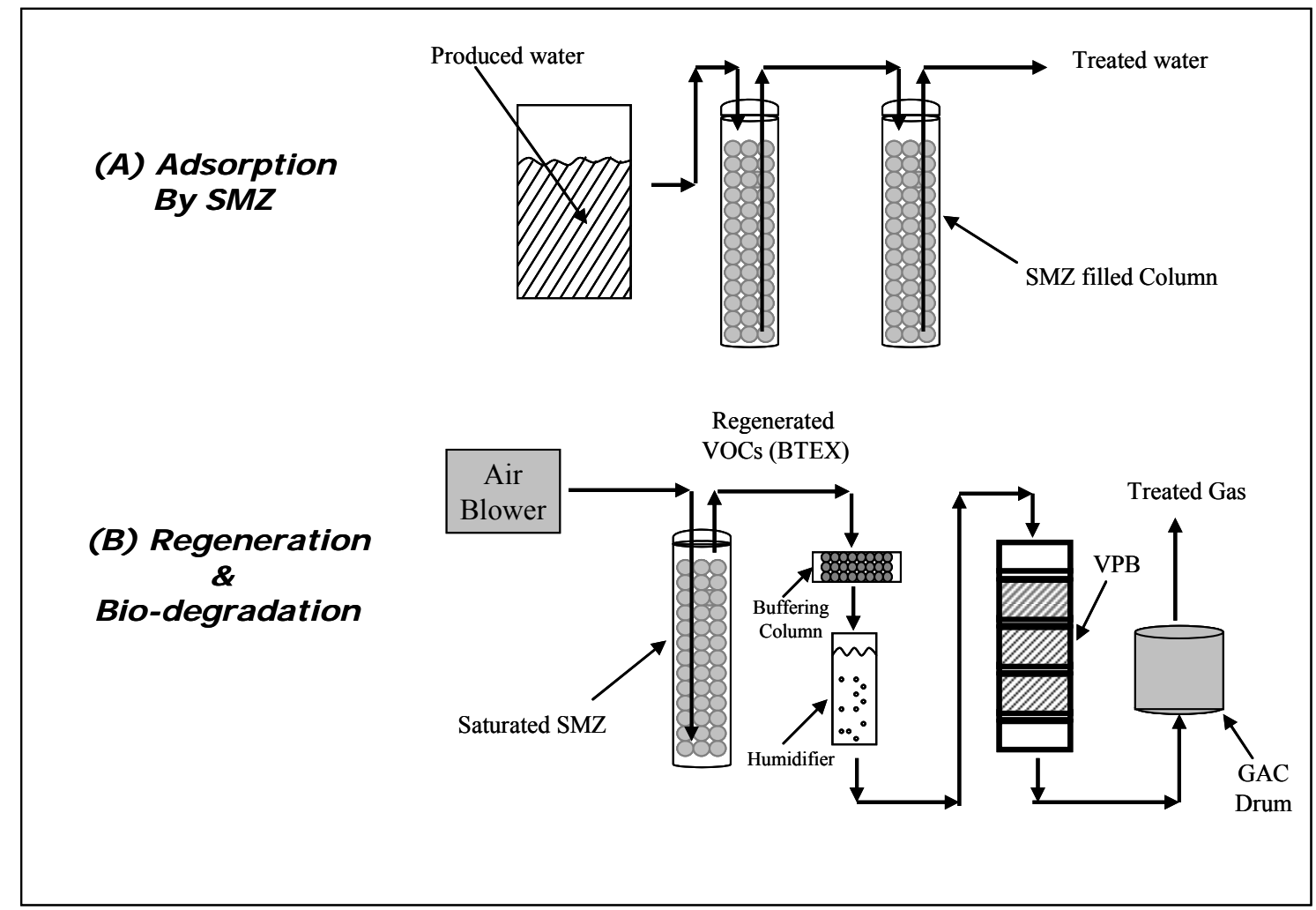

Figure 3-3. Schematic diagram of the SMZ/VPB treatment system used to treat produced water at the McGrath Salt Disposal/Treatment facility near Farmington, New Mexico. 


\subsection{Laboratory Membrane Bioreactor Studies}

\subsubsection{Bottle Studies}

A series of bottle tests were conducted to assess the ability of a mixed bacterial culture to degrade the two carboxylates (acetate and malonate) and the BTEX constituents typically detected in the produced water. Synthetic water that simulated the inorganic composition of produced water at a field site in Farmington, NM was used in the bottle studies (Katz et al., 2006). Two different synthetic solutions were investigated; one with $10 \mathrm{~g} / \mathrm{L}$ TDS which is the TDS level found at the New Mexico field site on August 2005 and one with a TDS level of $100 \mathrm{~g} / \mathrm{L}$ which represents the upper end of the TDS levels expected in produced water. Table 3-1 summarizes the composition of the two synthetic produced water solutions used in these experiments. In each experiment, acetate $(260 \mathrm{mg} / \mathrm{L})$ or malonate $(170 \mathrm{mg} / \mathrm{L})$ was provided as the sole carbon source in the synthetic produced water, which was inoculated with an adapted bacterial culture and amended to provide the nitrogen necessary for biological growth. The original culture was obtained from an activated sludge sample collected from the South Austin Wastewater Treatment Plant. The experimental system consisted of $250 \mathrm{ml}$-glass bottles each containing $100 \mathrm{ml}$ of synthetic produced water solution and $1 \mathrm{ml}$ of inoculum culture. The bottles were incubated at room temperature under aerobic conditions for two weeks.

Table 3-1. Composition of synthetic produced water solutions

\begin{tabular}{|c|c|c|}
\hline & $\mathbf{1 0} \mathbf{g} / \mathbf{L} \mathbf{T D S}(\mathbf{g} / \mathbf{L})$ & $\mathbf{1 0 0} \mathbf{g} / \mathbf{L} \mathbf{T D S}(\mathbf{g} / \mathbf{L})$ \\
\hline \hline $\mathrm{NH}_{4} \mathrm{Cl}$ & 0.3298 & 3.298 \\
\hline $\mathrm{KNO}_{3}$ & 0.7576 & 7.576 \\
\hline $\mathrm{MgSO}_{4}$ & 0.1159 & 1.159 \\
\hline $\mathrm{CaCl}$ & 0.1961 & 1.961 \\
\hline $\mathrm{KCl}$ & 0.1337 & 1.337 \\
\hline $\mathrm{NaCl}$ & 8.0214 & 80.214 \\
\hline $\mathrm{Na}_{2} \mathrm{SO}_{4}$ & 0.4456 & 4.456 \\
\hline $\mathrm{KH}_{2} \mathrm{PO}_{4}$ & 0.1000 & 1.000 \\
\hline
\end{tabular}

In a separate set of screening studies, the potential to biologically degrade BTEX compounds in produced water was assessed in a series of bottle experiments. As before, synthetic produced water with TDS levels of $10 \mathrm{~g} / \mathrm{L}$ and $100 \mathrm{~g} / \mathrm{L}$ were investigated. Each bottle was sealed an $\mathrm{d}$ then benzene (43 mg/L), toluene (43 mg/L), ethylbenzene (43 mg/L), $p$-xylene (43 $\mathrm{mg} / \mathrm{L}), m$-xylene $(43 \mathrm{mg} / \mathrm{L})$ or $o$-xylene $(17 \mathrm{mg} / \mathrm{L})$ was added to the bottle as the sole carbon and energy source. The bottles were incubated at room temperature under aerobic conditions for two weeks. 


\subsubsection{Membrane Bioreactor Studies}

A MBR was designed and constructed to assess the feasibility of using this technology to treat produced water containing carboxylates and BTEX compounds. A schematic of the experimental system is shown in Figures 3-4 \& 3-5 and the operation of the system is summarized in Table 3-2. One of the unique features of this bioreactor was that it could be sealed to enable collection of gas phase effluent samples.

Table 3-2. MBR experimental plan

\begin{tabular}{c|c}
\hline Experimental Phase & Supplied Compounds \\
\hline \hline Phase 1 & Carboxylates \\
\hline Phase 2 & Carboxylates + BTEX (gaseous) \\
\hline Phase 3 & Carboxylates + BTEX (aqueous) \\
\hline Phase 4 & Carboxylates \\
\hline
\end{tabular}

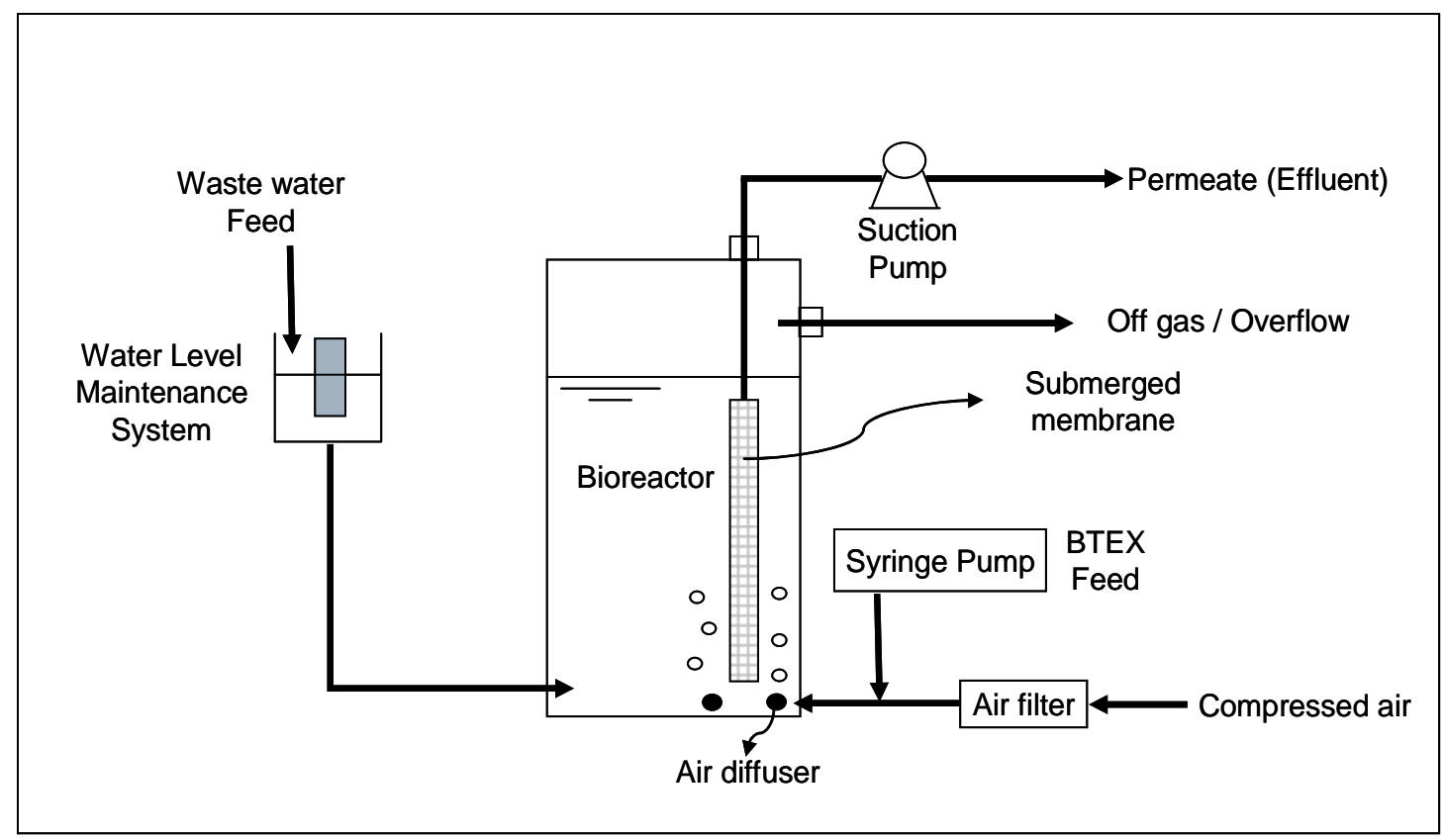

Figure 3-4. Schematic of experimental MBR system during Phases 1 \& 2 (Gaseous BTEX feeding). 


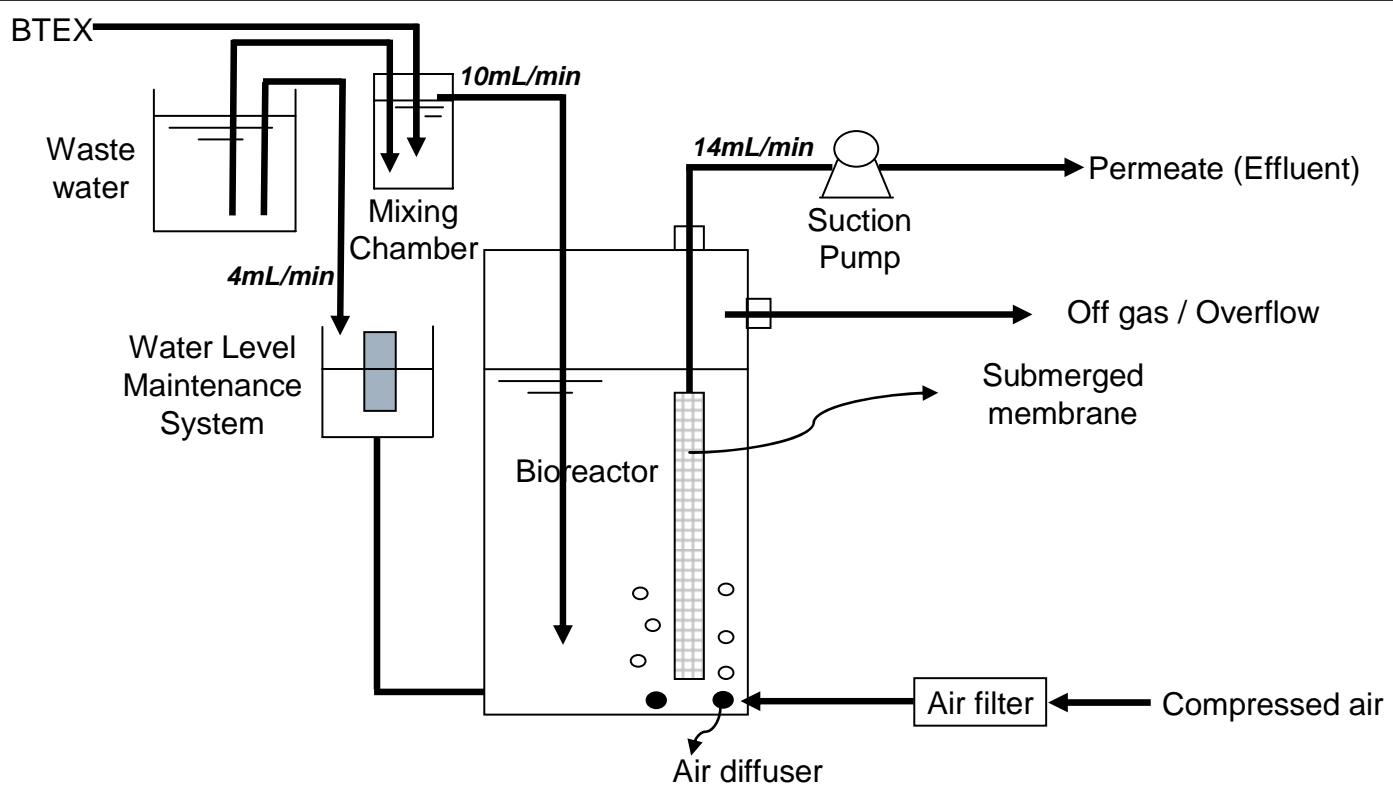

Figure 3-5. Schematic of experimental MBR system during Phases 3 \& 4 (Aqueous BTEX feeding).

The MBR experimental plan was divided into four separate phases. Figure 3-4 shows the schematic diagram for Phases $1 \& 2$, and Figure 3-5 for Phases $3 \& 4$. Periodically throughout the experiment, the $\mathrm{pH}$ of the influent produced water solution was adjusted by adding a dilute $\mathrm{HNO}_{3}$ solution to evaluate the effect of influent $\mathrm{pH}$ on the treatment process. For the first 54 days of operation (Phase 1), the only carbon sources provided to the MBR were the carboxylates, acetate and malonate. The objective of this phase of experiments was to examine the potential of the MBR to remove these carboxylates from saline wastewater.

On day 55, BTEX was also provided to the MBR through the aeration line located beneath the membrane (Phase 2). This phase of the experiment was intended to examine the capacity of the MBR to simultaneous remove both carboxylates and BTEX. The volatility and hydrophobicity of BTEX presented several experimental challenges. The MBR feed system was modified to allow BTEX to be introduced into the reactor in the gas phase through the aeration line. This simple and reliable approach had been successfully applied in the lab-scale VPB experiments discussed previously. In the field application, gas phase VOCs are present during produced water storage. Thus, not only does the modified feed system provide a convenient method to introduce BTEX into the MBR for our experimental system, it also provides an evaluation of the MBR system for gas phase treatment. However, in an actual field test, the BTEX would be dissolved in the influent produced water and thus it was deemed necessary to introduce liquid phase BTEX into the MBR during at least one phase of testing (Phase 3).

Prior to initiating Phase 3, a mixing chamber was installed upstream of the bioreactor as shown in Figure 3-5. 30\% of the carboxylate influent was directed to the MBR through 
the water level maintenance device employed in Phases $1 \& 2$ to maintain a constant water level in MBR. However, the remaining 70\% was mixed with pure aqueous BTEX in the mixing chamber, and this saturated BTEX solution was continuously delivered to the bottom of MBR with a peristaltic pump. This design provided a continuous and constant BTEX loading rate to the bioreactor. Prior to beginning Phase 3 experiments, preliminary testing was performed to quantify abiotic adsorptive or stripping losses of the BTEX from the MBR system. Influent (liquid phase) and effluent (liquid and gas phase) BTEX concentrations were measured for series of aeration rates $(2,3,5$, and $10 \mathrm{~L} / \mathrm{min})$ without biomass in MBR. This information was used to determine the volatilization rates for each BTEX constituent.

In the final phase of experimentation (Phase 4), the BTEX supply to MBR was terminated. Once again only carboxylates were supplied to the MBR as in Phase 1 to determine whether the presence of BTEX affected the MBR removal of the carboxylates. The experimental bioreactor depicted in Figures 3-4 \& 3-5 was $8 \mathrm{~L}$ in volume, rectangular in shape $(10 \mathrm{~cm} \times 22 \mathrm{~cm}$ x $49 \mathrm{~cm}$ high $)$ and constructed of 0.5 " Plexiglass. Preliminary testing showed that adsorption to the bioreactor was negligible. The system was aerated at $10 \mathrm{~L} / \mathrm{min}$ via a line air diffuser located directly beneath the bioreactor membrane. The aeration system provided sufficient oxygen to sustain the microorganisms and provided membrane scouring to minimize fouling. A flat sheet of microfiltration membrane consisting of a $0.4 \mu \mathrm{m}$ pore size, ultrasonically welded polyethylene sheet was suspended in the MBR as shown in the schematic. The dimensions of the membrane plate were $22.5 \mathrm{~cm} \times 32 \mathrm{~cm} \mathrm{x} 0.6 \mathrm{~cm}$ yielding a total membrane area of $1,170 \mathrm{~cm}^{2}$. Photographs of the experimental MBR system and polyethylene membrane sheet are provided in Figures 3-6 \& 3-7.

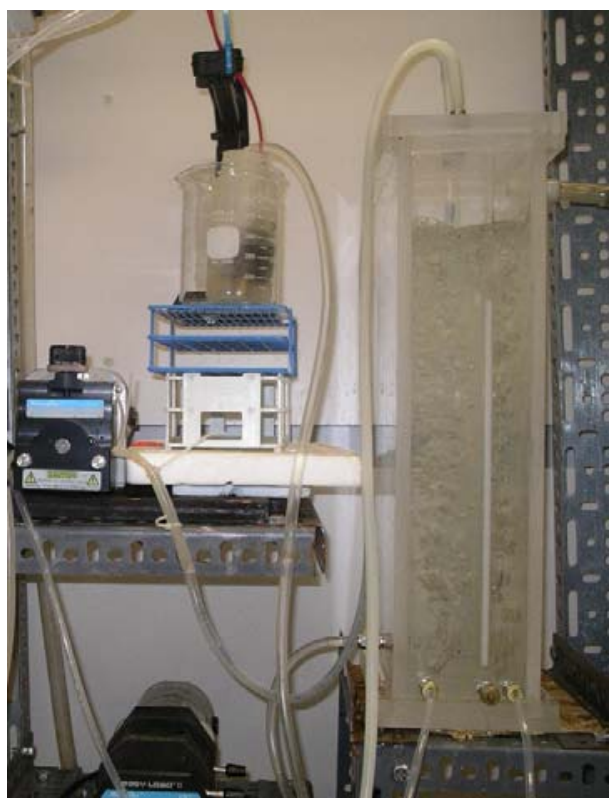

Figure 3-6. Experimental MBR system 


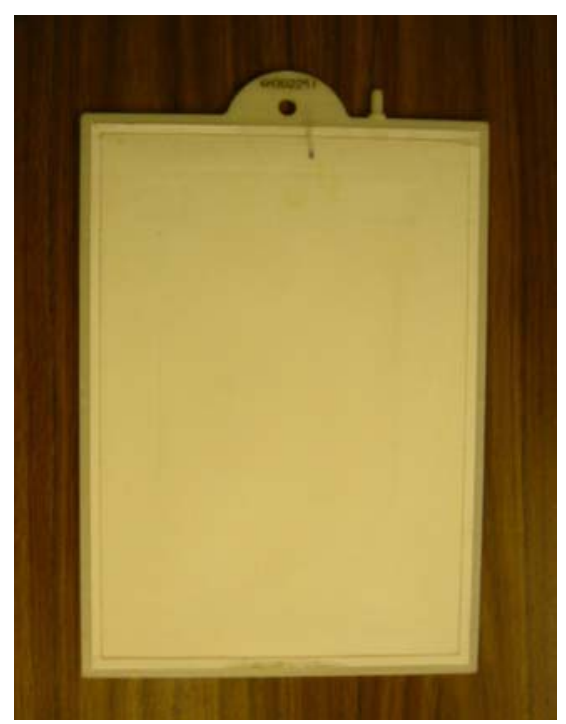

Figure 3-7. Ultrasonically welded polyethylene membrane sheet on an ABS plastic housing. Membrane was provided by Enviroquip, Inc. (Austin, TX).

A synthetic produced water solution with a TDS level of $10 \mathrm{~g} / \mathrm{L}$ was provided to the MBR at a rate of $20 \mathrm{~L} /$ day yielding a HRT of 9.6 hours in the system (Table 3-3). The SRT in the MBR was maintained at 100 days by withdrawing $80 \mathrm{ml}$ of biomass solution daily from the MBR. The composition of the synthetic produced water was selected to mimic the composition of the produced water found at the 2005 New Mexico field site (Table 3-4). Acetate and malonate concentrations were maintained at $260 \mathrm{mg} / \mathrm{L}$ and 170 $\mathrm{mg} / \mathrm{L}$, respectively throughout the study. BTEX concentrations were introduced starting on Day 55 are shown in Table 3-3.

\subsubsection{Analytical Methods}

Carboxylate concentrations in the influent and effluent of the MBR were measured using a Dionex DX-600 Ion Chromatograph (IC) with an AS 40 autosampler attached to. The IC was equipped with a Dionex CS25A conductivity detector, as ASRS ULTRA 4mm suppressor, an EG50 eluent generator, and an IonPac AS11-HC analytical column. The oven temperature was maintained at $30^{\circ} \mathrm{C}$ for each run, the suppressor current was set at $300 \mathrm{~mA}$, and the flow rate of the eluent $(\mathrm{KOH})$ through the column was $1 \mathrm{~mL} / \mathrm{min}$. The eluent concentration was set as follows: $1 \mathrm{mM}$ for the first 4 minutes, $2 \mathrm{mM}$ from 4.2 to 13.2 minutes, $10 \mathrm{mM}$ from 13.5 to 28 minutes, $2 \mathrm{mM}$ from 28.5 to 30 minutes, $30 \mathrm{mM}$ from 30.5 to 40 minutes, and $0.5 \mathrm{mM}$ from 40.5 to 44 minutes. During the bottle studies, aqueous samples were collected with $10 \mathrm{ml}$ gas tight syringes and also analyzed for carboxylates on the IC. For the analysis of BTEX during the bottle studies, gaseous samples were collected with $0.5 \mathrm{ml}$ gas-tight syringes from the head space of bottles and analyzed using a GC/FID (HP Model 5890). In the MBR experiments, aqueous samples were collected from the inlet and outlet of the MBR. Also, gaseous samples were collected from the aeration line and off gas line of the MBR and analyzed using GC/FID. 
Total suspended solids (TSS) and volatile suspended solids (VSS) were measured according to Standard Methods (APHA 1995) Sections 2540D and 2540E respectively. The TMP was measured in-line with a manometer connected to the tubing on the suction side of the permeate pump.

Table 3-3. Operating conditions of the MBR system

\begin{tabular}{|c|c|c|c|c|}
\hline Operational Parameters & Phase 1 & Phase 2 & Phase 3 & Phase 4 \\
\hline MBR Volume (L) & 8 & 8 & 8 & 8 \\
\hline Flow rate $(\mathrm{ml} / \mathrm{min})$ & 14 & 14 & 14 & 14 \\
\hline Aeration rate (L/min) & 10 & 10 & 10 & 10 \\
\hline HRT $^{1)}$ (hours) & 9.6 & 9.6 & 9.6 & 9.6 \\
\hline $\mathrm{SRT}^{2)}$ (days) & 100 & 100 & 100 & 100 \\
\hline Temperature $\left({ }^{\circ} \mathrm{C}\right)$ & 21 & 21 & 21 & 21 \\
\hline \multicolumn{5}{|l|}{ Carboxylates (mg/day) } \\
\hline Malonate & 3427 & 3427 & 3427 & 3427 \\
\hline Acetate & 5221 & 5221 & 5221 & 5221 \\
\hline BTEX (mg/day) & - & $\begin{array}{l}\text { Gaseous } \\
\text { Feeding }\end{array}$ & $\begin{array}{c}\text { Aqueous } \\
\text { Feeding }\end{array}$ & - \\
\hline Benzene & - & 460 & 460 & - \\
\hline Toluene & - & 840 & 840 & - \\
\hline Ethylbenzene & - & 50 & 50 & - \\
\hline$p \& m$-xylene & - & 310 & 310 & - \\
\hline o-xylene & - & 140 & 140 & - \\
\hline
\end{tabular}


Table 3-4. Composition of synthetic produced water solutions

\begin{tabular}{|c|c|}
\hline Chemical & Concentration $(g / \mathbf{L})$ \\
\hline \hline $\mathrm{NH}_{4} \mathrm{Cl}$ & 0.10 \\
\hline $\mathrm{KNO}_{3}$ & 0.10 \\
\hline $\mathrm{MgSO}_{4}$ & 0.12 \\
\hline $\mathrm{CaCl}_{2}$ & 0.22 \\
\hline $\mathrm{KCl}$ & 0.15 \\
\hline $\mathrm{NaCl}$ & 9.00 \\
\hline $\mathrm{Na}_{2} \mathrm{SO}_{4}$ & 0.46 \\
\hline $\mathrm{KH}_{2} \mathrm{PO}_{4}$ & 0.10 \\
\hline Acetate & 0.26 \\
\hline Malonate & 0.17 \\
\hline
\end{tabular}

\subsection{SMZ/MBR Field Studies}

\subsubsection{SMZ/MBR Field System}

A test of the coupled SMZ adsorption and MBR system was done at the same site that was used for the field testing of the VPB system described in Chapter 4 (i.e., a salt disposal/treatment facility near Farmington, New Mexico). Produced water delivered to the site is treated using sand filters, fiber-wound five-micron and one-micron filters prior to deep well re-injection. A Culligan fiberglass tank (14" ID, 48" H) was packed with SMZ (Bottom 65\%) and raw zeolite (Top 35\%) to a total packed capacity of $3.7 \mathrm{ft}^{3}$. With this packing method, any surfactant desorbed from the SMZ could be captured by the raw zeolite placed downstream of the SMZ. The SMZ was produced as described by Bowman et al. (2001) with 14-40 mesh zeolite particles as described in Chapter 4 (again the same as in the previous field trial). The same MBR (i.e., $8 \mathrm{~L}$ of total reactor volume) and polyethylene membrane $(0.4 \mu \mathrm{m}$ pore size $)$, operated in the laboratory tests and described in Chapter 6 were used in the field test. Biomass used in the laboratory test (Chapter 6) was also transported to the field site and used to reduce the acclimation period.

A schematic of the experimental system is shown in Figure 3-8 and the operating parameters of the system are summarized in Table 3-5. During the field test, produced water passed through the SMZ adsorption column prior to entering the MBR. The SMZ system was operated upstream of the MBR to assess carboxylate removal efficiencies in the MBR in the absence of BTEX and other hydrophobic contaminants which are removed on SMZ. The produced water flow rate through the SMZ column was set at 25 
$\mathrm{ml} / \mathrm{min}$. This produced water passed through a small Erlenmeyer flask containing a rubber cap before it was directed to the MBR. The design flow rate to the MBR was 14 $\mathrm{ml} / \mathrm{min}$, and the remaining SMZ treated produced water was discharged to a sump. For the operation of the MBR, external nutrients were supplied directly to the MBR as shown in Figure 3-8. A stock nutrient solution consisting of $4.0 \mathrm{~g} / \mathrm{L}$ of $\mathrm{KNO}_{3}, \mathrm{NH}_{4} \mathrm{Cl}$, and $\mathrm{KH}_{2} \mathrm{PO}_{4}$, was continuously pumped into the bioreactor. The resulting design HRT was 9.6 hours in the MBR. The SRT was 100 days by withdrawing $80 \mathrm{ml}$ of biomass solution daily from MBR. Compressed air was supplied at a flow rate of $7.5 \mathrm{~L} / \mathrm{min}$ to an air diffuser located directly beneath the bioreactor membrane.

Due to the accumulation of biomass on the membrane over time, the effluent flow rate slowly decreased with time resulting in an unbalanced flow rate between the influent and effluent streams. To address this problem, a water level controller (Vertical mounted liquid level switch, Omega Engineering Inc.) was installed to control the influent pump rate and to maintain a constant water level in the MBR.

After the system reached stable operating conditions, $2 \sim 5 \mathrm{~g} / \mathrm{L}$ of PAC (NUCHAR SA-T 1320-R-05, MeadWestvaco inc., Covington, VA) were added into the MBR (2g/L on Day 27 , another $3 \mathrm{~g} / \mathrm{L}$ on Day 29) to investigate the effect of PAC on the performance of the MBR, particularly for organic removal and potential flux increase. The average PAC particle size of $100 \mu \mathrm{m}$ was produced by passing the material through a $120 \times 200$ mesh sieve.

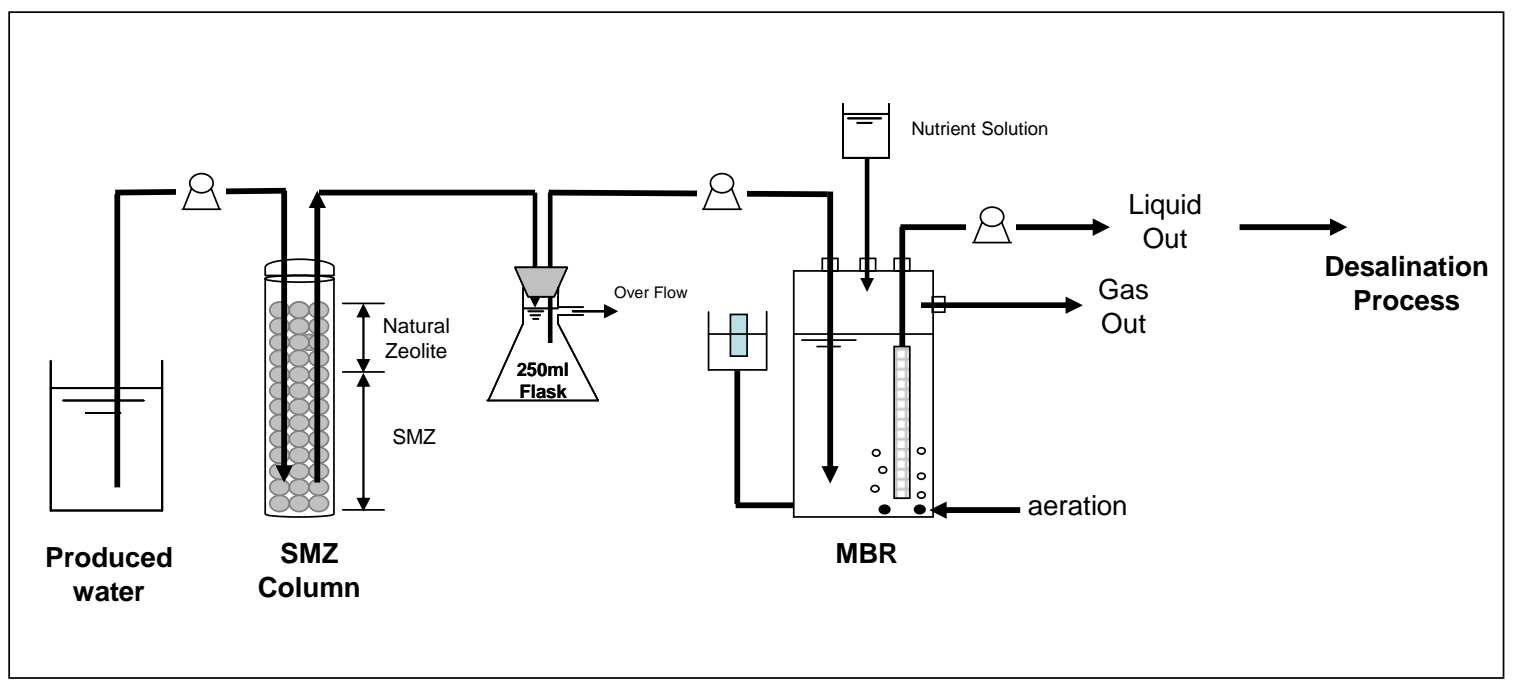

Figure 3-8. Schematic diagram of the SMZ/MBR treatment system used to treat produced water at the McGrath Salt Disposal/Treatment facility near Farmington, New Mexico. 
Table 3-5. Operating conditions of the SMZ/MBR system

\begin{tabular}{l|c}
\hline \multicolumn{1}{c|}{ Operational Parameters } & Values \\
\hline \hline SMZ column Volume (L) & 105 \\
MBR Volume (L) & 8 \\
Flow rate (ml/min) & \\
Through SMZ column & 25 \\
Through MBR & 14 \\
Aeration rate in MBR (L/min) & 7.5 \\
HRT ${ }^{1)}$ in MBR (hours) & 9.6 \\
SRT ${ }^{2)}$ in MBR (days) & 100 \\
PAC ${ }^{3)}$ amount (g/L) & $2 \sim 5$ \\
pH of influent & 8.5 \\
Temperature $\left({ }^{\circ} \mathrm{C}\right)$ & 21 \\
\hline${ }^{1)}$ HRT $:$ Hydraulic Retention Time $^{2)}$ SRT : Solids Retention Time & \\
${ }^{3)}$ PAC : Powdered Activated Carbon &
\end{tabular}

\subsubsection{SMZ/MBR Field Analytical Methods}

Treatment system monitoring included both on-site and off-site analyses. The on-site analyses included measuring aqueous phase BTEX concentrations as well as gas phase BTEX concentrations in the MBR off-gas. Off-site analyses of the produced water included analyzing VOCs, SVOCs, cations and anions, carboxylates and TOC concentrations.

The on-site aqueous and gaseous BTEX concentrations were measured using a HewlettPackard (HP) Model 5890A GC with a 10-m, 0.53-mm I.D. HP-5 capillary column and flame ionization detector. The carrier gas $(\mathrm{He})$ had a flow rate of $35 \mathrm{~mL} / \mathrm{min}$ and the split gas $(\mathrm{He})$ flow rate was $28 \mathrm{~mL} / \mathrm{min}$. No makeup gas was utilized. The analyses were performed isothermally at $55^{\circ} \mathrm{C}$, with an injector temperature of $210^{\circ} \mathrm{C}$ and detector temperature of $240^{\circ} \mathrm{C}$. For the analysis of BTEX concentrations in aqueous samples, 2.5 $\mathrm{mL}$ aliquots of each water samples were placed in a $10 \mathrm{~mL}$ vial fitted with a Teflon-faced butyl septum. The vial was placed in a heating block and equilibrated at $80^{\circ} \mathrm{C}$ for 15 minutes. A $0.5 \mathrm{~mL}$ gas-tight syringe was used to extract gaseous samples from the headspace for subsequent analysis on a GC. The BTEX concentrations in gaseous samples from the sampling ports of the MBR were analyzed by direct injection into the same GC. $p$-xylene and $m$-xylene were not resolved by this method and were treated as a 
single compound. On-site analyses also included DO (Dissolved Oxygen), temperature, conductivity, and TMP. The TMP was measured in-line with a manometer connected to the tubing on the suction side of the permeate pump.

Carboxylates concentrations were measured at the University of Texas in Austin using a Dionex AS 40 autosampler attached to DX-600 Ion Chromatograph (IC). The IC was equipped with a Dionex CS25A conductivity detector, as ASRS ULTRA 4mm suppressor, an EG50 eluent generator, and an IonPac AS11-HC analytical column. The oven temperature was maintained at $30^{\circ} \mathrm{C}$ for each run, the suppressor current was set at 300 $\mathrm{mA}$, and the flow rate of the eluent $(\mathrm{KOH})$ through the column was $1 \mathrm{~mL} / \mathrm{min}$. The eluent concentrarion was set as follows: $1 \mathrm{mM}$ for the first 4 minutes, $2 \mathrm{mM}$ from 4.2 to 13.2 minutes, $10 \mathrm{mM}$ from 13.5 to 28 minutes, $2 \mathrm{mM}$ from 28.5 to 30 minutes, $30 \mathrm{mM}$ from 30.5 to 40 minutes, and $0.5 \mathrm{mM}$ from 40.5 to 44 minutes.

Total suspended solids (TSS) and volatile suspended solids (VSS) were also measured at the University of Texas at Austin according to Standard Methods (APHA 1995) Section $2540 \mathrm{D}$ and $2540 \mathrm{E}$ respectively. 


\section{RESULTS AND DISCUSSION}

\subsection{Summary of Previous VPB Results}

Extensive biofiltration studies have examined the treatment of gas phase BTEX and verified that VPBs can be an efficient technique for removing these contaminants from waste gas streams. However, VPB performance is a strong function of several design and operating conditions including packing media selection, nutrient supply, EBCT, $\mathrm{pH}$, and biomass distribution. Also, VPBs have difficulty handling the transient feed conditions typically encountered in field applications.

To address these challenges, a series of experiments were completed as part of DOE Project No. DE-FC26-02NT15461. The major results from this work that are pertinent to the current research project are summarized below.

\subsubsection{Baseline Biofilter Experiments}

In the first phase of the research completed as part of DOE Project No. DE-FC2602NT15461, a VPB system was operated in the laboratory under stable, continuous feed conditions to evaluate the impact of key operational parameters that affect performance and to provide a baseline for subsequent experiments assessing performance under suboptimal conditions. Two biofilters, one packed with polyurethane foam (synthetic media) and one packed with a compost-based material (natural media) were investigated in this stage of the research. The biofilter system that was found to provide the most reliable removal of a BTEX-laden waste gas was selected for further testing in the laboratory under variable loading conditions and then, ultimately in the field as part of a produced water treatment system.

The experiments conducted with a lab-scale biofilter packed with polyurethane foam (synthetic media) and operated with a steady supply of VOCs indicate that this system can achieve high BTEX removal efficiencies once the nutrient delivery system is optimized. The xylene isomers were found to require the greatest biofilter bed depth for removal over long term operation indicating that these VOCs could ultimately control the size of the biofilter needed in a field application. Neither bed acidification nor significant pressure drop was observed after four months of operation indicating that the polyurethane foam biofilter has the potential to be used in field applications. However, frequent nutrient addition was required to maintain performance - a fact that would be cumbersome at some field applications where minimal operating support is provided.

The experiments conducted with a lab-scale biofilter packed with compost-based materials indicate that this system can achieve high BTEX removal efficiencies within two weeks of start up. Mixing of a concentrated nutrient solution during the biofilter start up ensured high removals of BTEX for extended periods without external nutrient addition. No bed acidification was observed during the operating period due to the buffering provided by the oyster shells in the bed. However, the original nutrient supply present in the compost packing material was eventually depleted, and an external nutrient 
supply was necessary for long term operation. The frequency of nutrient addition required was much lower than that required by the polyurethane foam biofilter. The pressure drop across the compost bed is the main drawback of natural media, but this problem could be minimized by mixing inert media with the compost. Considering the fact that many of these treatment systems are located in remote areas where minimal maintenance is desired, a compost-based packing media is a better choice than polyurethane foam.

\subsubsection{Response of Biofilters to Periodic Shutdown Conditions}

Biofilters packed with polyurethane foam or compost-based materials can achieve high BTEX removals during continuous operation, as demonstrated in the previous research. However, one challenge to field application of biofilters is frequent system shutdowns. These shutdowns may result from unintentional maintenance problems or may be intentional as part of scheduled shutdowns resulting from the operating schedule of the facility. As compared to other physicochemical treatment systems, biological treatment systems are more sensitive to unsteady operation, since periods of carbon deprivation can affect biomass metabolism and result in a deterioration of biofilter performance. It is therefore necessary to investigate the response of biofilters to periodic system shutdowns to better delineate the tolerance of biofilters for periodic shutdowns. For this reason, a series of periodic shutdown tests were conducted as summarized below.

The experiments conducted with lab-scale biofilters packed with polyurethane foam and compost-based materials demonstrated that both biofilters could recover rapidly from one-day and 2.8-day shutdowns indicating that these systems were resilient to short-term, discontinuous feed conditions. Both biofilters showed improved performance after repeated one-day shutdowns suggesting that the biomass could acclimate to repeated short-term shutdowns. As the shutdown period increased to 2.8 days, however, the negative impact on VOC removal efficiencies following resumption of the VOC feed was more significant. It is interesting to note, however, that in both the 1-day and 2.8-day shutdown tests, the biofilters required approximately the same time period ( 8 hours) to recover the VOC removal efficiency observed prior to each shutdown test.

Despite the promising results obtained with the polyurethane foam and compost-based biofilter during continuous and periodic shutdown feeds, one must consider the fact that the inlet concentration of VOCs during the loading period will not always be constant in the field as they were during the shutdown tests discussed above. In particular, a VPB that is treating the regeneration off-gas from a saturated SMZ adsorption column will be subjected to initially high inlet concentrations that then decline as the regeneration process continues.

\subsubsection{Response of Biofilter to Variable Loading Conditions}

Results of the previous experiments demonstrated that biofilters can effectively treat BTEX-contaminated waste gas streams under continuous feed conditions as well as after short-term shutdown periods. However, the constant VOC concentration supplied during 
the feed period of those previous tests is unlikely to occur in field applications. For example, a VPB treating the SMZ regeneration off-gas in an SMZ/VPB system will not be treating a constant influent composition. In the SMZ regeneration process, ambient air is sparged through the saturated SMZ column to remove the adsorbed BTEX contaminants. During regeneration, the initial contaminant concentrations in the gas stream are extremely high (on the order of thousands of $\mathrm{ppm}_{\mathrm{v}}$ ) but drop off exponentially as the sparging process continues (Figure 4-1). Benzene and toluene have very high initial concentrations as compared to the other chemicals present in the gas stream. This variable loading of BTEX to the VPB could result in lower VOC removals in the biofilter. It was, therefore, necessary to investigate the response of a VPB to this type of transient loading and to assess whether a load equalization system was warranted to improve the performance of the VPB system.

A single variable feed test was done to determine how the system would respond to the variations in BTEX concentration. The maximum BTEX concentration detected in the exit gas stream from the biofilter was $57 \mathrm{ppm}_{\mathrm{v}}$ when the inlet BTEX concentration was increased rapidly to $380 \mathrm{ppm}_{\mathrm{v}}$. (See Figure 4-2).

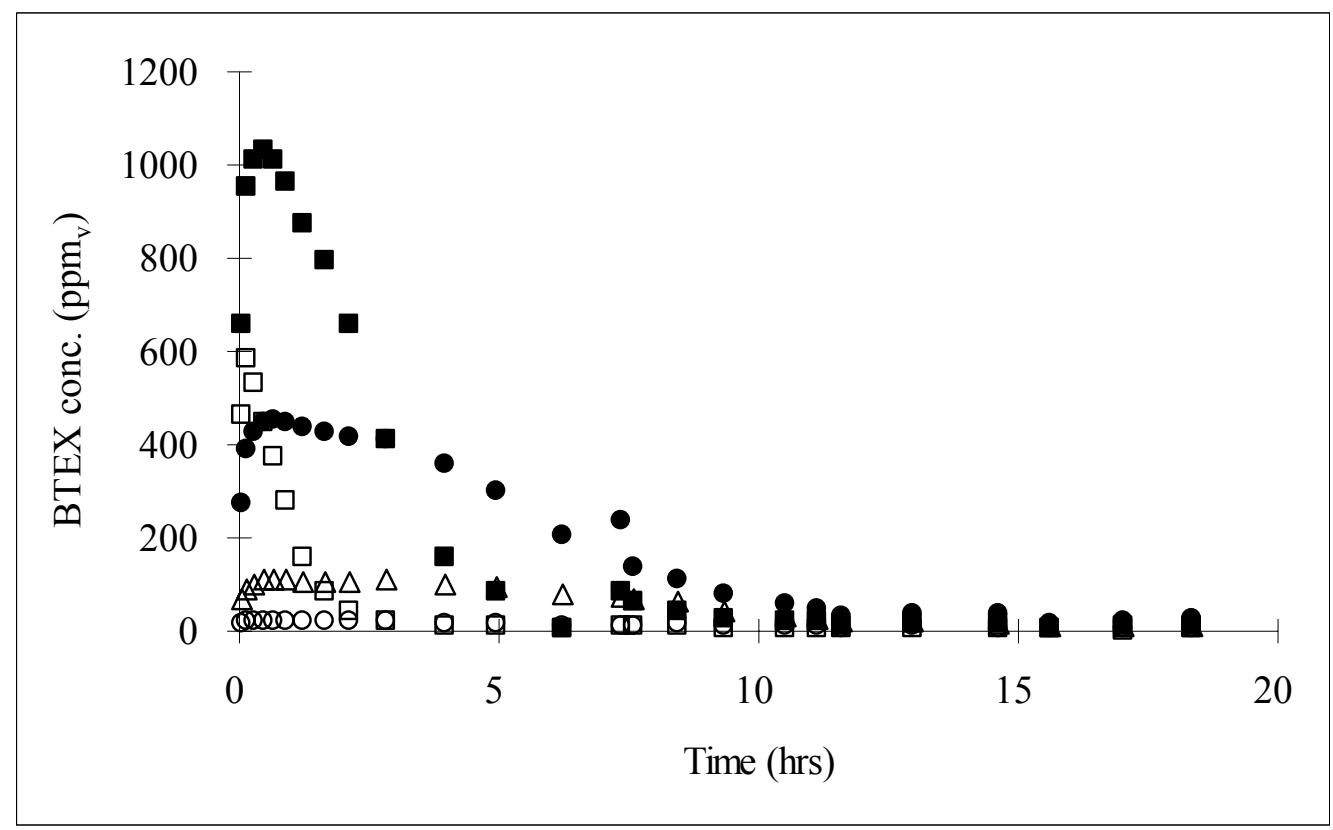

Figure 4-1. Typical concentration profile of gas phase effluent during the regeneration of a saturated $\mathrm{SMZ}$ column. Air flow rate for the regeneration was 7.5 ml/min. ( $\square$; Benzene, $\square$; Toluene, $\circ$; Ethylbenzene, $\bullet$; p\&m xylene, $\Delta$; o-xylene). Column dimensions; $0.4 \mathrm{~cm}$ (radius) X $10 \mathrm{~cm}$ (length). $\mathrm{SMZ}$ size; 0.15-0.18 mm. Experimental results provided by Craig Altare at New Mexico Tech (Altare et al., 2006) 


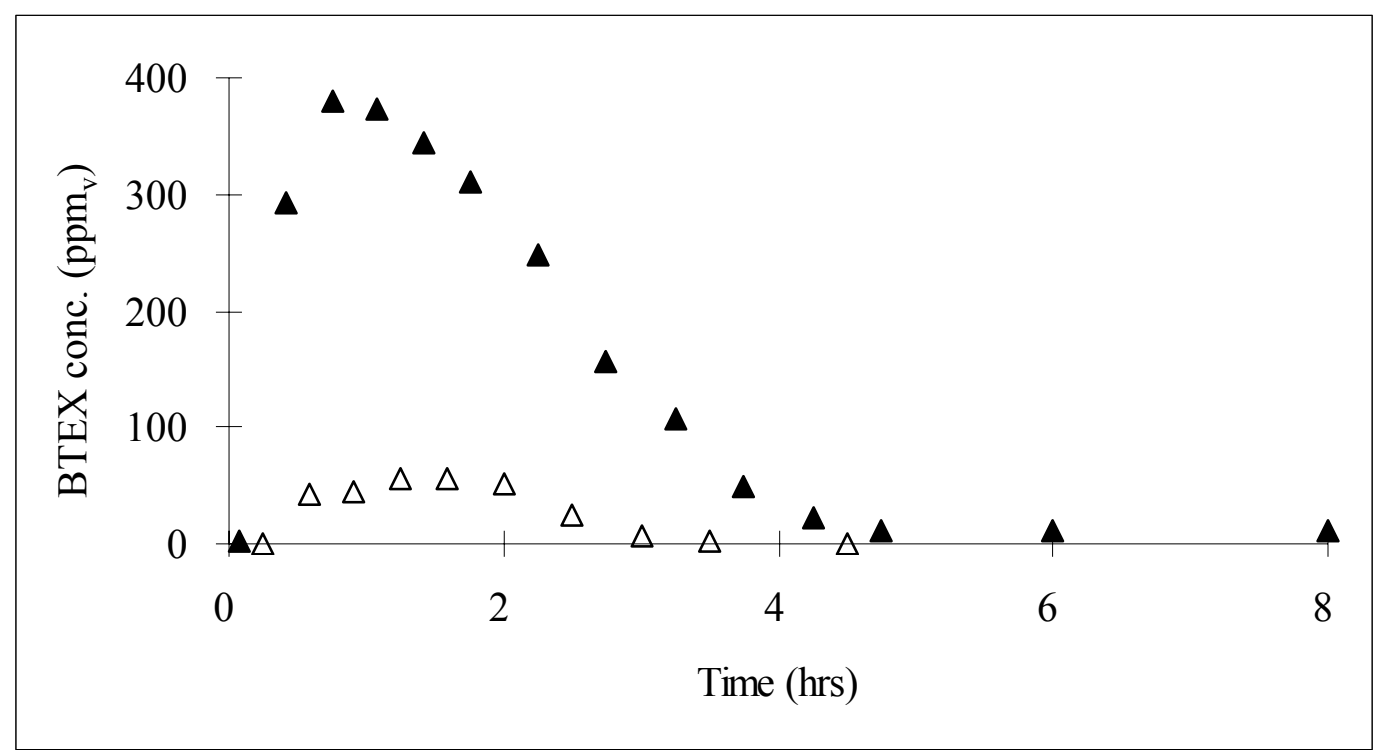

Figure 4-2. Response of the compost biofilter to a BTEX variable loading. The total BTEX concentration to the VPB was suddenly increased to $380 \mathrm{ppm}_{\mathrm{v}}$, and then decreased exponentially. ( $\triangle$; BTEX concentration introduced to VPB, and $\Delta$; effluent BTEX concentration from VPB)

Based on the results of the periodic shutdown tests, the previous history of the biofilter is expected to affect its response to variations in inlet concentration. Prior to conducting the single variable test, the biofilter had been continuously supplied a waste gas stream contaminated with $130 \mathrm{ppm}_{\mathrm{v}}$ BTEX and thus the biomass in the system would be expected to be quite active. In an actual field situation, the biofilter may receive the VOCs intermittently for a long time and thus the biodegradation capacity of the biomass may be diminished. For example, the actual period that the biofilter will receive a VOCladen waste gas streams in a produced water treatment system will depend on the regeneration frequency of the SMZ columns and how they are coupled to the downstream biofilter. Thus, it is important to determine how the biofilter would respond to cyclical variations in inlet BTEX concentration as would be expected when it is coupled with the SMZ columns. To address this issue, the biofilter was subjected to repeated variations in VOC loadings as described previously ( 8 hours on /16 hours off per day). Results showed that the maximum outlet BTEX concentration on the second day of the variable loading test increased to approximately $95 \mathrm{ppm}_{\mathrm{v}}$ where it remained for the rest of the cycles. Thus, the total BTEX removal efficiency at the point of maximum outlet concentration was approximately $75 \%$ (Figure 4-3). During these repeated variable loadings, the removal of benzene was most adversely affected, and the removal of toluene was found to be the most stable. 


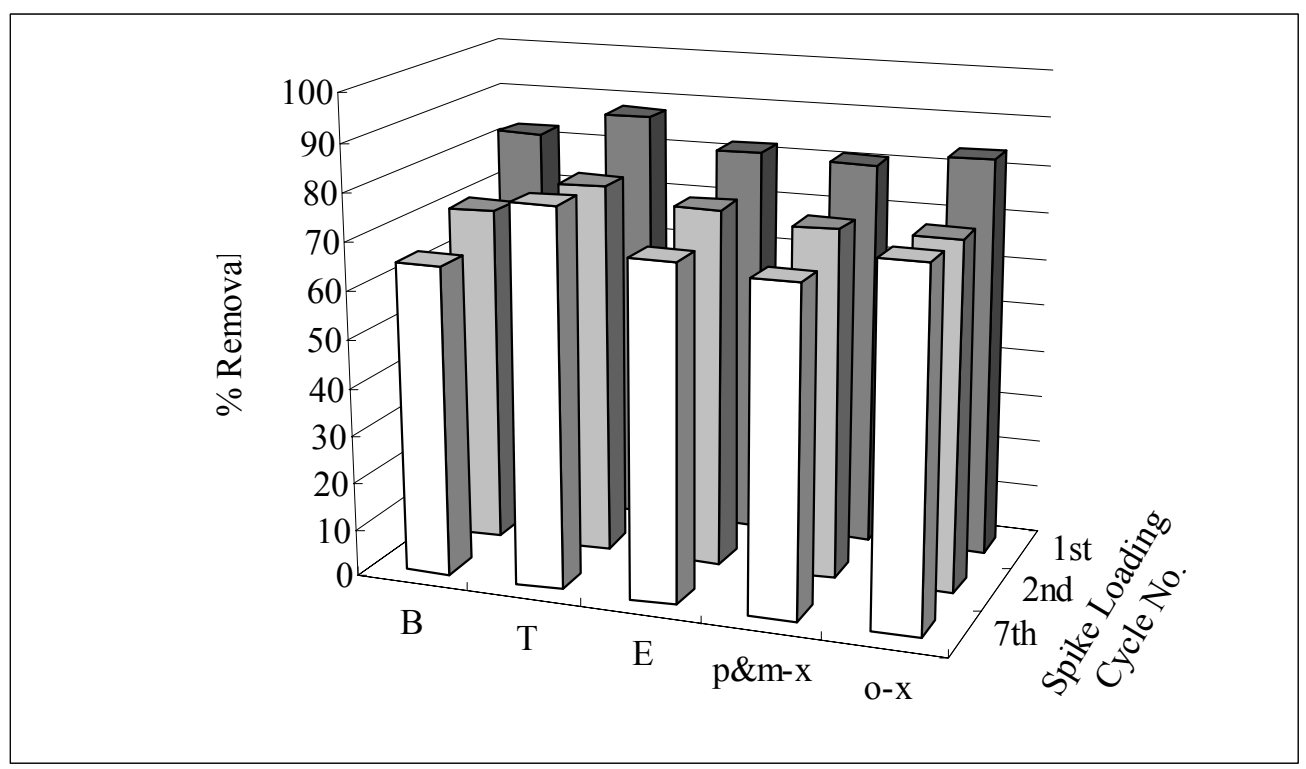

Figure 4-3. Response of the compost biofilter to repeated BTEX variable loading cycles. In each 24 hour cycle, a high loading of BTEX was provided for 8 hours as shown in Figure 3-13. During the remaining 16 hours of each cycle, clean air was passed through the biofilter. (B; benzene, $T$; toluene, $\mathrm{E}$; ethylbenzene, $p \& m-x$; para \& meta-xylene, $o-x$; ortho-xylene)

The removal of BTEX contaminants in the compost-based biofilter decreased to $75 \%$ when the biofilter was subjected to repeated variations in inlet BTEX concentration. Benzene removal was most adversely affected and toluene removal was found to be the least sensitive to the variable loading. These results indicate that biofilters have limited capacity to handle sudden variations in inlet VOC concentration even when the average inlet concentration is within tolerable ranges. The maximum BTEX concentrations expected from applications such as the SMZ/VPB system treating produced water are particularly challenging to VPBs. A sudden BTEX concentration variation on the order of thousands of $\mathrm{ppm}_{\mathrm{v}}$ is expected followed by an exponential decline in BTEX concentration. The biofiltration system evaluated in this task had difficulty treating a BTEX concentration variation on the order of $400 \mathrm{ppm}_{\mathrm{v}}$ and thus would not be expected to respond well when subjected to a higher variable load expected in an SMZ/VPB system. For such an application, a supplementary, load equalization system would be necessary to attenuate VOC concentrations entering the VPB and prevent the variable load from overwhelming the VOC degradation capacity of the biofilter.

\subsection{Load Equalization by a Fixed Bed Adsorption Column}

In wastewater treatment facilities, load equalization basins are used. They smooth out the pollutant concentrations to prevent the variable load from overwhelming the treatment capacity. Also, they protect the biomass from toxic effects due to shock loadings and from starvation conditions during periods of low carbon supply. However, the study of load equalization systems for gas phase treatment systems has been limited. One potential method for gas phase load equalization is to install a passive fixed bed 
adsorption column upstream of the VPB. The column would contain buffering agents to adsorb VOCs during periods of high concentration feed, and desorb VOCs during periods of low inlet concentration. Weber and Hartmans (1995) observed that the performance of a biofilter subjected to step feed increases in toluene concentration improved when a separate fixed bed adsorption column filled with GAC was placed upstream of the biofilter. Similarly, Moe and Li (2005) investigated performance of a GAC-fixed bed adsorption column coupled to a biofilter but, as in the earlier studies, only step increases in inlet VOC concentration were evaluated. Little attention has been directed toward investigating the utility of passive adsorbent-load equalization systems when they are subjected to fluctuating inlet VOC concentrations during the feeding period. Indeed, the variable concentration, transient loading conditions expected in a combined SMZ/VPB system is a challenging scenario. Since the duration of the peak concentration is relatively short, it is not economical to build the system based on the highest VOC concentration expected. In variable loading situations in which the initial concentration is high followed by a gradual decrease in influent concentration, the primary purpose of the load equalization system must be to reduce the high peak concentrations to levels that a given biofilter system can handle completely. The design of the load equalization system should be optimized to assure that the influent concentration to the downstream biofilter does not exceed the biofilter assimilation capacity.

In order to apply the load equalization system in the field, several factors must be considered. One of them is competitive adsorption effects (Crittenden et al., 1985; Ruthven, 1984; Yang, 1987) which affect the adsorption/regeneration of VOC constituents on the adsorbent. The other factor that must be considered is the humidity of the gas streams. For instance, Werner (1985) observed that TCE adsorption at a RH of $85 \%$ was only $9 \%$ of the amount adsorbed at a RH of $5 \%$ when $300 \mathrm{mg} / \mathrm{m}^{3}$ of TCE was applied to a GAC column. Cal et al. (1996) found that water vapor in a gas streams had little effect on benzene $\left(500 \mathrm{ppm}_{\mathrm{v}}\right)$ adsorption onto the activated carbon cloth until the $\mathrm{RH}$ exceeded $65 \%$, at which point a rapid decrease in adsorption capacity was observed. The regenerated gas stream from the SMZ column in a field test is believed to be water saturated; therefore, the impact of $\mathrm{RH}$ on the buffering capacity must be evaluated.

\subsubsection{Load Equalization for Dry-Gas Streams Containing A Single VOC}

Two adsorbents, SMZ and GAC, were tested as buffering agents to attenuate a variable loading of a single VOC under low RH (less than 10\%) conditions. Toluene was chosen as a target VOC in this experiment, since it showed the highest peak concentration during the early stages of SMZ regeneration, and its concentration dropped off exponentially as the sparging process continued in previous lab-scale tests (Figure 4-1).

\subsubsection{Load Equalization Test with SMZ}

Figure 4-4 shows the response of the SMZ column to the pre-saturation/regeneration cycle used to condition the SMZ column. Within one hour, the SMZ was saturated with toluene at a 10 second-EBCT and at a RH below 10\%. Also, the desorption of toluene 
from the SMZ after discontinuing the toluene feed was relatively fast. The total quantity of toluene adsorbed on the SMZ at saturation was calculated by an integration method and was determined to be $0.393 \mathrm{mg}$ toluene per gram of dry SMZ. The integration was done by integrating the influent and effluent VOC concentrations over the experimental run time and then taking their difference and multiplying by the total gas flow rate and dividing by the dry adsorbent mass. The total toluene desorbed during regeneration of the SMZ with air was nearly identical to the quantity adsorbed indicating that SMZ has little affinity to retain gas phase toluene and simple air sparging could completely remove all of the adsorbed toluene.

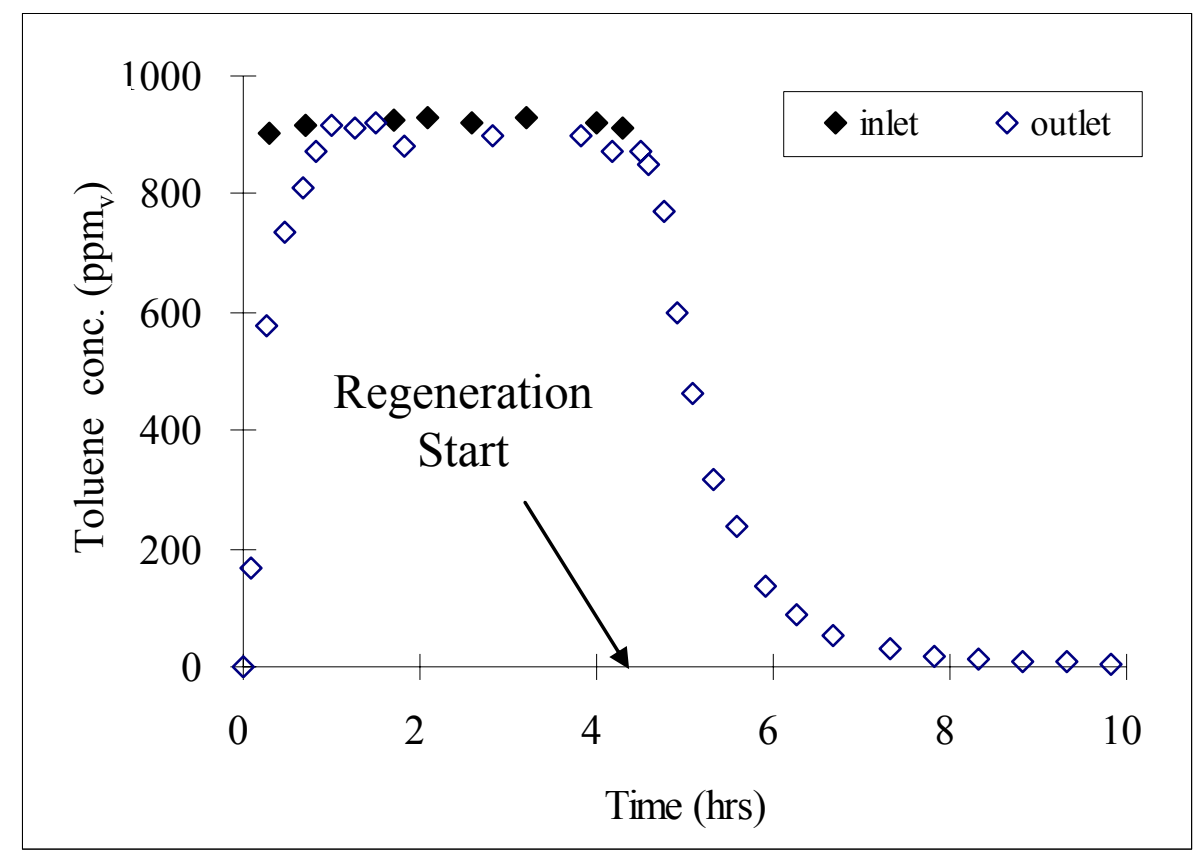

Figure 4-4. Pre-saturation/regeneration of the SMZ column with toluene. 10 secondEBCT

Figure 4-5 shows the response of the SMZ-fixed bed adsorption column to a $1000 \mathrm{ppm}_{\mathrm{v}}$ variation in inlet toluene concentration. The maximum outlet concentration from the fixed bed adsorption column was approximately $630 \mathrm{ppm}_{\mathrm{v}}$ (Figure 4-2). As seen in the previous transient loading test (in Section 3.3), the VPB operated in this research only achieved $75 \%$ removal when the maximum BTEX concentration was $380 \mathrm{ppm}_{\mathrm{v}}$; therefore, the buffered concentration $\left(630 \mathrm{ppm}_{\mathrm{v}}\right)$ in this SMZ-fixed bed adsorption column would overwhelm the VPB capacity. Considering that the duration of the toluene peak was only 15 minutes and the fixed bed adsorption column was operating at a relatively long EBCT of 10 seconds, this load equalization capacity is not sufficient to attenuate transient loadings of BTEX expected in applications such as the SMZ/VPB system. To reduce the inlet BTEX concentrations to a tolerable concentration range for a downstream VPB (i.e., below the upper limit that a given VPB could handle it completely), using a large mass of SMZ or dilution of the inlet air stream would be required. However, both of these solutions are not appropriate for large scale treatment in the field, since they subsequently 
enlarge the whole treatment system. Therefore, an alternative buffering agent is necessary.

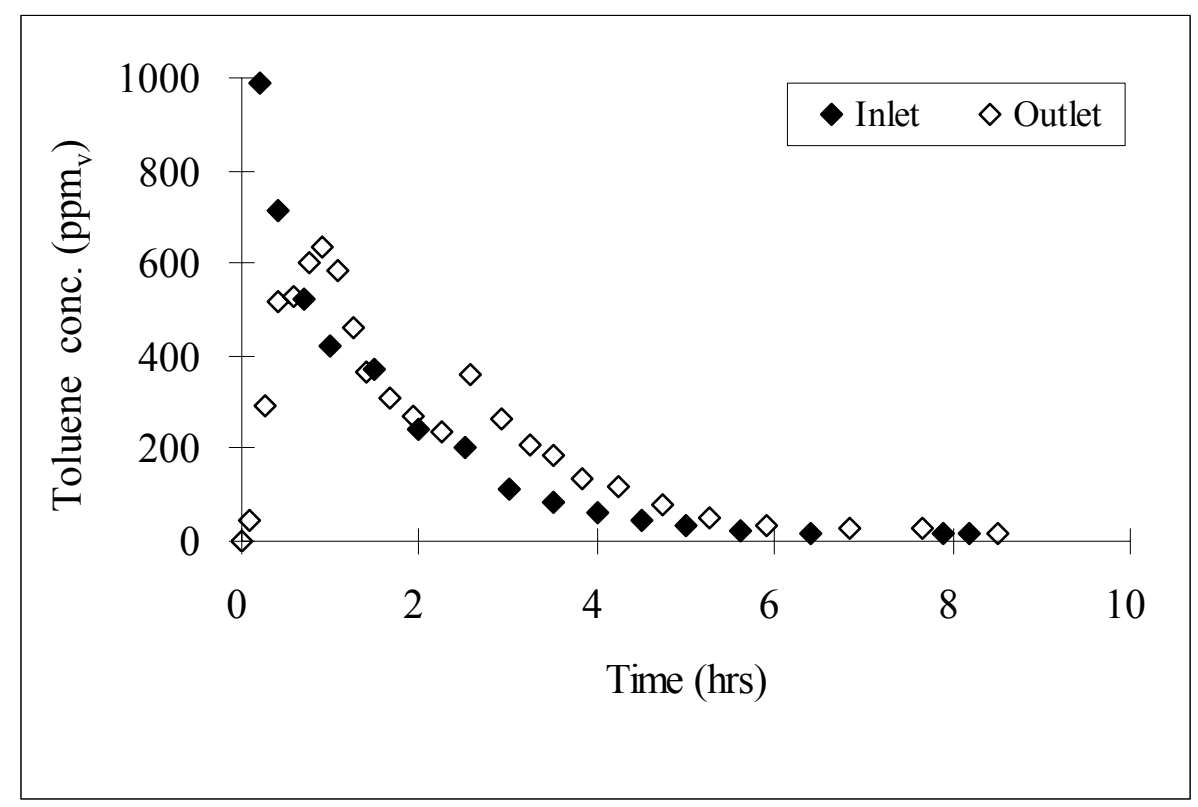

Figure 4-5. Response of the SMZ-packed column to a transient feed of toluene. 10 second-EBCT

\subsubsection{Load Equalization Test with GAC}

Figure 4-6 shows the response of the GAC column to the pre-saturation/regeneration cycle used to condition the GAC-fixed bed adsorption column. All of the toluene introduced to the GAC column was adsorbed onto the GAC for the first 4 hours of operation, and then gradual breakthrough of toluene through the column was observed. The system reached equilibrium 22.5 hours later at which point the inlet and outlet toluene concentrations were the same. When the inlet toluene feed was subsequently discontinued and clean air was passed through the fixed bed adsorption column at hour 22.5, the outlet concentration decreased rapidly for the first 7.5 hours. However, as the outlet toluene concentration declined below $200 \mathrm{ppm}_{\mathrm{v}}$, the release rate of adsorbed toluene slowed considerably. After 100 hours of air sparging, the outlet concentration remained above $15 \mathrm{ppm}_{\mathrm{v}}$, indicating that this gradual release of adsorbed VOC can prevent the biofilter from experiencing carbon-deprived conditions even during a shutdown period. The total quantity of toluene adsorbed on the GAC when the influent toluene concentration was held steady at $1000 \mathrm{ppm}_{\mathrm{v}}$ was calculated by the integration method, and determined to be $363.7 \mathrm{mg}$ toluene per gram of dry GAC. This adsorption capacity is three orders of magnitude greater than that of the SMZ. 


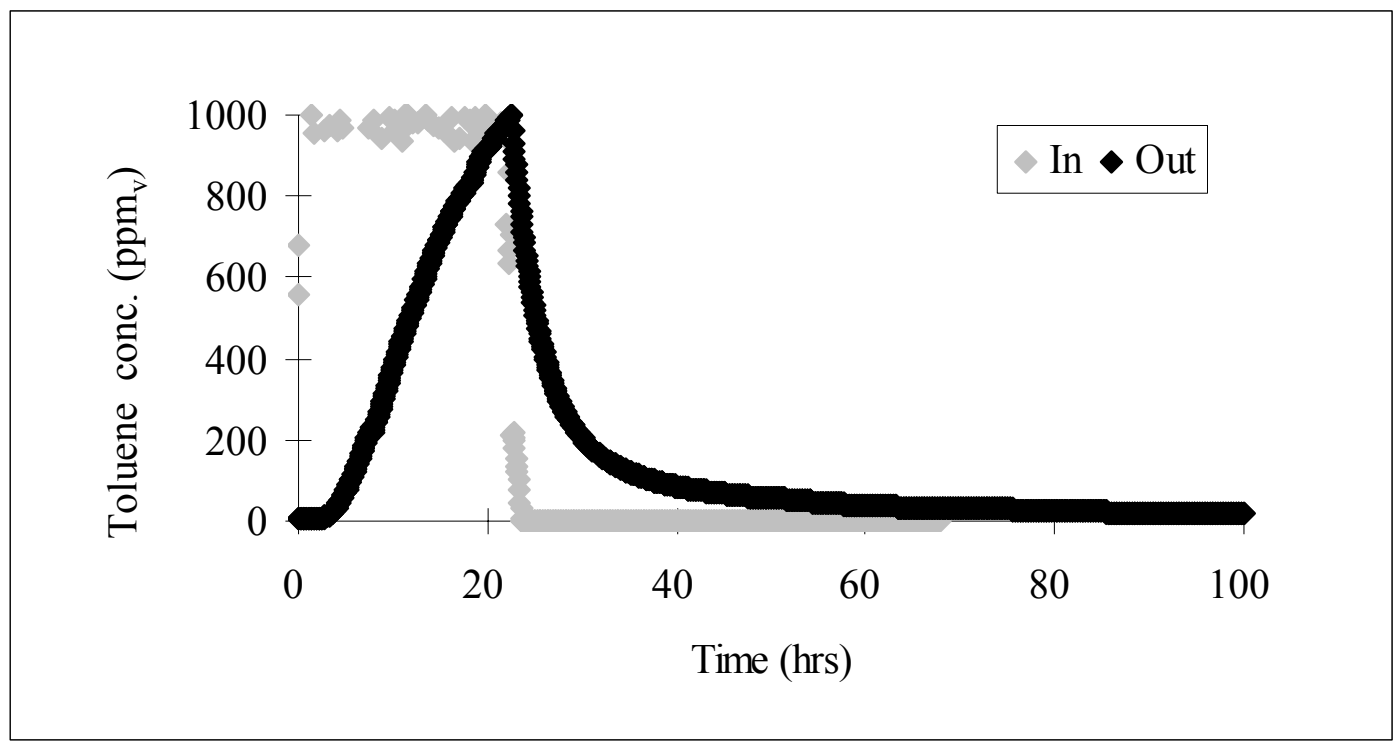

Figure 4-6. Pre-saturation/regeneration of the GAC column with toluene. 1 secondEBCT

Figure 4-7 shows the response of the GAC-fixed bed adsorption column to a sudden variation in inlet toluene concentration. The maximum outlet concentration from the fixed bed adsorption column remained below $30 \mathrm{ppm}_{\mathrm{v}}$ and this value remained relatively constant over 40 hours of operation, even though the maximum inlet toluene concentration was $1000 \mathrm{ppm}_{\mathrm{v}}$. This result implies that the GAC column can effectively buffer the peak VOC concentrations and prevent overloading a downstream biofilter. The gradual release of the adsorbed toluene also ensures that a downstream biofilter would receive a steady VOC supply even if the SMZ regeneration process does occur on a cyclical basis. 


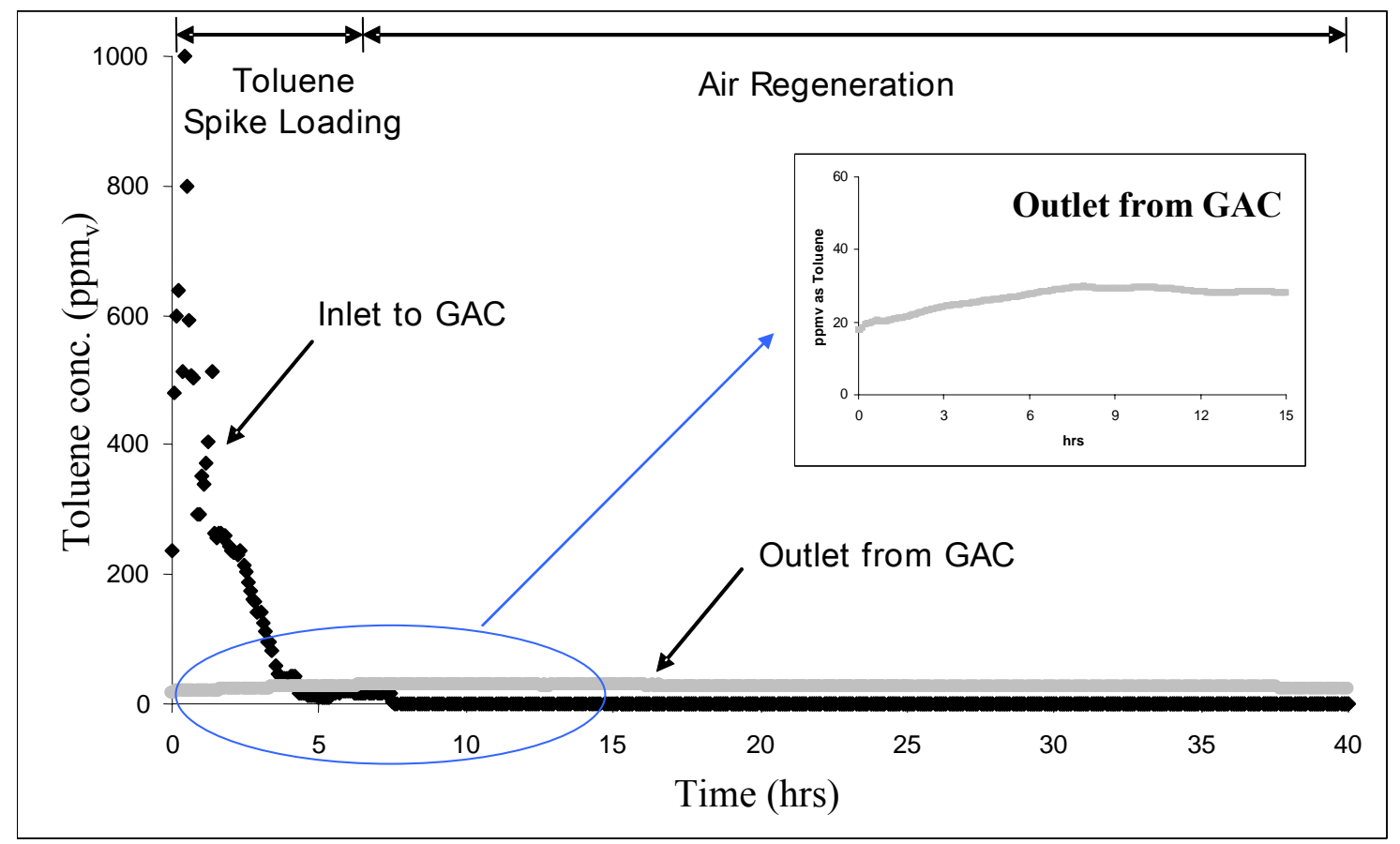

Figure 4-7. Response of the GAC-fixed bed adsorption column to a sudden increase in toluene concentration. Toluene was supplied for 8 hours as a transient load followed by 32 hours of clean air. GAC (BPL 4 x 6 mesh, Cargon Carbon Corp.) was used as a buffering agent. 1 second-EBCT

However, one concern with the results presented in Figure 4-7 is the question of how well the GAC column would handle repeated variations in VOC feed. To assess this question, the GAC column used in the previous experiments was subjected to several toluene adsorption/air regeneration cycles. Figure 4-8 presents the outlet toluene concentrations from the GAC-fixed bed adsorption column over several toluene adsorption/air regeneration cycles. As evident in Figure 4-8, the GAC effectively buffered the transients in inlet toluene concentration with a maximum breakthrough concentration of $65 \mathrm{ppm}_{\mathrm{v}}$ despite a peak inlet concentration of toluene of $1000 \mathrm{ppm}_{\mathrm{v}}$. This buffered concentration range could be successfully treated by the biofilter operated in this research. Even though the outlet concentration from the GAC-fixed bed adsorption column increased during the first five transient cycles (due to insufficient air stripping of the toluene), its increase was slowed as the transient feed tests continued. These results suggest that a small passive GAC-fixed bed adsorption column operated at a short EBCT can help buffer peak VOC concentrations as high as 1000 ppm $_{\mathrm{v}}$. For the SMZ/VPB application, the peak VOC concentrations are expected during the early stages of SMZ regeneration and the placement of a small GAC-fixed bed adsorption column upstream of the VPB should attenuate the VOC concentrations sufficiently to protect a downstream biofilter. 


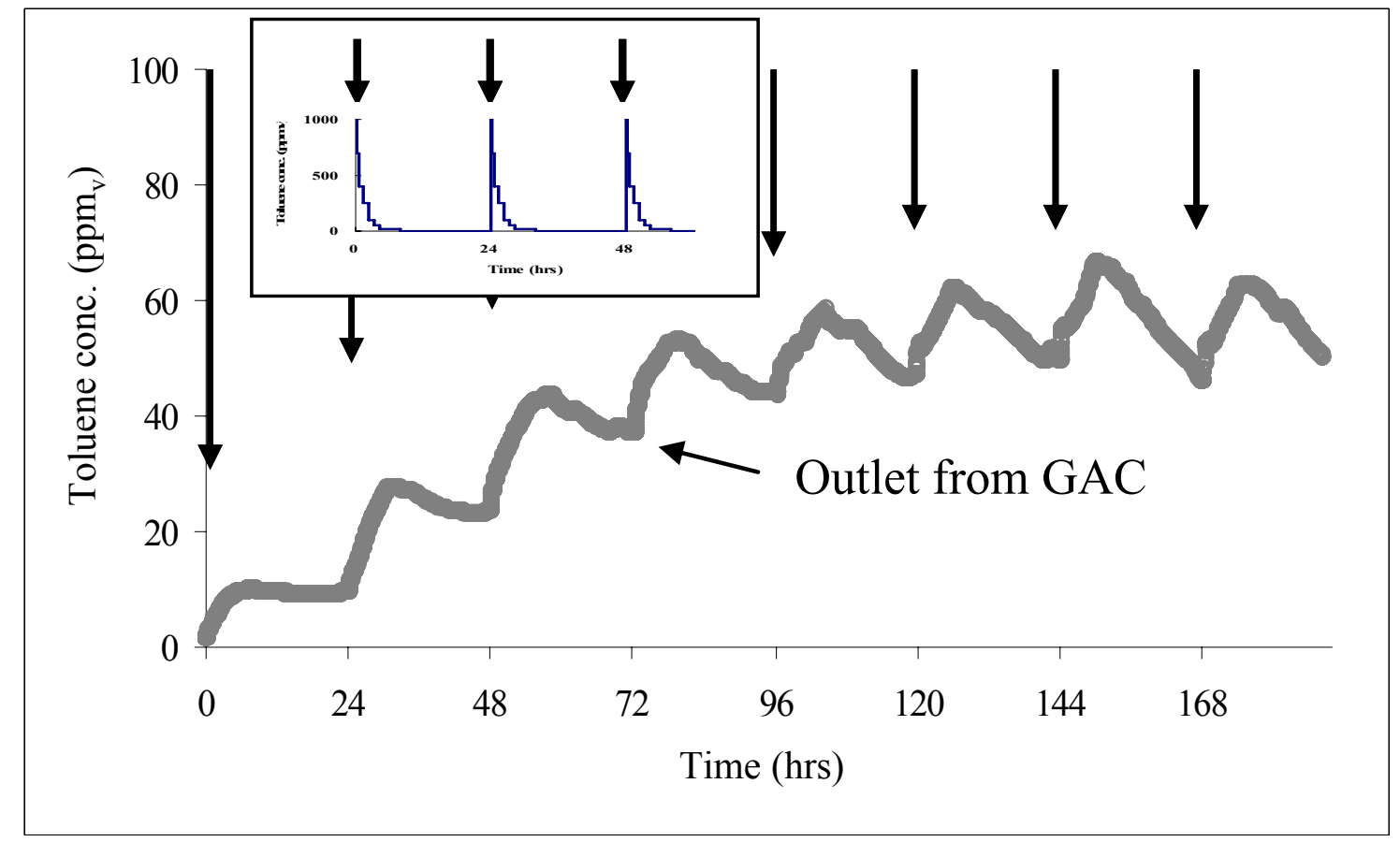

Figure 4-8. Response of the GAC-fixed bed adsorption column to repeated toluene transients. As depicted in the inset, each toluene transient was supplied for 8 hours followed by 16 hours of clean air. Each arrow represents the start of transient loading period.

\subsubsection{Summary}

The SMZ bed reduced a $1000 \mathrm{ppm}_{\mathrm{v}}$ toluene peak by only $37 \%$ even at ten second-EBCT, implying that SMZ is not an effective buffering agent for high variation of inlet concentration. However, buffering by the fresh GAC bed reduced a $1000 \mathrm{ppm}_{\mathrm{v}}$ toluene peak by $97 \%$ at a one second-EBCT under low RH (less than 10\%). The contaminant on the fresh GAC subsequently desorbed at a nearly steady rate resulting in a relatively low outlet concentration of approximately $25 \mathrm{ppm}_{\mathrm{v}}$, a concentration that is readily degradable by a VPB. In the field application of the SMZ/VPB system, the steady nature of the buffered feed stream during the air stripping phase is expected to prevent the biomass in the VPB from enduring starvation conditions between SMZ regeneration cycles. The results also indicated that the buffering capacity of the GAC diminished when sorbed VOCs were not regenerated sufficiently in a given regeneration period over repeated adsorption/air regeneration cycles. 


\subsubsection{Load Equalization for Water-Saturated Gas Streams Containing A VOC Mixture}

At high RHs, a majority of the GAC pores are filled with water condensate and the adsorption capacity is controlled by the aqueous-phase adsorption equilibria (Cortright, 1987). Thus, the GAC buffer column was tested at high RH. In addition, the design of a GAC system for treating SMZ regeneration effluent must consider the multi-component nature of the waste stream. To this end, data and mathematical modeling were used to assess the potential of the GAC-fixed bed adsorption column for treatment of a bi-solute waste stream at high RH. Basic hypotheses in this section are that internal mass transfer can be described using aqueous system mass transfer models, and external mass transfer can be described using gas phase models as in water saturated gas streams. To verify the hypothesis, liquid phase isotherms of benzene and toluene to GAC were measured, and then mass transfer coefficients were estimated using the short-bed adsorber (SBA) technique (Weber and Liu, 1980) in conjunction with the homogeneous surface diffusion model (HSDM) fixed bed adsorption code. These measured values were compared with literature correlations and used to predict the buffering behavior of GAC column for transient loading of VOCs.

\subsubsection{PAC Adsorption Isotherms}

Individual adsorption isotherms were performed on PAC for benzene and toluene, from which the Freundlich adsorption parameters, $K$ and $1 / n$, were estimated. The results of the individual adsorption isotherm studies are presented in Figure 4-9 and the resulting adsorption parameters are presented in Table 4-1. The isotherms parameters were determined by simple linear regression on a log-log plot, where $\mathrm{C}_{\mathrm{e}}$ is the liquid-phase equilibrium concentration and $\mathrm{q}_{\mathrm{e}}$ is the solid-phase equilibrium loading. As expected based on reported solubility and octanol/water partitioning data (Schwarzenbach et al., 2003), the PAC adsorption capacity for toluene was significantly higher than that for benzene at low concentrations.

Table 4-1. Summary of adsorption parameters from single component studies

\begin{tabular}{|c|c|c|c|}
\hline \multirow{2}{*}{ Chemical } & \multirow{2}{*}{$\begin{array}{c}\text { Equilibrium } \\
\text { Concentration } \\
(\mathrm{mg} / \mathrm{L})\end{array}$} & \multicolumn{2}{|c|}{ Freundlich Parameters } \\
\hline & & $\begin{array}{c}1 / n \\
-\end{array}$ & $\begin{array}{c}\boldsymbol{K} \\
(\mathrm{mg} / \mathrm{g})(\mathrm{L} / \mathrm{mg})^{1 / \mathrm{n}}\end{array}$ \\
\hline Benzene & $1.10 \sim 40.14$ & 0.577 & 47.2 \\
\hline Toluene & $1.17 \sim 41.85$ & 0.359 & 93.8 \\
\hline
\end{tabular}


Liquid phase benzene and toluene adsorption isotherms for Calgon BPL GAC have not been reported previously since BPL GAC is designed for gas phase adsorption. However, adsorption of these compounds to Calgon F-400 GAC has been reported and generally agrees with the Freundlich parameters for Calgon BPL GAC (Table 4-2).

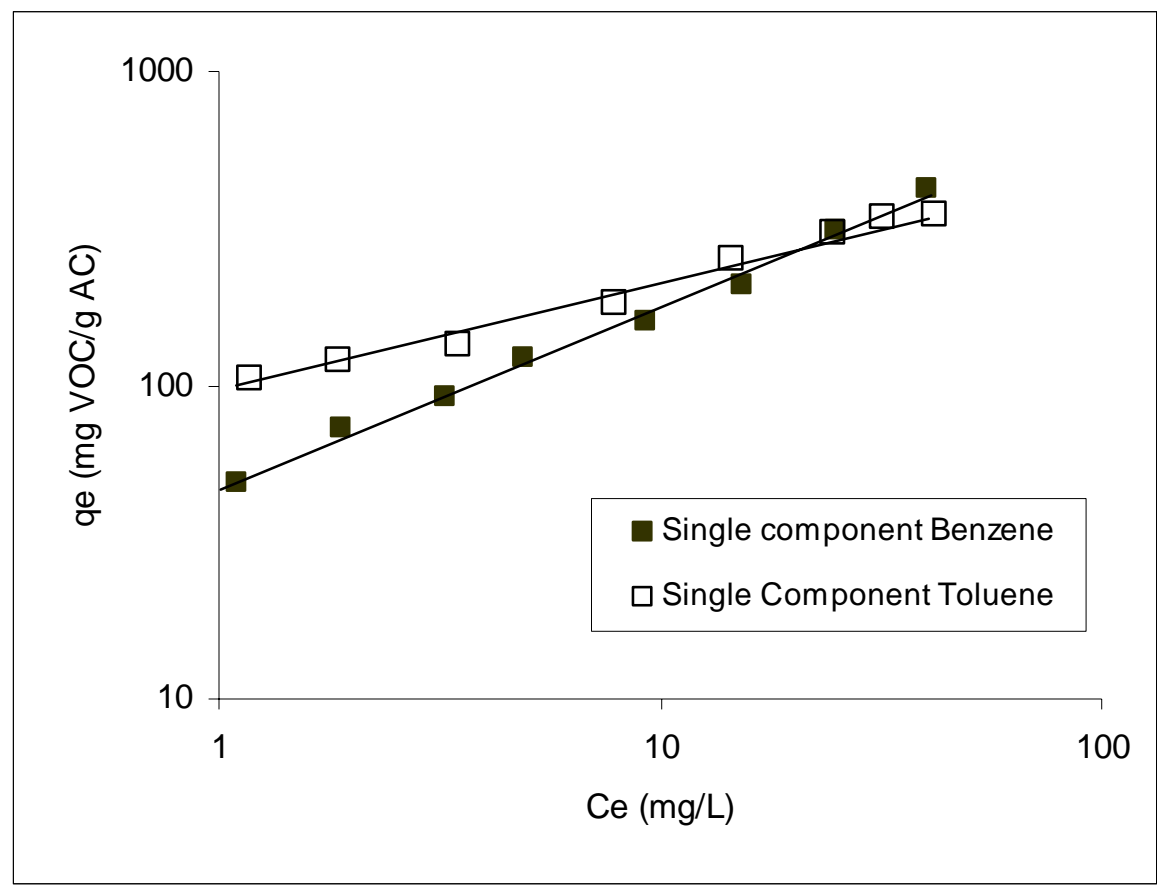

Figure 4-9. Individual adsorption isotherm for benzene and toluene, benzene $\mathbf{C}_{0}=$ $53 \mathrm{mg} / \mathrm{L}$, toluene $\mathrm{C}_{0}=52.5 \mathrm{mg} / \mathrm{L}$

Table 4-2. Freundlich parameters for benzene and toluene from previous studies.

\begin{tabular}{|c|c|c|c|c|}
\hline Chemicals & $\boldsymbol{K}$ & $\mathbf{1 / n}$ & GAC & Source \\
\hline \hline \multirow{2}{*}{ Benzene } & 50.1 & 0.533 & $\begin{array}{c}\text { Calgon F400 } \\
(100 \text { X 200) }\end{array}$ & Speth (1990) \\
\cline { 2 - 5 } & 17.8 & 0.398 & $\begin{array}{c}\text { Calgon F400 } \\
(16 \text { X 200) }\end{array}$ & Crittenden et al. (1987) \\
\cline { 2 - 5 } & $232.2^{*}$ & $0.170^{*}$ & Calgon BPL & Yaws (1995) \\
\hline \multirow{2}{*}{ Toluene } & 97 & 0.429 & $\begin{array}{c}\text { Calgon F400 } \\
(100 \text { X 200) }\end{array}$ & Speth (1990) \\
\cline { 2 - 5 } & 96 & 0.328 & $\begin{array}{c}\text { Calgon F400 } \\
(16 \text { X 200) }\end{array}$ & Crittenden et al. (1987) \\
\cline { 2 - 5 } & $305.4^{*}$ & $0.107^{*}$ & Calgon BPL & Yaws (1995) \\
\hline
\end{tabular}

${ }^{*}$ : Gas phase adsorption parameters. 
The equilibrium parameters from the single component isotherms were then used to predict competitive adsorption behavior for benzene and toluene. Dual-component isotherms were performed and the data were compared with data predicted by IAST. For dual component experiments, the accuracy of the IAST predictions for $\mathrm{C}_{\mathrm{e}}$ and $\mathrm{q}_{\mathrm{e}}$ was calculated as average percent error (APE) with the following equation (Crittenden et al., 1985).

$$
A P E=\frac{100}{N} \sum \frac{\left|X_{\text {data }}-X_{\text {IAST }}\right|}{X_{\text {data }}}
$$

where, the variable $X$ represents the parameter for which the error is being estimated (i.e., $\mathrm{C}_{\mathrm{e}}$ or $\mathrm{q}_{\mathrm{e}}$ for each chemical) and $\mathrm{N}$ is the number of measurements of variable $\mathrm{X}$. The experimental data, corresponding single-component isotherm, and IAST predictions are plotted in Figures 4-10 through 4-12. The deviation of the data from the single component isotherm is a measure of the extent of competition between benzene and toluene (Figure 4-10). The difference between the IAST prediction and the data measures how well the theory predicts the experimental results. As expected, for both VOCs, the single component estimate of adsorption capacity $\left(\mathrm{q}_{\mathrm{e}}\right)$ for a given liquid phase equilibrium concentration was greater than both the IAST prediction and the experimental data. In a multi-component test, solutes that exhibit non-1inear adsorption compete with each other for adsorption sites, reducing the adsorption capacity of the $\mathrm{GAC}$ for each compound relative to the single-solute case. In this experiment, the adsorption of toluene (the more strongly adsorbed compound) was impacted very little by the presence of benzene, but the adsorption capacity of benzene decreased significantly in the presence of toluene.

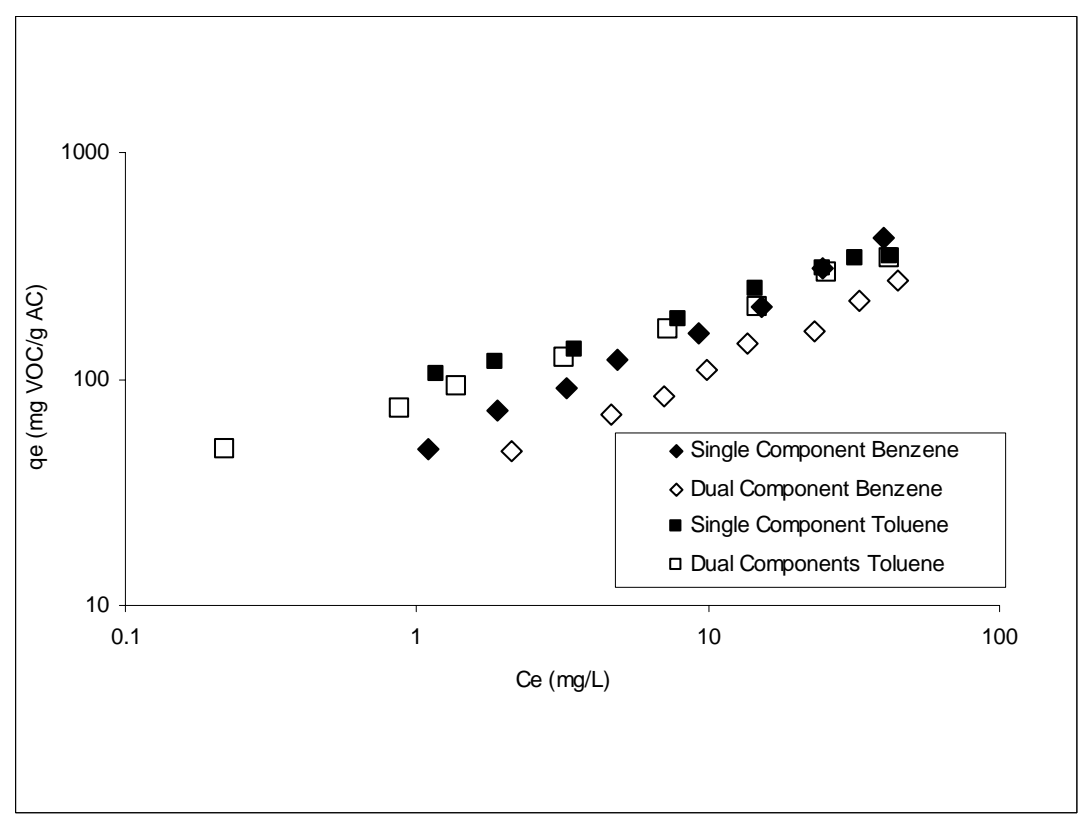

Figure 4-10. Benzene and toluene competitive isotherms, benzene $C_{0}=53 \mathrm{mg} / \mathrm{L}$, toluene $\mathrm{C}_{0}=52.5 \mathrm{mg} / \mathrm{L}$. 


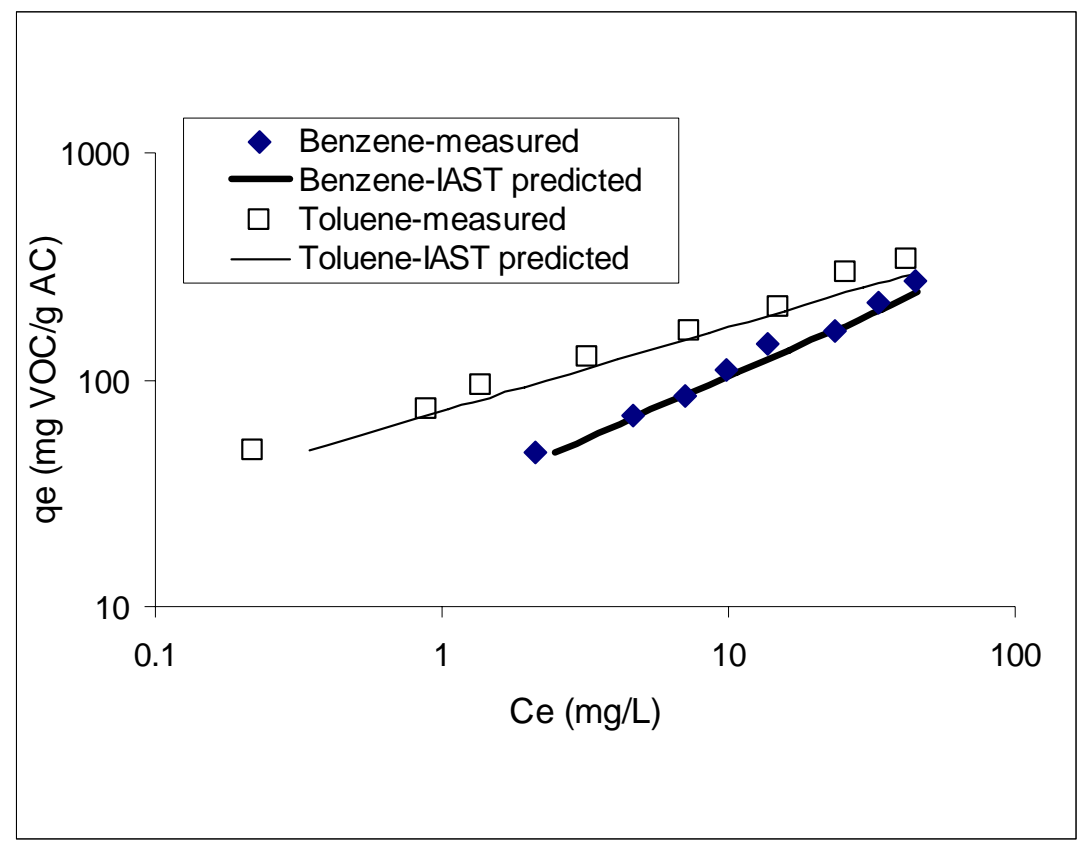

Figure 4-11. Benzene and toluene competitive isotherms, benzene $C_{0}=53 \mathrm{mg} / \mathrm{L}$, toluene $\mathrm{C}_{0}=\mathbf{5 2 . 5} \mathrm{mg} / \mathrm{L}$.

The reduction in adsorption capacity exhibited by benzene and toluene in a competitive environment matches very well with IAST predictions (Figure 4-11). Crittenden et al. (1985) defined the quality of APE as good, fair, or poor for values $<10 \%, 10 \sim 20 \%$, or $>20 \%$, respectively. In Figure 4-9, the predicted benzene curve had an average percent error (APE) of $6.8 \%$ in $\mathrm{C}_{\mathrm{e}}$ and $3.2 \%$ in $\mathrm{q}_{\mathrm{e}}$ and the predicted toluene curve had an APE of $23.6 \%$ in $\mathrm{C}_{\mathrm{e}}$ and $4.9 \%$ in $\mathrm{q}_{\mathrm{e}}$. These APE values indicate good agreement between the predicted and measured benzene and toluene except for the APE of toluene equilibrium concentration. In order to get more accurate predictions of multi-component adsorption by IAST, a correction factor, $\mathrm{P}$ was applied to the IAST equation (as a multiplier to $\mathrm{q}_{\mathrm{i}}$ ) to account for non-ideal mixing in real aqueous systems (Thacker et al., 1984). P values of 1.06 for benzene and 1.12 for toluene (Figure 4-12) were determined by minimizing the sum of squares of the residuals $\left(\mathrm{S}^{2}\right)$ of differences between predicted and measured single-solute data. That the values are close to one suggests that benzene and toluene exhibit near ideal behavior. Similar results have been observed previously (LilloRodensa et al., 2006) 


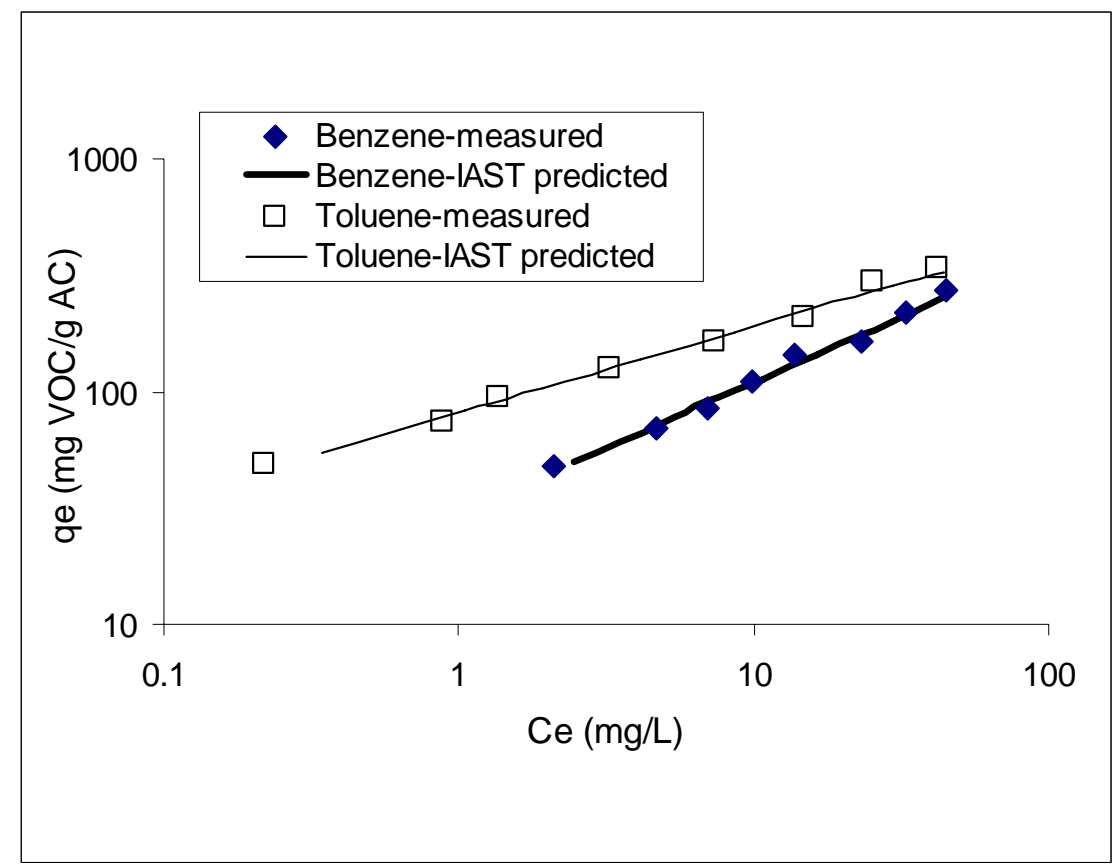

Figure 4-12. Benzene and toluene competitive isotherms, benzene $C_{0}=53 \mathrm{mg} / \mathrm{L}$, toluene $\mathrm{C}_{0}=\mathbf{5 2 . 5} \mathrm{mg} / \mathrm{L}, \mathrm{P}=\mathbf{1 . 0 6}$ for benzene, 1.12 for toluene.

\subsubsection{GAC Column Kinetics}

After the adsorption isotherms were completed, GAC column experiments were carried out to estimate adsorption kinetic parameters for benzene and toluene using the experimentally determined adsorption equilibrium parameters and correction factor, $\mathrm{P}$, as inputs to the HSDM. The HSDM code was modified to incorporate the correction factor (P) by Dr. Gerald E. Speitel Jr. (University of Texas at Austin). The SBA technique was used to determine values of both the film transfer coefficient $\left(k_{f}\right)$ and the surface diffusion coefficient $\left(D_{S}\right)$. In each test, the SBA was fed $500 \mathrm{ppm}_{\mathrm{v}}$ of benzene or $500 \mathrm{ppm}_{\mathrm{v}}$ of toluene and had a 1.2 second-EBCT. After acquiring the experimental data, HSDM was employed using single-component equilibrium isotherms, the correction factor $(\mathrm{P})$, and initial estimates of kinetic coefficients to obtain fitted effluent concentrations. Film transfer coefficients were initially calculated using the Gnielinski correlation and surface diffusion coefficients were calculated using the Sontheimer correlation (Sontheimer et al., 1988) for both gas and liquid phases. However, based on the assumption that gas phase film transfer and aqueous phase surface diffusion coefficients are appropriate for water saturated gas streams, the gas phase film transfer coefficient and the liquid phase surface diffusion coefficient were used as initial estimates in the HSDM (Table 4-3). Then, the kinetic parameters were adjusted to minimize the average residual sum of squares $\left(\mathrm{S}^{2}\right)$ between the HSDM fit and the measured data. Table 4-3 summarizes the calculated kinetic coefficients obtained from the literature correlations and the experimentally determined coefficients. The SBA experimental and fitted effluent concentrations for benzene and toluene are shown in Figures 4-13 and 4-14. As seen in Table 4-3, the 
measured film transfer coefficients $\left(k_{f}\right)$ are in the range of calculated gas phase values and surface diffusion coefficients $\left(D_{s}\right)$ are more consistent with liquid phase values. These results imply that the initial assumption that film transfer can be modeled as a gaseous system and surface diffusion as an aqueous system in water saturated gas streams seems reasonable.

Table 4-3. Comparison of calculated and experimentally determined kinetic coefficients

\begin{tabular}{|c|c|c|c|c|}
\hline \multirow{2}{*}{} & \multicolumn{2}{|c|}{$\begin{array}{c}\text { Film Transfer Coeff. }\left(\boldsymbol{k}_{f}\right) \\
(\mathbf{c m} / \mathbf{s e c})\end{array}$} & \multicolumn{2}{c|}{$\begin{array}{c}\text { Surface Diffusion Coeff. }\left(D_{s}\right) \\
\left(\mathbf{c m}^{2} / \mathbf{s e c}\right)\end{array}$} \\
\cline { 2 - 5 } & Benzene & Toluene & Benzene & Toluene \\
\hline $\begin{array}{c}\text { Calculated } \\
\text { (Liquid phase) }\end{array}$ & $3.88 \times 10^{-3}$ & $3.59 \times 10^{-3}$ & $7.91 \times 10^{-9}$ & $3.46 \times 10^{-9}$ \\
\hline $\begin{array}{c}\text { Calculated } \\
\text { (Gas phase) }\end{array}$ & $\mathbf{1 . 2 9}$ & $\mathbf{1 . 1 6}$ & $7.94 \times 10^{-5}$ & $3.52 \times 10^{-5}$ \\
\hline $\begin{array}{c}\text { Experimentally } \\
\text { Determined }\end{array}$ & $\mathbf{1 . 0 5}$ & $\mathbf{0 . 9 7}$ & $\mathbf{1 . 8 4} \times \mathbf{1 0}^{-\mathbf{8}}$ & $\mathbf{1 . 5 1 \times 1 0 ^ { - 8 }}$ \\
\hline
\end{tabular}

* Film transfer coefficients were calculated by the Gnielinski correlation and surface diffusion coefficients by the Sontheimer correlation (Sontheimer et al., 1988).

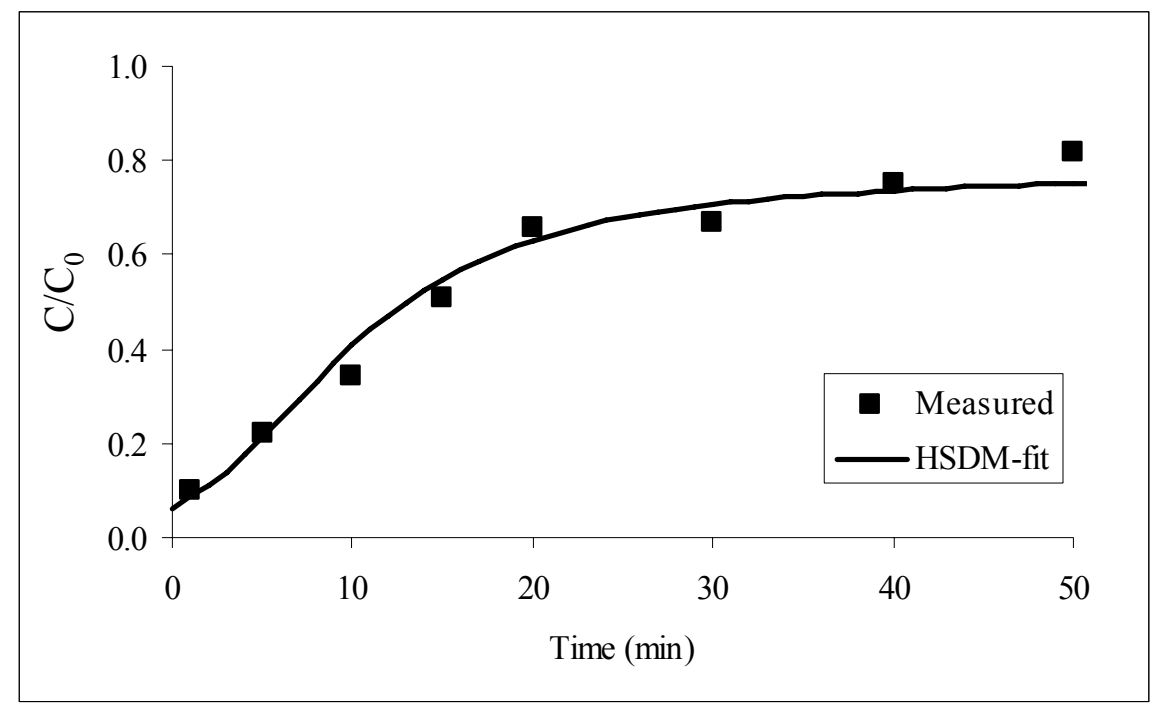

Figure 4-13. Benzene SBA data and HSDM fit for water saturated BPL GAC, $\mathrm{C}_{0}=$ 500 ppm $_{\mathrm{v}}$, 1.2 sec-EBCT. 


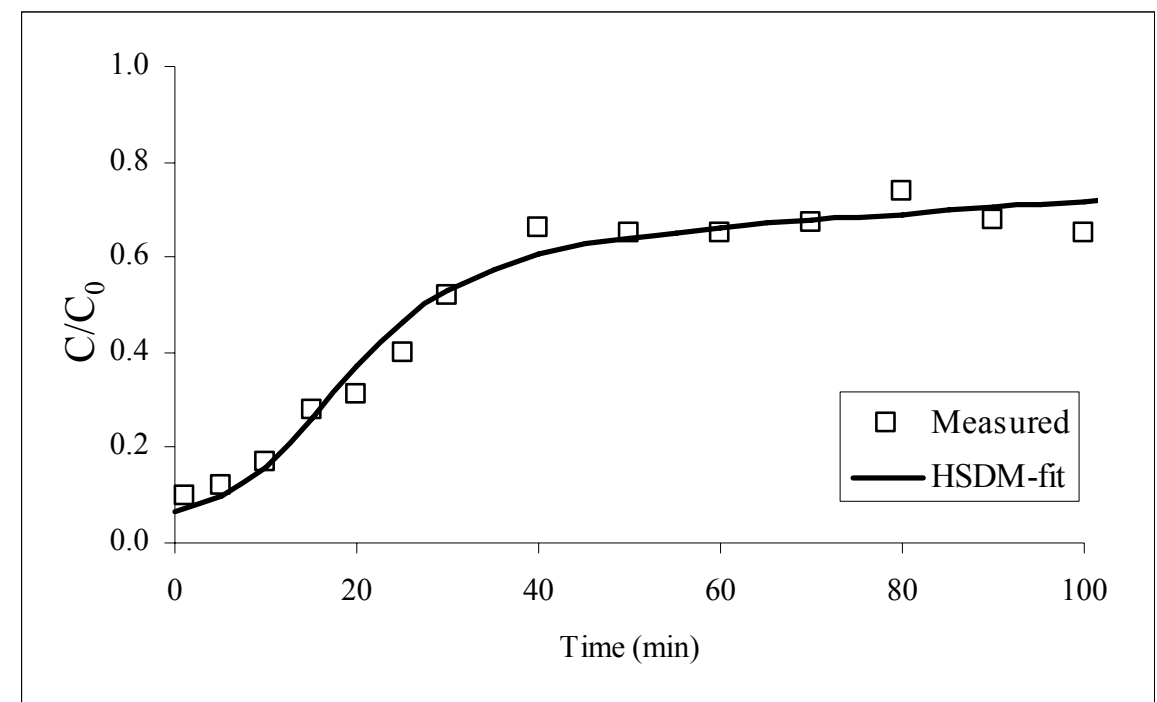

Figure 4-14. Toluene SBA data and HSDM fit for water saturated BPL GAC, $C_{0}=$ 500 ppm $_{\mathrm{v}}$, $1.2 \mathrm{sec-EBCT.}$

Single-solute and bi-solute column experiments with longer EBCTs (3-sec.) were conducted to evaluate the ability of the dynamic model to predict adsorption behavior using the equilibrium parameters determined from the bottle point experiments and the mass transfer coefficients determined from the single-solute SBA experiments. As shown in Figures 4-15 and 4-16, the HSDM predicted the experimental single-solute data very well using equilibrium parameters determined from the bottle point experiments and kinetic coefficients determined using the SBA approach.

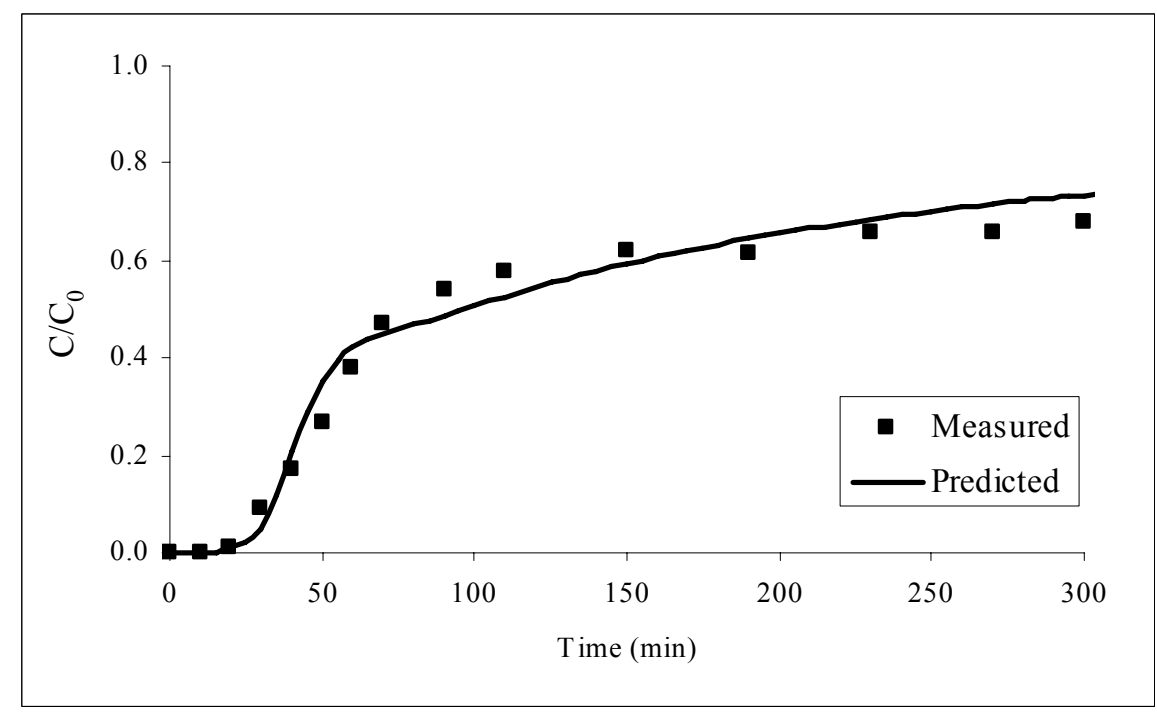

Figure 4-15. Benzene fixed bed adsorber data and HSDM-predictions for water saturated BPL GAC, $C_{0}=500$ ppm $_{\mathrm{v}}, 3$ sec-EBCT. 


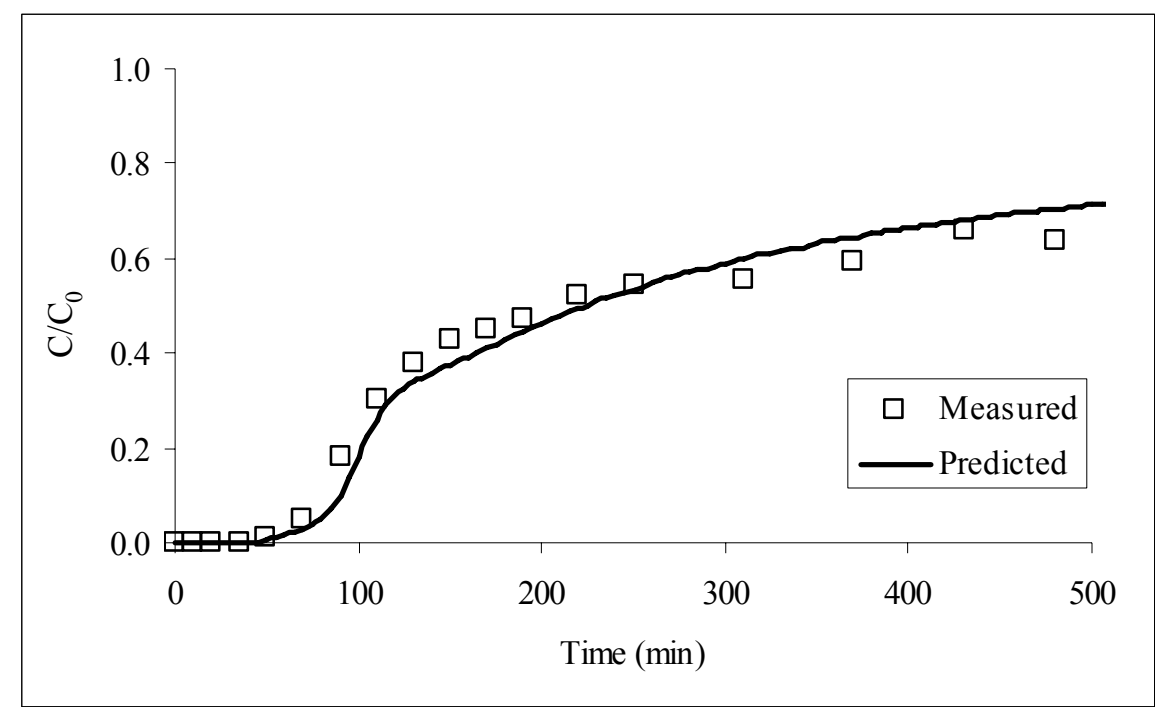

Figure 4-16. Toluene fixed bed adsorber data and HSDM-predictions for water saturated BPL GAC, $\mathrm{C}_{0}=500$ ppm $_{\mathrm{v}}, 3$ sec-EBCT.

A more rigorous test of the model is provided by comparison of the model with data collected in a bi-solute column experiment. As expected, early breakthrough was, observed for both benzene and toluene in the bi-solute experiment compared to the single-solute experiments. (Figure 4-17). Chromatographic displacement is evident in Figure 4-17 and 4-18, in which the effluent concentration of the less adsorbable chemical (benzene) is temporarily higher than its influent concentration (Weber and Smith, 1987). In this study, the compound with the lower adsorption capacity, benzene, broke through first, followed by the more adsorbable compound, toluene. However, when toluene breaks through, it displaces the benzene, yielding effluent benzene concentrations which exceed the influent concentration. HSDM predictions of this bi-solute experiment are very reasonable. These results suggest that HSDM can successfully predict the adsorption behavior of VOC mixtures in water saturated gas streams if the liquid phase adsorption isotherms, correction factor $(\mathrm{P})$, and kinetic coefficients are known. 


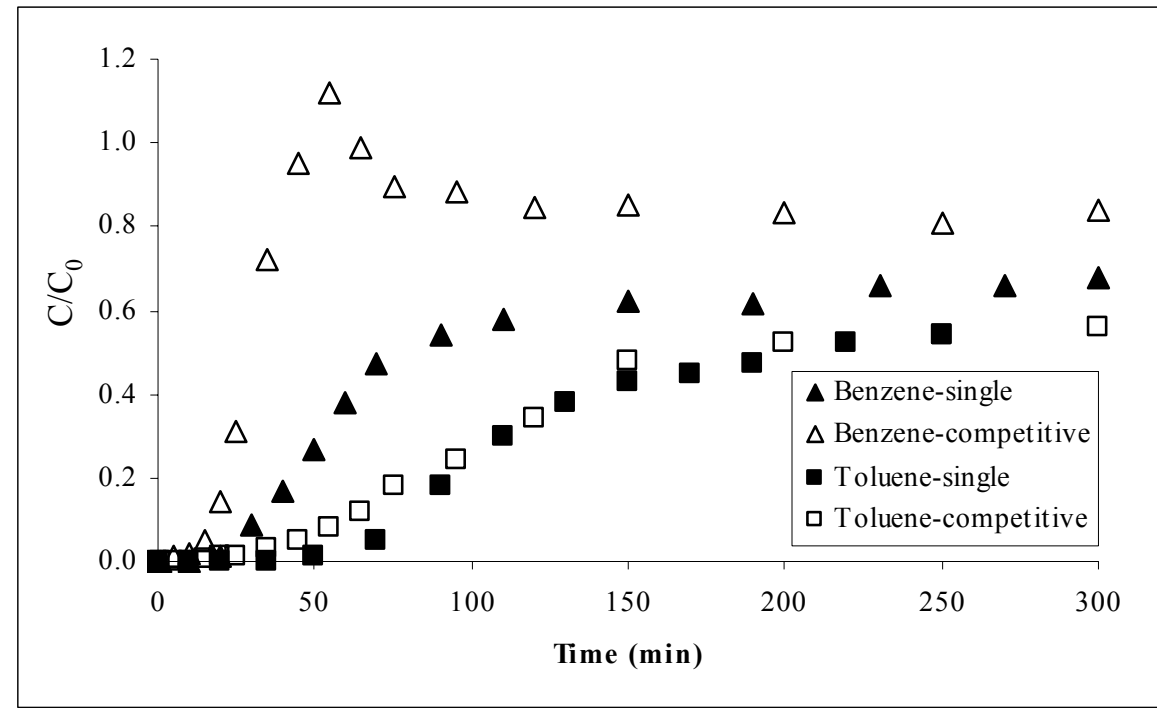

Figure 4-17. Single and bi-solute benzene and toluene column adsorption data, benzene $C_{0}=500$ ppm $_{\mathrm{v}}$, toluene $\mathrm{C}_{0}=500$ ppm $_{\mathrm{v}}, 3$ sec-EBCT.

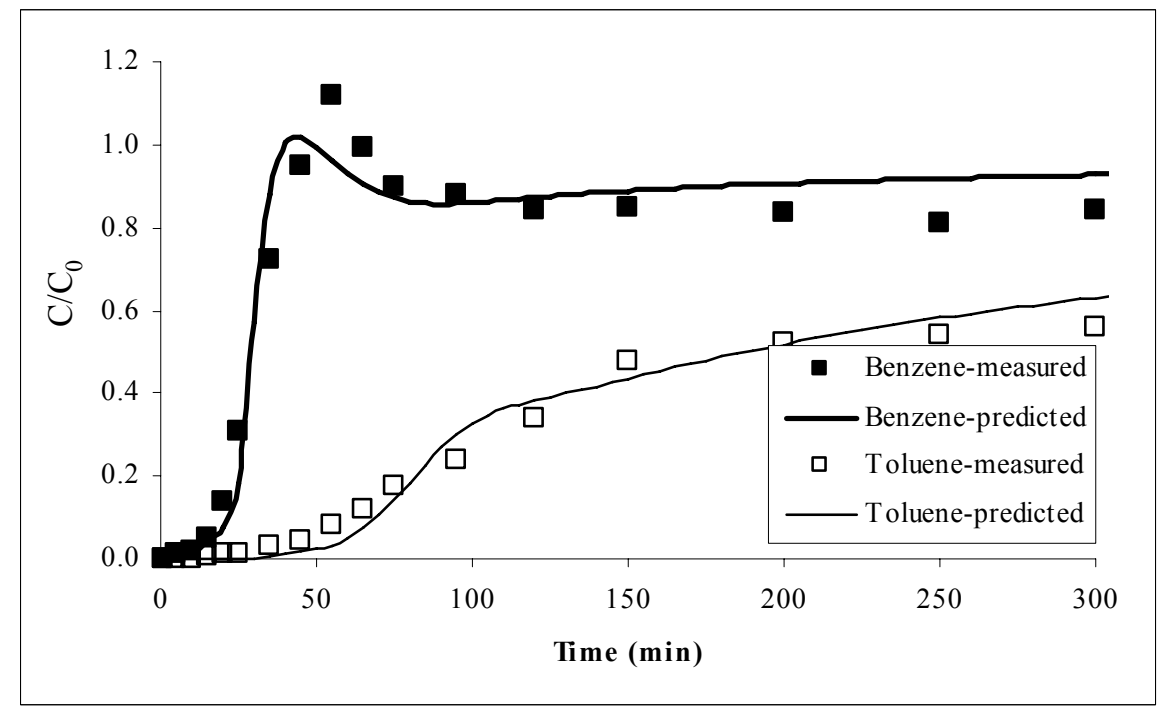

Figure 4-18. Measured and HSDM-predicted benzene and toluene adsorption in a fixed bed BPL GAC adsorber, benzene $C_{0}=500$ ppm $_{v}$, toluene $C_{0}=500$ ppm $_{v}, 3$ secEBCT

Finally, a variable influent flow containing toluene and benzene was fed to the fixed bed adsorption column described previously to evaluate the calibrated HSDM for its ability to predict the type of loading profile expected in the SMZ regeneration off-gas. As shown in Figure 4-17, the benzene and toluene variable influent mixture was designed to produce a peak concentration of $200 \mathrm{ppm}_{\mathrm{v}}$ for benzene and $500 \mathrm{ppm}_{\mathrm{v}}$ for toluene. The EBCT in the fixed bed adsorption column was maintained at 1.8 seconds. 
Figure 4-19 also confirms the efficiency of the fixed bed adsorption column for suppressing concentration peaks associated with the variable toluene influent. Indeed, the GAC column showed excellent buffering efficiency for toluene with a maximum effluent concentration of $12.1 \mathrm{ppm}_{\mathrm{v}}$ when supplied a peak concentration of $500 \mathrm{ppm}_{\mathrm{v}}$. However, the column was much less effective for buffering benzene concentration peaks with a maximum effluent concentration of $101 \mathrm{ppm}_{\mathrm{v}}$ when supplied a peak concentration of $200 \mathrm{ppm}_{\mathrm{v}}$. The results imply that the efficiency of the activated carbon-fixed bed adsorption column is dependent on the adsorption capacity of the individual components.

HSDM was used to predict the effluent concentrations of benzene and toluene from the fixed bed adsorption column for the variable loading data shown in Figure 4-19. As shown in Figure 4-20, the HSDM predictions for benzene and toluene in the mixture are consistent with the experimental data, which indicates that HSDM can successfully be used to predict the buffering behavior of VOC mixtures in water saturated gas streams if the liquid phase adsorption isotherms, correction factor $(\mathrm{P})$, and kinetic coefficients are known. The results also demonstrate the effectiveness of the SBA method for parameter estimation.

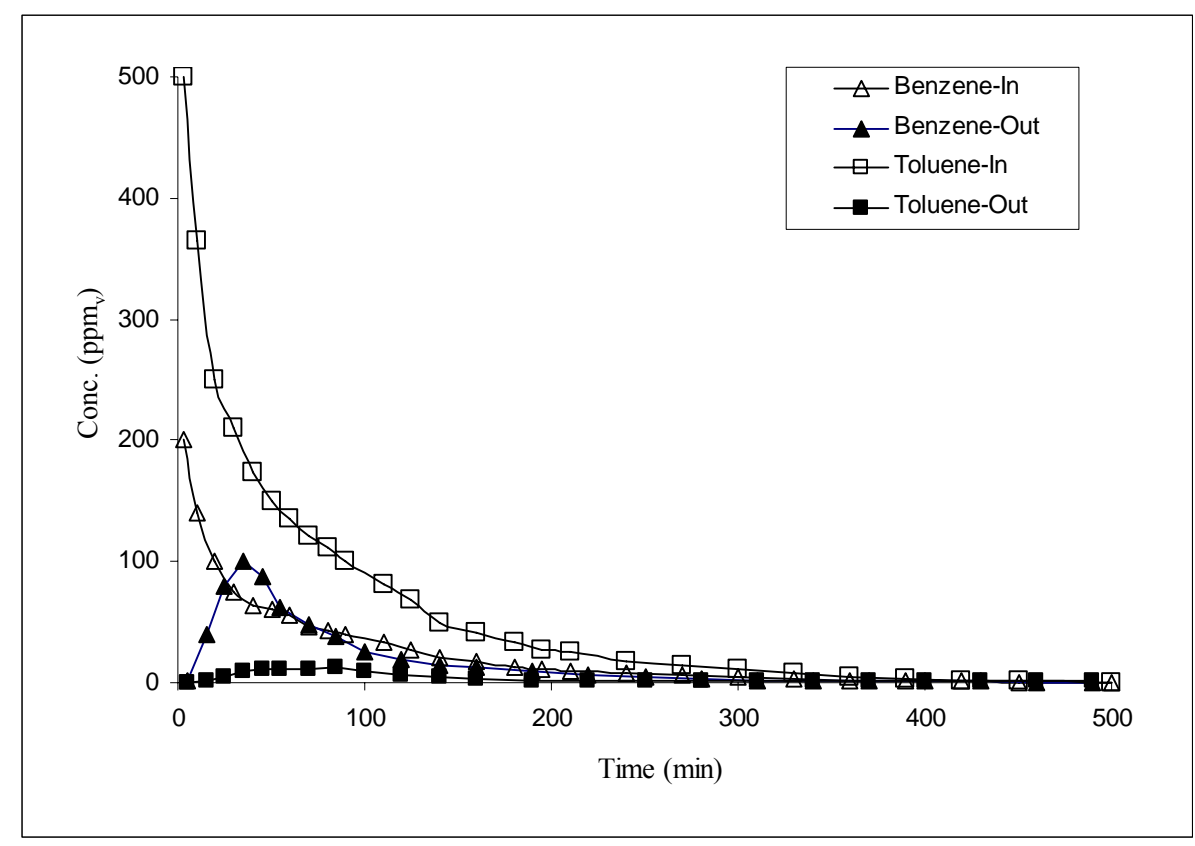

Figure 4-19. Measured benzene $\&$ toluene fixed bed adsorber data for varying influent concentrations. 1.8 sec-EBCT. 


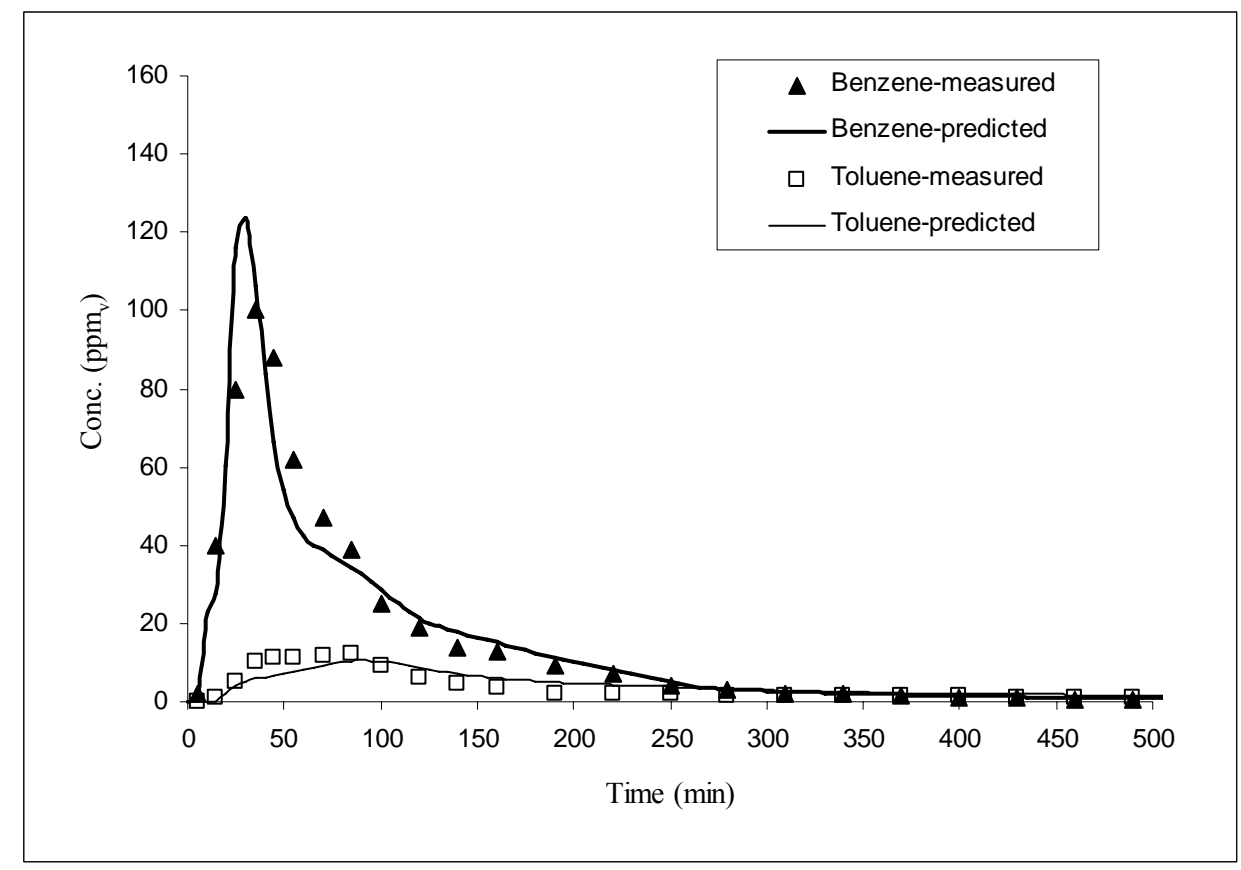

Figure 4-20. Measured and HSDM-predicted benzene \& toluene fixed bed adsorber data for varying influent concentrations shown in Figure 4-19, 1.8 sec-EBCT.

\subsubsection{HSDM Model Predictions for Developing Design Criteria}

The success of the HSDM predictions of the benzene and toluene data collected in the laboratory indicates that this model may be suitable for field-scale design of a fixed bed adsorption column for an SMZ/VPB system assuming that benzene and toluene are the major constituents in SMZ regenerated gas streams. To this end, laboratory determined adsorption and kinetic parameters were used in the HSDM for a range of variable loading scenarios of benzene and toluene mixtures and EBCTs. The shape of the influent profiles matched those used in the laboratory studies (see Figure 4-19). Figure 4-21 (A) shows the predicted results of buffered benzene and toluene mixtures at three different EBCTs $\left(1,3\right.$, and 5 seconds) for influent peak benzene and toluene concentrations of $200 \mathrm{ppm}_{\mathrm{V}}$ and $500 \mathrm{ppm}_{\mathrm{v}}$, respectively. Figure 4-21 (B) shows the buffered benzene concentrations with different inlet peak concentrations $\left(200,500\right.$, and $\left.1000 \mathrm{ppm}_{\mathrm{v}}\right)$ in a fixed EBCT (1 second). Results indicate that buffering efficiencies are strongly affected by the EBCTs and peak concentrations of VOCs. Given that the goal of the buffering is to attenuate the peak concentrations to approximately $150 \mathrm{ppm}_{\mathrm{v}}$ or less, even a one second-EBCT should be sufficient if the benzene and toluene concentrations are less than $200 \mathrm{ppm}_{\mathrm{v}}$. If the peak concentrations are higher, then a longer EBCT will be required. 
(A)

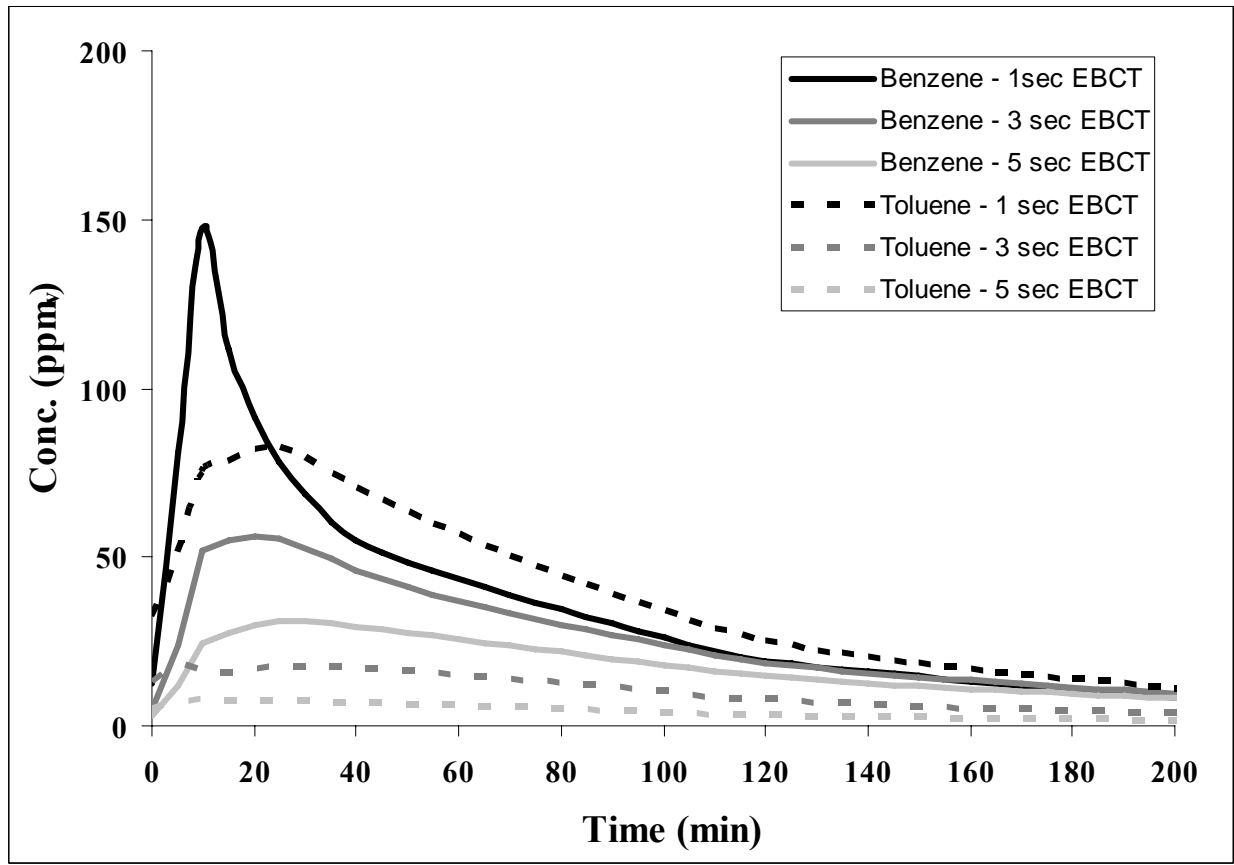

(B)

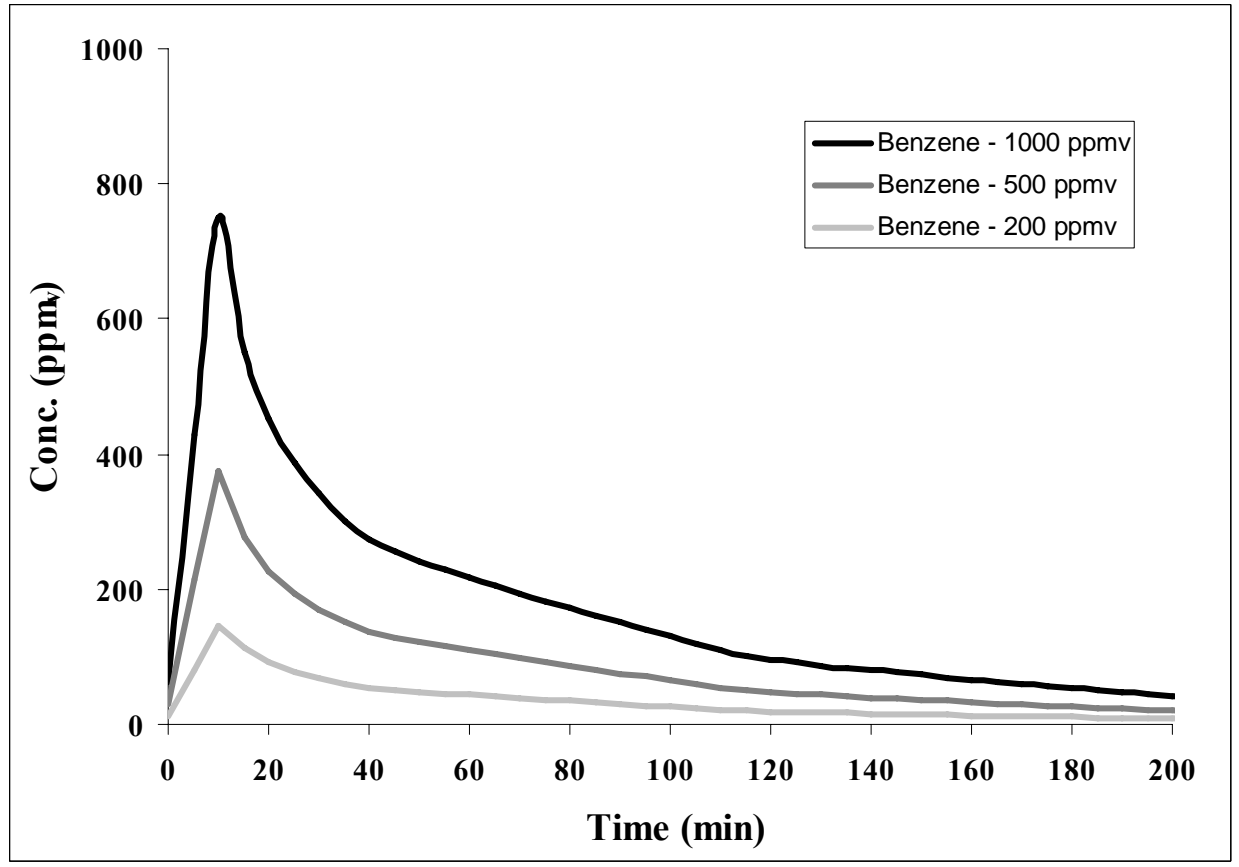

Figure 4-21. HSDM-predicted benzene \& toluene effluent concentrations from a GAC-fixed bed adsorption column. (A): at 1, 3, and 5 second-EBCTs. Inlet maximum concentrations: $200 \mathrm{ppm}_{\mathrm{v}}$ for benzene, $500 \mathrm{ppm}_{\mathrm{v}}$ for toluene. (B): at 200, $500,1000 \mathrm{ppm}_{\mathrm{v}}$ of inlet-benzene Maximum concentrations, $500 \mathrm{ppm}_{\mathrm{v}}$ of toluene Maximum concentration. 1 second-EBCT. 


\subsubsection{Summary}

Single-solute adsorption equilibrium parameters and SBA determined kinetic parameters were used to successfully predict benzene and toluene adsorption in GAC columns. SBA parameters for the film diffusion coefficient were more consistent with those predicted using a gas phase film transfer correlation whereas the experimentally determined surface diffusion coefficients were more consistent with aqueous surface diffusion estimates. Competitive adsorption of benzene and toluene was predicted very well by IAST. However, the accuracy of the model was improved by applying the correction factor $(\mathrm{P})$. The calibrated HSDM predicted very well the bi-solute column data under continuous and variable loading conditions. The experimental results and modeling obtained are important in understanding and predicting the behavior of GAC-fixed bed adsorption columns treating gas phase VOC mixtures in water saturated gas streams.

\subsection{Field Application of an SMZ/VPB System to Treat Produced Water}

Based on the lab tests of the VPB and GAC-fixed bed adsorption column, a field test of the load equalization and VPB system was completed as part of a field evaluation of an SMZ/VPB unit treating produced water (DE-FC26-02NT15461). More specifically, the objectives of the field test were to evaluate the performance of the coupled SMZ/VPB system treating actual produced water over a range of flow rates and over multiple sorption regeneration cycles. Also, the efficiency of a GAC-fixed bed adsorption column placed upstream of the VPB during SMZ regeneration was evaluated.

The chemical composition of the produced water was analyzed by DHL Analytical (Round Rock, TX) before the field test began (Table 4-2). The total VOC concentrations were approximately $20 \mathrm{mg} / \mathrm{L}$ and consisted primarily of toluene, $p \& m$-xylene, acetone, benzene, and $o$-xylene. The total BTEX concentration constituted about 80 percent of the total VOC concentration. Several polynuclear aromatic hydrocarbons were identified including naphthalene, and phenanthrene, but their total concentration was low $(<0.2$ $\mathrm{mg} / \mathrm{L}$ ). Metals and cations such as sodium, calcium, potassium, magnesium, barium, and selenium were also identified in the produced water samples. Three organic anions were detected in the influent produced water at the following average concentrations: acetate $(259 \mathrm{mg} / \mathrm{L})$, malonate $(170 \mathrm{mg} / \mathrm{L})$ and propionate $(30 \mathrm{mg} / \mathrm{L})$. 
Table 4-4. Composition of produced water at the saltwater processing facility, NM

\begin{tabular}{lc||cc}
\hline Analysis & $\begin{array}{c}\text { Concentration } \\
(\mathrm{mg} / \mathrm{L})\end{array}$ & Analysis & $\begin{array}{c}\text { Concentration } \\
(\mathrm{mg} / \mathrm{L})\end{array}$ \\
\hline Gasoline range organics (C6-C10) & 16 & Naphthalene & 0.03 \\
Diesel range organics (C10-C28) & 23.5 & 2-methylnaphthalene & 0.01 \\
Total dissolved solids (TDS) & 11,076 & Barium & 0.7 \\
Total organic carbon (TOC) & 318 & Calcium & 77.8 \\
Benzene & 2.2 & Magnesium & 25.4 \\
Toluene & 7.1 & Potassium & 74.7 \\
Ethylbenzene & 0.4 & Selenium & 0.014 \\
p\&m-xylene & 3.9 & Sodium & 3,700 \\
o-xylene & 1.1 & Bromide & 12 \\
Acetone & 3.1 & Chloride & 5,360 \\
Phenol & 1.2 & Sulfate & 408 \\
2-methylphenol & 0.6 & Acetate & 258.9 \\
4-methylphenol & 0.03 & Malonate & 171.6 \\
2,4-dimethylphenol & 0.01 & Propionate & 30.0 \\
\hline
\end{tabular}

\subsubsection{Adsorption of BTEX on the SMZ Column}

The breakthrough profiles of BTEX in produced water through the virgin SMZ columns are shown in Figure 4-22. Benzene breakthrough occurred first after 5 hours of operation at a 27 gph flow rate. Toluene breakthrough followed the benzene breakthrough, but the breakthrough of the other VOCs was much slower than that observed for benzene and toluene. Rapid breakthrough of benzene, compared to the other VOCs present is consistent with theoretical predictions based on solute hydrophobicity and lab test results, indicating the low affinity of benzene for SMZ (Ranck et al., 2005). This result implies that benzene removal will control the design of the SMZ adsorption system.

The performance of the pilot SMZ system was investigated at three produced water flow rates: $27 \mathrm{gph}, 10 \mathrm{gph}$ and $5 \mathrm{gph}$. As evident in Figure 4-23, the flow rate had no effect on SMZ performance for the first 10 pore volumes indicating that liquid phase mass transfer was not limiting under the conditions evaluated in the field test. The greatest difference in sorption is evident at later times when the SMZ column operated at 10 gph continued to sorb benzene and the virgin SMZ column operated at 27 gph became saturated. This difference in sorption is not likely a result of the different flow rates but rather due to the fact that the SVOCs and other organics that sorbed onto the SMZ column during the initial runs actually increased the sorption capacity of the SMZ for organics such as benzene. Batch equilibrium tests have confirmed this behavior for synthetic produced water (Ruckgaber, 2004). 


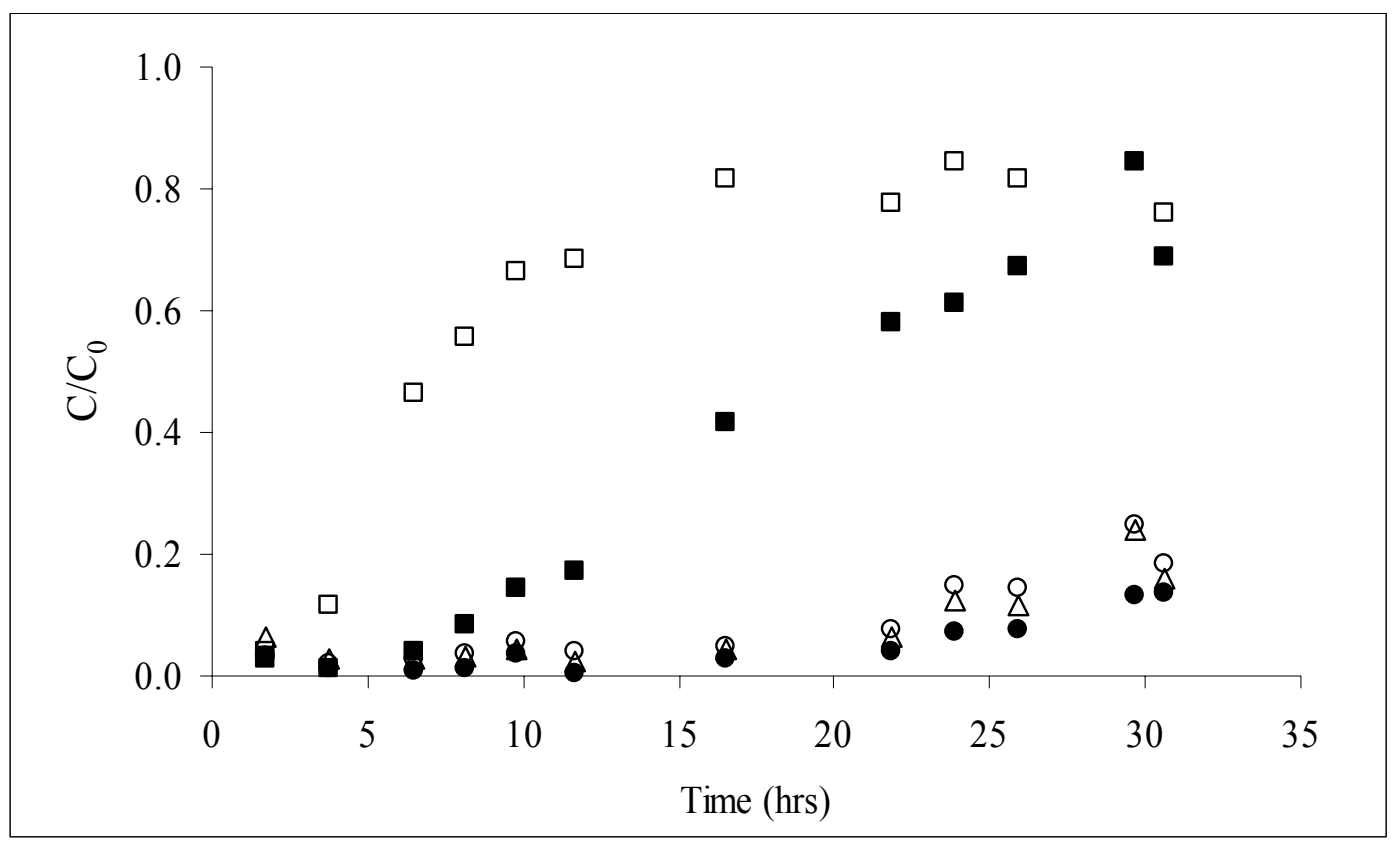

Figure 4-22. Breakthrough of BTEX on virgin SMZ at the flow rate of $27 \mathrm{gph}$. ( $\square$; Benzene, $\square$; Toluene, $\bigcirc$; Ethylbenzene, $\bullet$; p\&m xylene, $\Delta$; o-xylene). 1 hour-EBCT

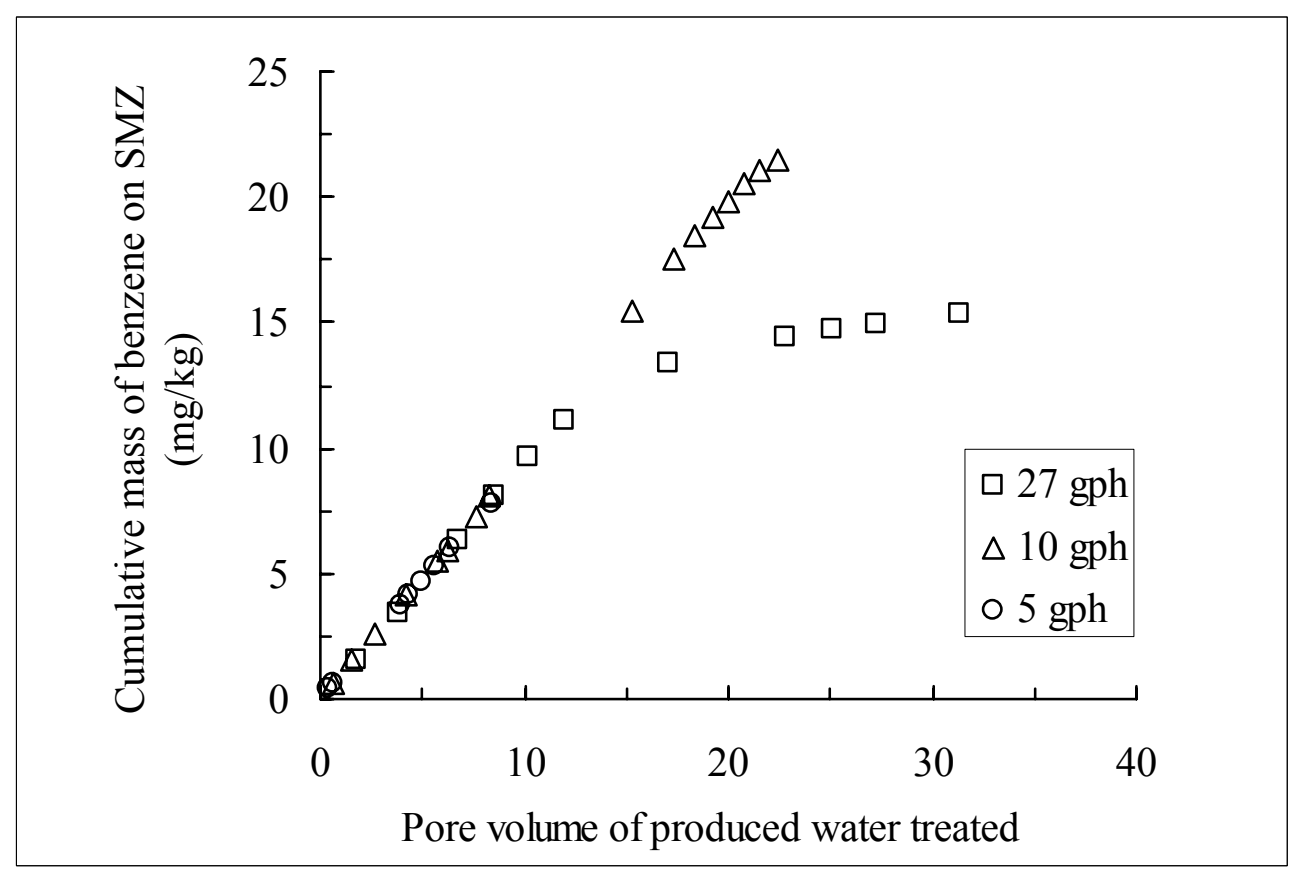

Figure 4-23. Cumulative mass of benzene adsorbed on SMZ at different produced water flow rates. 
To verify the above result, the adsorption of benzene on virgin and regenerated SMZ was compared in Figure 4-24. Again, adsorption on virgin SMZ refers to the test conducted at 27 gph flow rate, and adsorption on regenerated SMZ refers to the test conducted at 10 gph. As in Figure 4-24, regenerated SMZ provided higher sorption capacity for benzene than virgin SMZ. It is assumed that some semi-volatile compounds in produced water, which remained on the surface of SMZ even after air sparging, enhanced the sorption capacity for the next adsorption cycle.

As evident in Figure 4-24, benzene was observed in the effluent from the regenerated SMZ column immediately after it was placed back online and began treating produced water again. It is believed that this early breakthrough was due to the residual water that remained in the SMZ column even after the previous regeneration cycle because the configuration of the SMZ columns did not allow all of the water to be drained from the columns during regeneration. As a result, this BTEX laden water was carried over to the next sorption cycle when the SMZ column was reconnected to the system and produced water flowed through it again.

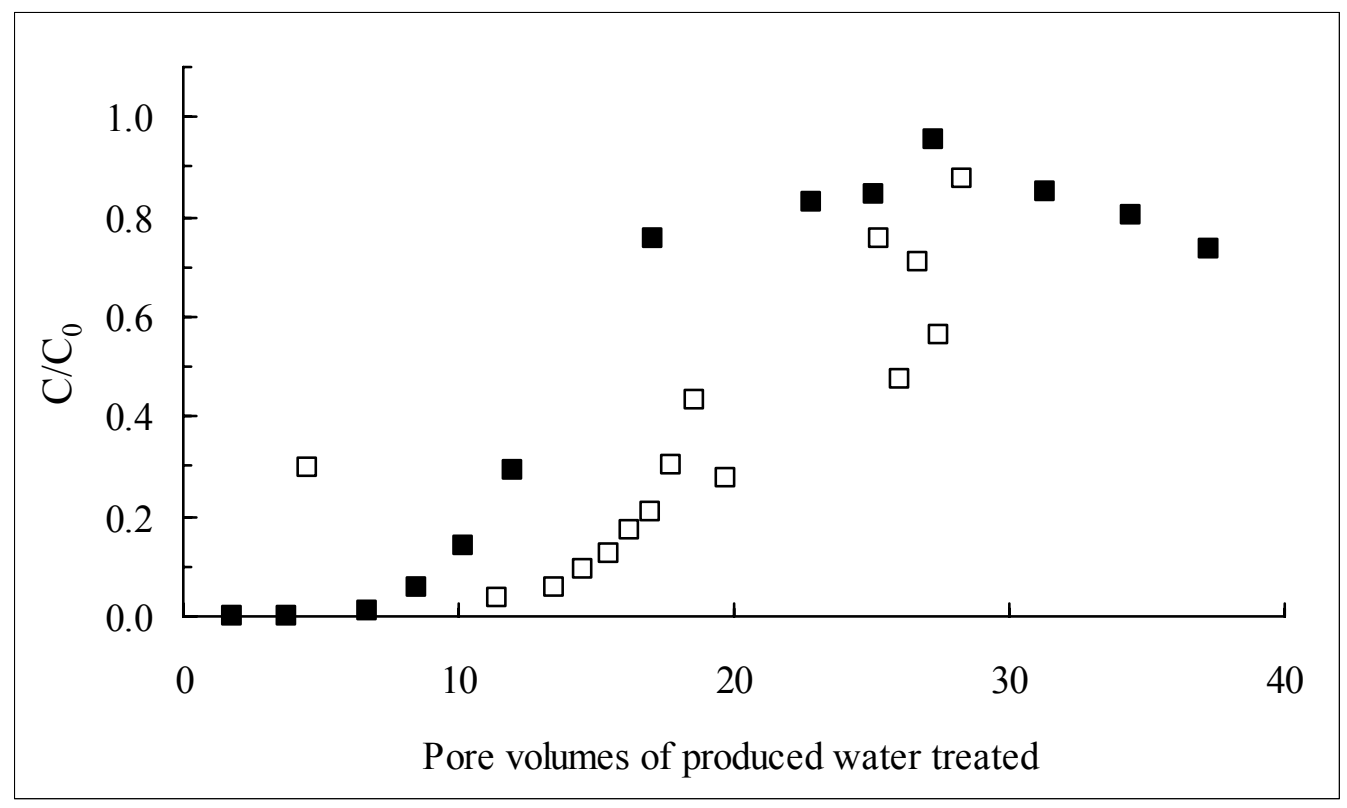

Figure 4-24. Comparison of benzene breakthrough curves on virgin and regenerated SMZ. ( $\square$; Benzene adsorption on virgin SMZ, $\square$; Benzene adsorption on regenerated $\mathrm{SMZ}$ ) 


\subsubsection{Treatment of BTEX by the VPB}

\subsubsection{Regeneration}

A typical BTEX concentration profile observed in the regenerated gas streams during the field test is presented in Figure 4-25 (A). Lab-scale regeneration results (Altare et al., 2007) are presented in Figure 4-25 (B) for comparison. In both cases, benzene desorption occurred very rapidly compared to the other chemicals. In laboratory tests, the SMZ column was completely saturated with BTEX before regeneration was initiated. However, in the field test, the SMZ sorption cycle was generally terminated when benzene reached $100 \%$ breakthrough even though the breakthrough percentage of the other components was incomplete: toluene $70 \%, o$-xylene $15 \%$, ethylbenzene and $p \& m$ xylenes $<10 \%$ breakthrough. As a result, the concentration of benzene in the regenerated gas stream was higher than the other compounds during the field test. Toluene levels were also high indicating that the downstream VPB would have to treat high levels of benzene and toluene initially if no load equalization system was in place. The peak concentrations of BTEX during the regeneration ranged from $490 \mathrm{ppm}_{\mathrm{v}}$ to $1120 \mathrm{ppm}_{\mathrm{v}}$ based on the SMZ breakthrough levels (i.e., 35 to 100\% breakthrough of benzene) present at the time regeneration began. As expected, these high concentrations decreased rapidly to below $100 \mathrm{ppm}_{\mathrm{v}}$ over 10 hours (Figure 4-25 (A)). The regenerated gas stream temperature fluctuated between 20 to $28{ }^{\circ} \mathrm{C}$, since ambient air was used for air sparging. The $\mathrm{RH}$ of the ambient air used for SMZ regeneration ranged between 26 to $70 \%$, however, the RH of the regenerated gas streams exiting the SMZ columns always remained above $90 \%$.

\subsubsection{GAC-Load Equalization}

During the field test, the regenerated gas stream was buffered by a fixed bed adsorption column containing a GAC sorbent. As shown in Figure 4-25, benzene and toluene were the major components present in the regenerated gas stream. The concentrations of these two chemicals in the gas stream entering and exiting the GAC column during a regeneration cycle are presented in Figure 4-26. The results indicate that the GAC columns effectively reduced the toluene and benzene concentration in the gas stream.

The GAC system was more effective at the 5 second-EBCT where it reduced the benzene concentrations to below $100 \mathrm{ppm}_{\mathrm{v}}$, an ideal level for successful biodegradation in the VPB operated in this research. However, those buffered VOC concentrations are higher than the concentrations predicted using HSDM. The discrepancies between the laboratory-based predictions and the field data are most likely due to the presence of significant concentrations of xylene and differences between the influent profiles used to generate the predictions and the field profiles. 
(A)

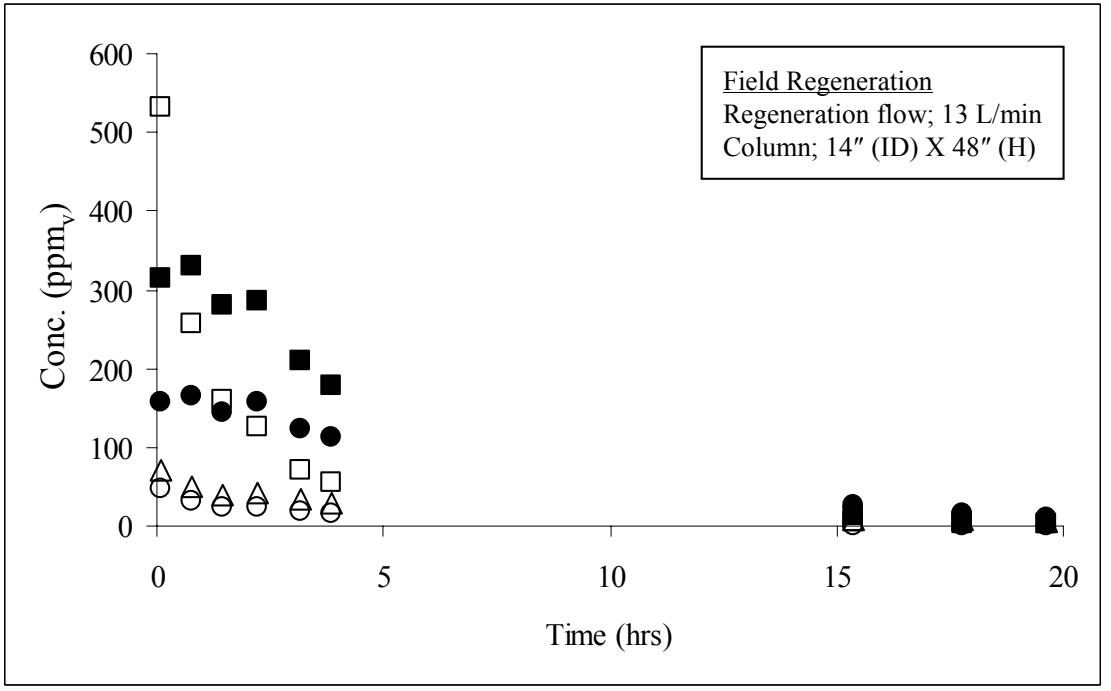

(B)

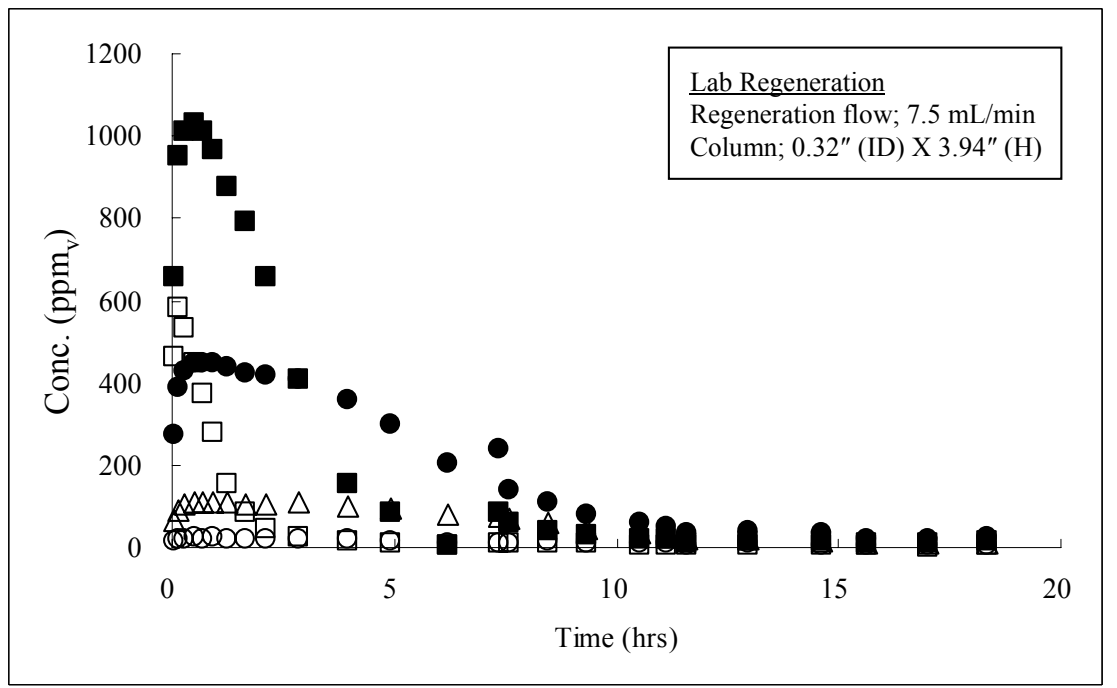

Figure 4-25. BTEX concentration profiles of gas phase effluent during regeneration of SMZ columns with air. (A): Regeneration in the field (B): Regeneration in the lab (Altare et al., 2007). In the field test, the SMZ column being regenerated was completely saturated with respect to benzene and only partially saturated with respect to the other VOCs. In the lab test, the SMZ column was completely saturated with BTEX prior to regeneration ( $\square$ : Benzene, $\square$ : Toluene, $\circ$ : Ethylbenzene, $\bullet$ : $p \& m$-xylene, $\Delta$ : o-xylene). 
(A)

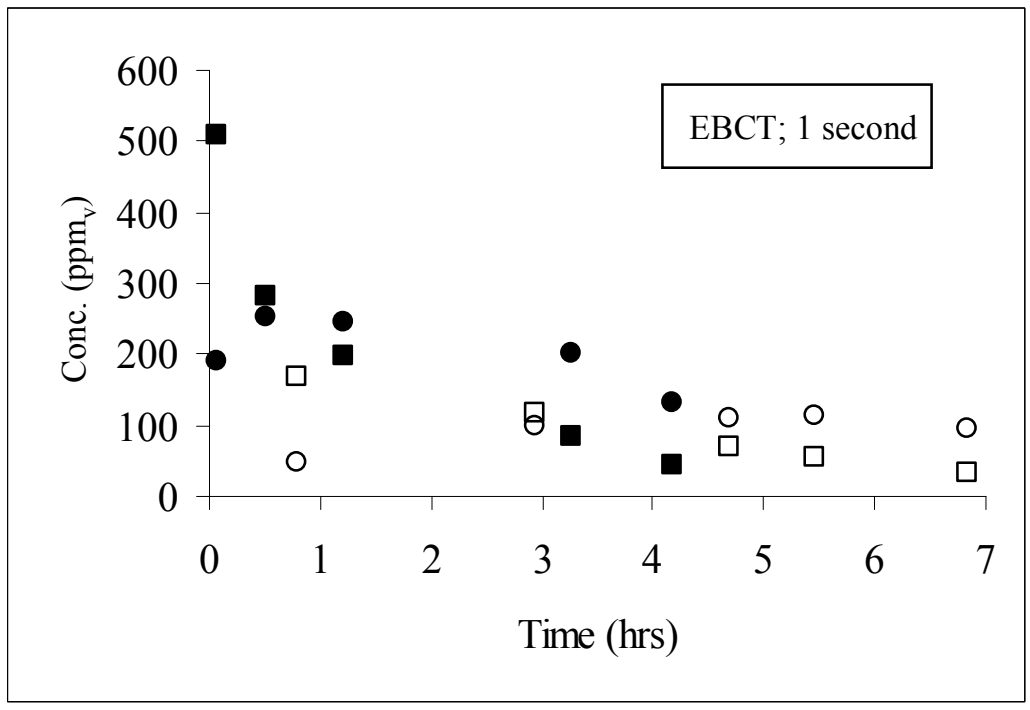

(B)

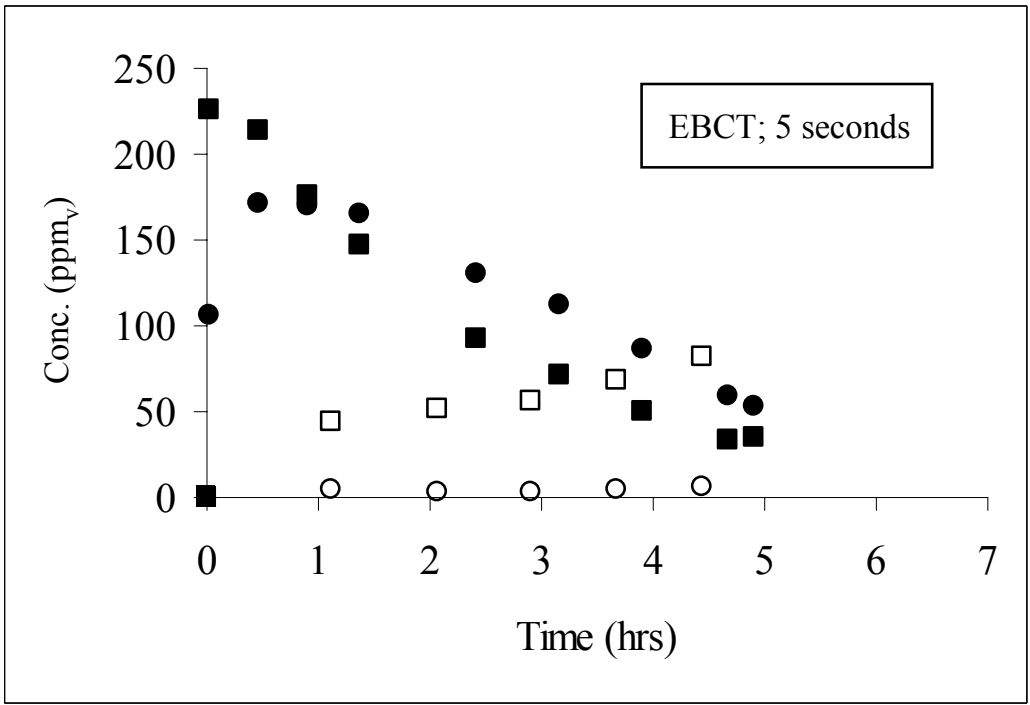

Figure 4-26. Response of the GAC-fixed bed adsorption column to regenerated VOCs from the saturated SMZ column. (A): 1 second-EBCT, (B): 5 second-EBCT. ( $\square$ : Benzene influent, $\square$ : Benzene effluent, $\bullet$ : Toluene influent, $\circ$ : Toluene effluent).

To explain those discrepancies resulted from the presence of xylene in the regenerated gas stream, a HSDM was used considering the xylene as well as benzene and toluene mixtures with a same influent profiles described previously (Figure 4-19). A para-xylene was chosen as the representative of three xylene isomers. Freundlich parameters of paraxylene $\left(K=172.1(\mathrm{mg} / \mathrm{g})(\mathrm{L} / \mathrm{mg})^{1 / \mathrm{n}}, 1 / n=0.311\right)$ were determined by the Polanyi theory (Polanyi, 1932) based on the toluene isotherms measured on BPL GAC. Also, kinetic coefficients $\left(k_{f}\right.$ and $\left.D_{s}\right)$ of toluene were used for para-xylene assuming similar behavior of both VOCs at the same operating conditions. Figure 4-27 shows the predicted results of buffered benzene concentrations at a five second-EBCT for influent peak benzene, toluene and para-xylene concentrations of $200 \mathrm{ppm}_{\mathrm{v}}, 500 \mathrm{ppm}_{\mathrm{v}}$, and $0 \sim 500 \mathrm{ppm}_{\mathrm{v}}$, 
respectively. Results indicate that buffering efficiency for benzene is strongly affected by the presence of para-xylene (the more adsorbable compound).

An additional explanation for the observed discrepancies is that the parameters used for the lab-scale predictions were measured on fresh GAC while data collected in the field was predominantly for adsorption and desorption from regenerated GAC.

If the VOCs adsorbed on the GAC during high influent concentration periods are not completely removed in a given buffering cycle, the fixed bed adsorption column will eventually accumulate VOCs as the feed cycles continue eventually resulting in a decrease in buffering efficiency. Figure 4-28 shows the response of the fixed bed adsorption column to repeated cycles of adsorption/regeneration. The BTEX concentrations introduced to the fixed bed adsorption column varied with observed peaks ranging between $490 \sim 570 \mathrm{ppm}_{\mathrm{v}}$. However, the BTEX concentration levels exiting the GAC-fixed bed adsorption column were steady at approximately $100 \mathrm{ppm}_{\mathrm{v}}$ and a decrease in buffering efficiency was not observed under the conditions of the field test. This result suggests that the regeneration times evaluated in the field test $(12.5 \mathrm{hrs}$ and 25 hrs) were sufficient to remove the adsorbed VOCs from the GAC in the fixed bed adsorption column. However, a rigorous mass balance of the total BTEX mass adsorbed and desorbed from the GAC could not be determined in the field due to limitations in the site operating schedule.

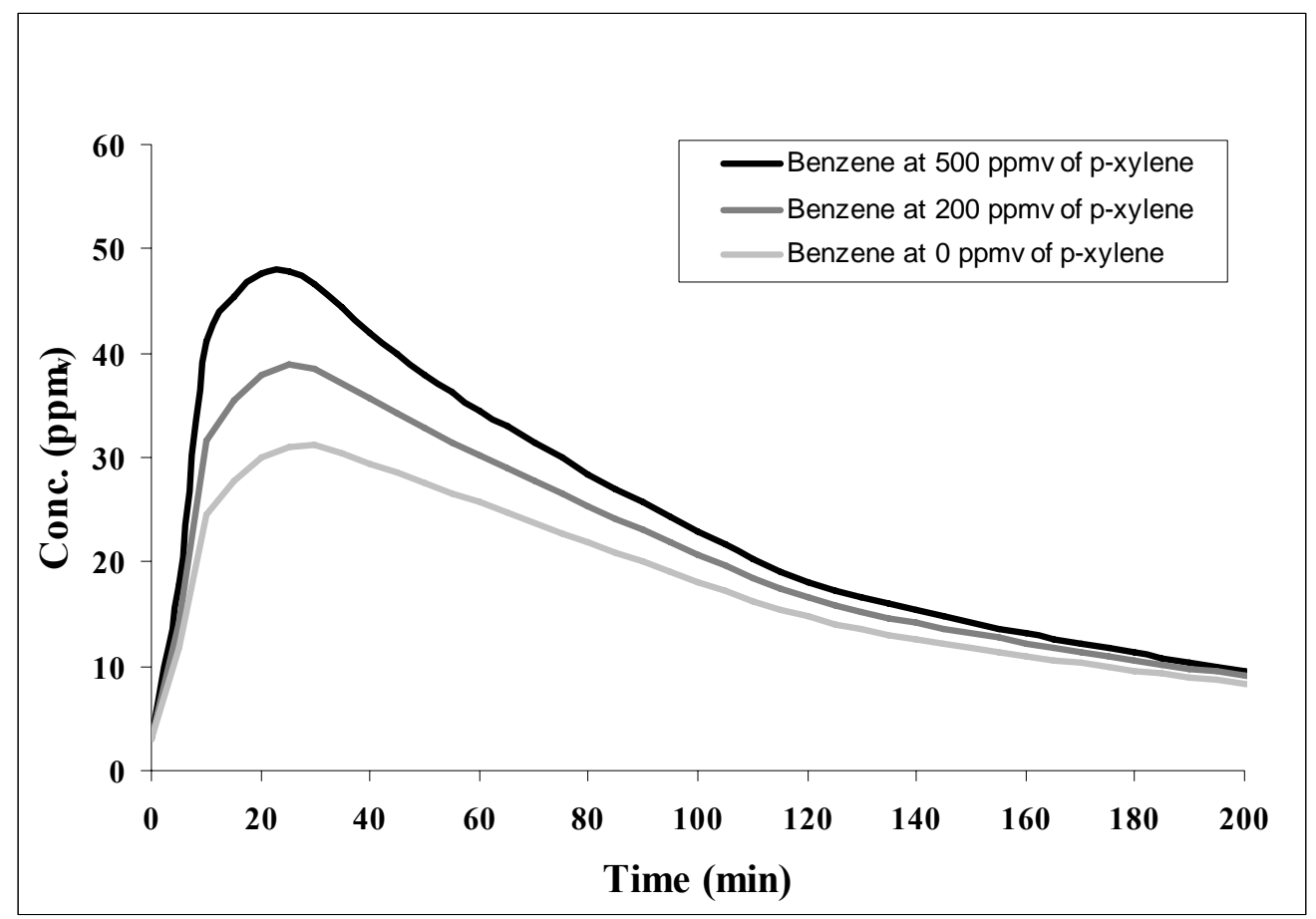

Figire 4-27 HSDM-predicted benzene effluent concentrations from a GAC-fixed bed adsorption column. Inlet maximum concentrations: $200 \mathbf{~ p m}_{\mathrm{v}}$ for benzene, 500 $\mathrm{ppm}_{\mathrm{v}}$ for toluene, and $0 \sim 500 \mathrm{ppm}_{\mathrm{v}}$ for para-xylene. 5 second-EBCT. 


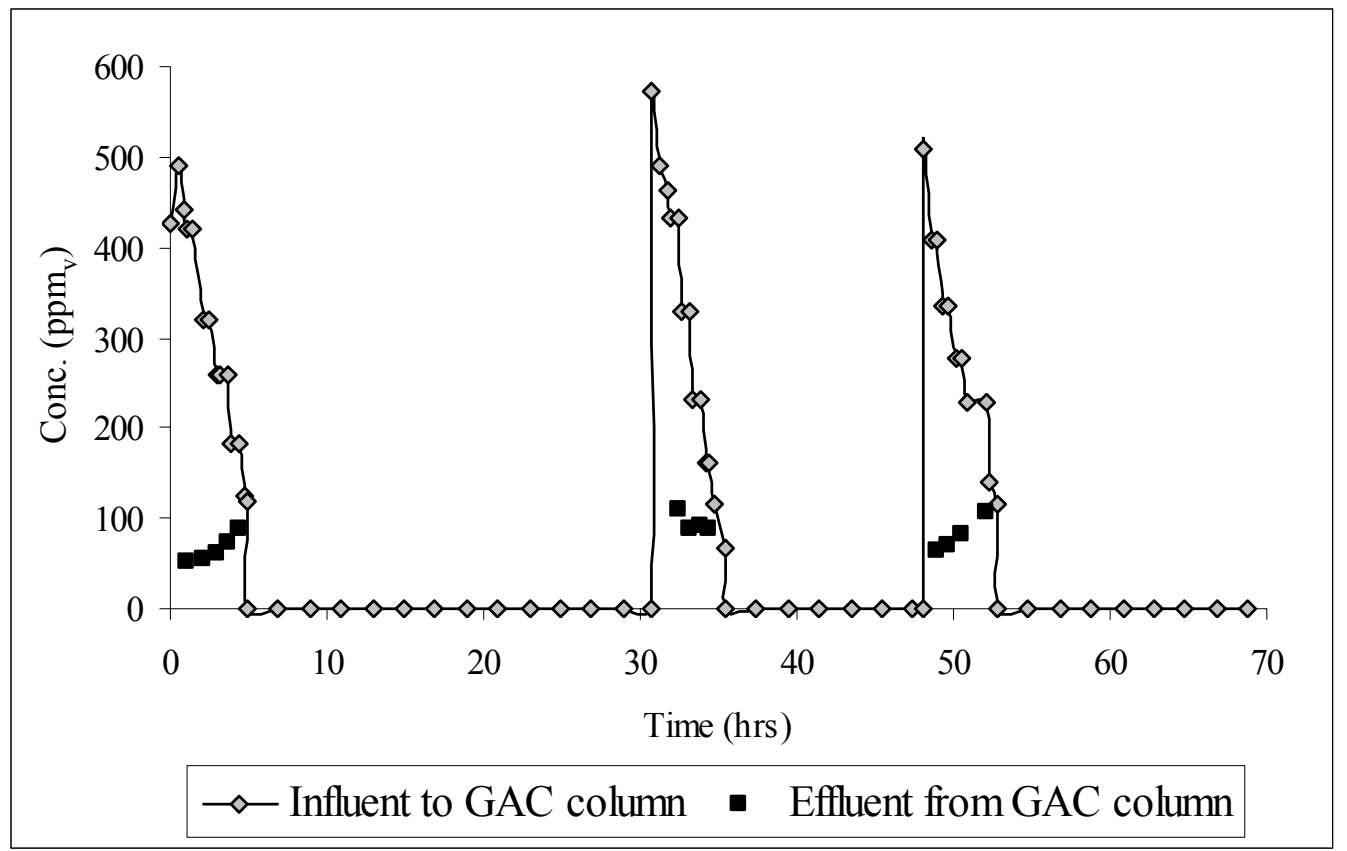

Figure 4-28. Buffering capacity of GAC (five second-EBCT) for repeated cycles of adsorption/regeneration. The BTEX concentrations exiting the fixed bed adsorption column between SMZ regeneration periods were not measured due to limitations imposed by the site operating schedule.

\subsubsection{VPB Performance}

After passing through the GAC-fixed bed adsorption column, the VOC-laden gas stream from the SMZ regeneration process was fed to the VPB. Figure 4-29 shows the subsequent removal of benzene and toluene in the VPB for two different operating conditions. During the beginning of the field trial, the VPB was operated with a microbial community that had been adapted to an inlet benzene concentration of $12 \mathrm{ppm}_{\mathrm{v}}$. As a result, poor benzene removal efficiencies were observed in the VPB when it was subjected to an inlet benzene concentration of $170 \mathrm{ppm}_{\mathrm{v}}$, as shown in Figure 4-29 (A). The toluene removal was better even when it was subjected to an inlet concentration of $110 \mathrm{ppm}_{\mathrm{v}}$. To improve the performance of the VPB and acclimate the microbial population to a higher benzene concentration, a surrogate BTEX feed containing $90 \mathrm{ppm}_{\mathrm{V}}$ benzene, $20 \mathrm{ppm}_{\mathrm{v}}$ toluene, $5 \mathrm{ppm}_{\mathrm{v}}$ ethylbenzene, $10 \mathrm{ppm}_{\mathrm{v}}$ para \& meta-xylene and 5 $\mathrm{ppm}_{\mathrm{V}}$ ortho-xylene) was provided to the VPB during the shutdown periods. As a result, the biomass in the VPB became accustomed to high benzene levels and removed more than $95 \%$ of the benzene introduced to the column during the regeneration process (Figure 4-29 (B)). These results along with similar results obtained in the SMZ sorption and regeneration experiments suggest that benzene will control the design and operation of the coupled SMZ/VPB for BTEX removal from the produced water evaluated in this study. 
(A)

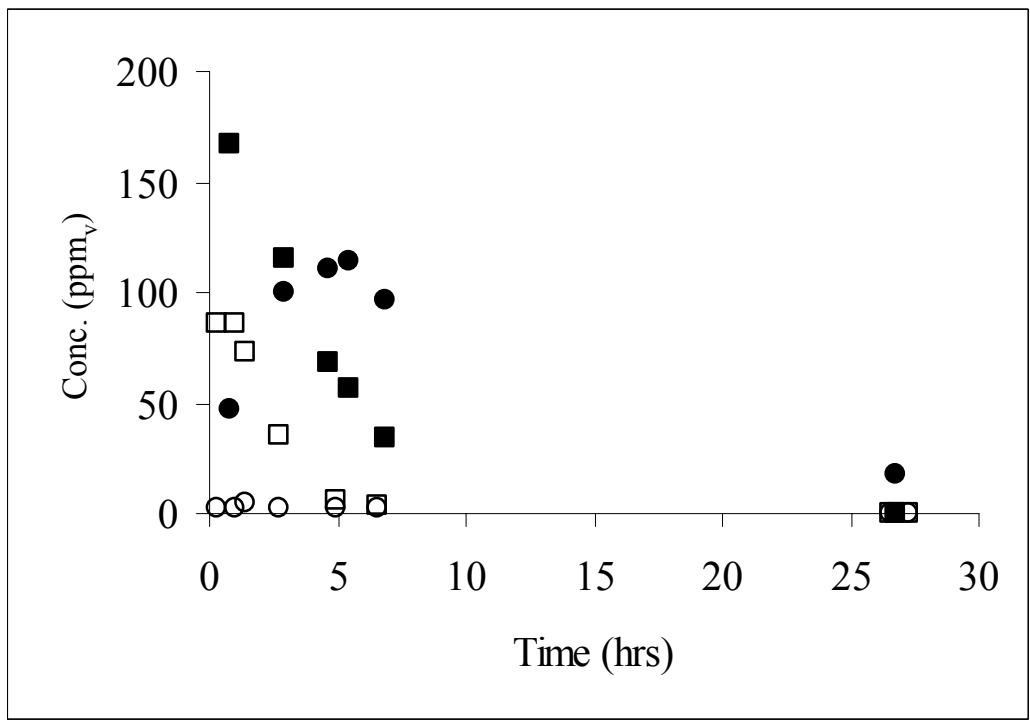

(B)

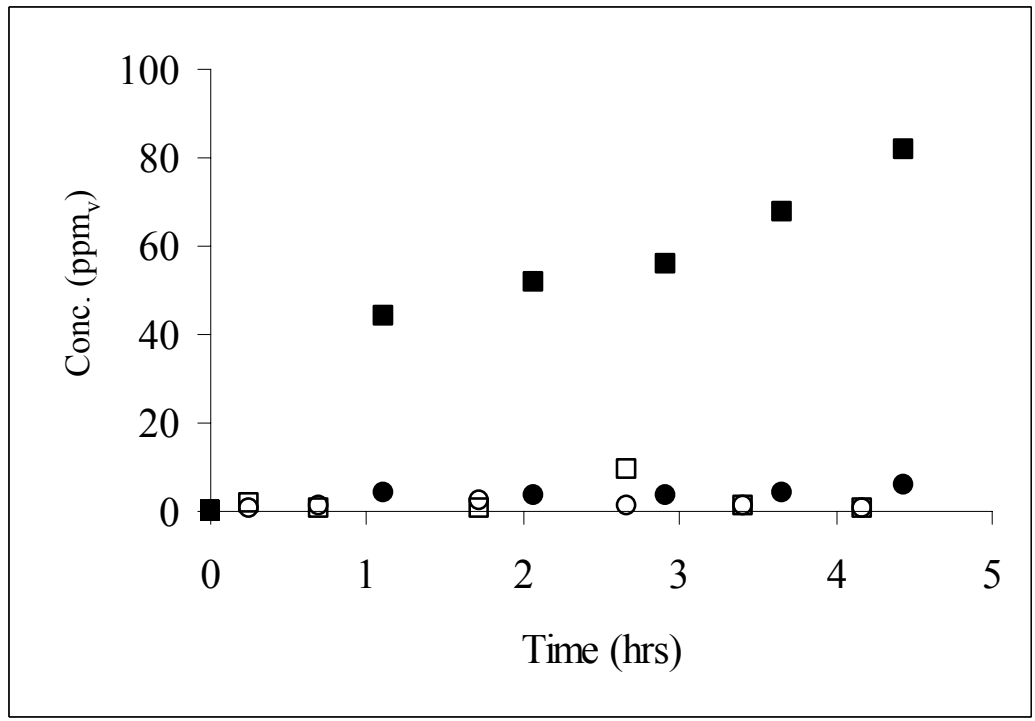

Figure 4-29. Performance of the VPB treating the VOC-laden gas exiting the GACfixed bed adsorption column during the SMZ/VPB field trial. (A): Biomass accustomed to low concentrations $\left(12 \mathrm{ppm}_{\mathrm{v}}\right)$ of benzene, (B): Biomass accustomed to higher concentrations $\left(90 \mathrm{ppm}_{\mathrm{v}}\right)$ of benzene. ( $\square$ : Benzene influent to VPB, $\square$ : Benzene effluent from VPB, •: Toluene influent to VPB, $\circ$ : Toluene effluent from VPB).

\subsubsection{Carboxylate Removal by SMZ}

The removal of carboxylates by the SMZ column was also determined. Three organic anions were detected in the influent produced water at the following average concentrations: acetate $(259 \mathrm{mg} / \mathrm{L})$, malonate $(170 \mathrm{mg} / \mathrm{L})$ and propionate $(30 \mathrm{mg} / \mathrm{L})$. 
A typical breakthrough curve for the carboxylates through the SMZ column during the field trial is presented in Figure 4-30. As is evident in the figure, the organic anions were poorly removed in the SMZ column. These results are not surprising as the carboxylates are highly soluble anions and at these concentrations the anion exchange capacity of the SMZ would be rapidly exhausted.

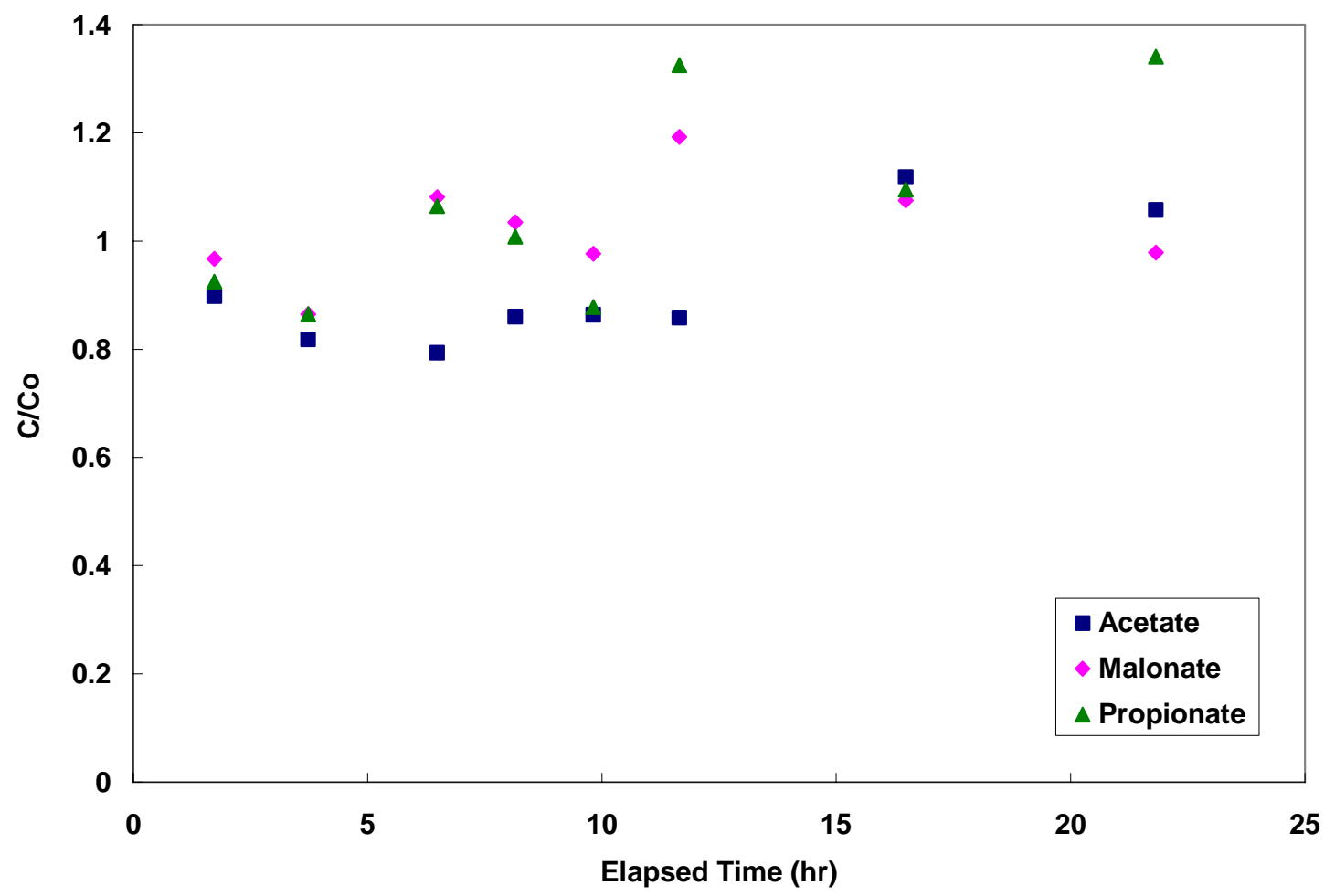

Figure 4-30. Breakthrough curves for carboxylates on virgin SMZ during the field trial in New Mexico. The produced water flow rate was $27 \mathrm{gph}$.

\subsubsection{Summary}

In the field test, the coupled treatment system of SMZ columns and a VPB performed well over repeated feed and regeneration cycles demonstrating the viability of the process. Of the BTEX components present in the produced water, benzene had the lowest adsorption affinity for the SMZ and thus controlled the sorption cycle length. Regeneration of the SMZ using air sparging was found to be sufficient in the field to maintain the SMZ adsorption capacity and to allow continuous operation of the system. As expected, the BTEX concentrations in the regeneration off gas streams were initially very high in a given regeneration cycle. However, a GAC-fixed bed adsorption column placed upstream of the VPB reduced the peak BTEX concentrations to acceptable levels for the VPB, and a decrease in buffering efficiency was not observed after repeated adsorption/regeneration cycles under the conditions evaluated in the field test. As a result, the VPB was able to maintain stable performance over the entire SMZ regeneration 
period despite the intermittent nature of the feed. Benzene was found to be the chemical controlling removal rates during $\mathrm{SMZ}$ adsorption and regeneration, GAC-load equalization, and biodegradation in the VPB. The carboxylates were detected in the influent produced water, but they were not effectively removed in the SMZ columns. While not hazardous, the presence of these carboxylates in the effluent water has implications for potential post-treatment options. In particular, carboxylates represent a significant fraction of the TOC present in produced water and would be expected to contribute to fouling of an RO membrane. Therefore, removal of carboxylates by a MBR process was evaluated as a means of reducing the carboxylate concentrations.

\subsection{Membrane Bioreactor Experiments}

During the field trial of the SMZ/VPB system, the organic and inorganic composition of the produced water was determined and the removal of each of these constituents by the SMZ column was investigated. The results indicated that several carboxylates such as acetate and malonate were present in the influent produced water at a total concentration on the order of $400 \mathrm{mg} / \mathrm{L}$. As discussed in previous chapters, the carboxylates were not effectively removed in the SMZ columns although the BTEX components were removed. In particular, beneficial uses of the treated produced water require the removal of the dissolved salts from the produced water. Reverse osmosis is a proven technology for desalination but the presence of organics can foul the membrane (Agenson and Urase, 2007). Thus, a technology to efficiently remove the carboxylates from the produced water is desirable.

One option for removing organics such as acetate and malonate from produced water is to use a MBR system. Although direct biological treatment of briny produced water can be challenging, many of the organic contaminants in produced water are amenable to biological treatment. Indeed, several researchers have recently developed biological treatment systems that can treat high salinity waters containing dissolved organics (Bakx et al., 2000; Dalmacija et al., 1996; Scholz et al., 2005; Tellez et al., 2005). The objective of this phase of the research was to investigate the feasibility of utilizing a MBR system to pretreat produced water to a level sufficient for subsequent treatment in a reverse osmosis system. To this end, a series of laboratory-scale studies were conducted to examine the removal of BTEX and carboxylates in a submerged MBR treating synthetic produced water.

\subsubsection{Bottle Studies}

Rapid biodegradation of acetate and malonate was observed in both the $10 \mathrm{~g} / \mathrm{L}$ and 100 $\mathrm{g} / \mathrm{L}$ TDS solutions although the removal rate of acetate was more rapid than that of malonate (Figures 4-31 \& 4-32). As expected, the removal of carboxylates in more saline water (100 g/L TDS solution) was slower than in the lower salinity water (10 g/L TDS solution). BTEX degradation was observed in the $10 \mathrm{~g} / \mathrm{L}$ TDS solution, but little to no degradation was observed in the $100 \mathrm{~g} / \mathrm{L}$ TDS solutions over the two week incubation period. These results suggest that carboxylates can be biodegraded in high TDS solutions, but the removal of BTEX constituents may be more difficult under these conditions. 
These bottle tests also imply that the carboxylates and BTEX constituents in produced water can be removed simultaneously via biodegradation as long as the salinity level is not too high.

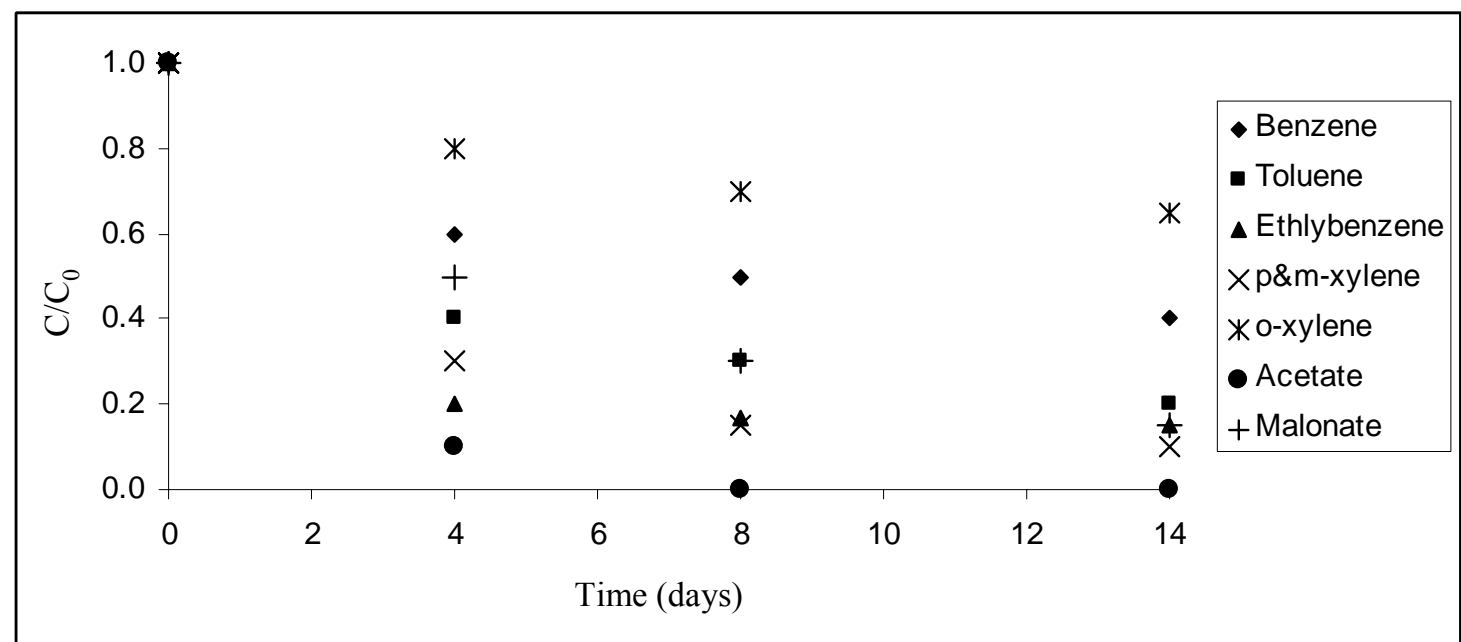

Figure 4-31. Removal of carboxylates and BTEX in a synthetic produced water solution containing $10 \mathrm{~g} / \mathrm{L}$ TDS.

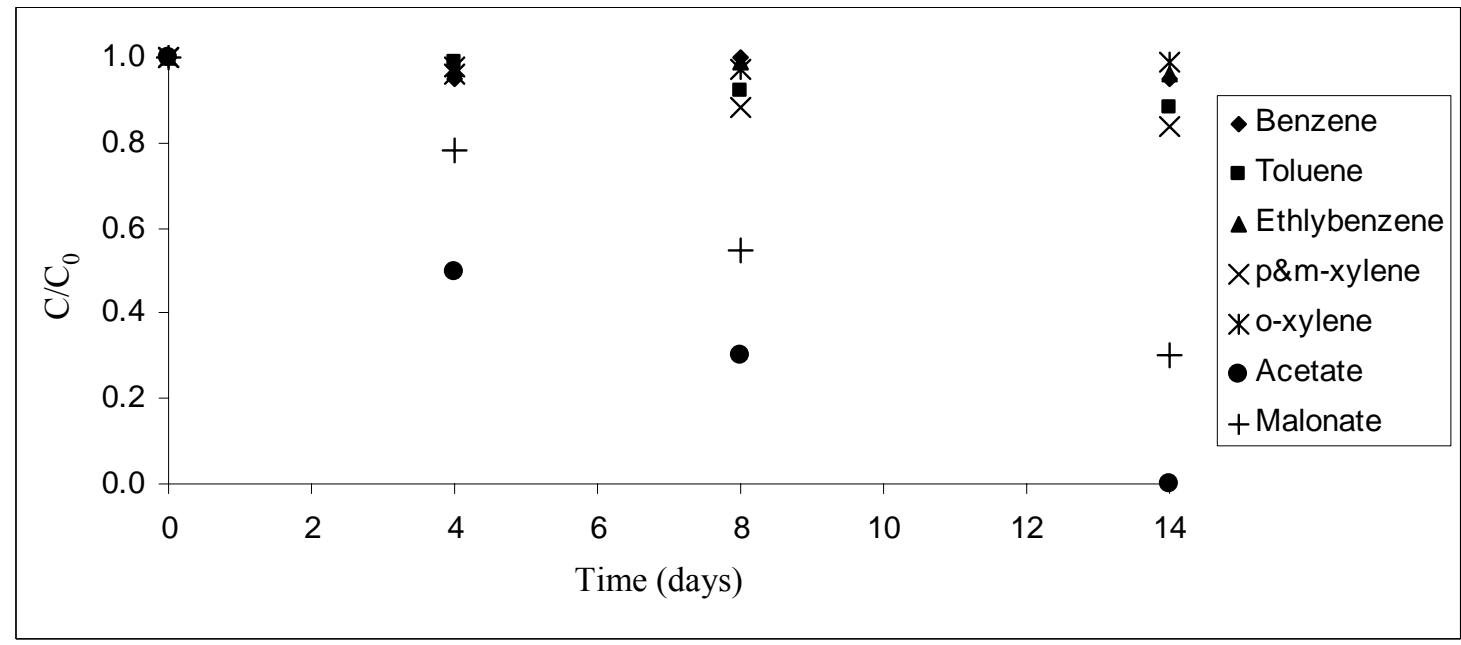

Figure 4-32. Removal of carboxylates and BTEX in a synthetic produced water solution containing $100 \mathrm{~g} / \mathrm{L}$ TDS.

\subsubsection{MBR System}

\subsubsection{Carboxylate Removal during Phases 1 \& 2}

The MBR system employed in this research yielded more than 99\% removal (effluent concentrations were below detection levels) of the acetate in the produced water feed and $85 \%$ removal of the influent malonate (Figure 4-33) during the first 43 days of operation. 
The $\mathrm{pH}$ of the influent stream was 4.8 (due to the malonic acid in the feed) while the $\mathrm{pH}$ of the outlet stream increased to 8.0 during this period as a result of the microbial oxidation of acetate and malonate. To determine whether the removal of malonate could be improved by adjusting the $\mathrm{pH}$ of the solution in the MBR, the $\mathrm{pH}$ in the bioreactor was adjusted to 7.0 by the addition of dilute $\mathrm{HNO}_{3}$ on Day 43. The removal of malonate increased to $95 \%$ when the $\mathrm{pH}$ was adjusted to 7.0 and subsequently decreased back to approximately $85 \%$ removal when the $\mathrm{pH}$ adjustment was discontinued on Day 63 . Since the response of the system to the $\mathrm{pH}$ change (from 8.0 to 7.0) was so rapid, it is unlikely that a microbial population shifted to a new circumstance. Rather, the change of chemical species by the $\mathrm{pH}$ decrease seems reasonable explanation. To verify this, potential malonate species were analyzed by MINEQL program, and presented in Table 4-3. As shown in Table, approximately $5 \%$ of malonate $(-2)$ was changed to the metal associated complexes (more accessible species to biomass) as the $\mathrm{pH}$ decreased to 7.0. Observed results in this study indicate that the $\mathrm{pH}$ in the bioreactor is an important parameter that affects malonate removal but not acetate removal (which remained essentially constant during the $\mathrm{pH}$ adjustment period). These results also suggest that biodegradation of carboxylates in produced water is quite feasible despite the high salinity conditions.

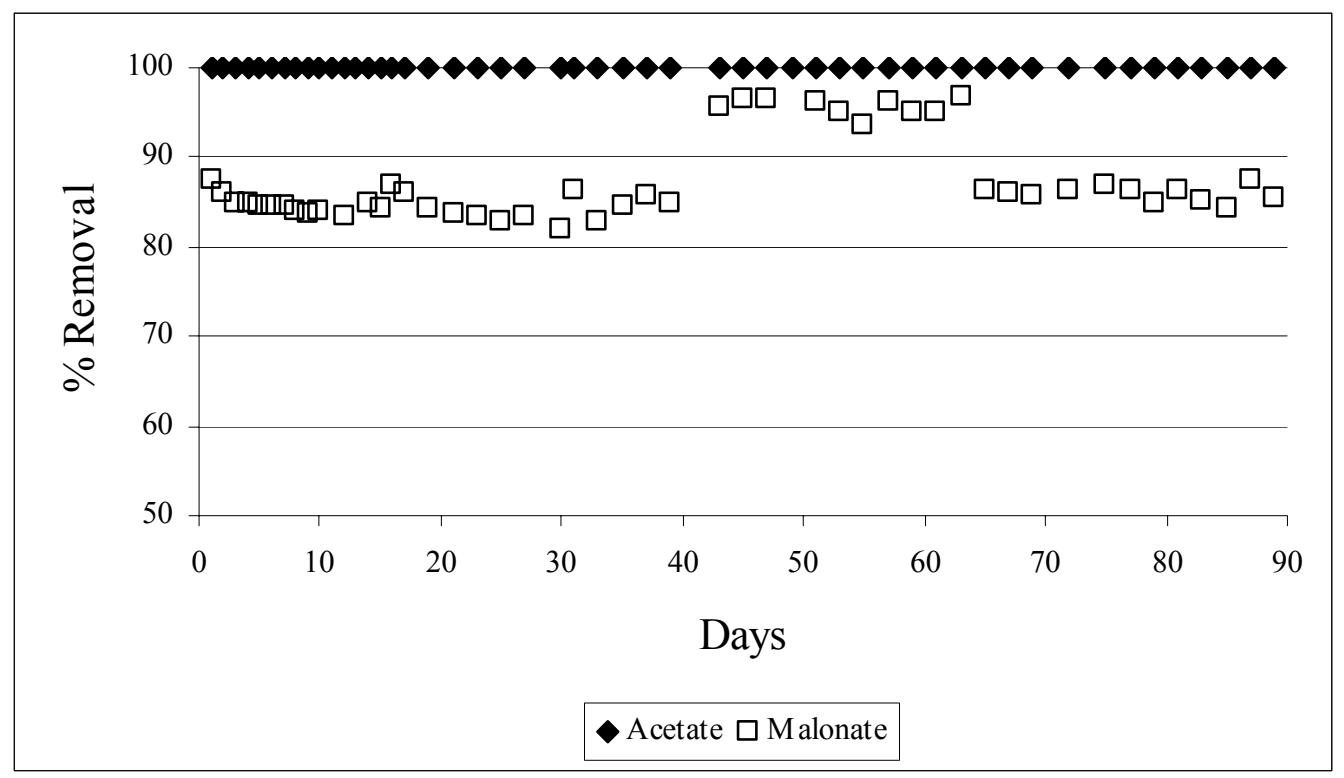

Figure 4-33. Removal of acetate and malonate in the MBR during Phases 1 \& 2 
Table 4-5. Potential malonate species in the MBR at different pHs.

\begin{tabular}{|cc|c|c|}
\hline \multirow{2}{*}{ Species } & \multicolumn{2}{c|}{ \% Total } \\
\cline { 3 - 4 } & & $\mathbf{p H ~ 8}$ & $\mathbf{p H ~ 7}$ \\
\hline Malonate & $(-2)$ & 80.1 & 75.2 \\
\hline Mg-Malonate & $(0)$ & 0.0 & 4.4 \\
\hline Na-Malonate & $(-1)$ & 19.1 & 18.3 \\
\hline H-Malonate & $(-1)$ & 0.0 & 1.5 \\
\hline
\end{tabular}

\subsubsection{BTEX Removal during Phase 2}

BTEX was introduced into the system at concentrations ranging from $0.83 \mathrm{ppm}_{\mathrm{v}}$ ethylbenzene to $19 \mathrm{ppm}_{\mathrm{v}}$ toluene by vaporization into the aeration line. The BTEX mixture was provided to the MBR at a rate of $1,800 \mathrm{mg}$ per day from Day 55 through Day 90. As shown in Figure 4-34, the amount of BTEX in the liquid phase effluent decreased to below $5 \mu \mathrm{g} / \mathrm{L}$ as the experiment continued. With the exception of benzene, the maximum concentrations of the aromatic hydrocarbons detected in the liquid phase effluent at the beginning of test are far below the MCLs (Maximum Contaminant Levels) set by the U.S. EPA for drinking water (Table 4-4). By the end of the experiment, all of the effluent BTEX constituents were below their respective MCLs.

The difference between the quantity of BTEX introduced to the MBR and the measured quantities exiting in the liquid and gas phases were used to estimate the BTEX removal in the system due to biodegradation. Results indicate that $80 \%$ of the BTEX supplied to the MBR was biodegraded in the MBR (Figure 4-34). The remaining fraction exited the reactor in the gas phase. The results of this experiment verify that simultaneous BTEX and carboxylate biodegradation can occur in an MBR treating produced water.

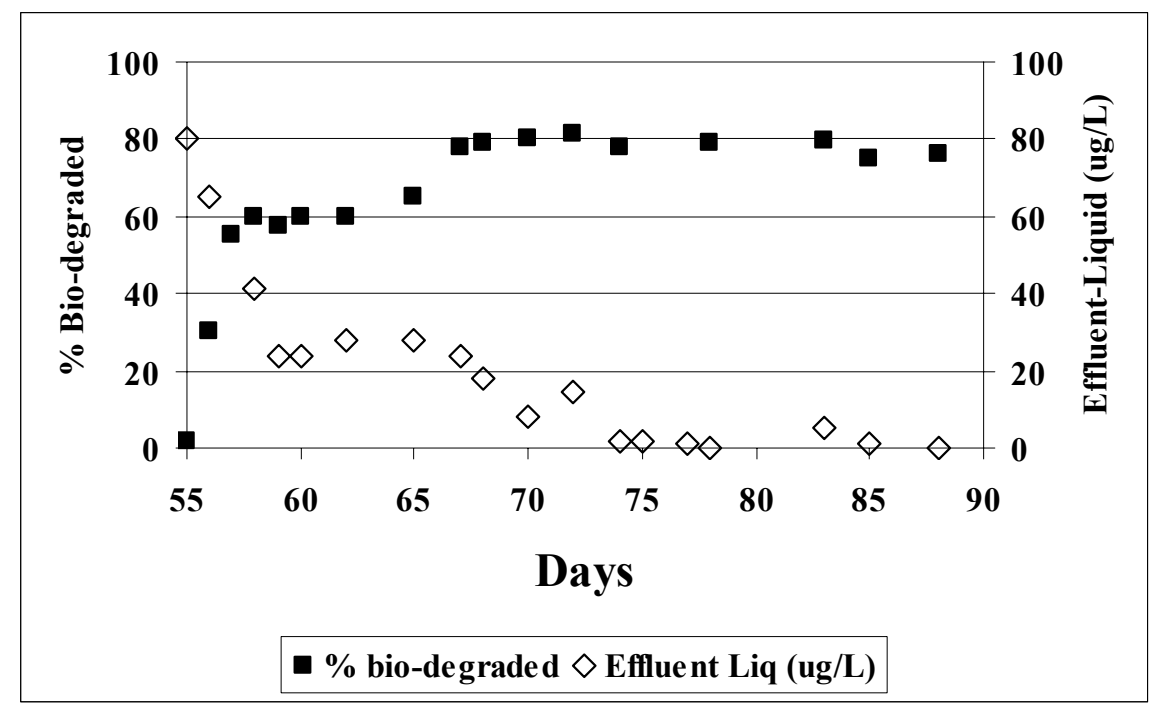

Figure 4-34. BTEX removal in the MBR during Phase 2 
Table 4-6. Maximum BTEX concentrations in the MBR liquid phase effluent during Phase 2

\begin{tabular}{|c|c|c|}
\hline Chemicals & Effluent $(\boldsymbol{\mu g} / \mathbf{L})$ & $\operatorname{MCLs}^{\mathbf{1}}(\boldsymbol{\mu g} / \mathbf{L})$ \\
\hline \hline Benzene & 21 & 5 \\
\hline Toluene & 40 & 1,000 \\
\hline Ethylbenzene & 1 & 700 \\
\hline Xylene (total) & 17 & 10,000 \\
\hline \hline Sum (BTEX) & 79 & 11,705 \\
\hline
\end{tabular}

${ }^{1)}$ Maximum Contaminant Levels in Drinking water by US EPA

\subsubsection{Biomass Concentrations and Trans-Membrane Pressure during Phases 1\&2}

Biomass concentrations (MLVSS) of approximately $1 \mathrm{~g} / \mathrm{L}$ were maintained in the MBR when only carboxylates were supplied to the reactor (Day 1 through Day 55, Figure 4-35). For comparison, a second MBR was operated as part of another research project treating the same influent carboxylate concentration, at the same HRT (9.6 hours) but in a nutrient solution instead of the briny solution found in the synthetic produced water feed (Garcia, 2007). This MBR achieved similar carboxylates removal but produced higher biomass

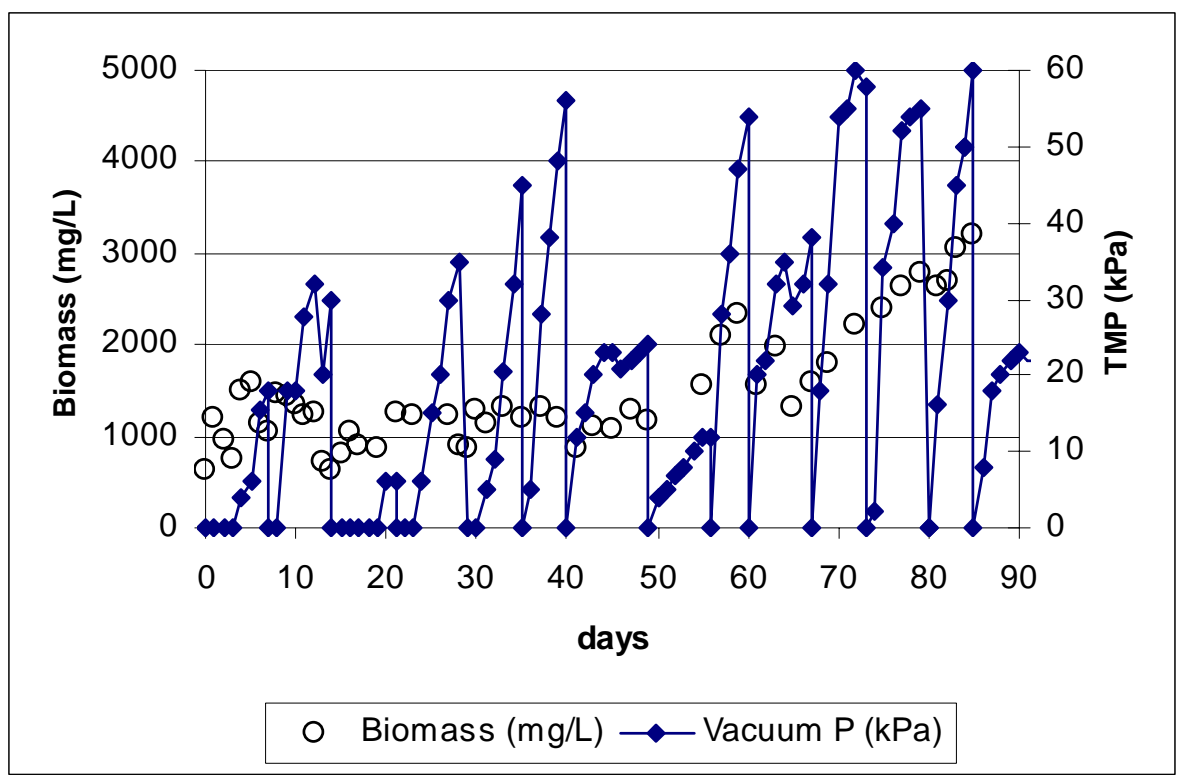

Figure 4-35. Biomass concentrations (MLVSS) and TMP in the MBR during Phases $1 \& 2$. 
concentrations of approximately $4.5 \mathrm{~g} / \mathrm{L}$. Since high biomass concentrations will tend to yield higher bio-fouling rates, it is of interest to note that treating briny produced water in an MBR resulted in lower biomass concentrations. This result is not unexpected since microorganisms in high ionic strength solutions have to expend greater energy to maintain their internal osmotic pressure within acceptable limits and thus have less energy available for biomass production. While the biomass concentration in the MBR was quite low when only carboxylates were present in the bioreactor, the biomass concentrations did increase after the introduction of the BTEX compounds to the MBR on Day 55 (Phase 2).

Membrane fouling, resulting from the formation of a layer or cake on the membrane and/or the intrusion of molecules, colloids, and particles in the porous structure, is one of the main drawbacks of MBR systems. Membrane fouling reduces the trans-membrane flux achievable in the MBR system and ultimately increases the TMP (Marrot et al., 2004). As expected, the TMP in this MBR system increased with time as shown in Figure 6-9, and it was suspected that the formation of inorganic precipitates was responsible. One way to decrease membrane fouling due to the formation of precipitates is to decrease the $\mathrm{pH}$ of the MBR solution. As shown in Figure 4-35, the TMP initially decreased $(25 \mathrm{kPa})$ when the $\mathrm{pH}$ of the MBR was adjusted from 8.0 to 7.0 (Day 43 through Day 63) suggesting that $\mathrm{pH}$ control can help minimize the TMP. However, note that the biomass concentration in the MBR increased when BTEX was added to the system and the TMP began to rise again. To investigate the $\mathrm{pH}$ effect on TMP, the $\mathrm{pH}$ of the MBR solution was sequentially decreased to 2.5 by adding dilute $\mathrm{HNO}_{3}$ directly to the MBR reactor at the end of biotic experiment. As shown in Figure 4-36, the TMP decreased dramatically as the $\mathrm{pH}$ of the MBR solution decreased. However, maintaining the $\mathrm{pH}$ of the MBR solution below 5.0 to reduce the TMP could inhibit the microbial activity in the MBR. Additional experiments will be necessary to determine the optimal $\mathrm{pH}$ level that maintains biological activity and reduces membrane fouling and TMP to acceptable levels.

Other possible options to reduce membrane fouling are to increase aeration in the vicinity of the membranes, add coagulants to the MBR solution, high-frequency backpulsing, or chemical washing (Marrot et al., 2004). In this research, $10 \mathrm{~L} / \mathrm{min}$ of air was supplied via a line diffuser located directly beneath the membrane to reduce the membrane fouling as well as to supply oxygen to the MBR. Also the membrane was cleaned every week by submersion in a $0.5 \%$ hypochlorite $(\mathrm{NaOCl})$ solution for 2 hours. As a result, the TMP increases were periodic in nature; after each cleaning the pressure dropped to approximately $0 \mathrm{kPa}$ and subsequently rose to $60 \mathrm{kPa}$ over the next week of operation. Submerged type-MBRs typically have TMP values on the order of approximately $50 \mathrm{kPa}$ (Marrot et al., 2004). Thus, the MBR treating the produced water in this research was within this range. 


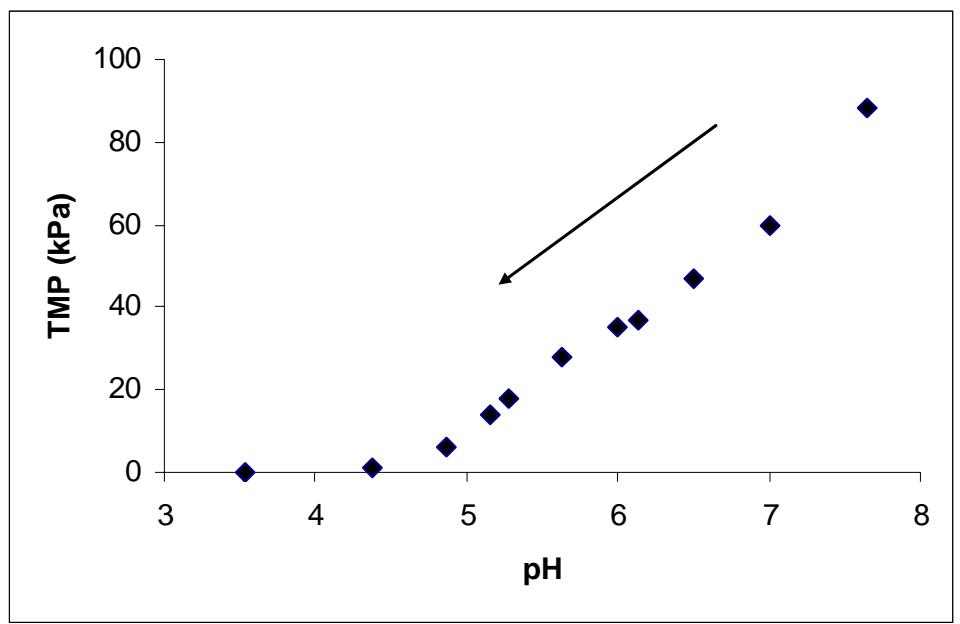

Figure 4-36. TMP change as the $\mathrm{pH}$ was decreased in the MBR.

\subsubsection{Abiotic Studies for BTEX Volatilization}

Before beginning the operation of the MBR in Phases $3 \& 4$, abiotic tests were performed with liquid phase BTEX. During the test, no carboxylates were provided. First, only toluene $(90 \mathrm{mg} / \mathrm{L}, 1880 \mathrm{mg} /$ day $)$ was provided to the $\mathrm{MBR}$, and the aeration was varied between from 0 to $10 \mathrm{~L} / \mathrm{min}$. Influent and effluent aqueous phase VOC concentrations as well as effluent gas phase concentrations were monitored to calculate a mass balance on the reactor for each air flow rate and to determine volatilization rates as a function of aeration rate. The results are shown in Table 4-5.

$90 \%$ of the toluene was recovered in the aqueous effluent when the air flow was disconnected from the MBR. The remaining 10\% was thought to have been lost to the atmosphere via volatilization as preliminary testing showed that adsorption to the reactor walls was minimal. Aeration flow rates of 2, 3, 5, and $10 \mathrm{~L} / \mathrm{min}$ yielded $88 \% \sim 92 \%$ recovery of toluene in the gas phase, resulting in $91 \% \sim 94 \%$ total recovery (in the offgas and liquid effluent). Even for the lowest aeration rate $(2 \mathrm{~L} / \mathrm{min}), 88 \%$ of the toluene volatilized. For the operation of $\mathrm{MBR}$, at least $5 \mathrm{~L} / \mathrm{min}$ aeration is required to avoid oxygen depleted conditions in the MBR and to provide scouring of the membrane. This suggests that greater than $90 \%$ of the BTEX will be volatilized in the MBR due to aeration. As expected, as the aeration rate increased, the liquid phase toluene concentration decreased to $0.85 \mathrm{mg} / \mathrm{L}$ at the $10 \mathrm{~L} / \mathrm{min}$ aeration rate which is below the toluene drinking water MCL. 
Table 4-7. Recovery of toluene with different air flow rate during abiotic MBR operation

\begin{tabular}{|c|c|c|c|c|c|c|c|}
\hline $\begin{array}{c}\text { Aeration } \\
\text { rate }\end{array}$ & $\begin{array}{c}\text { Influent } \\
\text { (Liquid) }\end{array}$ & \multicolumn{2}{|c|}{$\begin{array}{c}\text { Effluent } \\
\text { (Liquid) }\end{array}$} & \multicolumn{2}{|c|}{$\begin{array}{c}\text { Effluent } \\
\text { (Gas) }\end{array}$} & $\begin{array}{c}\text { Eff Sum } \\
\text { (L + G) }\end{array}$ & $\begin{array}{c}\text { Total } \\
\text { Recovery }\end{array}$ \\
\hline$(\mathrm{L} / \mathrm{min})$ & $(\mathrm{mg} /$ day) & $(\mathrm{mg} /$ day) & $(\%)$ & $(\mathrm{mg} /$ day) & $(\%)$ & $(\mathrm{mg} /$ day $)$ & $(\%)$ \\
\hline \hline 0 & 1793 & 1628 & 90.8 & & & 1628 & 90.8 \\
\hline 2 & 1814 & 58 & 3.2 & 1598 & 88.1 & 1656 & 91.3 \\
\hline 3 & 1807 & 48 & 2.6 & 1623 & 89.8 & 1671 & 92.5 \\
\hline 5 & 1771 & 29 & 1.6 & 1635 & 92.3 & 1664 & 93.9 \\
\hline 10 & 1822 & 17 & 0.9 & 1670 & 91.7 & 1687 & 92.6 \\
\hline
\end{tabular}

Using a mass balance on the MBR, a VOC first order volatilization coefficient $\left(K_{V}\right)$ was calculated. The mass balance equations are shown below and the results are summarized in Table 4-6.

General statement:

$$
\begin{aligned}
& \text { Rate of accumulation Rate of flow of Rate of flowof } \\
& \text { of VOC within = VOC in to the - VOC out of the } \\
& \text { the systemboundary systemboundary systemboundary } \\
& \text { Amount of VOC } \\
& +\begin{array}{l}
\text { removal through } \\
\text { systemboundary }
\end{array} \\
& \text { by stripping }
\end{aligned}
$$

Symbolic representation:

$$
\frac{d C}{d t} V=Q C_{\text {in }}-Q C_{\text {out }}-K_{V} C_{\text {out }} V
$$

Where;

$\mathrm{dC} / \mathrm{dt}=$ rate of change in VOC concentration in reactor

$\mathrm{Q}=$ Liquid flow rate

$\mathrm{C}_{\text {in }}=$ Influent VOC concentration (Liquid phase) 
$\mathrm{C}_{\text {out }}=$ Effluent VOC concentration (Liquid phase)

$\mathrm{V}=\mathrm{V}$ olume of reactor

$\mathrm{K}_{\mathrm{V}}=$ overall $\mathrm{VOC}$ volatilization coefficient, $1 / \mathrm{hr}$

If steady-state conditions are assumed, then

$$
\begin{aligned}
& 0=\frac{Q C_{\text {in }}-Q C_{\text {out }}}{V}-K_{V} C_{\text {out }} \\
& K_{V}=\frac{Q C_{\text {in }}-Q C_{\text {out }}}{V C_{\text {out }}}
\end{aligned}
$$

The volatilization rates were also determined for the BTEX mixture at a $10 \mathrm{~L} / \mathrm{min}$ aeration rate. $90.56 \mathrm{mg} / \mathrm{L}$ of BTEX mixture was provided to the MBR in the liquid phase, and influent and effluent liquid phase BTEX concentrations were monitored. As shown in Table 4-7, more than $98.9 \%$ of BTEX was stripped to the gas phase, and only $1.1 \%$ of the BTEX was detected in the liquid effluent. Volatilization rate coefficients for individual BTEX compounds were calculated as described above and are summarized in Table 4-7.

Table 4-8. Toluene volatilization coefficients measured in the MBR

\begin{tabular}{c|c}
\hline $\begin{array}{c}\text { Aeration rate } \\
(\mathrm{L} / \mathrm{min})\end{array}$ & $\begin{array}{c}\boldsymbol{K}_{\boldsymbol{V}} \\
(1 / \mathrm{hr})\end{array}$ \\
\hline 2 & 2.95 \\
\hline 3 & 3.66 \\
\hline 5 & 6.15 \\
\hline 10 & 10.27 \\
\hline
\end{tabular}

Table 4-9. BTEX volatilization rate coefficients $\left(K_{V}\right)$ measured in the MBR (10 $\mathrm{L} / \mathrm{min}$ aeration rate).

\begin{tabular}{|c|c|c|c|}
\hline Compounds & $\begin{array}{c}\mathbf{C}_{\text {in }} \\
(\mathrm{mg} / \mathrm{L})\end{array}$ & $\begin{array}{c}\mathbf{C}_{\text {out }} \\
(\mathrm{mg} / \mathrm{L})\end{array}$ & $\begin{array}{c}\boldsymbol{K}_{\boldsymbol{V}} \\
(1 / \mathrm{hr})\end{array}$ \\
\hline \hline Benzene & 23.12 & 0.213 & 11.29 \\
\hline Toluene & 41.03 & 0.418 & 10.20 \\
\hline Ethylbenzene & 2.21 & 0.029 & 7.90 \\
\hline$p \& m$-xylene & 15.11 & 0.230 & 6.79 \\
\hline o-xylene & 9.09 & 0.130 & 7.24 \\
\hline \hline Sum & 90.56 & 1.020 & 9.22 \\
\hline
\end{tabular}




\subsubsection{Biomass Concentrations and Carboxylate Removal during Phases $3 \& 4$}

During Phase 3, liquid phase BTEX was supplied with acetate $(260 \mathrm{mg} / \mathrm{L})$ and malonate $(170 \mathrm{mg} / \mathrm{L})$ simultaneously. The biomass concentration (MLVSS) increased gradually up to $3 \mathrm{~g} / \mathrm{L}$, which is the same level measured in Phase 2 in which gas phase BTEX was supplied with carboxylates. In Phase 1 , the biomass concentration in the MBR was $1 \mathrm{~g} / \mathrm{L}$ when only carboxylates were provided as a sole carbon source; however, it increased to 3 $\mathrm{g} / \mathrm{L}$ as gaseous BTEX was provided in Phase 2 . In Phase 4 , the, liquid phase BTEX supply was disconnected (on Day 25), and the biomass concentration was also diluted to $1 \mathrm{~g} / \mathrm{L}$ manually (Phase 4). Only carboxylates were provided to the MBR and the biomass concentration was monitored. As shown in Figure 6-11, the biomass concentration in the MBR remained nearly $1 \mathrm{~g} / \mathrm{L}$ until the end of the test. This result implies that an increase of biomass concentration from $1 \mathrm{~g} / \mathrm{L}$ to $3 \mathrm{~g} / \mathrm{L}$ resulted from the BTEX addition to the MBR. To estimate the biomass production through the substrate consumption, yield coefficient (Y, mass of cell synthesized per mass of substrate consumed) were calculated by the stoichiometric and bacterial energetics (Rittaman and McCarty, 2001). Results indicate that Y values of BTEX (average $1.02 \mathrm{mg}$ cell $/ \mathrm{mg}$ substrate) are several times higher than those of carboxylates ( 0.35 for acetate and 0.30 for malonate). However, the introduced amounts of BTEX to the MBR were 4.8 times less than carboxylate amounts (Table 3-3), thus the biomass production in the MBR due to BTEX degradation should be $40 \%$, and biomass production due to the carboxylates degradation should be $60 \%$ of total biomass produced in MBR.

Carboxylate removal in Phases $3 \& 4$ was similar to the previous phases with more than $99 \%$ removal of the acetate in the produced water feed and $88 \%$ removal of the influent malonate (Figure 4-37). These carboxylate removals (averaging 95\% overall removal) were not affected by the biomass concentration change or presence or absence of BTEX supply suggesting that the MBR could be effectively used to remove carboxylates from the produced water.

\subsubsection{BTEX Removal during Phase 3}

Figure 4-38 and Table 4-8 shows the BTEX removal in the MBR during the biotic experiment where liquid phase BTEX $(90.56 \mathrm{mg} / \mathrm{L})$ and carboxylates were provided simultaneously to the MBR. As shown in the figure, the amount of BTEX in the liquid phase effluent decreased to below $5 \mu \mathrm{g} / \mathrm{L}$ as the experiment continued. Mass balance calculations were performed to calculate the amount of BTEX removed by biological activity. The calculation was performed by subtracting the total mass rate of BTEX in the liquid and gas phase effluent from the mass rate of BTEX supplied to the MBR. Losses of VOCs due to adsorption were ignored based on the abiotic tests. Results showed that the biological removal of BTEX increased up to $94.78 \%$ as the experiment continued which was a higher removal efficiency than observed in Phase 2 where BTEX was provided in gaseous phase. This result is not surprising given the volatility of BTEX. Removal of BTEX by volatilization was $5.21 \%$, resulting in a $99.99 \%$ overall removal efficiency (Table 4-8). 


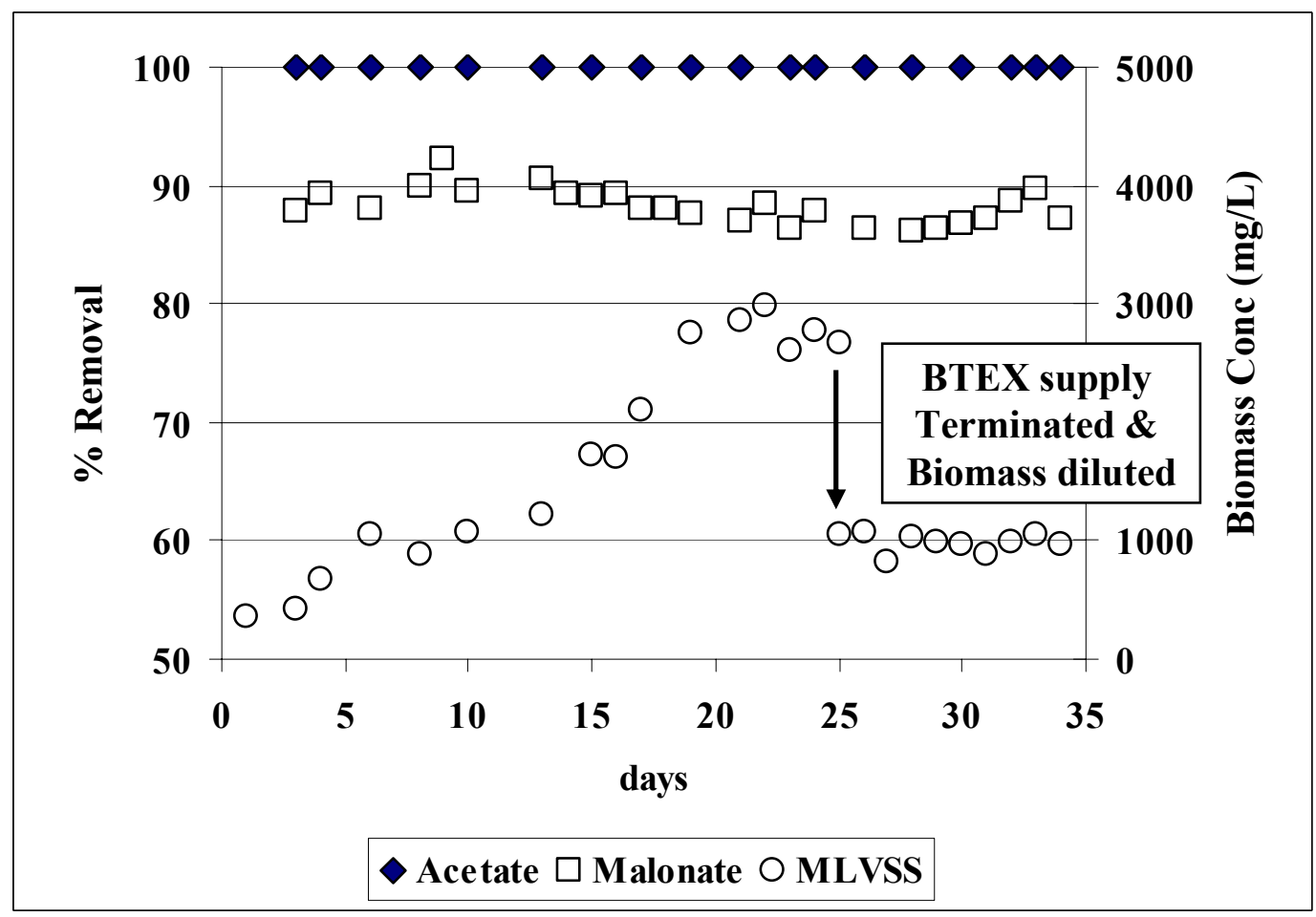

Figure 4-37. Carboxylate removal and biomass concentration in the MBR during Phases 3 \& 4

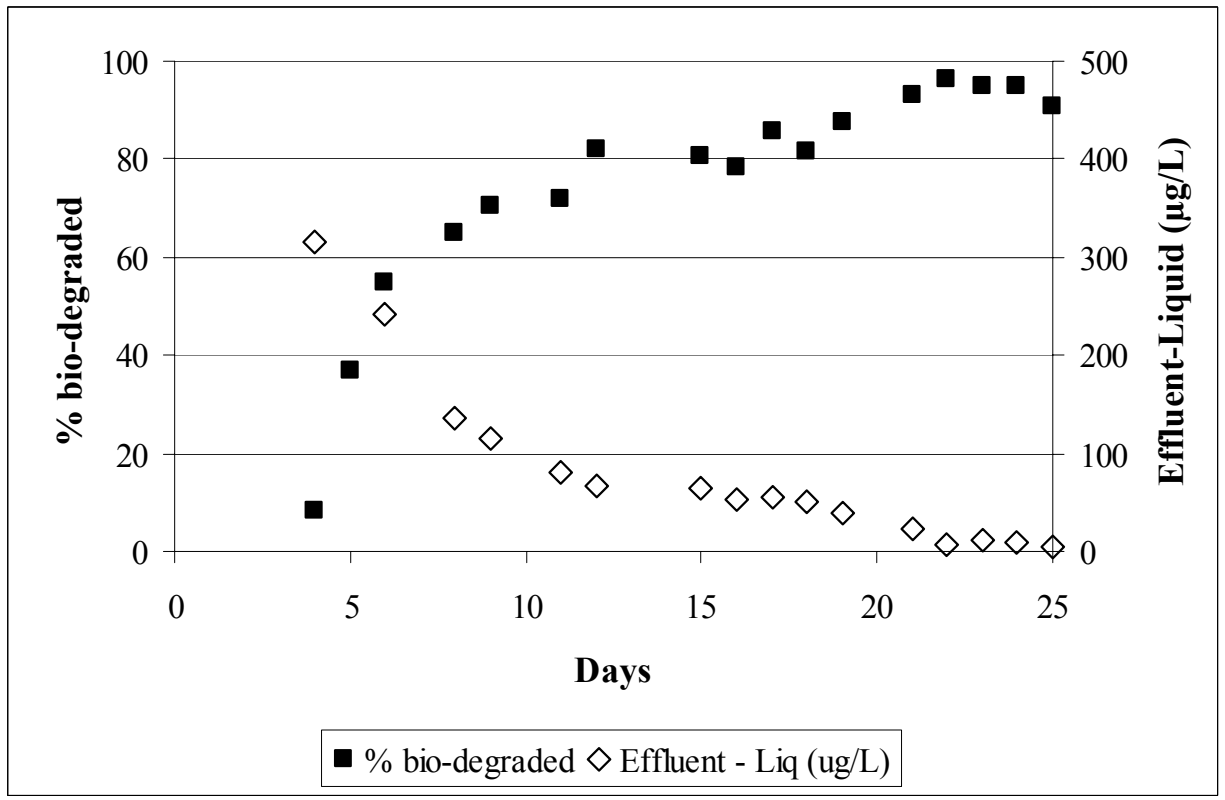

Figure 4-38. BTEX removal in the MBR during Phase 3 
Table 4-10. BTEX removal in the MBR during Phase 3.

\begin{tabular}{c|c}
\hline Removal of BTEX & $\%$ \\
\hline \hline Removal by Biodegradation & 94.78 \\
\hline Removal by Volatilization & 5.21 \\
\hline Total Removal & 99.99 \\
\hline
\end{tabular}

BTEX biodegradation coefficients $\left(k_{d} \bullet \mathrm{X}\right)$ were also calculated using mass balance equations. Since the BTEX concentrations (S) in MBR of this study were far less than the reported half saturation concentrations (Ks), which ranges from $0.13 \mathrm{mg} / \mathrm{L}$ of benzene to $0.32 \mathrm{mg} / \mathrm{L}$ of ethylbenzene (Bielefeldt and Stensel, 1999), first order biodegradation coefficients $\left(k_{d} \bullet \mathrm{X}\right)$ were calculated for a given biomass concentration. The equations are presented below and the results are summarized in Table 4-9.

General word statement:

\begin{tabular}{|c|c|c|c|}
\hline $\begin{array}{l}\text { Rate of accumulation } \\
\text { of VOC within } \\
\text { the systemboundary }\end{array}$ & \multicolumn{2}{|c|}{$\begin{aligned} & \text { Rate of flow of } \\
= & \text { VOC in to the } \\
& \text { system boundary }\end{aligned}$} & $\begin{array}{l}\text { Rate of flowof } \\
\text { VOC out of the } \\
\text { systemboundary }\end{array}$ \\
\hline $\begin{array}{r}\text { Amount } \\
+\begin{array}{r}\text { removal } \\
\text { system } b \\
\text { bystripp }\end{array}\end{array}$ & $\begin{array}{l}\text { Amount of VOC } \\
\text { removal through } \\
\text { systemboundary } \\
\text { by stripping }\end{array}$ & \multicolumn{2}{|c|}{$\begin{array}{l}\text { Amount of VOC } \\
\text { removal through } \\
\text { systemboundary } \\
\text { bybiomass }\end{array}$} \\
\hline
\end{tabular}

Symbolic representation:

$$
\frac{d C}{d t} V=Q C_{\text {in }}-Q C_{\text {out }}-K_{V} C_{\text {out }} V-k_{d} X C_{\text {out }} V
$$

Where;

$d C / d t=$ rate of change in VOC concentration in reactor

$Q=$ Liquid flow rate

$C_{\text {in }}=$ Influent VOC concentration (Liquid phase)

$C_{\text {out }}=$ Effluent VOC concentration (Liquid phase)

$V=$ Volume of reactor 
$K_{V}=$ overall VOC volatilization coefficient, $1 / \mathrm{hr}$

$X=$ Biomass Concentration (mass of cell/L)

$k_{d}=$ first order specific VOC degradation coefficient, L/hr-mass of cell

$k_{d} \bullet X=$ first order VOC biodegradation coefficient, $1 / \mathrm{hr}$

If steady-state conditions are assumed, then

$$
k_{d} X=\frac{Q C_{\text {in }}-Q C_{\text {out }}-K_{V} C_{\text {out }} V}{V C_{\text {out }}}
$$

Table 4-11. BTEX biodegradation coefficients $\left(k_{d} \bullet X\right)$ measured in the MBR (10 $\mathrm{L} / \mathrm{min}$ aeration rate, and $\mathrm{X}=1.0 \mathrm{~g}$-cell $/ \mathrm{L})$.

\begin{tabular}{|c|c|c|c|c|}
\hline Compounds & $\begin{array}{c}\mathbf{C}_{\text {in }} \\
(\mathrm{mg} / \mathrm{L})\end{array}$ & $\begin{array}{c}\mathbf{C}_{\text {out }} \\
(\mathrm{mg} / \mathrm{L})\end{array}$ & $\begin{array}{c}\boldsymbol{K}_{\boldsymbol{V}} \\
(1 / \mathrm{hr})\end{array}$ & $\begin{array}{c}\boldsymbol{k}_{\boldsymbol{d}} \boldsymbol{} \mathbf{X} \\
(1 / \mathrm{hr})\end{array}$ \\
\hline \hline Benzene & 23.12 & 0.058 & 11.29 & 30.5 \\
\hline Toluene & 41.03 & 0.051 & 10.20 & 74.2 \\
\hline Ethylbenzene & 2.21 & 0.004 & 7.90 & 50.0 \\
\hline$p \& m$-xylene & 15.11 & 0.019 & 6.79 & 76.6 \\
\hline o-xylene & 9.09 & 0.015 & 7.24 & 56.3 \\
\hline
\end{tabular}

The measured kinetic coefficients $\left(K_{V}\right.$ and $\left.k_{d} \bullet \mathrm{X}\right)$ were used to predict removal in the field test.

\subsubsection{Summary}

The effectiveness of a submerged MBR for simultaneous removal of carboxylates and hazardous BTEX constituents from saline produced water was evaluated. Result of batch biodegradation studies indicated that carboxylates can be biodegraded in produced water with a very high TDS concentration, but the removal of BTEX constituents is more difficult under high saline conditions. An aerobic, submerged MBR achieved $92 \%$ removal of carboxylates (100\% acetate and $85 \%$ malonate removal) at a 9.6-hr HRT. Adding BTEX to the produced water feed increased the biomass concentration in the MBR but did not affect the carboxylate removal. Approximately $80 \%$ of BTEX was biodegraded in the MBR when it was provided in the gaseous phase. However, biological removal of BTEX was increased up to 95\% when same amount of BTEX was introduced via the aqueous phase. Results of this chapter imply that MBRs can achieve high removal of carboxylates and BTEX constituents simultaneously in brine wastewater. However, fouling by inorganic precipitates is a problem that leads to high TMP and ultimately reduced flux across the membrane. Decreasing the $\mathrm{pH}$ of the solution crossing the membrane was effective at reducing the TMP, but a balance is required between maximizing biological activity at a given $\mathrm{pH}$ while minimizing the TMP. 


\subsection{Field Application of SMZ/MBR System To Treat Produced Water}

Based on the lab tests of the MBR, the MBR system was incorporated into a field evaluation of an SMZ/MBR process train to treat produced water for reuse. The primary objective of the field test was to evaluate a coupled SMZ/MBR system treating actual produced water with respect to its ability to reduce carboxylate concentrations and thereby minimize fouling of a downstream desalination system. A secondary objective of the field trial was to assess the efficiency of the SMZ/MBR system for the removal of BTEX in actual produced water.

The chemical composition of the produced water was analyzed by GEL laboratories LLC. (Charleston, SC) and summarized on Table 4-10. The total dissolved solid measurement of $10,717 \mathrm{mg} / \mathrm{L}$ was similar to the value determined in our previous field test. TOC concentration was $571 \mathrm{mg} / \mathrm{L}$, and several VOCs and SVOCs were detected with BTEX comprising the major percentage by mass. Several anions were identified including chloride, sulfate, acetate, and bromide. Metals and cations such as sodium, calcium, potassium, magnesium, and barium were also identified in the produced water samples.

Biomass concentrations (MLVSS) of approximately $1 \mathrm{~g} / \mathrm{L}$ were maintained during the entire field trial which was comparable to the laboratory MBR concentration. Considering the fact that a typical activated sludge system has biomass concentrations of $3 \mathrm{~g} / \mathrm{L}$ while MBR typically have even higher biomass concentrations of up to $30 \mathrm{~g} / \mathrm{L}$ (Jefferson et al., 2000; Yamamoto et al., 1989), this biomass concentration is very low. Since high biomass concentrations tend to yield higher bio-fouling rates, it is of interest to note that treating briny produced water in an MBR resulted in lower biomass concentrations.

The influent $\mathrm{pH}$ of the produced water was 8.5 and increased slightly $(\mathrm{pH}=8.8)$ during the MBR operation period. The dissolved oxygen concentration in the MBR was maintained at approximately $2.5 \mathrm{mg} / \mathrm{L}$. 
Table 4-12. Composition of produced water at the field salt water disposal facility, NM, 2007

\begin{tabular}{|c|c|}
\hline Analysis & Concentration (mg/L) \\
\hline $\begin{array}{l}\text { Total suspended solids (TDS) } \\
\end{array}$ & 10717.00 \\
\hline Total organic carbon (TOC) & 571.00 \\
\hline Oil \& Grease & 45.40 \\
\hline \multicolumn{2}{|l|}{ Volatile Organics } \\
\hline 2-Hexanone & 0.47 \\
\hline Benzene & 1.07 \\
\hline Carbon Disulfide & 0.15 \\
\hline Ethylbenzene & 0.46 \\
\hline Toluene & 4.74 \\
\hline Xylene (total) & 4.63 \\
\hline Acetone & 2.17 \\
\hline \multicolumn{2}{|l|}{ Semi-Volatile Organics } \\
\hline Phenol & 0.26 \\
\hline Naphthalene & 0.05 \\
\hline 2-Methylnaphthalene & 0.06 \\
\hline bis(2-Ethylbhxyl)phthalate & 0.36 \\
\hline $\mathrm{m}, \mathrm{p}$-Cresols & 0.11 \\
\hline o-Cresols & 0.11 \\
\hline \multicolumn{2}{|l|}{ Anions } \\
\hline Bromide & 18.10 \\
\hline Sulfate & 484.00 \\
\hline Chloride & 5540.00 \\
\hline Acetate & 150.00 \\
\hline \multicolumn{2}{|l|}{ Cations } \\
\hline Barium & 4.06 \\
\hline Calcium & 108.00 \\
\hline Iron & 1.37 \\
\hline Magnesium & 28.80 \\
\hline Manganese & 0.44 \\
\hline Potassium & 104.00 \\
\hline Sodium & 4160.00 \\
\hline
\end{tabular}

\subsubsection{Carboxylate Removal}

One of the important objectives of this field test was to remove carboxylates from produced water. The predominant organic anion detected in this produced water was acetate, and its concentration was measured before and after the SMZ column, and after the MBR. The influent acetate concentration varied from $120 \mathrm{mg} / \mathrm{L}$ to $170 \mathrm{mg} / \mathrm{L}$ during the experiment. Consistent with the previous field test, the SMZ column had little effect on the removal of carboxylates from produced water (Figure 4-39). However, acetate 
was removed to below detection limits in the MBR, indicating that the MBR system was very effective for treatment of carboxylates in produced water.

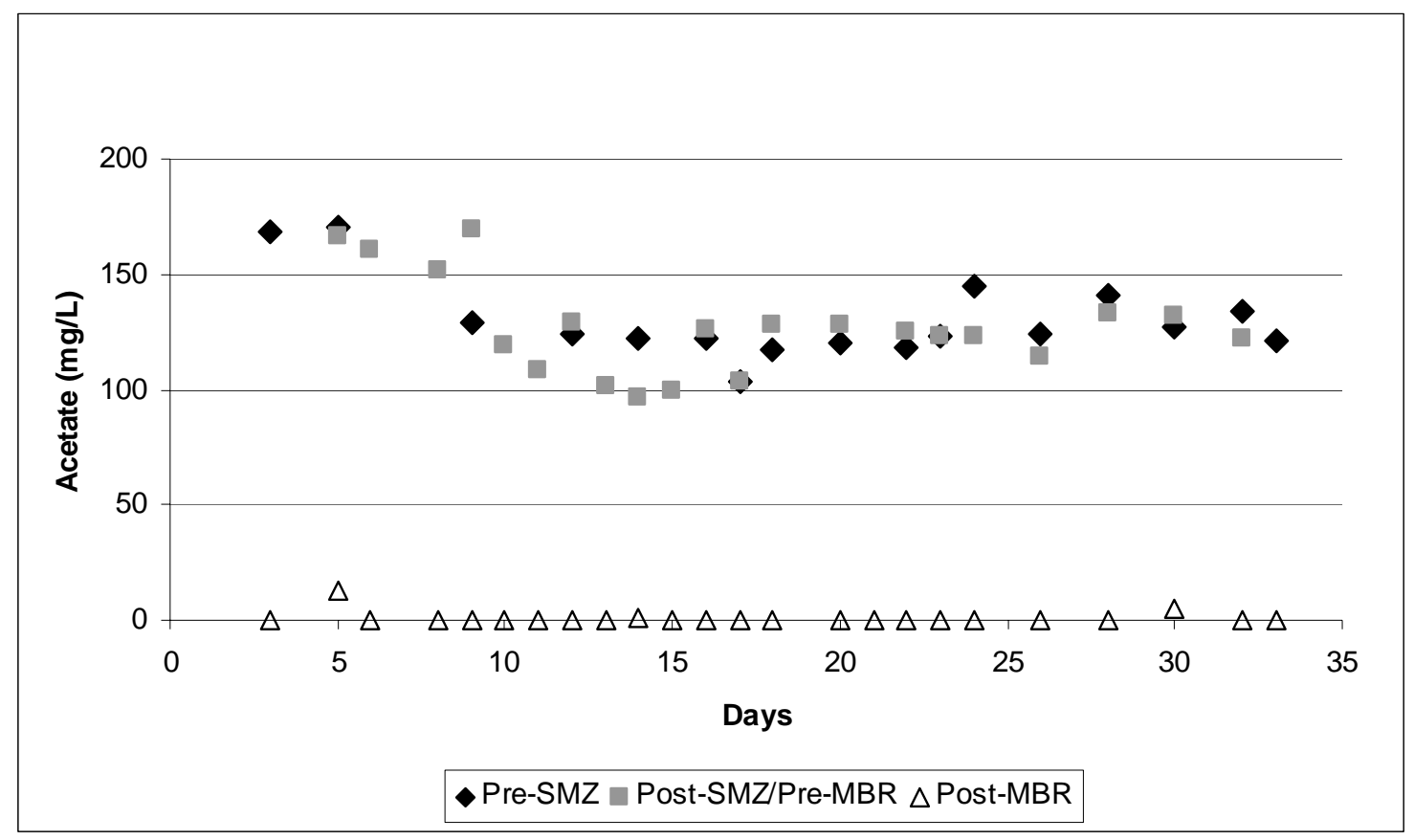

Figure 4-39. Acetate concentrations during SMZ/MBR operation.

\subsubsection{TOC Removal}

Figure 4-40 shows the TOC concentrations in the SMZ/MBR system. The influent produced water contained an average TOC of $580 \mathrm{mg} / \mathrm{L}$ which was reduced to $350 \mathrm{mg} / \mathrm{L}$ in the SMZ column. However, as the SMZ column became saturated, the TOC level increased to $480 \mathrm{mg} / \mathrm{L}$. This increase could be attributed to the increase in the effluent BTEX concentrations from the SMZ column. The TOC level in the effluent from the MBR decreased to approximately $150 \mathrm{mg} / \mathrm{L}$, providing an overall TOC removal of $74 \%$ in the SMZ/MBR system.

PAC addition to the MBR on Day 27 resulted in an even more dramatic decrease in TOC. As shown in Figure 4-40, the MBR effluent TOC concentration after PAC addition decreased to $45 \mathrm{mg} / \mathrm{L}$, providing an overall $92 \%$ removal of TOC. The necessity for PAC addition will depend on the particular treatment goals and final end use of the treated water. 


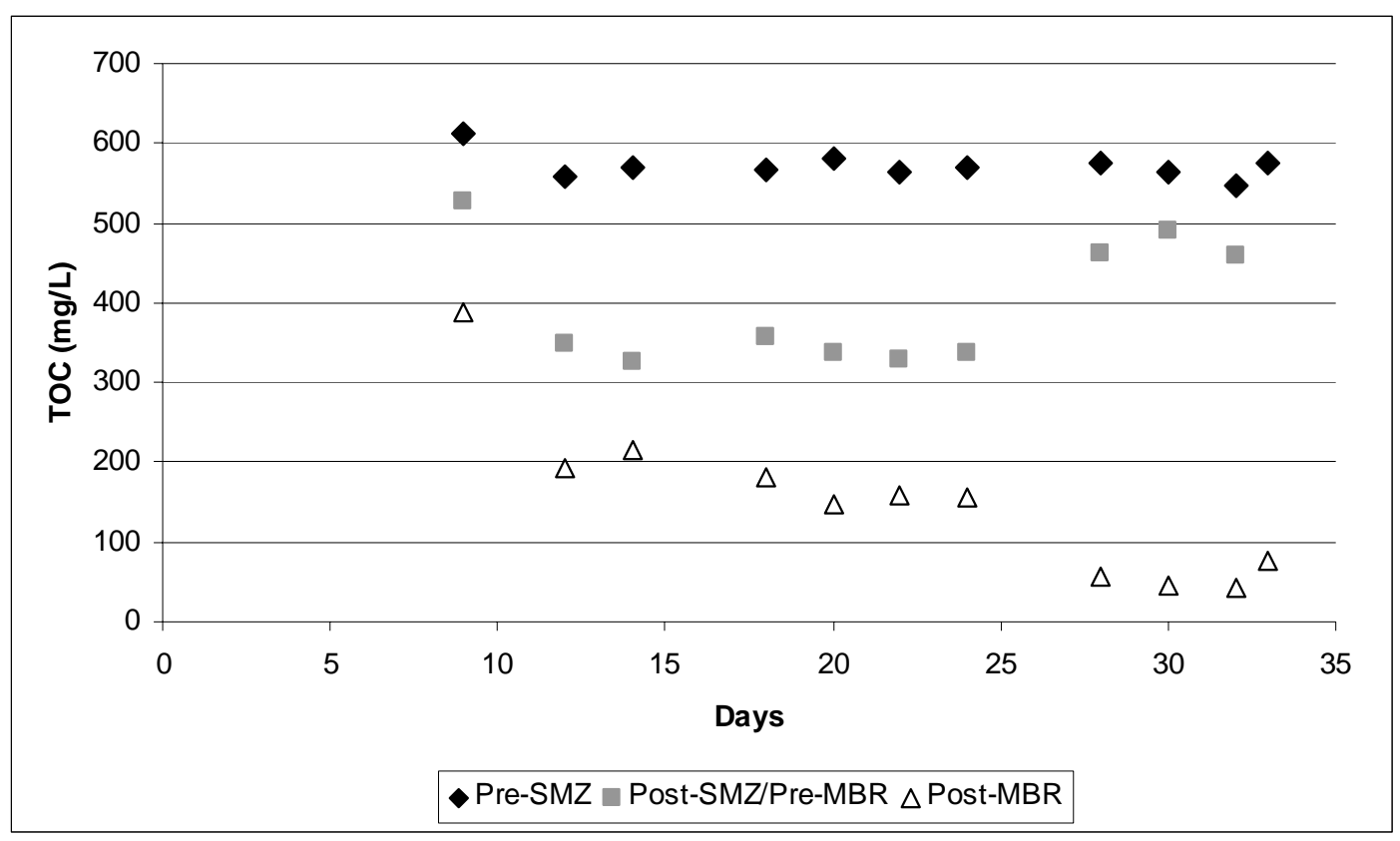

Figure 4-40. TOC concentrations during SMZ/MBR operation.

\subsubsection{BTEX Removal}

BTEX are classified as hazardous materials even at low concentrations. For the discharge to surface or reuse applications, removal of these VOCs is strongly recommended. The previous SMZ/VPB field trial demonstrated that BTEX removal from produced water could be achieved using SMZ, and suggested that VPB treatment of the off-gas from any produced water would be effective regardless of the salt concentration since the BTEX are extracted and treated separately from the briny produced water. The lab-scale MBR experiment showed that the MBR could also remove these BTEX compounds in moderate salinity water, as described in previous chapter. Therefore, BTEX removal was also monitored in this field test. Figure 4-41 shows the BTEX concentration of produced water prior to and after SMZ and MBR treatment. As shown in the figure, the BTEX concentration in the influent produced water to the SMZ system decreased as the experiment progressed (from $70 \mathrm{mg} / \mathrm{L}$ to 10 $\mathrm{mg} / \mathrm{L}$ ). This decrease resulted from the increase in head space (and subsequent BTEX volatilization) in the produced water-storage tank used to supply water to the system. The BTEX concentrations in the SMZ treatment column effluent increased gradually as shown in the figure, due to slow breakthrough of BTEX from the SMZ. Individual analysis of BTEX compounds showed that only benzene exhibited complete breakthrough during the field test. A maximum BTEX concentration of almost $5 \mathrm{mg} / \mathrm{L}$ in the SMZ column effluent occurred at the end of the field test. The average BTEX concentration exiting the MBR ranged from $0.01 \mathrm{mg} / \mathrm{L}$ to $0.55 \mathrm{mg} / \mathrm{L}$ with an average value of $0.117 \mathrm{mg} / \mathrm{L}$ (Figure 4-41). With the exception of benzene, the maximum concentrations of the aromatic hydrocarbons detected in the liquid phase effluent from the MBR are far below the MCLs (Maximum Contaminant Levels) set by the U.S. EPA 
for drinking water (Table 4-11). These low BTEX concentrations in the MBR effluent resulted from a combination of volatilization and biodegradation.

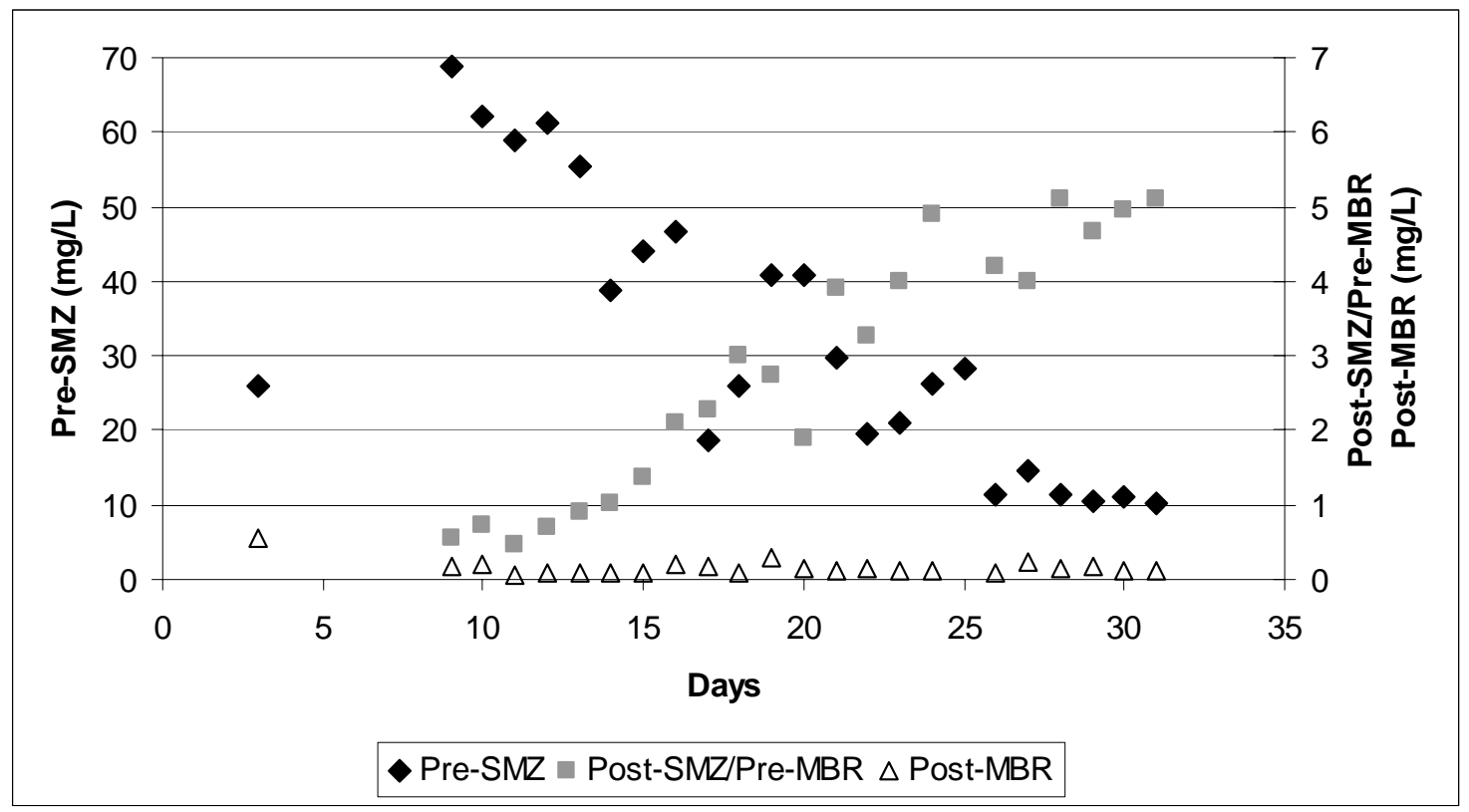

Figure 4-41. Liquid phase BTEX concentrations during SMZ/MBR operation.

Table 4-13. Maximum BTEX concentrations in the MBR liquid phase effluent

\begin{tabular}{|c|c|c|}
\hline Chemicals & Effluent $(\boldsymbol{\mu g} / \mathbf{L})$ & $\operatorname{MCLs}^{\mathbf{1})}(\boldsymbol{\mu g} / \mathbf{L})$ \\
\hline \hline Benzene & 88.0 & 5.0 \\
\hline Toluene & 230.5 & $1,000.0$ \\
\hline Ethylbenzene & 48.8 & 700.0 \\
\hline Xylene (total) & 182.7 & $10,000.0$ \\
\hline \hline Sum (BTEX) & 550.0 & $11,705.0$ \\
\hline
\end{tabular}

${ }^{1)}$ Maximum Contaminant Levels in Drinking water by US EPA

To provide a basis for determining the relative contribution of each of these mechanisms to BTEX removal, gas phase BTEX concentrations from the MBR were measured in addition to the aqueous phase concentrations. Figure 4-42 shows the total mass of BTEX introduced to the MBR (all liquid phase) per day and the total mass of BTEX (liquid and gas phase) exiting the reactor per day. Using mass balance calculations, the difference between these two values was attributed to BTEX removal by biodegradation. As shown in Figure 4-42, up to $95 \%$ of the BTEX introduced into the MBR was biodegraded, indicating that the MBR could be used effectively to remove VOCs from produced water 
without additional treatment. Removal of BTEX by volatilization was $2.9 \%$, resulting in 97.8\% overall removal efficiency (Table 4-12).

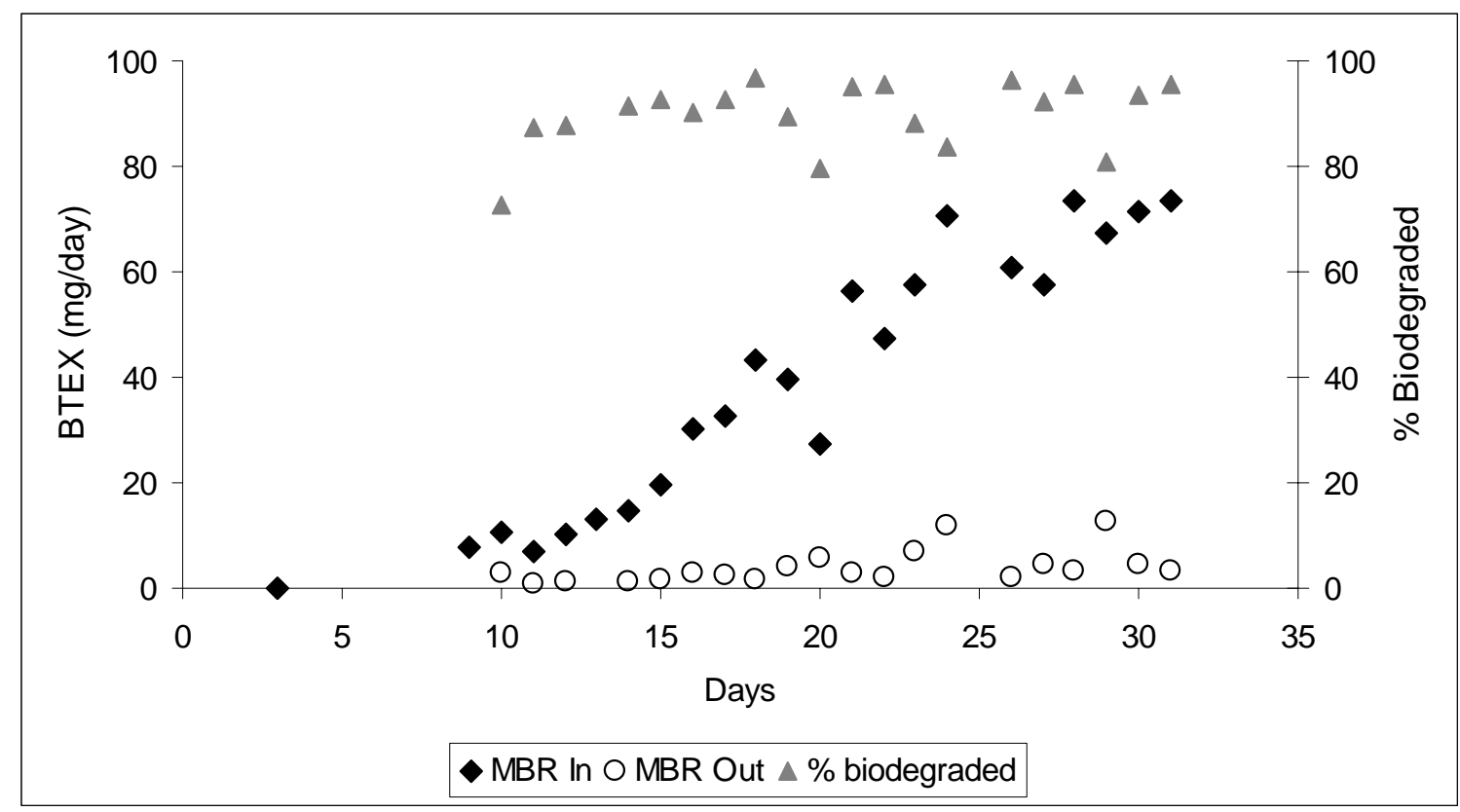

Figure 4-42. BTEX amount degraded by biomass in the MBR.

Table 4-14. BTEX removal in the MBR.

\begin{tabular}{c|c}
\hline Removal of BTEX & $\%$ \\
\hline \hline Removal by Biodegradation & 94.9 \\
\hline Removal by Volatilization & 2.9 \\
\hline Total Removal & 97.8 \\
\hline
\end{tabular}

Kinetic coefficients $\left(K_{V}\right.$ and $\left.k_{d} \bullet \mathrm{X}\right)$ measured in the laboratory test were modified and used to predict the benzene effluent concentrations from the field MBR system. Benzene was the only VOC evaluated because the SMZ column removed the other BTEX compounds to below detection throughout most of the MBR testing. Effluent benzene concentrations from the MBR were estimated using the mass balance equations shown below in conjunction with a modified volatilization coefficient and the laboratory determined biodegradation coefficient. The laboratory determined volatilization coefficient $\left(K_{V}\right)$ was modified to account for the different aeration rates used in the field test by linear correlation between volatilization coefficients and aeration rates observed in the toluene abiotic laboratory test for aeration rates ranging from $2 \mathrm{~L} / \mathrm{min}$ to $10 \mathrm{~L} / \mathrm{min}$.

General word statement: 


\begin{tabular}{|c|c|c|}
\hline $\begin{array}{l}\text { Rate of accumulation } \\
\text { of VOC within } \\
\text { the svstemboundary }\end{array}$ & $\begin{aligned} & \text { Rate of flow of } \\
= & \text { VOC in to the }\end{aligned}$ & $\begin{array}{l}\text { Rate of flow of } \\
\text { VOC out of the }\end{array}$ \\
\hline
\end{tabular}

Amount of VOC
removal through
systemboundary
bystripping $\quad \begin{aligned} & \text { Amount of VOC } \\ & \text { removal through } \\ & \text { systemboundary } \\ & \text { bybiomass }\end{aligned}$

Symbolic representation:

$$
\frac{d C}{d t} V=Q_{l} C_{\text {in }(l)}-Q_{l} C_{\text {out }(l)}-K_{V} C_{\text {out }(l)} V-k_{d} X C_{\text {out }(l)} V
$$

Where;

$\mathrm{dC} / \mathrm{dt}=$ rate of change in VOC concentration in reactor

$\mathrm{Q}_{1}=$ Liquid flow rate

$\mathrm{C}_{\mathrm{in}(1)}=$ Influent VOC concentration (Liquid phase)

$\mathrm{C}_{\text {out }(1)}=$ Effluent VOC concentration (Liquid phase)

$\mathrm{V}=$ Volume of reactor

$\mathrm{K}_{\mathrm{V}}=$ overall VOC volatilization coefficient, $1 / \mathrm{hr}$

$\mathrm{X}=$ Biomass Concentration (mass of cell/L)

$\mathrm{k}_{\mathrm{d}}=$ first order specific VOC degradation coefficient, L/hr-mass of cell

$\mathrm{k}_{\mathrm{d}} \bullet \mathrm{X}=$ first order VOC biodegradation coefficient, $1 / \mathrm{hr}$

If steady-state conditions are assumed, then

$$
C_{\text {out }(l)}=\frac{Q_{l} C_{\text {in }(l)}}{Q_{l}+K_{V} V+k_{d} X V}
$$

As shown in Table 4-13, lab-determined kinetic coefficients estimated 25\% lower concentrations than measured in the field test. These results seem quite reasonable given that the composition of the synthetic produced water used in the laboratory was a fairly 
simplified representation of the composition of the actual produced water. To identify whether the differences in the measured and predicted values were due to a decrease in the volatilization rate or due to a decrease in the biodegradation rate, values of the rate coefficients were determined from the field data and compared to the laboratory values. First, the volatilization rate coefficient $\left(K_{V}\right)$ was calculated. It was assumed that the mass rate of VOCs removal by stripping (i.e., $K_{V} C_{\text {out(l) }} V$ in equation 4-6) was equal to the VOC mass detected in the exit gas per unit time $\left(Q_{g} C_{\text {out }(g)}\right)$.

Symbolic representation:

$$
\begin{aligned}
& K_{V} C_{\text {out }(l)} V=Q_{g} C_{\text {out }(g)} \\
& K_{V}=\frac{Q_{g} C_{\text {out }(g)}}{K_{V} C_{\text {out }(l)}}
\end{aligned}
$$

Where;

$\mathrm{K}_{\mathrm{V}} \mathrm{C}_{\text {out(1) }} \mathrm{V}=$ Amount of VOC removal through system boundary by Stripping $\mathrm{Q}_{\mathrm{g}}=$ Gas flow rate

$\mathrm{C}_{\text {out (1) }}=$ Effluent $\mathrm{VOC}$ concentration (Liquid phase)

$\mathrm{C}_{\text {out }(\mathrm{g})}=$ Effluent VOC concentration (Gas phase)

$\mathrm{V}=$ Volume of reactor

$\mathrm{K}_{\mathrm{V}}=$ overall volatilization rate, $1 / \mathrm{hr}$

Next, the overall VOC biodegradation coefficient $\left(k_{d} \bullet \mathrm{X}\right)$ was calculated by the following equations assuming steady-state conditions.

$$
\begin{aligned}
& \frac{d C}{d t} V=Q_{l} C_{\text {in }(l)}-Q_{l} C_{\text {out }(l)}-K_{V} C_{\text {out }(l)} V-k_{d} X C_{\text {out }(l)} V \\
& k_{d} X=\frac{Q_{l} C_{\text {in }(l)}-Q_{l} C_{\text {out }(l)}-K_{V} C_{\text {out }(l)} V}{V C_{\text {out }(l)}}
\end{aligned}
$$

Where;

$\mathrm{K}_{\mathrm{V}} \cdot \mathrm{C}_{\text {out(l) }} \cdot \mathrm{V}=$ Amount of $\mathrm{VOC}$ removal through system boundary by Stripping

$\mathrm{Q}_{1}=$ Liquid flow rate

$\mathrm{C}_{\text {in(I) }}=$ Influent VOC concentration (Liquid phase)

$\mathrm{C}_{\text {out (1) }}=$ Effluent VOC concentration (Liquid phase)

$\mathrm{V}=$ Volume of reactor

$\mathrm{K}_{\mathrm{V}}=$ overall volatilization rate coefficient, $1 / \mathrm{hr}$

$\mathrm{X}=$ Biomass Concentration (mass of cell/L)

$\mathrm{k}_{\mathrm{d}}=$ first order specific VOC degradation coefficient, $\mathrm{L} / \mathrm{hr}$-mass of cell

$\mathrm{k}_{\mathrm{d}} \cdot \mathrm{X}=$ first order VOC biodegradation coefficient, $1 / \mathrm{hr}$ 
As shown in Table 4-14, the field-measured $K_{V}$ and $k_{d} \bullet X$ were $51 \%$ and $78 \%$ of the labmeasured values. Thus, both biodegradation and volatilization were reduced in the field system. There are several possible explanations for this discrepancy. As stated previously, the field produced water contained a broader range of compounds than the synthetic produced water used in the lab test. The $\mathrm{pH}$ of the produced water in the field test (8.8) was somewhat higher than in the lab test (8.0) and the dissolved oxygen level $(2.5 \mathrm{mg} / \mathrm{L})$ was lower than in the lab test $(3.5 \mathrm{mg} / \mathrm{L})$. All of these factors may have contributed to a reduction in biodegradation rates. The most probable reason for the decrease in the volatilization rate was the foam observed in the MBR during field operation. The raw produced water exhibited significant foaming when it was shaken in a $10 \mathrm{ml}$ vial suggesting that an unidentified surfactant was present in the raw produced water. This surfactant appears to have penetrated through the SMZ column and into the MBR. The presence of foam in the MBR may have limited the mass transfer of BTEX compounds to the reactor headspace and decreased the volatilization rate as compared to the lab tests with synthetic produced water. Nonetheless, the predictions of effluent benzene concentrations were reasonable and suggest that the removal of benzene from produced water is primarily controlled by biodegradation.

Table 4-15. Benzene concentrations measured in field test and estimated using laboratory-determined kinetic coefficients.

\begin{tabular}{|c|c|c|c|c|}
\hline \multirow{2}{*}{$\begin{array}{c}K_{V} \\
(1 / \mathrm{hr})\end{array}$} & \multirow{2}{*}{$\begin{array}{c}k_{d} \bullet \mathrm{X}^{1)} \\
(1 / \mathrm{hr})\end{array}$} & $\begin{array}{c}\mathrm{C}_{\text {in }}(\mathrm{mg} / \mathrm{L}) \\
\text { Measured }\end{array}$ & \multicolumn{2}{|c|}{$\mathrm{C}_{\text {out }}(\mathrm{mg} / \mathrm{L})$} \\
\cline { 4 - 5 } & & & Measured & Estimated \\
\hline \hline 8.07 & 30.54 & 4.374 & $\mathbf{0 . 0 1 6}$ & $\mathbf{0 . 0 1 2}$ \\
\hline
\end{tabular}

${ }^{1)}$ Measured in lab test with biomass concentration of $1 \mathrm{~g} / \mathrm{L}$.

Table 4-16. Kinetic coefficients $\left(K_{V}\right.$ and $\left.k_{d} \bullet X\right)$ for benzene removal in field test and comparison with values in lab test.

\begin{tabular}{|c|c|c|c|}
\hline \multicolumn{2}{|c|}{$K_{V}(1 / \mathrm{hr})$} & \multicolumn{2}{c|}{$k_{d} \bullet X(1 / \mathrm{hr})$} \\
\hline Field-measured & Lab-measured & Field-measured & Lab-measured \\
\hline \hline 4.13 & 8.07 & 23.93 & 30.54 \\
\hline
\end{tabular}




\subsubsection{Trans-Membrane Pressure}

One of the main drawbacks of the MBR system is membrane fouling which reduces the flux through the membrane and increases the TMP. As described in Section 2.7.3, there are several possible methods to reduce the TMP in a MBR including physical removal techniques and chemical washes. During the initial 14 days of operation during the field MBR test, daily brushing of the membrane surface was used solely to prevent excessive membrane fouling and maintain the flux through the membrane (Figure 4-43). This method was sufficient to maintain the TMP levels below $30 \mathrm{kPa}$ after brushing. However, after two weeks of operation, this simple brushing technique was not capable of reducing the TMP level to below $30 \mathrm{kPa}$ and the TMP increase accelerated. Several membrane washing methods were then attempted to determine if they could clean the membrane and reduce the TMP during operation. The different methods attempted in the field included submerging the membrane for several hours in one of the following solutions: (1) $0.5 \%$ hypochlorite $(\mathrm{NaOCl})$ solution , (2) $1 \%$ citric acid $\left(\mathrm{C}_{6} \mathrm{H}_{8} \mathrm{O}_{7}\right)$ solution, and (3) $1 \%$ nitric acid $\left(\mathrm{HNO}_{3}\right)$ solution. However, these washing techniques had little impact on membrane clogging. On Day 27, $2 \mathrm{~g} / \mathrm{L}$ of PAC was added to the MBR, and another $3 \mathrm{~g} / \mathrm{L}$ was added two days later. Adding PAC to the MBR is believed to enhance the removal of organic matter through contaminant adsorption. Also, in some systems, PAC addition has been shown to decrease the TMP by increasing the average floc size and providing a shear force on the membrane (Ng et al., 2006; Park et al., 1999; Seo et al., 2004). However, PAC addition to the MBR had little impact on membrane clogging in this field test.

During the laboratory-scale evaluation of the MBR, it was found that decreasing the $\mathrm{pH}$ of the influent below 7.0 decreased the TMP to below $25 \mathrm{kPa}$ (Figure 4-35). In the field, the $\mathrm{pH}$ of the effluent from the MBR was 8.8 which enhanced the potential for forming inorganic precipitants that would foul the membrane and high TMP was not unexpected. Unfortunately, logistical constraints during the field trial precluded the implementation of a $\mathrm{pH}$ control system in the field to be able to confirm that reducing the $\mathrm{pH}$ of the solution in the MBR would reduce TMP and prevent fouling of the membrane. Future studies with actual produced water will be required to evaluate the impact of $\mathrm{pH}$ reduction or frequent membrane backwashing on TMP. 


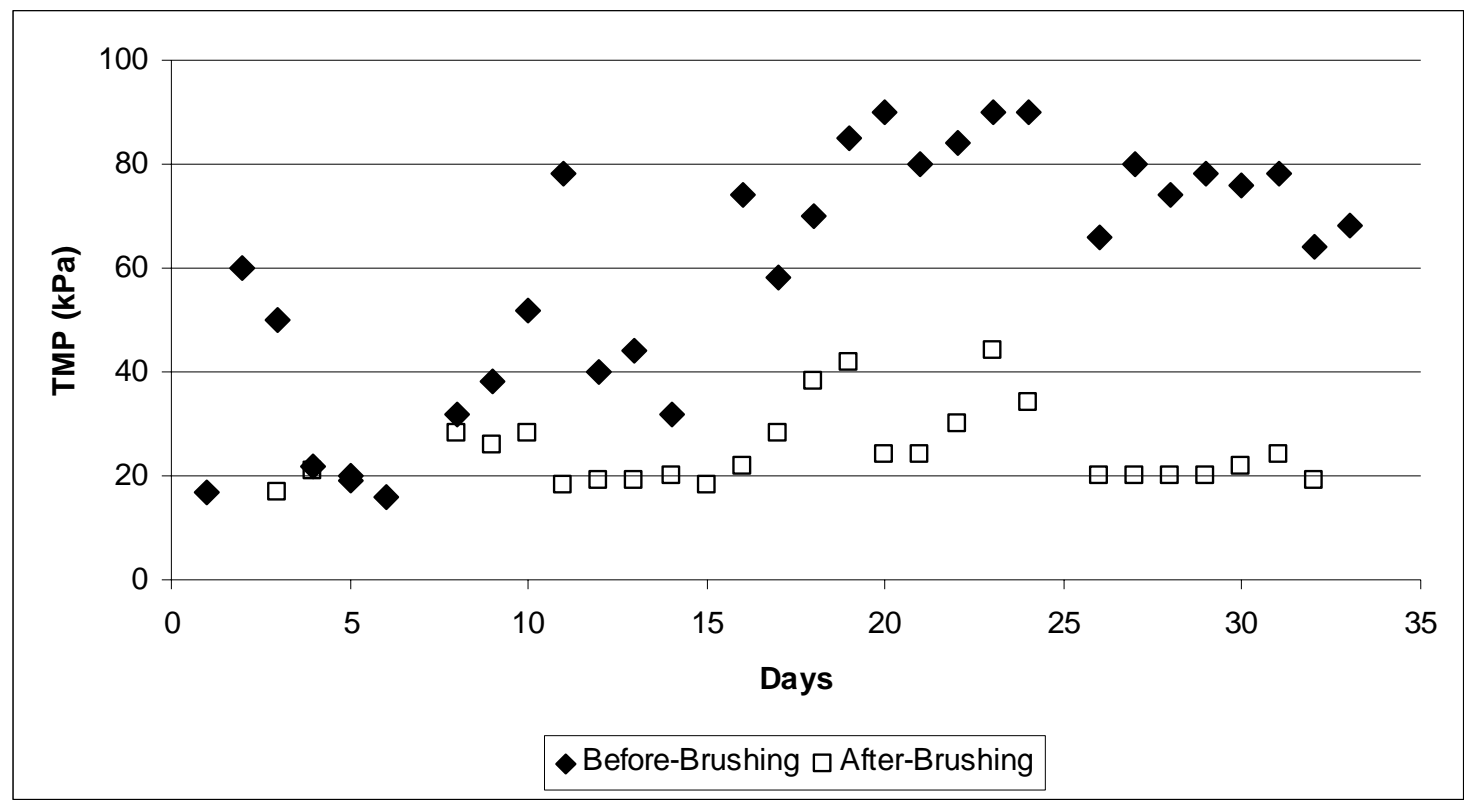

Figure 4-43. TMP in the MBR system during the field test.

\subsubsection{Summary}

The MBR system was operated as part of a field evaluation of an SMZ/MBR unit to pretreat produced water for potential reuse applications. Consistent with the results of the previous field trial, acetate (the predominant organic anion detected in the produced water) was not removed by the SMZ column. However, it was removed to below detection limits in the MBR, indicating that the MBR system was very effective for removing carboxylates from produced water. When the influent produced water containing $580 \mathrm{mg} / \mathrm{L}$ of TOC was supplied to the SMZ/MBR system, the SMZ column reduced up to approximately $40 \%$ of the influent TOC prior to breakthrough. After subsequent treatment in the MBR, greater than $74 \%$ of the influent TOC was removed and when the MBR was supplemented with PAC, the overall TOC removal efficiency of the SMZ/MBR system increased to $92 \%$.

While most of the BTEX constituents of the produced water adsorbed onto SMZ during the field trial, approximately $95 \%$ of the BTEX that penetrated the SMZ and entered the MBR was biodegraded in the MBR. These results confirm that a MBR can be used to remove VOCs from produced water that has moderate TDS levels (e.g., $10 \mathrm{~g} / \mathrm{L}$ ). Kinetic coefficients $\left(K_{V}\right.$ and $\left.k_{d} \bullet X\right)$ measured in the laboratory test were modified and used to predict the benzene effluent concentrations from the field MBR system. The predicted effluent benzene concentrations were reasonable and suggest that the removal of benzene from produced water is primarily controlled by biodegradation.

As the field experiment progressed, severe membrane clogging was observed that resulted in high TMP and reduced flux through the membrane. Several cleaning methods, including physical and chemical membrane washing, had little effect on reduction of 
fouling. Further studies are required to optimize the system to reduce membrane fouling through either $\mathrm{pH}$ control and/or frequent membrane backwashing. 


\section{REFERENCES}

Abumaizar, R. J., Kocher, W., Smith, E. H. (1998). "Biofiltration of BTEX contaminated air streams using compost-activated carbon filter media." Journal of Hazardous Materials 60(2): 111-126.

Agenson, K. O., Urase, T. (2007). "Change in membrane performance due to organic fouling in nanofiltration (NF)/reverse osmosis (RO) applications." Separation and Purification Technology 55(2): 147-156.

Al-Ahmad, M., Aleem, F. A. A., Mutiri, A., Ubaisy, A. (2000). "Biofouling in RO membrane systems Part 1: Fundamentals and control." Desalination 132(1-3): 173-179

Allen, D. T., Rosselot, K. S. (1994). "Pollution Prevention at the Macro Scale - Flows of Wastes, Industrial Ecology and Life-Cycle Analyses." Waste Management 14(34): 317-328.

Alonso, C., Suidan, M. T., Sorial, G. A., Smith, F. L., Biswas, P., Smith, P. J., Brenner, R. C. (1997). "Gas treatment in trickle-bed biofilters: Biomass, how much is enough?" Biotechnology and Bioengineering 54(6): 583-594.

Al-Rayes, A. W., Kinney, K. A., Seibert, A. F., Corsi, R. L. (2001). "Load dampening system for vapor phase bioreactors." Journal of Environmental EngineeringASCE 127(3): 224-232.

Altare, C. R., Bowman, Robert S., Katz, Lynn E., Kinney, Kerry A., Sullivan, Enid J. (2007). "Regeneration and long-term stability of surfactant-modified zeolite for removal of volatile organic compounds from produced water." Microporous and Mesoporous Materials 105(n3): 305-316.

API (2000). "Overview of exploration and production waste volumes and waste management practices in the United States". Washington. D.C, American Petroleum Institute.

API (2002). "Predictors of water-soluble organics in produced water - A literature review". Washington, D.C, American Petroleum Institute.

Aziz, C. E., Georgiou, G., Speitel, G. E. (1999). "Cometabolism of chlorinated solvents and binary chlorinated solvent mixtures using M-trichosporium OB3b PP358." Biotechnology and Bioengineering 65(1): 100-107.

Bakx, T., Boom, S., Ramaekers, H. (2000). "Treatment of oil-contaminated water from naval warships." Water 21: 37-38.

Berube, P. R., Hall, E. R., Sutton, P. M. (2006). "Parameters governing permeate flux in an anaerobic membrane bioreactor treating low-strength municipal wastewaters: A literature review." Water Environment Research 78(8): 887-896.

Bessa, E., Sant Anna, G. L., Dezotti, M. (2001). "Photocatalytic/H2O2 treatment of oil field produced waters." Applied Catalysis B-Environmental 29(2): 125-134. 
Bielefeldt, A. R., Stensel, H. D. (1999). "Evaluation of biodegradation kinetic testing methods and long-term variability in biokinetics for BTEX metabolism." Water Research 33(3): 733-740.

Bohn, H. (1992). "Consider Biofiltration for Decontaminating Gases." Chemical Engineering Progress 88(4): 34-40.

Bouhabila, E., Ben Aim, R., Buisson, H. (2001). "Fouling characterisation in membrane bioreactors." Separation and Purification Technology 22-3(1-3): 123-132.

Bouhabila, E. H., Ben Aim, R., Buisson, H. (1998). "Microfiltration of activated sludge using submerged membrane with air bubbling (application to wastewater treatment)." Desalination 118(1-3): 315-322.

Bowman, R. S., Haggerty, G. M., Huddleston, R. G., Neel, D., Flynn, M. M. (1995). "Sorption of Nonpolar Organic-Compounds, Inorganic Cations, and Inorganic Oxyanions by Surfactant-Modified Zeolites". Surfactant-Enhanced Subsurface Remediation. 594: 54-64.

Bowman, R. S., Li, Z., Roy, S.J., Burt, T., Johnson, T.L., Johnson, R.L. (2001). "Pilot test of a surfactant-modified zeolite permeable barrier for groundwater remediation". Physicochemical groundwater remediation. J. A. S. a. S.Burns. New York, Kluwer Academic/Plenum: 161-185.

Burnett, D. B. (2004). "Potential for Beneficial Use of Oil and Gas Produced Water". www.twdb.state.tx.us, Clobal Petroleum Institute, Texas Water Resources Institute, Texas A \& M University.

Cal, M. P., Rood, M. J., Larson, S. M. (1996). "Removal of VOCs from humidified gas streams using activated carbon cloth." Gas Separation \& Purification 10(2): 117121.

Calabrese, E. J. (1993). "Principles and Practices For Petroleum Contaminated Soils". New York, Lewis Publishers.

Chagnot, E., Taha, S., Martin, G., Vicard, J. F. (1998). "Treatment of nitrogen oxides on a percolating biofilter after pre-concentration on activated carbon." Process Biochemistry 33(6): 617-624.

Chang, K. S., Lu, C. Y., Lin, M. R. (2001). "Treatment of volatile organic compounds from polyurethane and epoxy manufacture by a trickle-bed air biofilter." Journal of Bioscience and Bioengineering 92(2): 126-130.

Chen, C. Y., Wu, S. C. (1998). "The influence of relative humidity on the adsorption of toluene by soils - Interpretation with the adsorption energy distribution functions." Chemosphere 37(8): 1437-1444.

Chen, T. K., Chen, J. N. (2004). "Combined membrane bioreactor (MBR) and reverse osmosis (RO) system for thin-film transistor - liquid crystal display TFT-LCD, industrial wastewater recycling." Water Science and Technology 50(2): 99-106.

Chen, X. B., Yang, W. S., Liu, J., Lin, L. W. (2005). "Synthesis of zeolite NaA membranes with high permeance under microwave radiation on mesoporous- 
layer-modified macroporous substrates for gas separation." Journal of Membrane Science 255(1-2): 201-211.

Cherry, R. S., Thompson, D. N. (1997). "Shift from growth to nutrient-limited maintenance kinetics during biofilter acclimation." Biotechnology and Bioengineering 56(3): 330-339.

Chitwood, D. E., Devinny, J. S., Reynolds, F. E. (1999). "Evaluation of a two-stage biofilter for treatment of POTW waste air." Environmental Progress 18(3): 212221.

Choi, D. S., Devinny, J. S., Deshusses, M. A. (2004). "Behavior of field-scale biotrickling filter under non-steady state conditions." Journal of Environmental Engineering-ASCE 130(3): 322-328.

Choo, K. H., Kang, I. J., Yoon, S. H., Park, H., Kim, J. H., Adiya, S., Lee, C. H. (2000). "Approaches to membrane fouling control in anaerobic membrane bioreactors." Water Science and Technology 41(10-11): 363-371.

Corsi, R. L., Seed, L. (1995). "Biofiltration of BTEX: Media, substrate, and loadings effects." Environmental Progress 14(3): 151-158.

Cortright, R. D., Crittenden, R.C., Rick, B. G., Tang, S.R., Perram, D.L., Rigg, T.J. (1987). "An Evaluation of the Technical Feasibility of the Air Stripping Solvent Recovery Process", AWWA research foundation: 15-19.

Cox, H. H. J., Deshusses, M. A. (1999). "Chemical removal of biomass from waste air biotrickling filters: Screening of chemicals of potential interest." Water Research 33(10): 2383-2391.

Cox, H. H. J., Deshusses, M. A. (2002). "Effect of starvation on the performance and reacclimation of biotrickling filters for air pollution control." Environmental Science \& Technology 36(14): 3069-3073.

Crittenden, J. C., Cortright, R. D., Rick, B., Tang, S. R. (1988). "Using GAC to Remove VOCs from Air Stripper Off-Gas." Journal American Water Works Association 80(5): 73-84.

Crittenden, J. C., Luft, P., Hand, D. W. (1985). "Prediction of Multicomponent Adsorption Equilibria in Background Mixtures of Unknown Composition." Water Research 19(12): 1537-1548.

Crittenden, J. C., Luft, P., Hand, D. W., Oravitz, J. L., Loper, S. W., Arl, M. (1985). "Prediction of Multicomponent Adsorption Equilibria Using Ideal Adsorbed Solution Theory." Environmental Science \& Technology 19(11): 1037-1043.

Dalmacija, B., Karlovic, E., Tamas, Z., Miskovic, D. (1996). "Purification of highsalinity wastewater by activated sludge process." Water Research 30(2): 295-298.

Darby, E. B. (2006). "Engineering and Economic Assessment of a Surfactant Modified Zeolite/Vapor Phase Biofilter Process for Treatment of Produced Water". Master's report, Austin, TX, University of Texas at Austin. 
Deeb, R. A., Hu, H. Y., Hanson, J. R., Scow, K. M., Alvarez-Cohen, L. (2001). "Substrate interactions in BTEX and MTBE mixtures by an MTBE-degrading isolate." Environmental Science \& Technology 35(2): 312-317.

Delhomenie, M. C., Heitz, M. (2005). "Biofiltration of air: A review." Critical Reviews in Biotechnology 25(1-2): 53-72.

Deshusses, M. A. (1997). "Transient behavior of biofilters: Start-up, carbon balances, and interactions between pollutants." Journal of Environmental Engineering-ASCE 123(6): 563-568.

Dirk-Faitakis, C., Allen, D. G. (2003). "Biofiltration of cyclic air emissions of alphapinene at low and high frequencies." Journal of the Air \& Waste Management Association 53(11): 1373-1383.

du Plessis, C. A., Strauss, J. M., Riedel, K. H. J. (2001). "BTEX catabolism interactions in a toluene-acclimatized biofilter." Applied Microbiology and Biotechnology 55(1): 122-128.

Ergas, S. J., Schroeder, E. D., Chang, D. P. Y., Morton, R. L. (1995). "Control of Volatile Organic-Compound Emissions Using a Compost Biofilter." Water Environment Research 67(5): 816-821.

Fan, F. S., Zhou, H. D., Husain, H. (2006). "Identification of wastewater sludge characteristics to predict critical flux for membrane bioreactor processes." Water Research 40(2): 205-212.

Fang, C. S., Lin, J. H. (1988). "Air Stripping for Treatment of Produced Water." Journal of Petroleum Technology 40(5): 619-624.

Fuick, K. W. (1992). "Toxicity Identification and Characteristics of Produced Water Discharges From Colorado and Wyoming". New York, NY, Plenum Press.

Gander, M. A., Jefferson, B., Judd, S. J. (2000). "Membrane bioreactors for use in small wastewater treatment plants: membrane materials and effluent quality." Water Science and Technology 41(1): 205-211.

Garcia, H. A. (2007). "Degrading Malonate Waste in a Membrane Bioreactor: Modeling and Experiments". Master's thesis. Civil, Architecture, and Environmental Engineering. Austin, TX, University of Texas at Austin.

Gilbert, Y., Le Bihan, Y., Buelna, G., Lessard, P. (2005). "Application of respirometry to monitoring the biomass activity of a biofilter on an organic bed used to treat pig manure." Water Quality Research Journal of Canada 40(2): 155-163.

Gribbins, M. J., Loehr, R. C. (1998). "Effect of media nitrogen concentration on biofilter performance." Journal of the Air \& Waste Management Association 48(3): 216226.

Gui, P., Huang, X., Chen, Y., Qian, Y. (2003). "Effect of operational parameters on sludge accumulation on membrane surfaces in a submerged membrane bioreactor." Desalination 151(2): 185-194. 
Gwon, E. M., Yu, M. J., Oh, H. K., Ylee, Y. H. (2003). "Fouling characteristics of NF and RO operated for removal of dissolved matter from groundwater." Water Research 37(12): 2989-2997.

Hansen, B. R., Davies, S. R. H. (1994). "Review of Potential Technologies for the Removal of Dissolved Components from Produced Water." Chemical Engineering Research \& Design 72(A2): 176-188.

Hays, T., Arthur, D. (2004). "Overview of Emerging Produced Water Treatment Technologies". Presented at the 11th Annual International Petroleum Environmental Conference, Albuquerque, NM, October 12 - 15.

Hu, A. Y., Stuckey, D. C. (2007). "Activated carbon addition to a submerged anaerobic membrane bioreactor: Effect on performance, transmembrane pressure, and flux." Journal of Environmental Engineering-ASCE 133(1): 73-80.

Huang, X., Gui, P., Qian, Y. (2001). "Effect of sludge retention time on microbial behavior in a submerged membrane bioreactor." Process Biochemistry 36(10): 1001-1006.

Huddleston, R. (1990). "Surface-altered hydrophobic zeolites as sorbents for hazardous organic compounds". Soccoro, N.M, New Mexico Institute of Mining and Technology.

IOGCC and ALL. (2006). "A Guide to Practical Management of Produced Water from Onshore Oil and Gas Operations in the United States". prepared for U.S. Department of Energy, National Energy Technology Laboratory, by the Interstate Oil and Gas Compact Commission and ALL Consulting, October, : http://www.all-1lc.com/IOGCC/ProdWtr/ProjInfo.htm.

Janks, J. S., Cadena, F. (1992). "Investigations into the Use of Modified Zeolites for Removing Benzene, Toluene, and Xylene From Saline Produced Water". Produced Water. F. R. E. J.P.Ray. New York, NY, Plenum Press: 473-487.

Jefferson, B., Laine, A. L., Judd, S. L., Stephenson, T. (2000). "Membrane bioreactors and their role in wastewater reuse." Water Science and Technology 41(1): 197204.

Jorio, H., Bibeau, L., Heitz, M. (2000). "Biofiltration of air contaminated by styrene: Effect of nitrogen supply, gas flow rate, and inlet concentration." Environmental Science \& Technology 34(9): 1764-1771.

Jorio, H., Kiared, K., Brzezinski, R., Leroux, A., Viel, G., Heitz, M. (1998). "Treatment of air polluted with high concentrations of toluene and xylene in a pilot-scale biofilter." Journal of Chemical Technology and Biotechnology 73(3): 183-196.

Jutras, E. M., Smart, C. M., Rupert, R., Pepper, I. L., Miller, R. M. (1997). "Field-scale biofiltration of gasoline vapors extracted from beneath a leaking underground storage tank." Biodegradation 8(1): 31-42.

Katz, L. E., Kinney, K.A., Bowman, R.S., Sullivan, E.J. (2006). "Treatment of Produced Water Using a Surfactant Modified Zeolite/Vapor Phase Bioreactor System". Final Technical Report, DOE Award Number DE-FC26-02NT15461. 
Kennes, C., Thalasso, F. (1998). "Waste gas biotreatment technology." Journal of Chemical Technology and Biotechnology 72(4): 303-319.

Kinney, K. A., Loehr, R. C., Corsi, R. L. (1999). "Vapor-phase bioreactors: Avoiding problems through better design and operation." Environmental Progress 18(3): 222-230.

Kishino, H., Ishida, H., Iwabu, H., Nakano, I. (1996). "Domestic wastewater reuse using a submerged membrane bioreactor." Desalination 106(1-3): 115-119.

Kurian, R., Nakha, G., Bassi, A. (2006). "Biodegradation kinetics of high strength oily pet food wastewater in a membrane-coupled bioreactor (MBR)." Chemosphere 65(7): 1204-1211.

Laurenzis, A., Heits, H., Wubker, S. M., Heinze, U., Friedrich, C., Werner, U. (1998). "Continuous biological waste gas treatment in stirred trickle-bed reactor with discontinuous removal of biomass." Biotechnology and Bioengineering 57(4): 497-503.

Lee, E. Y., Jun, Y. S., Cho, K. S., Ryu, H. W. (2002). "Degradation characteristics of toluene, benzene, ethylbenzene, and xylene by Stenotrophomonas maltophilia T3c." Journal of the Air \& Waste Management Association 52(4): 400-406.

Lee, J., Ahn, W. Y., Lee, C. H. (2001). "Comparison of the filtration characteristics between attached and suspended growth microorganisms in submerged membrane bioreactor." Water Research 35(10): 2435-2445.

Leson, G., Smith, B. J. (1997). "Petroleum environmental research forum field study on biofilters for control of volatile hydrocarbons." Journal of Environmental Engineering-ASCE 123(6): 556-562.

Leson, G., Winer, A. M. (1991). "Biofiltration - an Innovative Air-Pollution Control Technology for Voc Emissions." Journal of the Air \& Waste Management Association 41(8): 1045-1054.

Li, C. N., Moe, W. M. (2005). "Activated carbon load equalization of discontinuously generated acetone and toluene mixtures treated by biofiltration." Environmental Science \& Technology 39(7): 2349-2356.

Li, Z. H., Bowman, R. S. (1998). "Sorption of perchloroethylene by surfactant-modified zeolite as controlled by surfactant loading." Environmental Science \& Technology 32(15): 2278-2282.

Li, Z. H., Bowman, R. S. (2001). "Regeneration of surfactant-modified zeolite after saturation with chromate and perchloroethylene." Water Research 35(1): 322-326.

Lillo-Rodenas, M. A., Fletcher, A. J., Thomas, K. M., Cazorla-Amoros, D., LinaresSolano, A. (2006). "Competitive adsorption of a benzene-toluene mixture on activated carbons at low concentration." Carbon 44(8): 1455-1463.

Lin, C. K., Tsai, T. Y., Liu, J. C., Chen, M. C. (2001). "Enhanced biodegradation of petrochemical wastewater using ozonation and BAC advanced treatment system." Water Research 35(3): 699-704. 
Lu, C. Y., Chu, W. C., Lin, M. R. (2000). "Removal of BTEX vapor from waste gases by a trickle bed biofilter." Journal of the Air \& Waste Management Association 50(3): 411-417.

Madigan, M. T., Martinko, J.M, Parker, J. (2000). "Brock biology of microorganism", Prentice Hall.

Mallakin, A., Ward, O. P. (1996). "Degradation of BTEX compounds in liquid media and in peat biofilters." Journal of Industrial Microbiology 16(5): 309-318.

Marrot, B., Barrios-Martinez, A., Moulin, P., Roche, N. (2004). "Industrial wastewater treatment in a membrane bioreactor: A review." Environmental Progress 23(1): 59-68.

Martin, F. J., Loehr, R. C. (1996). "Effect of periods of non-use on biofilter performance." Journal of the Air \& Waste Management Association 46(6): 539546.

Medina, V. E., Webster, T., Ramaratnam, M., Devinny, J. S. (1995). "Treatment of Gasoline Residuals by Granular Activated Carbon-Based Biological Filtration." Journal of Environmental Science and Health Part a-Environmental Science and Engineering \& Toxic and Hazardous Substance Control 30(2): 407-422.

Mochidzuki, K., Takeuchi, Y. (1999). "The effects of some inhibitory components on biological activated carbon processes." Water Research 33(11): 2609-2616.

Moe, W. M., Irvine, R. L. (2000). "Polyurethane foam medium for biofiltration. I: Characterization." Journal of Environmental Engineering-ASCE 126(9): 815-825.

Moe, W. M., Li, C. N. (2005). "A design methodology for activated carbon load equalization systems applied to biofilters treating intermittent toluene loading." Chemical Engineering Journal 113(2-3): 175-185.

Moe, W. M., Qi, B. (2004). "Performance of a fungal biofilter treating gas-phase solvent mixtures during intermittent loading." Water Research 38(9): 2259-2268.

Mohseni, M., Zhao, J. L. (2006). "Coupling ultraviolet photolysis and bilofiltration for enhanced degradation of aromatic air pollutants." Journal of Chemical Technology and Biotechnology 81(2): 146-151.

Morgan, P., Lewis, S. T., Watkinson, R. J. (1993). "Biodegradation of Benzene, Toluene, Ethylbenzene and Xylenes in Gas-Condensate-Contaminated Groundwater." Environmental Pollution 82(2): 181-190.

Morgenroth, E., Schroeder, E. D., Chang, D. P. Y., Scow, K. M. (1996). "Nutrient limitation in a compost biofilter degrading hexane." Journal of the Air \& Waste Management Association 46(4): 300-308.

Myers, A. L., Prausnitz, J.M. (1965). "Thermodynamics of Mixed-Gas Adsorption." American Institute of Chemical Engineers Journal 11(1): 121-127.

Neel, D., Bowman, R.S. (1992). "Sorption of organics to surface-altered zeolites". 36th Annual New Mexico Water Conference, Las Cruces, N.M, New Mexico Water Resources Research Institute. 
Negri, M. C., Hinchman, R.C. (1997). "Biotreatment of produced waters for volume reduction and contaminant removal". 4th Annual Int. Petroleum Environmental Conf., Tulsa, Okla, Integrated Petroleum Environmental Consortium.

Ng, C. A. S., D., Fane, A. G. (2006). "Operation of membrane bioreactor with powdered activated carbon addition." Separation Science and Technology 41(7): 1447-1466.

Ning, R. Y., Troyer, T. L. (2007). "Colloidal fouling of RO membranes following MF/UF in the reclamation of municipal wastewater." Desalination 208(1-3): 232-237.

Ognier, S., Wisniewski, C., Grasmick, A. (2002). "Characterisation and modelling of fouling in membrane bioreactors." Desalination 146(1-3): 141-147.

Ottengraf, S. P. P., Vandenoever, A. H. C. (1983). "Kinetics of Organic-Compound Removal from Waste Gases with a Biological Filter." Biotechnology and Bioengineering 25(12): 3089-3102.

Pakula, R., Freeman, A. (1996). "A new continuous biofilm bioreactor for immobilized oil-degrading filamentous fungi." Biotechnology and Bioengineering 49(1): 2025.

Park, H., Choo, K. H., Lee, C. H. (1999). "Flux enhancement with powdered activated carbon addition in the membrane anaerobic bioreactor." Separation Science and Technology 34(14): 2781-2792.

Park, J. (2004). "Biodegradation of paint VOC mixtures in biofilters". Dissertation. Civil Engineering. Austin, TX, The University of Texas at Austin.

Park, J., Kinney, K. A. (2001). "Evaluation of slip feed system for vapor-phase bioreactors." Journal of Environmental Engineering-ASCE 127(11): 979-985.

Peel, R. G., Benedek, A. (1980). "Attainment of Equilibrium in Activated Carbon Isotherm Studies." Environmental Science \& Technology 14(1): 66-71.

Polanyi, M. (1932). "Section III. - Theories of the adsorption of gases. A general survey and some additional remarks." Transactions of the Faraday Society 28: 316-333.

Quinlan, C., Strevett, K., Ketcham, M., Grego, J. (1999). "VOC elimination in a compost biofilter using a previously acclimated bacterial inoculum." Journal of the Air \& Waste Management Association 49(5): 544-553.

Ranck, J. M., Bowman, R. S., Weeber, J. L., Katz, L. E., Sullivan, E. J. (2005). "BTEX removal from produced water using surfactant-modified zeolite." Journal of Environmental Engineering-ASCE 131(3): 434-442.

Randtke, S. J., Snoeyink, V. L. (1983). "Evaluating GAC Adsorptive Capacity." Journal American Water Works Association 75(8): 406-413.

Rosenberger, S., Kraume, M. (2003). "Filterability of activated sludge in membrane bioreactors." Desalination 151(2): 195-200.

Ruckgaber, M. E. (2004). "Sorption of Polar and Non-Polar Organics and Metals onto Surfactant-Modified Zeolite". Thesis. Civil and Environmental Engineering. Austin, The University of Texas at Austin. 
Ruiz, J., Bilbao, R., Murillo, M. B. (1998). "Adsorption of different VOC onto soil minerals from gas phase: Influence of mineral, type of VOC, and air humidity." Environmental Science \& Technology 32(8): 1079-1084.

Ruthven, D. M. (1984). "Principles of adsorption and adsorption processes". New York, NY, John Wiley \& Sons.

Santos, S. M., Wiesner, M. R. (1997). "Ultrafiltration of water generated in oil and gas production." Water Environment Research 69(6): 1120-1127.

Scholz, M., Martin, R. J. (1997). "Ecological equilibrium on biological activated carbon." Water Research 31(12): 2959-2968.

Scholz, W. G., Rouge, P., Bodalo, A., Leitz, U. (2005). "Desalination of mixed tannery effluent with membrane bioreactor and reverse osmosis treatment." Environmental Science \& Technology 39(21): 8505-8511.

Schwarzenbach, R.P., Gschwend, P.M., Imboden, D.M. (2003). "Environmental Organic Chemistry". $2^{\text {nd }}$ Ed. Wiley-Interscience. Hoboken, NJ.

Seo, G. T., Ahan, H. I., Kim, J. T., Lee, Y. J., Kim, I. S. (2004). "Domestic wastewater reclamation by submerged membrane bioreactor with high concentration powdered activated carbon for stream restoration." Water Science and Technology 50(2): 173-178.

Smet, E., Chasaya, G., VanLangenhove, H., Verstraete, W. (1996). "The effect of inoculation and the type of carrier material used on the biofiltration of methyl sulphides." Applied Microbiology and Biotechnology 45(1-2): 293-298.

Smet, E., Van Langenhove, H., Philips, G. (1999). "Dolomite limits acidification of a biofilter degrading dimethyl sulphide." Biodegradation 10(6): 399-404.

Smet, E., VanLangehove, H., Verstraete, W. (1996). "Long-term stability of a biofilter treating dimethyl sulphide." Applied Microbiology and Biotechnology 46(2): 191196.

Smith, F. L., Sorial, G. A., Suidan, M. T., Breen, A. W., Biswas, P., Brenner, R. C. (1996). "Development of two biomass control strategies for extended, stable operation of highly efficient biofilters with high toluene loadings." Environmental Science \& Technology 30(5): 1744-1751.

Sofia, A., Ng, W. J., Ong, S. L. (2004). "Engineering design approaches for minimum fouling in submerged MBR." Desalination 160(1): 67-74.

Song, J., Kinney, K. A. (2001). "Effect of directional switching frequency on toluene degradation in a vapor-phase bioreactor." Applied Microbiology and Biotechnology 56(1-2): 108-113.

Sontheimer, H., Crittenden, J.C., Summers, R.S (1988). "Activated Carbon for Water Treatment". Univ. of Karlsruhe, Fed. Rep. of Germany, DVGW-Forschungsstelle, Engler-Bunte-Institute. 
Sorial, G. A., Smith, F. L., Suidan, M. T., Pandit, A., Biswas, P., Brenner, R. C. (1997). "Evaluation of trickle bed air biofilter performance for BTEX removal." Journal of Environmental Engineering-ASCE 123(6): 530-537.

Sperandio, M., Masse, A., Espinosa-Bouchot, M. C., Cabassud, C. (2005). "Characterization of sludge structure and activity in submerged membrane bioreactor." Water Science and Technology 52(10-11): 401-408.

Speth, T. F., Miltner, R.J. (1990). "Technical Note: Adsorption Capacity of GAC for Synthetic Organics". Journal AWWA, Research and Technology.

Stephenson, M. T. (1992). "Components of Produced Water - a Compilation of Industry Studies." Journal of Petroleum Technology 44(5): 548-561.

Storey, J. M. E., Luo, W., Isabelle, L. M., Pankow, J. F. (1995). "Gas-Solid Partitioning of Semivolatile Organic-Compounds to Model Atmospheric Solid-Surfaces as a Function of Relative-Humidity .1. Clean Quartz." Environmental Science \& Technology 29(9): 2420-2428.

Swanson, W. J. (1996). "Bench-Scale Biofiltration of VOC Waste Gases: Effects of Loading, Nutrients and Chemical Mixtures", Thesis, University of Texas at Austin.

Swanson, W. J., Loehr, R. C. (1997). "Biofiltration: Fundamentals, design and operations principles, and applications." Journal of Environmental Engineering-ASCE 123(6): 538-546.

Tang, H. M., Hwang, S. J. (1997). "Transient behavior of the biofilters for toluene removal." Journal of the Air \& Waste Management Association 47(11): 11421151.

Tang, H. M., Hwang, S. J., Hwang, S. C. (1996). "Waste gas treatment in biofilters." Journal of the Air \& Waste Management Association 46(4): 349-354.

Tellez, G. T., Nirmalakhandan, N., Gardea-Torresdey, J. L. (2005). "Kinetic evaluation of a field-scale activated sludge system for removing petroleum hydrocarbons from oilfield-produced water." Environmental Progress 24(1): 96-104.

Thacker, W. E., Crittenden, J. C., Snoeyink, V. L. (1984). "Modeling of Adsorber Performance - Variable Influent Concentration and Comparison of Adsorbents." Journal Water Pollution Control Federation 56(3): 243-250.

Thibaud, C., Erkey, C., Akgerman, A. (1993). "Investigation of the Effect of Moisture on the Sorption and Desorption of Chlorobenzene and Toluene from Soil." Environmental Science \& Technology 27(12): 2373-2380.

Thoma, G. J., Bowen, M. L., Hollensworth, D. (1999). "Dissolved air precipitation/solvent sublation for oil-field produced water treatment." Separation and Purification Technology 16(2): 101-107.

Thomas, J. M., Gordy, V. R., Fiorenza, S., Ward, C. H. (1990). "Biodegradation of BTEX in Subsurface Materials Contaminated with Gasoline - Granger, Indiana." Water Science and Technology 22(6): 53-62. 
USEPA (2000). "Profile of the oil and gas extraction industry". Washington, S.C., United States Environmental Protection Agency.

van Groenestijn, J. W., Doddema, H.J., Kok, H.J.G., Koster, T.P.M. (1994). "Combined photochemical and biological treatment of off-gases". Proceedings of the 2nd International Symposium on Environmental Biotechnology, Jul 4-6 1994, Brighton, UK, Publ by Inst of Chemical Engineers, Rugby, Engl.

Vidic, Ravisav D. (1997) "Development of Novel Activated Carbon-Based Adsorbents for Control of Mercury Emission from Coal-Fired Power Plants" Semi-Annual Technical Report. DOE Award Number : DE-FG22-96PC96212

Visvanathan, C., Yang, B. S., Muttamara, S., Maythanukhraw, R. (1997). "Application of air backflushing technique in membrane bioreactor." Water Science and Technology 36(12): 259-266.

Wani, A. H., Branion, R. M. R., Lau, A. K. (1997). "Biofiltration: A promising and costeffective control technology for odors, VOCs and air toxics." Journal of Environmental Science and Health Part a-Environmental Science and Engineering \& Toxic and Hazardous Substance Control 32(7): 2027-2055.

Wani, A. H., Branion, R. M. R., Lau, A. K. (1998). "Effects of periods of starvation and fluctuating hydrogen sulfide concentration on biofilter dynamics and performance." Journal of Hazardous Materials 60(3): 287-303.

Weber, F. J., Hartmans, S. (1995). "Use of Activated Carbon as a Buffer in Biofiltration of Waste Gases with Fluctuating Concentrations of Toluene." Applied Microbiology and Biotechnology 43(2): 365-369.

Weber, F. J., Hartmans, S. (1996). "Prevention of clogging in a biological trickle-bed reactor removing toluene from contaminated air." Biotechnology and Bioengineering 50(1): 91-97.

Weber, W. J., Liu, K.T. (1980). "Determination of mass transport parameters for fixedbed adsorbers." Chemical Engineering Communications 6(1-3): 49-60.

Werner, M. D. (1985). "The Effects of Relative-Humidity on the Vapor-Phase Adsorption of Trichloroethylene by Activated Carbon." American Industrial Hygiene Association Journal 46(10): 585-590.

Williams, T. O., Miller, F. C. (1992). "Odor Control - Biofilters and Facility Operations .2." Biocycle 33(11): 75-79.

Woertz, J. R., Kinney, K. A., McIntosh, N. D. P., Szaniszlo, P. J. (2001). "Removal of toluene in a vapor-phase bioreactor containing a strain of the dimorphic black yeast Exophiala lecanii-corni." Biotechnology and Bioengineering 75(5): 550558.

Wright, W. F. (2005). "Transient response of vapor-phase biofilters." Chemical Engineering Journal 113(2-3): 161-173.

Wright, W. F., Schroeder, E. D., Chang, D. P. Y., Romstad, K. (1997). "Performance of a pilot-scale compost biofilter treating gasoline vapor." Journal of Environmental Engineering-ASCE 123(6): 547-555. 
Yamamoto, K., Hiasa, M., Mahmood, T., Matsuo, T. (1989). "Direct Solid-Liquid Separation Using Hollow Fiber Membrane in an Activated-Sludge Aeration Tank." Water Science and Technology 21(4-5): 43-54.

Yang, R. T. (1987). "Gas separation by adsorption processes". Butterworths, Boston, MA.

Yang, W. B., Cicek, N., Ilg, J. (2006). "State-of-the-art of membrane bioreactors: Worldwide research and commercial applications in North America." Journal of Membrane Science 270(1-2): 201-211.

Yaws, C. L. (1995). "Adsorption-Capacity Data for 283 Organic Compounds." Environmental Engineering Work May-June.

Yerushalmi, L., Guiot, S. R. (1998). "Kinetics of biodegradation of gasoline and its hydrocarbon constituents." Applied Microbiology and Biotechnology 49(4): 475481.

Yoon, S. H., Collins, J. H., Musale, D., Sundararajan, S., Tsai, S. P., Hallsby, G. A., Kong, J. F., Koppes, J., Cachia, P. (2005). "Effects of flux enhancing polymer on the characteristics of sludge in membrane bioreactor process." Water Science and Technology 51(6-7): 151-157.

Zammit, K., DiFilippo, M. (2004). "Use of Produced Water in Recirculating Cooling Systems at Power Generating Facilities, Deliverable Number 3 - Treatment and Disposal Analysis", Semi-Annual Technical Progress Report, Department of Energy Award No. 41906.

Zilli, M., Fabiano, B., Ferraiolo, A., Converti, A. (1996). "Macro-kinetic investigation on phenol uptake from air by biofiltration: Influence of superficial gas flow rate and inlet pollutant concentration." Biotechnology and Bioengineering 49(4): 391-398. 